\title{
AUGUSTIN RENAUDET
}

Professeur à la Sorbonne

\section{MACHIAVEL}

\section{Étude d'histoire des doctrines politiques}

\author{
Huitème édition
}

Gallimard, Paris, 1942

Un document produit en version numérique par Jean-Marc Simonet, bénévole, Courriel : Jean-Marc_Simonet@uqac.ca

Dans le cadre de la collection: "Les classiques des sciences sociales" Site web : $\underline{\text { http://classiques.uqac.ca/ }}$

Une collection développée en collaboration avec la Bibliothèque Paul-Émile-Boulet de l'Université du Québec à Chicoutimi Site web : $\underline{\text { http://bibliotheque.uqac.ca/ }}$ 
Cette édition électronique a été réalisée par Jean-Marc Simonet, ancien professeur des Universités, bénévole.

Courriel : Jean-Marc_Simonet@uqac.ca

A partir de :

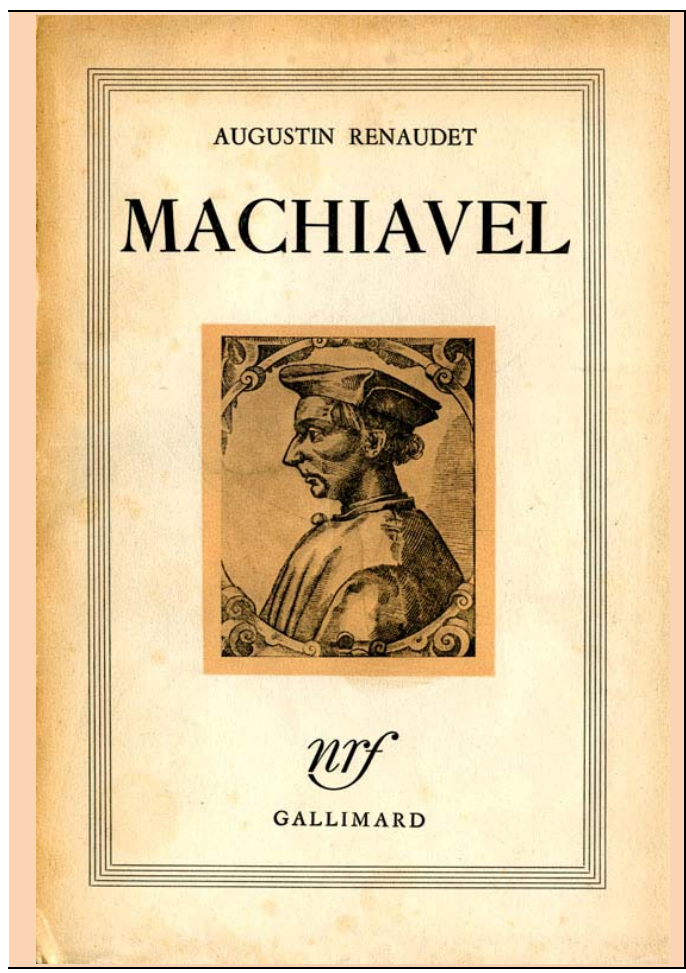

\section{Augustin Renaudet}

Professeur à la Sorbonne

\section{MACHIAVEL}

Étude d'histoire des doctrines politiques

huitième édition

Gallimard, Paris, 1942, 320 pages.

Polices de caractères utilisées :

Pour le texte: Times New Roman, 14 et 12 points.

Édition électronique réalisée avec le traitement de textes Microsoft Word 2004 pour Macintosh.

Mise en page sur papier format : LETTRE US, 8.5' $\mathrm{x} 11$ ",

Édition numérique réalisée le 28 février 2011 à Chicoutimi, Ville de Saguenay, Québec.

Fait avec

Macintosh 


\section{A ENRICHETTA BEATRICE}




\section{Table des matières}

Introduction. - Le problème de la pensée politique dans l'Italie de la Renaissan$\underline{\text { ce }}$ Machiavel et Guichardin. - Leur désaccord avec Dante et la ruine de l'ordre idéal chrétien. - La politique des humanistes et le mépris du monde moderne. - Le réalisme et la curiosité du monde moderne.

\section{PREMIÈRE PARTIE : MACHIAVEL}

Chapitre I. - La formation de Machiavel

I. La jeunesse d'un républicain dans la Florence de Laurent le Magnifique; Machiavel et Savonarole. - II. Le secrétaire de la Seconde Chancellerie; politique et diplomatie ; le retour des Médicis en septembre 1512. - III. La leçon des faits; l'invasion; princes et républiques; grandeur et décadence de César Borgia ; l'étranger, l'Empire et la France.

Chapitre II. - Le problème politique dans l'œuvre de Machiavel

Les soirées de San Casciano; histoire et science politique. — La réforme politique de l'Italie ; l'État unitaire ; les destructions nécessaires : l'autorité impériale, le pouvoir temporel des papes, les féodaux. — La réforme morale ; Machiavel et le Christianisme.

Chapitre III. - Illusions et incertitudes

I. L'appel au prince ; Julien de Nemours et Laurent d'Urbino ; le rôle providentiel des Médicis. - II. La réforme de l'État florentin et le second appel aux Médicis. - III. Machiavel au service des Médicis ; la révolution de mai 1527 ; la mort de Machiavel. - IV. Vains espoirs et faux calculs.

Chapitre IV. - Science positive ; enquête limitée

$\underline{\text { I. Fondation de la science positive de la politique; Machiavel et l'antiquité ; }}$ Aristote, Polybe et Tite-Live ; Machiavel et Montesquieu. - II. La méthode ; Machiavel et Léonard de Vinci ; retour éternel et résurrection des cho$\underline{\text { ses mortes. }-~ I I I . ~ P o l i t i q u e ~ d ' a b o r d ; ~ e n q u e ̂ t e ~ s t r i c t e m e n t ~ p o l i t i q u e . ~-~ I V . ~}$ Caractère sommaire du programme républicain de Machiavel; caractère sommaire de son programme monarchique.

Chapitre V. - Machiavel historien 
Machiavel historiographe officiel de Florence. - I. La tradition classique en histoire ; Tite-Live, Cicéron, les humanistes, et Machiavel. - II. Les Istorie fiorentine; Théodoric, les papes, les empereurs, les princes, les républiques, les condottieri ; les luttes politiques à Florence ; Cosme et Laurent de Médicis.

\section{SECONDE PARTIE : LA DOCTRINE DE MACHIAVEL}

\section{Chapitre I. - Le gouvernement légal}

Le Prince et les Discours sur la première Décade de Tite-Live. - $\underline{\text { I. Le pac- }}$ te constitutionnel; l'Église et l'État. - II. Les droits individuels; liberté personnelle; sûreté ; liberté politique ; propriété ; danger des lois agraires. - III. Les luttes politiques et la vie des partis; l'utilisation des talents par l'État et la défense de la constitution. - IV. La réforme de l'État; le retour $\underline{\text { aux principes; la dictature. }-\underline{\mathrm{V}} \text {. La fondation d'une monarchie légale; les }}$ restaurations légales de la monarchie. - VI. Le gouvernement légal des prêtres dans l'État pontifical : ses forces et ses dangers.

Chapitre II. - Les créations de la force

I. Théorie du pouvoir monarchique fondé sur la force ; l'exemple de César Borgia. - II. Théorie de la conquête ; critique de la politique française en Italie ; les violences permises. - III. Intérêt et limites de la doctrine de Machiavel ; manque d'une étude sur César ; le mythe de César Borgia.

Chapitre III. - La paix, la guerre, les traités

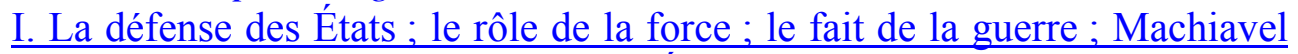
et les prophètes désarmés; Dante et Érasme. - II. L'éthique de la force guidée par la raison; les devoirs militaires des gouvernements; les bénéfices de la guerre; la conduite de la guerre. - III. Les traités; la violation licite des traités; le chapitre XVIII du Prince.

Chapitre IV. - Le gouvernement de l'opinion publique

I. Opinion et raison d'État; l'hypocrisie politique et le chapitre XVIII du Prince. - II. Cas où il faut mépriser l'opinion : finances, défense de l'État, affaires militaires. - III. Cas où il faut en tenir compte : religion; guerre; la propagande et la guerre.

\section{Chapitre V. - L'esprit de Machiavel}

I. Double doctrine, monarchique et républicaine; sommaire et pourtant classique. - II. Machiavel Romain, républicain, jacobin, étranger au christianisme comme à l'éthique humaniste. - III. L'éthique de Machiavel : le 
service du citoyen et du soldat ; l'État, juge des devoirs de l'individu, discipline sa vie spirituelle, règle son activité sociale, ne lui doit qu'un minimum de liberté. - IV. Condamnation de tout gouvernement de famille ou de classe ; réalisme et positivisme; rôle du calcul et du génie ; rejet de toute doctrine préconçue, acceptation de toute hardiesse justifiée par la raison; bassesse et grandeur des hommes; utilisation de toutes les forces humaines; primauté et discipline de la raison.

\section{$\underline{\text { ADDENDA }}$}

$\underline{\text { INDEX }}$

$\underline{\text { Notes de fin }}$ 


\section{Introduction}

\section{Le problème de la pensée politique dans l'Italie de la Renaissance}

Dès que l'on essaie de saisir la pensée politique de la Renaissance italienne, deux noms s'imposent à l'esprit : Machiavel et Guichardin. Deux œuvres dont le caractère a, depuis quatre siècles, frappé, surpris, étonné historiens, moralistes ou théoriciens du droit. Une méthode strictement positive, appliquée à l'étude des rapports que la société humaine institue entre les individus et l'État, entre les peuples, entre les États. Une politique strictement positive, qui subordonne à ses fins le droit et la morale, évalue et calcule exactement les moyens, ne considère les sentiments ou les passions des hommes, leurs croyances ou leurs idées, que pour mesurer les forces ou les faiblesses qui peuvent aider ou contrarier son jeu. Cette science positive du gouvernement se propose un seul but : la fondation de l'État, la conservation, l'accroissement, la grandeur de l'État. Elle se définit et se développe, chez Machiavel, pour soutenir une conception républicaine de l'État, dans les Discours sur la première Décade de Tite-Live. Plus dépouillée, étroitement et résolument simplifiée, elle s'offre, dans le livre du Prince, à servir une monarchie qui reste à fonder. Elle anime d'une vie austère et dédaigneuse toute l'œuvre de Guichardin, les vingt livres de son Histoire d'Italie, son Histoire de Florence, les deux livres de ses Dialogues sur le Gouvernement de Florence, ses Souvenirs politiques et civils.

L'État, pour l'un comme pour l'autre, n'est plus la cité antique, ni la libre commune du Moyen Age, ni la seigneurie italienne des deux derniers siècles. Mais pas davantage il ne ressemble à la monarchie de France ou d'Angleterre, qui, médiévale à demi en dépit de quelques 
traits déjà modernes, continue ${ }_{\mathrm{p} 010}$ d'invoquer le droit féodal et le devoir du vassal envers le suzerain. Machiavel fonde l'État sur un fait historique, d'ordre à la fois matériel et spirituel, l'existence de la nation. Il imagine un État national, encore trop confusément défini pour accueillir tous les peuples d'Italie, assez fort du moins pour les attirer et les conduire, pour repousser les invasions étrangères, pour assurer la sauvegarde de cette patrie italienne, dont Pétrarque déjà semblait entrevoir l'image. Guichardin, aussi profond et plus exact dans l'analyse, pourtant inégal à Machiavel par la vigueur de la pensée, et parce que, sceptique et las, plus aisément réconcilié avec une époque dont il sait les misères, il compte moins sur un avenir qu'il sait incertain et menaçant, a toutefois rompu avec la tradition qui restreignait à l'horizon d'une cité l'œuvre de l'historien; il a le premier, pour une brève période sans doute, mais riche d'événements et de leçons, composé l'histoire de l'Italie entière, et, répondant au désir de Machiavel, démontré l'existence de la nation italienne.

Ces deux œuvres étonnent par la nouveauté de la méthode et par un esprit nouveau. Contemporains de Machiavel et de Guichardin, Érasme, dans les Adages et l'Institutio principis christiani, Thomas More dans l'Utopie, débattent également les plus hautes questions de morale politique et sociale. Tous deux ont tenu compte des leçons positives qu'ils recevaient des faits. On retrouverait aisément chez Érasme le souvenir très précis des institutions représentatives que ses compatriotes des Pays-Bas devaient, dans la seconde moitié du XVI ${ }^{\mathrm{e}}$ siècle, défendre contre Philippe II, et qui servirent de base au régime républicain des Provinces-Unies. Il serait facile de retrouver, alliés à la fantaisie de Thomas More, le goût d'indispensables libertés, et la plus exacte connaissance de l'économie anglaise. Mais l'un et l'autre n'avaient cessé d'admettre que la morale chrétienne dût nécessairement discipliner les rapports des souverains entre eux ou avec les peuples. Ils s'étaient, comme les philosophes antiques, comme Platon et Aristote, comme les théologiens du Moyen Age, posé la question du bon gouvernement; ils ne pouvaient douter qu'elle ne fût d'ordre moral ; chrétiens, ils en avaient demandé la solution à la morale chrétienne. Machiavel et Guichardin réduisent la politique à l'art de capter, de cultiver et d'ordonner des forces, hors de l'éthique païenne comme du christianisme. 
Les contemporains n'ont pas manqué de s'en apercevoir; et d'abord les étrangers, peu sensibles à l'inspiration nationale qui p011 exalte Machiavel, et communique parfois à sa doctrine certaine grandeur tragique et désespérée. Ils ne pouvaient lire sans surprise, au livre du Prince, ni le chapitre XVIII qui démontre l'imprudence et l'erreur des souverains fidèles à leur parole; ni les louanges prodiguées à la duplicité d'Alexandre VI ou de Ferdinand le Catholique ; ni la glorification de César Borgia. On n'ignorait guère que la politique fût le règne de la violence ou de la fraude; mais nul encore ne s'était, avec une telle indifférence au souverain bien des philosophes ou à la perfection évangélique, accommodé de la fatalité qui imposait aux hommes la loi de l'âge de fer, ou de la sentence divine qui leur infligeait la loi du péché. Nul n'avait, dans un monde abandonné à la violence, professé avec moins de trouble et de remords la poursuite du succès temporel. En France, dès les dernières années de François $\mathrm{I}^{\mathrm{er}}$ ou le début du règne d'Henri II, ce que l'on nomme aussitôt machiavélisme désigne une tyrannie hypocrite et perfide. Catholiques et protestants s'indignent à l'envi, défendent et la tradition chrétienne, et la tradition humaine de la sagesse antique. Le Discours de la servitude volontaire, composé entre 1546 et 1551 par Étienne de la Boëtie, est antimachiavéliste. En 1576, le huguenot Étienne Gentillet réfute le Prince dans ses Discours de l'art de gouverner. Moins scandaleux, Guichardin n'inspire guère plus de confiance. Montaigne, qui s'est soigneusement gardé de prononcer contre Machiavel un réquisitoire banal, résume pour lui-même, en une page des Essais, l'impression suspecte que lui a laissée une longue pratique de l'Histoire d'Italie :

"Voicy ce que ie meis, il y a environ dix ans, en mon Guicciardin... : Il est historiographe diligent, et duquel, à mon advis, autant exactement que de nul aultre, on peult apprendre la vérité des affaires de son temps : aussi, en la plus part, en a il esté acteur luy mesme, et en rang honorable. Il n'y a aulcune apparence que par haine, faveur ou vanité il ayt desguisé les choses : de quoy font foy les libres iugements qu'il donne des grands, et notamment de ceulx par lesquels il avait esté avancé et employé aux charges, comme du pape Clément septiesme... I'ai aussi remarqué cecy, que tant d'âmes et d'effects qu'il iuge, de tant de mouvements et conseils, il n'en rapporte iamais un seul à la vertu, religion et conscience, comme si ces parties-là estoient du tout esteinctes au monde; et de toutes les actions, pour bel- 
les par apparence qu'elles soient d'elles-mêmes, il en p012 reiecte la cause à quelque occasion vicieuse ou à quelque proufict. Il est impossible d'imaginer que, parmy cet infini nombre d'actions de quoy il iuge, il n'y en ayt eu quelqu'une produicte par la voye de la raison : nulle corruption peult avoir saisi les hommes si universellement, que quelqu'un n'eschappe de la contagion. Cela me faict craindre qu'il y aye un peu du vice de son goust; et peult estre advenu qu'il ayt estimé d'aultruy selon soy. " ${ }^{\text {i }}$

Sans quitter l'Italie, mieux vaut marquer le contraste éclatant où s'opposent le réalisme de Machiavel et la tradition de Dante, telle qu'elle se développe dans la Divine Comédie, particulièrement dans le Purgatoire et le Paradis, ou dans les argumentations latines du traité De la Monarchie, qui en offrent l'indispensable glose.

Dante, comme les philosophes antiques, Platon ou Aristote, comme les maitres de la scolastique et saint Thomas, qu'il suit le plus souvent, comme deux siècles après lui Érasme et Thomas More, cherche à résoudre le problème du bon gouvernement. Sans doute ne concevrait-on pas qu'il n'ait aucunement tiré profit, même à son insu, de ce que le spectacle du réel a pu lui enseigner. Sa propre expérience de la politique et de la lutte des partis à Florence et dans les villes italiennes, son amitié pour la classe noble des grands propriétaires fonciers, qui est la sienne, son mépris des familles nouvelles, venues de la campagne et trop vite enrichies dans le négoce, ont pu l'incliner vers certaines préférences doctrinales. Ses regrets d'un régime social et politique en voie de lente dégradation attristent, au cœur même du poème du Paradis, dans ce ciel de Mars où il rencontre son trisaïeul mort à la croisade, des entretiens dont trop de rancunes partisanes troublent la sérénité ii . Mais ces propos d'émigré ne touchent que le gouvernement intérieur de Florence ; et la véritable question que Dante, philosophe et théologien catholique, veut débattre, est celle du régime qui convient au monde chrétien tout entier. L'État particulier, la nation particulière, ne captivent pas longtemps son attention. Sa pensée embrasse l'universel : c'est l'ordre du monde chrétien qu'il entend p013 définir. Ordre tout idéal, qu'il fonde, en philosophe et en théologien, sur des principes philosophiques et religieux. 
Cet ordre est celui d'une réforme et d'une restauration, dont le poète cherche les éléments dans le passé. Réforme morale, intellectuelle, spirituelle de l'individu, affranchi du péché, instruit par le savoir encyclopédique d'Aristote, éclairé par la théologie rationaliste de saint Thomas, illuminé par la théologie mystique de saint Bonaventure, conduit par l'ascèse et la méditation jusqu'au seuil mystérieux des grâces d'oraison accordées à saint Bernard et aux maîtres franciscains. Réforme de la société chrétienne, par la restauration des deux pouvoirs divinement chargés de la guider dans le temporel et le spirituel, afin que l'intellect humain, sous la garantie d'une paix universelle, atteigne à l'accomplissement de son effort vers la connaissance, l'âme humaine à l'éternelle béatitude. Restauration de l'Empire, restitution à César de la magistrature à la fois romaine et chrétienne que Dieu lui conféra pour pacifier les peuples désunis ; restauration du Saint-Siège, déchu et captif, par le retour de la papauté à l'esprit de ses origines, par son renoncement à la richesse et à la puissance, sa conversion volontaire à l'humilité et à la pauvreté, selon les exemples et l'enseignement, récents encore, de saint François.

Ainsi la doctrine politique de Dante est à la fois rationaliste et mystique. Lorsqu'il définit le but suprême où tend la société humaine sur terre, et qu'il le montre dans le progrès indéfini de l'esprit, il argumente en philosophe intellectualiste comme Aristote ou saint Thomas iii. C'est le mystique, d'autre part, qui fonde en Dieu, outre l'autorité spirituelle de l'Église, la magistrature chrétienne et romaine de l'empereur ; magistrature du Droit éternel, dont la révélation, poursuivie obscurément depuis les premiers jours du monde, s'est imposée avec éclat par la prédication de l'Évangile et la réconciliation de la Rome impériale avec l'Église chrétienne, et pourtant ne sera pas consommée avant la fin des temps iv . C'est le mystique également qui, p014 malgré le démenti des faits, malgré la décadence de l'Empire qu'il n'a pas vu se relever et les usurpations triomphantes des Capétiens, malgré la déchéance du Saint-Siège leur complice et leur prisonnier dans l'exil d'Avignon, attend la venue de l'envoyé divin qui rétablira l'Empire et réformera l'Église ${ }^{\mathrm{v}}$. Ce mystique enfin accueille les prophéties de Joachim de Flore et les espérances des Franciscains spirituels; Dante assiste comme eux avec une inébranlable confiance aux tribulations qui doivent annoncer et préparer la revanche des saints ${ }^{\text {vi }}$. 
Nul accord possible entre le Prince et la Divine Comédie, entre Machiavel et l'Alighieri. Un politique positif, qui s'établit au cœur de la société humaine telle qu'il la trouve, et, avec les matériaux qu'elle lui offre, bâtit un État particulier, national, italien ; un réformateur visionnaire, qui méprise et qui hait le monde réel, et qui, à l'aide de pures idées, reconstruit, dédaigneux des nations, un abri éternel pour toute l'humanité chrétienne. Dante, fidèle sujet de l'Empereur, reconnaît en César la marque du sceau divin ; il damne éternellement Brutus et Cassius, les deux plus grands criminels de l'histoire humaine après le disciple qui trahit Jésus. Machiavel hait l'Empire romain pour son despotisme, méprise le Saint-Empire médiéval pour son impuissance créatrice de désordre, place Jules César au niveau de Catilina vii. Dante compte encore sur le Saint-Siège, une fois réformé, pour la restauration de l'ordre chrétien; Machiavel ne croit pas la papauté réformable, l'accuse d'avoir démoralisé l'Italie, d'y entretenir la division et la faiblesse, et la juge indigne de confiance dans le présent et dans l'avenir viii. Parmi tous les esprits de la Renaissance italienne, Machiavel est le plus étranger à l'Évangile, le moins accessible à la foi dont ${ }_{\mathrm{p} 015}$ vécut Dante, le plus indifférent à la morale chrétienne, qu'il accuse d'avoir, chez les modernes, affaibli l'énergie des caractères. Il ne voit dans la religion qu'un instrument aux mains de l'homme d'État. Les vertus qu'exaltent les moralistes ne sont également que des moyens dont l'homme d'État peut user, comme il peut user du crime. Il absoudrait les violences et les trahisons de César Borgia, si elles avaient réussi à fonder, entre la Tyrrhénienne et l'Adriatique, une puissance capable de dominer et de régénérer l'Italie centrale ${ }^{\mathrm{ix}}$. Mais Dante aurait rejeté César Borgia au septième cercle de l'Enfer, dans le fleuve bouillant de sang humain où baignent éternellement, guettés par des Centaures sagittaires, les tyrans meurtriers ; et Machiavel luimême aurait trouvé sa place et son châtiment dans la huitième fosse du huitième cercle, parmi les conseillers de fraude, emprisonnés dans des flammes vivantes, avec Ulysse et Diomède.

$$
\text { *** }
$$

Il y eut donc entre l'époque où le poète, entre 1312 et 1321, composait le Purgatoire, le Paradis, le De Monarchia, et le temps où Machiavel écrivit le Prince et les Discours sur la première Décade de 
Tite-Live, c'est-à-dire les quinze années qui suivent le premier retour des Médicis en août 1512, un revirement complet de la pensée politique en Italie. Dante et Machiavel n'ont en commun que l'espérance d'un prochain renouvellement du monde, grâce à l'action d'un homme de génie envoyé par le destin. Mais désaccord profond sur l'étendue et les limites de ce renouvellement, que Machiavel borne à l'Italie, que Dante veut étendre jusqu'aux extrêmes limites du monde chrétien; désaccord sur les moyens de ce renouvellement ; moyens dont le poète catholique subordonne le choix à la morale et à l'Évangile; dont l'homme d'État subordonne le choix à l'intérêt d'un État idéal sans doute, mais temporel.

Pourtant c'est bien à Dante qu'il faut remonter pour saisir les lointaines origines de la pensée politique au temps de la Renaissance italienne. Les écrivains $\mathrm{du} \mathrm{XVI}^{\mathrm{e}}$ siècle lisent et savent la Divine Comédie, vénèrent Dante et se souviennent sans cesse de lui, ne serait-ce que pour le contredire. On ne les comprend, on ne saisit le sens profond de leur pensée, qu'une fois confrontée ${ }_{\mathrm{p} 016}$ avec ce qu'elle nie, avec ce passé qu'elle porte en elle et dont elle rejette l'héritage. Il faut rechercher quelles notions nouvelles, quelles vues nouvelles sur le monde et sur les hommes elle a pu acquérir au cours de ces deux siècles, de quelles expériences elle a pu s'enrichir, à quelles méthodes nouvelles et à quelles nouvelles disciplines elle a su se plier, quelles désillusions elle a subies et quelles tristesses, devant le tumulte de l'histoire européenne et le drame ininterrompu de l'histoire italienne.

Il apparaît d'abord que rien ne subsiste de l'ordre traditionnel et chrétien que Dante avait voulu restaurer ${ }^{\mathrm{x}}$.

Ni le Saint-Siège, ni le Saint-Empire ne gardent assez de prestige pour imposer aux peuples et aux États leur double autorité. Les papes avignonnais, de Clément V à Grégoire XI, retenus au delà des monts par la monarchie capétienne, sont tombés vis-à-vis d'elle, comme Dante l'avait prévu, dans une dépendance que seuls les revers de la France dans la guerre anglaise ont par moment allégée. Le Saint-Siège rétabli à Rome en 1377, s'ouvre, dès l'année suivante, le drame du Grand Schisme, et bientôt les conciles réformateurs vont mettre en question jusqu'à la suprématie du pape sur les Églises. Jamais 
l'autorité pontificale n'a été plus débile ou plus menacée. Les progrès de la fiscalité, le cumul des bénéfices, l'indifférence religieuse des prélats, lèsent les intérêts et troublent les consciences. Dans cette Italie trop longtemps désertée, le Saint-Siège ne reconstitue ses domaines que par la force d'armes mercenaires, l'abus des censures spirituelles, l'astuce d'une diplomatie qui ne repousse pas le concours de seigneurs malfaisants ou scélérats. Il n'a triomphé des conciles qu'au moyen d'ententes et de concordats qui abandonnent en partie aux princes les dignités et les richesses des Églises nationales. Les papes de la fin du $\mathrm{XV}^{\mathrm{e}}$ siècle, souverains temporels occupés de politique et de guerre, ne pourraient plus, même s'ils en avaient conservé le désir, imposer aux États l'arbitrage suprême de l'Évangile. Cependant la doctrine impériale, formulée par Dante, n'a pas survécu à la déchéance de l'Empire. Louis de Bavière, sur lequel le poète ${ }_{\mathrm{p} 017}$ avait peut-être reporté son dernier espoir, n'a su qu'ouvrir un schisme sans avenir, avant de succomber dans sa lutte contre Jean XXII et Clément VI. Charles IV a par deux fois offert aux villes d'Italie le spectacle de sa faiblesse quémandeuse. Les princes et les peuples n'admettent désormais ni l'essence divine ni le rôle universel de la fonction impériale. Elle ne confère à Frédéric III aucun prestige en Allemagne, en Italie, en Europe. Malgré le mariage de Maximilien avec la fille de Charles le Téméraire, on ne saurait encore prévoir l'accablante accumulation d'héritages en vertu de laquelle Charles-Quint revendiquera de nouveau la monarchie universelle. La royauté française y opposera la notion positive et moderne de l'équilibre des forces; l'échec du plus grand des Habsbourg et son abdication, rendront manifeste, en 1556, l'irrémédiable déchéance de l'Empire.

Il ne peut donc plus être question désormais de soumettre, comme le voulait Dante, à la double conduite de Pierre et de César, les États chrétiens. Il ne leur reste que de résoudre, chacun pour soi et à son avantage, le problème du meilleur gouvernement. Les légistes français refusent au pape le droit de contrôler, d'après l'Évangile, la conduite de leur maître. Bien moins encore entendent-ils respecter l'empereur. Si Philippe le Bel en 1308, paraît désirer la couronne impériale, si François I ${ }^{\mathrm{er}}$, en 1519 , s'y porte candidat, l'un et l'autre ne souhaitent que d'étendre au loin, en vue de fins matérielles, une puissance toute matérielle. Pour Philippe le Bel comme pour Charles $\mathrm{V}$ et pour Louis XI, la politique est affaire d'intérêt et de calcul. Elle ne connaît 
d'autre objet que la grandeur et la puissance de l'État; elle ne suit que l'expérience et la raison; elle néglige les droits et les prétentions de César et de Pierre. La royauté anglaise, assistée de son Parlement, ignore également l'empereur et défend contre le Saint-Siège l'Église nationale. Les princes et seigneurs allemands règlent leur conduite d'après un égoïsme étroit. Partout où les bourgeois se gouvernent euxmêmes, dans les villes commerçantes de l'Allemagne du Sud ou du centre, à Augsbourg, Nuremberg ou Francfort, dans les villes du Nord qu'unit la Ligue hanséatique, dans les cités flamandes des Pays-Bas, les intérêts matériels des classes créatrices de la richesse dominent la politique.

En Italie, où, plus qu'en aucun pays, les souvenirs de l'histoire ancienne, la pratique de la libre discussion dans les assemblées communales et des entretiens diplomatiques dans les conseils p018 $_{\text {des ligues, }}$ ont pu affiner l'esprit des hommes d'État, et leur intelligence de problèmes que l'apparition précoce de certaines formes essentielles de l'économie capitaliste posait en termes déjà modernes, l'art de gouverner obéit aux règles d'une technique positive, qui définit exactement ses méthodes et ses fins, et s'affranchit de toute considération religieuse et morale. Les tyrans qui, dès le XII ${ }^{\mathrm{e}}$ siècle, établissent dans les principales villes du Nord leur domination, et dont les Visconti de Milan, au XIV ${ }^{\mathrm{e}}$ siècle, les Sforza, leurs successeurs, au XV ${ }^{\mathrm{e}}$, présentent les types les plus accomplis, ne consacrent leurs soins et leur effort qu'à fonder, maintenir, perpétuer la puissance de l'État. Ils créent des monarchies absolues, despotiques, souvent inhumaines, souvent soucieuses, en revanche, d'un exact gouvernement des choses. Dans les républiques, à Venise, Gênes ou Florence, l'intérêt de l'État se confond avec les avantages positifs de la classe maîtresse du capital, du prestige social, de l'autorité politique. Ainsi, dans le premier tiers $\mathrm{du} \mathrm{XV}^{\mathrm{e}}$ siècle, naît à Florence, de la puissance de la Banque, la puissance politique des Médicis.

L'apparition et le développement de l'humanisme détournaient alors les esprits vers d'autres méthodes, pour constituer la science du monde moral, rechercher et définir les lois des sociétés humaines, et pour en déduire les principes d'une politique nouvelle. 
Le triomphe de l'humanisme fut à la fois enrichissement et appauvrissement. Ce fut un bienfait, pour le Moyen Age finissant, que la connaissance plus exacte de l'antiquité, de la civilisation antique, de la pensée et de la science antiques, de l'art littéraire des anciens, que le contact enfin repris avec le génie ranimé du paganisme. Mais ce bienfait ne compensa pas entièrement le dédaigneux et sommaire abandon de certaines traditions morales, intellectuelles et spirituelles, léguées par le Moyen Age, et souvent de très haut prix. Ce fut un appauvrissement que la décadence finale de la scolastique parisienne et occidentale, si robuste encore, si réellement grande et féconde au temps de Pétrarque. Ce fut un appauvrissement que la décadence de la mystique, si puissante au $\mathrm{XIV}^{\mathrm{e}}$ siècle, si vigoureuse encore dans le premier tiers du XV siècle avec Jean Gerson, si capable encore d'un effort véhément pour appréhender le divin. L'humanisme, dans la seconde moitié du siècle, resta la seule ${ }_{p 019}$ force spirituelle véritablement vivante et neuve ; mais il faut regretter ce qui alors semblait périr.

Il le faut d'autant plus que l'humanisme demeurait incomplet et décevant. Pétrarque, le grand initiateur, avait légué à sa postérité la flamme et l'enthousiasme d'une passion et d'une poésie qui, pour parler comme Machiavel, ressuscitaient les choses mortes ${ }^{x i}$. L'effort des humanistes rendait aux modernes l'expérience morale, psychologique, sociale et politique des anciens : tout ce qui semblait nécessaire pour recommencer sur des bases nouvelles, puisque tel avait été le désir de Pétrarque, l'éducation de l'esprit humain. Pourtant, ils ne surent pas organiser, en une synthèse originale et vigoureuse, les nouvelles données qu'ils avaient acquises sur l'homme et le monde. Ils ne surent même pas définir avec précision et clarté les nouveaux principes d'analyse et de synthèse, de recherche et de construction, que, depuis la renaissance pétrarquiste, l'esprit humain cherchait confusément. Ce qui manqua le plus à l'humanisme du $\mathrm{XV}^{\mathrm{e}}$ siècle, ce qu'il fallut attendre en Occident jusqu'à Descartes, ce fut un Discours de la Méthode.

Cette faiblesse apparait dans leur effort pour reconstituer la science du gouvernement. Pétrarque avait eu deux politiques; l'une, toute d'idées, de formules et de réminiscences dantesques, revêtues d'éloquence classique et de rhétorique cicéronienne, et qui, à force de redondance et de prolixité, semble une réduction à l'absurde de la doctrine de Dante. Mais il avait, en même temps, ébauché le programme d'une politique humaniste, et, tant bien que mal, tenté de 
l'insérer dans le système d'une philosophie qui voulait rester chrétienne. Politique assez verbale et médiocre, dont il avait tiré les éléments non du réel, exactement étudié, mais des livres. En vain ses voyages à travers l'Europe, ses amitiés princières, lui auraient permis de comprendre ces modernes qui acclamaient son génie et qu'il méprisait. Mais, depuis les Romains, le monde lui paraissait vide. C'est uniquement dans les fastes de la Rome consulaire, glorifiée par TiteLive, qu'il étudiait les hommes, les peuples et l'art des les régir. Il engageait à la fois l'histoire et la science du gouvernement dans des voies où elles s'égaraient. La politique italienne ${ }_{\mathrm{p} 020}$ et la politique européenne lui avaient échappé. Les intérêts économiques, dont les chroniqueurs florentins, avant lui, savaient démêler le jeu, dédaigné des historiens antiques, lui parurent choses triviales et sans gloire. L'évolution politique et sociale qui transformait la commune en seigneurie ne retint pas son attention. Mais de l'antiquité romaine il n'avait compris l'étude qu'à la manière des moralistes, pour en tirer des exemples, des anecdotes, quelques biographies exaltantes, et l'affirmation de la loi qui entraîne à la décadence et à la ruine les peuples trop assurés, par des succès trop constants, d'un avenir de quiétude ${ }^{\text {xii }}$. Sur l'histoire ainsi réduite à une science auxiliaire de l'éthique, il fondait une politique nécessairement réduite à quelques thèmes de déclamation morale. Son enthousiasme de poète avait dégagé du passé romain l'idéal oratoire et conventionnel d'un gouvernement républicain, héroïque et vertueux. Il ne dit jamais comment il eût réformé ces États chrétiens, dont les chefs n'étaient à ses yeux que des tyrans, selon un idéal de liberté civique ; et lui-même s'accordait trop aisément avec les Visconti. Dédaigneuse du réel, appuyée sur l'autorité de quelques textes anciens, la politique de Pétrarque apparaît ainsi comme une scolastique nouvelle, assez peu capable d'éclairer l'intelligence et de guider l'action. Elle n'a pas été désavouée par les humanistes florentins.

Pourtant ces hommes se trouvaient mêlés, dès la première génération, comme chanceliers, comme orateurs, aux affaires d'une commune que la décadence de ses institutions conduisait insensiblement de l'oligarchie au principat; mêlés aux affaires générales de l'Italie, en un temps où naissait à Milan la plus puissante des tyrannies modernes ; mêlés aux disputes du Grand Schisme, des conciles et du SaintSiège restauré. Ils n'auraient eu qu'à fermer les livres et ouvrir les 
yeux : ils le faisaient quand ils devaient agir. Mais ils ne surent ni oublier leurs lectures ni fonder sur une science positive des faits l'art de gouverner les hommes. Pétrarque leur avait laissé le goût du lieu commun, de la phrase cicéronienne. Il avait surtout compromis d'avance les progrès d'une science politique inspirée d'une fausse notion de l'histoire. Les humanistes florentins, en histoire ${ }_{\mathrm{p} 021}$ et en politique, n'ont pas réussi, malgré l'intérêt et la grandeur de leur travail, à s'affranchir de ses leçons xiii.

Us ont, sans doute, pris plaisir à conter les plus récentes annales de leur cité. Mais ils semblent poser en principe que la description réelle du monde contemporain ne saurait apporter à l'esprit humain nul bénéfice. L'essentiel, au contraire, est d'y rechercher et d'y retrouver ce qui, défiguré par de longs siècles de barbarie, survit, chez les individus et dans la cité, du passé antique. Quand l'histoire étudie les modernes, elle accomplit une œuvre vaine, à moins d'adopter, comme règle essentielle de méthode, la réduction des types individuels et des formes sociales et politiques à l'exemplaire romain. Peut-être cet effort pour dégager, d'une comparaison entre le présent et l'antique, certains caractères permanents de la société humaine, contenait-il en germe une sociologie qui restait à construire. Du moins les Florentins savaient-ils que leur ville était fille de la république romaine, que leur constitution gardait les libertés des temps consulaires; drapant leur histoire à la romaine, ils pensaient mieux comprendre leur génie ${ }^{\text {xiv }}$. Mais le simple récit des faits dut subir quelques déformations. Lorsque Lionardo Bruni, chancelier florentin, conte l'histoire de son peuple, histoire qu'il sait et dans laquelle il a joué un rôle, ce vigoureux esprit, l'un des éducateurs de l'humanisme européen, se montre capable de critiquer les textes et les documents, de suivre avec diligence l'évolution des lois et des coutumes; et pourtant il efface trop souvent ce qui offre un caractère local et particulier, comme pour faciliter cette réduction au type romain, qui seule donne aux modernes la clef de leurs destinées ${ }^{\mathrm{xv}}$. Poggio $\mathrm{p} 022$ Bracciolini, qui fut lui aussi chancelier, et, par ses découvertes de textes antiques, enrichit le patrimoine de l'esprit humain, ne peut, lorsqu'il résume un siècle de guerres florentines, qu'imiter vainement les narrations et les harangues de Tite-Live.

Or une doctrine politique se nourrit de la méditation de l'histoire. Dante a longuement réfléchi sur l'histoire universelle. Pétrarque la connaît mal et l'aborde avec des idées de moraliste et de poète. Les 
héritiers de son effort ont hérité de son esprit. En vain Lionardo Bruni, qui rêve, en 1422, d'une fédération de libres cités italiennes conduites par Florence, sait vigoureusement définir les principes des libertés florentines et de l'égalité florentine devant la loi ${ }^{\text {xvi }}$. Les humanistes faiblissent, quand ils essaient d'atteindre à quelques vues d'ensemble sur le gouvernement. Leurs écrits politiques forment sans doute la partie la moins précieuse de leur œuvre. Ils développent en latin oratoire des lieux communs empruntés à l'antiquité sur la vertu des citoyens, des magistrats et des généraux. Si l'on ne savait que la plupart d'entre eux ont participé à la vie active, on douterait qu'ils aient jamais connu les hommes autrement que par les livres ${ }^{\text {xvii }}$.

Une idée, toutefois, de caractère positif, leur reste définitivement p023 acquise. Ils écartent toute conception religieuse de la société humaine; ils ne voient dans l'État qu'une création purement naturelle des hommes vivant en société. Mais une insuffisante connaissance du passé, une médiocre aptitude à dresser la théorie des faits contemporains, parce que, pour les interpréter, ils ne disposent que de critères mal appropriés, leur interdisent toute vigoureuse construction de doctrine : assez réalistes pour ne plus accepter le rêve de Dante, non pour fonder la science objective de la politique. Ils sont, comme Pétrarque, Romains et républicains. Ils exaltent Scipion l'Africain, glorifié par Cicéron et Pétrarque, le grand citoyen vainqueur d'Hannibal : Scipion qui, dans les fresques siennoises ou florentines, symbolise le bon gouvernement. Ils méprisent César, corrupteur du peuple et destructeur de l'État; ils l'accusent d'avoir préparé l'asservissement du monde à un Tibère ou à un Néron. La décadence romaine commence pour eux avec l'Empire. Contre César, Poggio Bracciolini compose un volume d'invectives, et s'accorde avec Lionardo Bruni pour maudire la tradition du dictateur. Ils la voient revivre, misérable et dégénérée; dans les institutions barbares du Saint-Empire romain-germanique. La cérémonie gothique du couronnement impérial consacre, de façon dérisoire, la suprême déchéance des libertés romaines, abolies par César. Il leur déplaît que Dante ait damné Marcus Brutus xviii.

Mais la politique républicaine des humanistes florentins manque de vigueur originale. Aucun d'eux n'a réussi à l'exposer avec méthode, n'en a défini les principes ou les conclusions. Nul n'a tenté d'opposer, 
au De Monarchia de Dante, un De legibus ou un De republica. Il manquait à ces lettrés, curieux de beau style, l'habitude d'une analyse attentive à discerner les éléments des questions, l'usage d'une dialectique habile à suivre l'enchaînement des idées, à les ordonner en systèmes. La faiblesse théorique de leurs doctrines s'aggrave d'une impuissance évidente à guider la pratique. Fondées sur une assimilation hasardeuse entre la Rome consulaire et la commune florentine, elles négligent à l'excès la différence des temps, des mœurs, des croyances, de l'économie. Elles font abstraction de toutes les données modernes et concrètes de la politique. Elles négligent la lutte des classes, parce que la philosophie humaniste de l'histoire la dédaigne ; p024 elles travestissent la lutte des partis à la romaine. Elles ne semblent même pas tenir un compte exact du prestige croissant des Médicis, de l'autorité personnelle et princière qu'ils fondent en marge de la constitution. Bien avant Montesquieu, ils avaient, élèves de Cicéron et de TiteLive, reconnu dans la vertu le principe essentiel du gouvernement républicain ; et pourtant ils ne surent pas voir la tyrannie déjà établie au cœur d'une république sans vertu.

Dans les cours de l'Italie du Nord, auprès des Visconti de Milan, des Este de Ferrare, des Gonzague de Mantoue, s'était développée une politique également humaniste, mais réconciliée avec les formes monarchiques du gouvernement, et qui, malgré le respect dû à Guarino de Vérone, ne mérite qu'une brève mention. Inégaux aux Florentins par la culture et le goût des idées, les humanistes du Nord comptent moins encore dans l'histoire de la pensée politique. Les Florentins n'avaient pas réussi à construire une théorie originale et moderne du régime républicain. Les humanistes attachés aux cours princières ne surent pas construire une théorie originale et moderne de l'État monarchique, ni écrire, avant Machiavel, le livre du Prince ${ }^{\text {xix }}$.

Mais le siècle de l'humanisme est en même temps le siècle des conteurs ; à côté de la postérité de Pétrarque vécut la postérité de Boccace. La comédie humaine du Décameron avait, trente ans après la mort de Dante, répondu à la Divine Comédie. Boccace et les conteurs qui, pendant deux siècles, ont poursuivi son œuvre, décrivent la société comme elle est, les hommes comme ils agissent. On peut se demander si ce réalisme sans illusions, qui toutefois permettait aux artistes 
de découvrir, dans un monde ${ }_{\mathrm{p} 025}$ aisément vulgaire, tant de grandeur et de beauté, ne devait pas, à la longue, renouveler la science politique, la guider vers une étude plus expérimentale des faits, et plus riche d'enseignements.

Le réalisme des conteurs n'est que la manifestation, plaisante sans doute, mais en somme inférieure et parfois triviale, d'une nouvelle forme de pensée, qui apparaît en Italie comme dans tout l'Occident, et qui, d'un effort lent, mais irrésistible, rajeunit la vie de l'esprit. Dès le lendemain de la mort de Dante, se développe le travail d'une science positive, qui déjà se réclame de l'expérience. Peu importe que les origines en soient anglaises et françaises, et quelle apparaisse d'abord chez les physiciens d'Oxford et les nominalistes parisiens. Pour mesurer la puissance de ce mouvement, il suffit de rappeler que, suspendu en Angleterre et en France, il se poursuit en Italie et en Allemagne ; et qu'il aboutit à Léonard de Vinci, à Copernic et à Galilée ${ }^{\mathrm{xx}}$. Il suffit de rappeler que, dès la fin $d u X V^{\mathrm{e}}$ siècle et les premières années du siècle suivant, Léonard de Vinci pratique les sciences expérimentales, en décrit les méthodes, en mesure le pouvoir, en pressent l'avenir. Comme l'humanisme, dans le domaine de la politique, n'avait su que ruiner l'idéal de Dante et ne lui substituer qu'une scolastique oratoire, il était fatal que ce positivisme scientifique, ce besoin de ne rien fonder que sur l'expérience, finît par imposer ses méthodes à la science politique, où l'humanisme cherchait encore sa voie.

Or les générations des dernières décades $d u X V^{\mathrm{e}}$ siècle allaient prendre à se considérer, elles et leur œuvre, un plaisir grandissant. Les modernes, honnis par Pétrarque, étaient de moins en moins certains que leur siècle fût si pauvre de génie. Déjà Poggio Bracciolini, dans une lettre de 1433, avait exprimé ce doute; en 1460, son successeur à la chancellerie florentine, Benedetto Accolti, composait un Dialogue sur l'excellence de ses contemporains : Dialogus de praestantia virorum sui aevi ${ }^{\mathrm{xxi}}$. Dès lors, il ne pouvait plus être question de s'humilier à jamais devant l'antiquité. L'Italie, brusquement, apparut telle qu'elle était : riche de types humains originaux et vigoureux. Cette originalité p026 et cette vigueur se manifestaient dans la maîtrise des artistes, dans l'éclat d'une civilisation créatrice de richesse et de beauté. On pouvait donc se demander si le monde moderne était aussi indigne d'étude que Pétrarque et les premiers humanistes l'avaient proclamé ; si, pour fonder la science et l'art de la politique, ce n'était pas une méthode stérile 
et décevante que d'adopter, comme norme et comme modèle, un passé dont l'interprétation même restait incertaine, puisque l'histoire des Romains, à la fois républicaine et impériale, offrait en égale abondance des arguments de force égale aux partisans de la République et de la monarchie.

Il était réservé à Machiavel de créer à la fois la critique de ce passé ambigu, médiocrement compris des humanistes, et l'étude de ces temps modernes trop longtemps méprisés. Il fut conduit à l'intelligence du passé par son expérience des affaires contemporaines. Il comprit le monde moderne parce que nul dédain préconçu, d'ordre littéraire ou philosophique, ne lui interdisait de se divertir au spectacle que les événements déroulaient sous ses yeux. C'est parce qu'il pouvait confronter, comme il le dit, une lecture ininterrompue des choses antiques et une longue expérience des choses modernes ${ }^{\text {xxii }}$, qu'il tenta d'instituer la science positive de la politique, et de rechercher l'esprit des lois qui règlent le gouvernement des peuples, la fondation et la conservation des États. Mais pour que la méthode strictement positive selon laquelle, à la même époque, Léonard de Vinci ébauchait l'exploration scientifique du monde matériel, fût enfin admise à l'étude des réalités politiques et sociales, il fallait encore qu'une suite tragique de guerres, d'invasions et de révolutions eût bouleversé la vie italienne, jeté le trouble dans les esprits et les consciences, et définitivement révélé la puissance de ces forces nouvelles, déchaînées à travers le monde moderne, et que, libéré de la théologie dantesque, l'humanisme, sans bien les connaître et les mesurer, tentait de soumettre à une discipline abstraite, anachronique et vaine. 


\title{
PREMIERE PARTIE
}

\author{
MACHIAVEL
}

$\underline{\text { Table des matières }}$

\section{Chapitre premier}

\section{La formation de Machiavel}

A Florence, dans une sombre rue au delà de 1'Arno, quelques maisons appartenaient à la famille des Machiavelli ; l'une des plus anciennes de Toscane, originaire de Montespertoli, petit bourg entre Val d'Elsa et Val di Pesa. Bien qu'elle dît avoir possédé cette terre à titre de fief, elle n'appartenait pas à la vieille noblesse foncière, écartée des affaires publiques depuis 1293 et les Ordonnances de justice : elle était de la bourgeoisie. Les Machiavelli possédaient encore, près de San Casciano, dans la Val di Pesa, un petit domaine qui devait, en 1512 , offrir asile à la disgrâce du secrétaire florentin. Ils étaient probablement inscrits à l'Art des notaires et des juges, corporation riche, peu aimée du petit peuple, mais cultivée et d'esprit curieux. Guelfes depuis le XIII ${ }^{\mathrm{e}}$ siècle, ils se vantaient d'avoir donné à la république cinquante prieurs et douze gonfaloniers. Ils n'aimaient guère les Médicis. Girolamo Machiavelli, exilé sous Cosme, avait intrigué contre lui dans les cités et les cours princières ; trahi par un petit seigneur de Lunigiana et ramené à Florence, il y était mort en prison. Le père de Niccolò, Bernardo, né en 1428, jurisconsulte et homme d'étude, remplit diverses fonctions d'ordre financier et judiciaire, fut de ceux qui, 
sans amitié pour les Médicis, évitèrent avec eux une lutte inégale. Bartolommea de' Nelli, qu'il avait épousée en 1458, venait d'une antique famille de Florence ; intelligente et cultivée, on lui attribua des Laudi qui n'ont pas survécu. Ils eurent deux fils et deux filles ; Niccolò, le second enfant, naquit à Florence le 3 mai 1469. p030

De sa jeunesse mieux vaut dire que l'on ne sait rien, sauf qu'il apprit le droit et n'en poussa pas loin l'étude. C'est uniquement d'après son œuvre que l'on peut imaginer son apprentissage intellectuel. Il entre dans la vie publique en juin 1498, secrétaire de la seconde chancellerie de la République florentine, à vingt-neuf ans. On peut admettre que sa première instruction est alors achevée ${ }^{\text {xxiii }}$. p031

Table des matières

\section{I}

Machiavel a grandi sous Laurent le Magnifique. Il a vingt-trois ans lorsque Laurent meurt, encore jeune, le 8 avril 1492. Il s'est formé sous le gouvernement médicéen, l'une des apparitions les plus originales de l'histoire italienne et de l'histoire européenne, en cette fin du $\mathrm{XV}^{\mathrm{e}}$ siècle où les États modernes poursuivent leur lent travail de développement et d'organisation. p032

Le gouvernement de Laurent le Magnifique est sans nul doute une tyrannie. Le mot, prononcé par les contemporains, a été retenu par Guichardin, qui définit exactement les hommes et les choses ${ }^{\text {xxiv }}$. Non pas une tyrannie militaire, comme celles qui prévalent dans l'Italie du Nord, et dont à Milan le gouvernement des Sforza offre le type accompli. La tyrannie civile, bourgeoise, d'une famille de banquiers, devenue, par la puissance de l'argent, maîtresse de l'État. Une tyrannie qui évite l'apparence de l'illégalité, qui affecte le respect des formes républicaines et de la constitution. Une tyrannie qui évite avec soin l'appareil militaire : les Médicis n'endosseront la cuirasse que devenus, après 1530 et par la grâce de Charles-Quint, ducs de Florence. Tout l'art de la politique, chez Laurent comme chez Cosme, son grand-père, se réduit à peupler conseils et magistratures d'hommes dévoués à sa maison, liés à l'avenir de sa maison par tous leurs inté- 
rêts ; à introduire prudemment dans la constitution, avec l'aveu des conseils et des assemblées, certaines retouches, en petit nombre, mais essentielles, et qui, sans en altérer le caractère général, ni, apparemment du moins, l'esprit, facilitent les progrès, insensibles et décisifs, du pouvoir personnel. Comme les tyrannies antiques, ou les tyrannies italiennes depuis le Moyen Age, le régime présente des caractères démagogiques. Contre la riche bourgeoisie qui, jusqu'en 1434 et au triomphal retour de Cosme, quelques mois exilé, dominait, oligarchie étroite et jalouse, la politique de la cité, les Médicis s'appuient sur les classes populaires et se ménagent par divers moyens leur faveur: une fiscalité légère aux petits et lourde à la vieille richesse ; une économie qui, soigneusement dirigée, assure les subsistances à bas prix ; la multiplication des fêtes, le divertissement d'un carnaval sans fin. Rien là d'ailleurs qui ne soit conforme aux maximes élémentaires du despotisme $^{\mathrm{xxv}} \cdot \mathrm{p} 033$

Mais ces banquiers florentins, qui savent la puissance de l'esprit, n'en ont pas laissé échapper le gouvernement. Républiques, seigneuries et le Saint-Siège avaient de bonne heure reconnu dans l'humanisme une force spirituelle dont il importait de capter l'appui. Les Visconti avaient attiré Pétrarque ; les papes attiraient d'éminents latinistes dans les bureaux de la Curie. La république florentine s'était honorée de choisir pour chanceliers des maîtres du savoir ancien : Coluccio Salutati, Lionardo Bruni. Par calcul et par goût, Cosme se fit le protecteur le plus libéral et le plus éclairé de l'humanisme. Mais il entendait garder et il garda le contrôle des intelligences. Laurent, comme son grand-père, les gouverna : plus hautain, et pourtant plus proche des artistes et des écrivains ; poète lui-même et homme du métier. Les Florentins pouvaient être reconnaissants au régime de cette suprématie de l'art et du génie que la politique de Laurent et sa ferveur intellectuelle assuraient à leur cité ${ }^{\text {xxvi }}$. Le néoplatonisme de Marsile Ficin régna, philosophie officielle, seule p034 $_{4}$ propre, d'après le maître de l'État, à discipliner les esprits et les cœurs. L'humanisme, jadis républicain, ne refusa pas de servir le pouvoir personnel.

Le régime, sous Laurent, se resserrait de jour en jour. Certaines apparences civiques subsistèrent. Laurent ne tenait pas de cour, afin de ne pas heurter la tradition, et de vivre à sa guise : fastueux seulement s'il recevait, en son palais de Via Larga, quelque étranger illustre. Mais rien ne se décida que par lui. Jaloux de son autorité, soup- 
çonneux, et, depuis la conspiration des Pazzi, meurtriers, en 1478, de son frère Julien, plus prompt encore à douter des hommes, il n'admettait en sa confiance que de rares fidèles, et ne laissait grandir personne auprès de lui. Les sentences de mort et d'exil, les confiscations, les taxes arbitraires, avaient détruit ou dispersé l'opposition. Il surveillait toutes les démarches des citoyens, même dévoués au régime, interdisait les mariages entre familles trop puissantes, et dictait au besoin les arrêts des tribunaux. Ses allures devenaient plus impérieuses, ses ordres plus péremptoires, et sa magnificence aimait à se voiler de mystère.

Nul désormais ne se dissimula plus le caractère du gouvernement. Beaucoup de citoyens parlaient avec amertume d'un régime qui, sur les ruines des libertés publiques, exaltait une famille et satisfaisait l'avidité d'une clientèle. Certains rappelaient diverses malversations commises par Laurent et ses amis au détriment des finances publiques. Tous se sentaient environnés d'un réseau d'espionnage et de délation. Les apologistes des Médicis durent reconnaître que Florence n'était plus une cité libre ni Laurent un simple citoyen; mais jamais on n'avait vu tyran meilleur ni plus aimable. Les plus hostiles admettaient du moins la supériorité de son génie. Quelques acquisitions territoriales, et le prestige accru de la République, depuis qu'entre les États de la péninsule il s'appliquait heureusement à maintenir un exact équilibre de forces, et que les étrangers la comparaient à l'aiguille de la balance italienne, parurent compenser les inconvénients d'un despotisme contenu dans les limites de l'opportunité, et qui, malgré quelques actes de répression et de vengeance, ne fut jamais un gouvernement de terreur ${ }^{\text {xxvii }}$. p035

Les Machiavelli, sous Laurent, étaient demeurés tacitement républicains. Quand Machiavel, en 1498, entra dans la vie politique, il était républicain. Malgré le paradoxe désespéré qu'il soutint dans le livre du Prince, on peut dire qu'il demeura tel jusqu'au dernier jour.

Républicain de sentiment, d'abord. Il est un authentique représentant de cette démocratie florentine qui garde le culte des libertés publiques, se méfie de quiconque essaie de prendre les allures d'un maître. Il n'admet pas volontiers un pouvoir personnel qui lui refuserait, 
pour parler comme Montesquieu, l'illusion d'obéir et de commander à des égaux, et de n'avoir que des égaux pour maîtres ${ }^{\text {xxviii }}$. Républicain aussi de doctrine, et qui, de bonne heure sans doute, a pris l'habitude de fonder la politique sur la méditation de l'histoire.

La certitude républicaine de Machiavel se nourrit d'abord d'une tradition communale et florentine. Il reste attaché aux institutions, aux lois, aux assemblées, aux magistratures de la cité ; ces institutions, moyennant quelques retouches, lui paraissent, dans l'ensemble, suffisantes pour assurer les libertés du citoyen ; c'est-à-dire le droit essentiel de n'être régi que par des lois librement débattues devant les assemblées et les conseils dont il fait partie ou dont il a librement élu les membres. Tradition civique, mal compatible avec le despotisme ingénieux et dur de Cosme et de Laurent.

A l'appui de sa certitude, Machiavel invoque la tradition consulaire p036 de Rome: tradition d'école, venue à lui par les livres et par l'école. Il sait l'histoire romaine : il a lu Tite-Live et Polybe. Il sait qu'entre la seconde guerre punique et le temps des Gracques la république romaine a réalisé la forme idéale d'un gouvernement capable d'assurer les libertés des citoyens et de développer la vigueur d'un État armé pour la conquête ${ }^{\text {xxix }}$. Plus tard, Rome n'a fait que décliner, perdre les vertus d'où provenaient ses forces vives et profondes. Machiavel déteste l'Empire, refuse tout respect au nom de César, à son œuvre et à sa mémoire. Comme les humanistes florentins du $\mathrm{XV}^{\mathrm{e}}$ siècle, il se range parmi les admirateurs de Scipion, et ne se réconciliera jamais avec le vainqueur de Pharsale ${ }^{\mathrm{xxx}}$.

Mais l'Empire romain survit sous le nom chrétien de Saint Empire, et l'empereur barbare continue de porter le nom romain de César. Les humanistes du Nord qui, au-dessus de la grandeur républicaine de Scipion, élèvent la grandeur impériale de César, s'accordent avec les gibelins pour respecter, dans le monde moderne, l'autorité de l'empereur. Les adversaires de César et les négateurs de son œuvre s'accordent avec les guelfes pour refuser l'hommage à ses modernes héritiers. Les Florentins nient les droits du Saint Empire ; la commune républicaine, soutien des cités guelfes, se glorifie d'avoir repoussé, en 1313, après un long siège, les armées d'Henri VII. Machiavel a recueilli cette tradition anti-gibeline : il dédaigne la pauvre majesté de Frédéric III ou de Maximilien ${ }^{\text {xxxi }}$. 
Cette aversion pour le gouvernement des Médicis, ce sentiment républicain et cette doctrine républicaine, éloignèrent sans doute Machiavel de l'humanisme, tel qu'il achevait de se ${ }_{\mathrm{p} 037}$ développer dans l'entourage de Laurent et de se rallier à une tyrannie qui le comblait de largesses. Machiavel n'a rien de commun avec les maîtres qui, au temps de son adolescence, ont pris la direction des esprits. Peu lui importe la conciliation que Marsile Ficin essaie du néoplatonisme alexandrin et de la mystique chrétienne, et son effort pour définir les dogmes simplifiés d'une religion naturelle où s'apaisera le désir de tous les hommes de bonne volonté. Peu lui importe que Pic de la Mirandole, élève des scolastiques, des philosophes arabes et des kabbalistes, croie entrevoir au terme de combinaisons hasardeuses la métaphysique moderne qu'appelait déjà l'angoisse de Pétrarque. Toute cette spéculation lui demeure étrangère. S'il aime à philosopher, à dégager de faits exactement connus quelques idées générales, la discipline positive, rationnelle et scientifique d'Aristote lui conviendrait mieux que l'idéalisme platonicien. Toute forme religieuse de pensée lui demeure indifférente et presque suspecte. Nul esprit ne fut moins que le sien curieux de métaphysique ou de mystique.

Machiavel pourtant avait vu sous Laurent les lettres toscanes, rajeunies au contact de l'antiquité gréco-latine, atteindre à l'expression parfaite. Luigi Pulci, pour la joie des esprits familiers avec la tradition française des chansons de geste et l'épopée antique, achevait en 1482, dans le Morgante maggiore, de conter les fantastiques aventures, parfois émouvantes et plus souvent bouffonnes, de Roland et de son écuyer gigantesque. Machiavel put y retrouver parfois sa propre ironie, son irrespect à l'endroit des grandeurs de chair, des illusions et des croyances dont se bercent les hommes. Dans l'œuvre de Laurent le Magnifique, il put goûter le réalisme de certaines évocations champêtres, le laisser-aller et l'effronterie de certains chants carnavalesques, une philosophie désabusée et prête à cueillir la joie sans trop compter sur le lendemain, plutôt que telles Laudi pieuses, que tels drames pour représentations sacrées, que les pages de l'Altercazione où, d'un style plus tendu, le maître de Florence discutait avec Marsile du souverain bien et de la suprême connaissance ${ }^{\text {xxxii }}$. Mais le talent classique d'Ange Politien, l'hellénisme des œuvres toscanes où s'exprime le mieux sa vision de poète et d'artiste, eurent probable- 
ment peu de séduction ${ }_{\text {p038 }}$ pour un homme qui n'était pas au fond assez curieux d'art ou de poésie pour se plaire, dans les Stanze par la giostra, à tant d'habiles réminiscences alexandrines et virgiliennes. Le toscan dont il allait bientôt user n'était pas une langue d'école, mais une langue parlée, de prix inestimable à force de justesse et de plénitude. Au latin classique, elle put emprunter parfois la forme et l'élan de la période ; mais cette éloquence, née de l'émotion et de la certitude, est celle à laquelle naturellement savaient atteindre, hors de toute convention académique, les hommes d'État florentins, habitués à retrouver presque sans recherche, pour défendre les intérêts de la République, la gravité romaine.

Ainsi Machiavel n'est pas l'élève du plus récent humanisme. Il a lu Tite-Live, les traités politiques et les discours de Cicéron ; il a lu Virgile, parce que toute l'âme et toutes les traditions du passé romain revivent dans l'Énéide. Mais la dernière école florentine savait le grec, aimait l'art et la poésie de la Grèce ; il ne semble pas que la renaissance des études helléniques, si active à Florence dans la seconde moitié $\mathrm{du} X \mathrm{X}^{\mathrm{e}}$ siècle, ait enrichi ou seulement orné l'esprit de Machiavel. Il a lu, comme depuis le Moyen Age tout esprit porté à réfléchir sur le gouvernement des hommes, la Politique d'Aristote ; il a lu Polybe, historien de Rome, pour s'instruire sur Rome et non sur la Grèce ; mais rien ne prouve qu'il ait lu les textes originaux ; il reste obstinément Romain et ne sera jamais Grec ${ }^{\text {xxxiii }}$. Humaniste sans doute par sa connaissance de l'antiquité, par l'effort qu'il tente pour découvrir, dans l'antiquité mieux comprise et comparée au monde moderne, quelques-uns des traits fondamentaux de la société humaine, quelques-unes des lois essentielles qui la régissent. Mais son admiration du passé consulaire de Rome, son culte des souvenirs de la République romaine, peuvent paraître, sous Laurent, choses presque démodées. Par là, Machiavel n'est pas du temps où il a reçu sa formation première. Il s'accorde avec le vieil humanisme républicain de Coluccio Salutati, de Lionardo Bruni, de Poggio Bracciolini; avec l'humanisme révolutionnaire et antipapal dont la tradition se transmet à Rome de Cola di Rienzo à Stefano Porcari et Pomponio Leto ; plutôt qu'avec l'humanisme érudit et subtil de Marsile Ficin, de Pic de la Mirandole, d'Ange Politien, qui, à la splendeur du génie ${ }_{\mathrm{p} 039}$ antique, demandent une parure nouvelle pour la magnificence princière de Laurent. 
Mieux vaut dire que l'éducation de son génie ne doit rien à aucune école. Mieux vaut discerner en lui quelques traits communs avec deux grands esprits, très supérieurs aux platoniciens de Florence, dont l'un fut son aîné, l'autre son contemporain : Laurent Valla et Léonard de Vinci ; le premier, dont il n'a peut-être pas lu les œuvres, adressées aux philologues, aux linguistes, aux dialecticiens, aux théoriciens du droit ecclésiastique ; le second dont il n'a pu qu'ignorer les notes manuscrites sur les sciences de la nature. Volontairement limitée à l'ordre des faits politiques, l'œuvre de Machiavel répond à ces besoins nouveaux, rationalistes et positifs, de l'intelligence italienne, qui s'étaient exprimés dans les discussions critiques, dans l'exégèse philosophique et religieuse de Laurent Valla, qui s'exprimaient alors dans l'immense enquête scientifique de Léonard. Même défiance que chez Valla et même ironie à l'égard des doctrines et des systèmes en possession d'un respect traditionnel ; même volonté de ne fonder aucune affirmation, aucune théorie, que sur l'expérience; même désir que chez Léonard d'explorer le monde réel, de le comprendre, d'y mesurer le pouvoir de l'esprit, et d'ordonner en un système rationnel et positif les règles de l'action humaine ${ }^{\text {xxxiv }}$.

***

Machiavel, comme tous les contemporains, sait la Divine Comédie et la cite. Mais Dante est pour les Florentins de la fin du XV siècle un homme d'un autre âge, et le culte qu'ils rendent à sa mémoire ne témoigne pas d'une intelligence exacte de son œuvre. Rien en réalité n'est plus étranger à la génération de Politien et de Laurent qu'une doctrine religieuse fondée sur la double base du rationalisme thomiste et de la mystique franciscaine. Rien n'est plus étranger qu'une doctrine politique fondée sur la restauration de l'Empire et la réforme du Saint-Siège. p040 Florence, cité guelfe, n'a jamais admis la pensée gibeline du poète exilé. Ses hommes d'État, à la fin $d u X V^{\mathrm{e}}$ siècle, méprisent un empereur incapable d'imposer l'obéissance aux villes et aux États allemands. Ses banquiers savent que Frédéric ou Maximilien ont la bourse vide. Mais Florence, quoique cité guelfe, n'accorde au pape que peu de respect. Ses banquiers connaissent trop bien le secret des finances pontificales. Ses ambassadeurs en cour de Rome ont suivi de trop près l'évolution qui transforme les papes en princes italiens, plus soucieux de soutenir les intérêts temporels de leur État que de 
guider, comme l'eût voulu Dante, les chrétiens dans les voies spirituelles. La République florentine a vu trop souvent les papes entrer dans des ligues politiques; elle s'est, pour des questions d'intérêts temporels, trouvé en guerre avec eux. Laurent le Magnifique a fini par diriger à peu près complètement la politique d'Innocent VIII. Mais il ne pensait nul bien du pape, ni de son entourage, ni de cette cour de Rome envahie par l'esprit mondain, étrangère au souci de pratiquer la loi de l'Évangile ou d'en hâter le règne. Pour la grandeur de sa famille, il tirait parti des abus romains. Son fils Jean, le futur Léon X, fait cardinal à treize ans, on l'avait envoyé à l'Université de Pise, apprendre en hâte ce qu'il lui fallait savoir de théologie et de droit canon; et quand ensuite il était parti pour Rome, Laurent avait pris soin de lui rappeler qu'il allait entrer dans la sentine de tous les vices ${ }^{\mathrm{xxxv}}$. Ainsi, à Florence, où l'on avait oublié la scolastique dantesque à tel point que l'Académie platonicienne tentait de reconstruire la théologie sur de nouvelles bases, où l'on ne parlait de l'empereur que pour en rire et du pape que pour discuter sa politique italienne et blâmer son gouvernement de l'Église, le système d'idées qui soutient la Divine Comédie était devenu inintelligible ${ }^{\text {xxxvi }}$. Cristoforo Landino, qui pourtant aimait le poème sacré, n'en savait tirer que les froides allégories d'un spiritualisme cicéronien; Pic de la Mirandole préférait les vers de Laurent. Machiavel, comme sa génération, n'a guère compris Dante et p041 n'a point partagé sa foi. D'accord avec lui pour exalter la grandeur spirituelle de l'Italie et déplorer son esclavage, il blâme sévèrement les dures invectives du partisan gibelin contre Florence ${ }^{\text {xxxvii }}$. Il a condamné la politique de Dante; de l'ordre chrétien du monde, tel que le De Monarchia, le Purgatoire et le Paradis en décrivent l'idéal, Machiavel n'a pas voulu. Parmi les hommes de cette génération, un seul, aussi grand que Dante, a compris son œuvre : Michel-Ange.

Machiavel connaît sans doute assez peu les œuvres latines de Pétrarque ; on ne les lisait plus guère, bien qu'elles aient tenu dans l'histoire de l'esprit un rôle capital, orienté pour deux siècles l'humanisme, avec ses ambitions et ses incertitudes. Du Canzoniere, dont toute la lyrique de la Renaissance italienne répète et amplifie les thèmes avec une habileté raffinée et monotone, Machiavel, aisément cynique, ne semble pas avoir tiré quelque nourriture spirituelle. Il sait, comme ses contemporains, rimer des sonnets à la manière de Pétrarque ; mais il n'a rien retenu de lui, en dehors de cette passion nationa- 
le, faite d'orgueil et de douleur, qui avait trouvé dans quelques canzoni certaines expressions d'une rhétorique émouvante ; l'essence même de la poésie de Pétrarque lui échappe.

Il est plus proche de Boccace et de l'école des conteurs florentins, à qui le Décameron offrait un modèle inégalé. Par toute une partie de ses œuvres, il reste leur élève. Telle nouvelle, tel récit de ses lettres familières, telle scène de ses comédies, la Clizia ou la Mandragola, rappellent évidemment Boccace ou les conteurs florentins, avec l'originalité d'une observation plus impitoyable, d'une expression plus dure et parfois cruelle. Lecteur des poètes toscans, Machiavel manie aisément la tierce rime et l'octave, sait les règles de la canzone, pratique les formes les plus graves ou les plus familières de la poésie. Mais il n'a pas reçu les dons du poète, et sa grandeur n'apparaîtra que dans ses œuvres en prose ; et dans cette prose qui est certainement la plus drue, la plus vigoureuse et la plus expressive qu'on ait écrite en Toscane, et ne doit sa perfection à aucun enseignement d'école. p042

$$
\text { *** }
$$

Laurent le Magnifique est mort dans la nuit du 8 au 9 avril 1492. Deux ans plus tard, Charles VIII descend en Italie, conquiert sans obstacle ni résistance le royaume de Naples, et le perd aussi vite. Le nouveau maître de Florence, Pierre de Médicis, incapable de dominer les difficultés intérieures, incapable de manœuvrer habilement et avec honneur parmi les dangers de l'invasion française, prend la fuite, le 8 novembre 1494, devant le peuple en révolte. Ainsi se vérifie la prédiction de Cosme l'Ancien: «Je connais les humeurs de ce lieu : cinquante ans ne passeront pas que nous n'en soyons chassés. » On restaure, hâtivement et dans l'enthousiasme, la République. Mais tout aussitôt elle s'abandonne à la conduite du dominicain Jérôme Savonarole : héritier de la tradition de réforme ascétique et monacale qui, depuis le Moyen Age, protestait contre la décadence de l'esprit chrétien dans l'Église et la société, contre l'invasion de l'Église par l'ambition temporelle, la recherche de la richesse et de la puissance; héritier de cet esprit d'apocalypse, qui, depuis le XIII siècle, la prédication de Joachim de Flore et la diffusion de l'Évangile éternel, prophétisait le renouvellement du monde, la vengeance et la justice divine, la victoire finale des saints. Pendant quatre ans, Savonarole gouverne Florence, essaie d'y fonder une république chrétienne et puritaine, tente 
l'entreprise qu'un demi-siècle plus tard Calvin put réussir à Genève. Il se brise contre l'indifférence sceptique de la bourgeoisie, contre la haine des partisans que les Médicis ont conservés, contre la force toujours redoutable du pape et du Saint-Siège, que nul schisme nouveau n'est venu affaiblir, et dont Florence, ville guelfe, ne peut rejeter l'obédience. Après un procès tragique et dérisoire, Savonarole est pendu et brûlé, le 23 mai 1498, devant le palais de la Seigneurie.

La fondation d'une démocratie puritaine, guidée par un moine, a posé, devant l'esprit de Machiavel, un problème inattendu : celui du rôle que peuvent jouer, dans la vie politique des peuples, les inspirés, les voyants, les prophètes, les mystiques, les hommes qui ne sont pas des réalistes ; qui ne fondent pas leur action sur l'étude et l'évaluation exacte des forces sociales et politiques; qui négligent les données des faits et de l'histoire, en infléchissent l'évolution dans un sens inattendu, p043 et, sans s'arrêter à la coutume, aux traditions et au legs du passé, tentent de reconstruire la société humaine selon quelques vues de l'esprit. Machiavel est moins réaliste qu'on n'a voulu dire. Sous le masque de calculateur glacé dont une tradition faussement historique persiste à couvrir ses traits, il est, à ses heures, comme Dante, Pétrarque ou Michel-Ange, un enthousiaste et un visionnaire : les dernières pages du Prince peuvent en témoigner. Il ne rejette aucunement le rôle historique de ceux qu'il appelle les prophètes; des hommes supérieurs qui, soudain, modifient le cours de l'histoire, imposent aux peuples un ordre nouveau, « Je ne suis pas, écrira Montesquieu, son lecteur attentif, du nombre de ceux qui regardent la République de Platon comme une chose idéale et purement imaginaire, et dont l'exécution serait impossible. Ma raison est que la République de Lycurgue paroît d'une exécution tout aussi difficile que celle de Platon, et que, cependant, elle a été si bien exécutée qu'elle a duré autant qu'aucune république que l'on connoisse, dans sa force et sa splendeur » ${ }^{x x x v i i i}$. Pareillement, Machiavel admet sans hésiter l'intervention d'un législateur de génie, Numa ou Moïse. Seuls, pourtant, les prophètes armés ont vaincu ; les prophètes sans armes ont péri. Nul réformateur d'État ne peut vaincre par la seule force de la parole, de la persuasion, de l'esprit; il y faut encore la force matérielle. Savonarole n'a pas voulu, ou n'a pas pu, ou n'a pas su en user. Il a péri comme les prophètes juifs en lutte avec les rois d'Israël ${ }^{\text {xxxix }}$. 
Capable, autant que les plus grands Florentins, d'enthousiasme et de passion, Machiavel est en même temps l'un des esprits les plus critiques, les plus portés au doute et à l'ironie, qu'ait produit un peuple enclin à rire d'autrui et de soi-même. Aussi, devant un prophète, commence-t-il par douter. Il a certainement douté en face de Savonarole : il a soupçonné l'artifice et l'imposture : «Le moine, dit-il dans une lettre du 8 mars 1497, observe les circonstances pour mieux colorer ses mensonges. $\gg{ }^{\mathrm{xl}}$. Artifice ou même imposture, il s'en serait accommodé ${ }_{\mathrm{p} 044}$ si le réformateur en avait su jouer habilement. Machiavel autorise sans hésiter l'homme de génie à tromper les peuples pour leur bien; mais il doit tromper avec art, et l'œuvre doit justifier les moyens. Savonarole a soutenu, par un faible mensonge, une œuvre de faible vertu.

Machiavel n'aime pas les gens d'Église. Il méprise les moines, les tient pour fourbes, hypocrites et simulateurs : il a, dans sa comédie de la Mandragola, imaginé le personnage de fra Timoteo. Cette méfiance, ce mépris et cette moquerie, conformes à une vieille tradition joyeuse et plaisante, qui n'est pas spécialement florentine ou italienne, n'ajoutent rien d'original ou d'imprévu à ce que Machiavel a pu lire dans Boccace ou l'œuvre des nouvellistes. Ce qui compte, c'est le jugement qu'il porte, à maintes reprises, sur le catholicisme. Question capitale, puisque la réforme de l'Église, dans son chef et dans ses membres, fut déjà réclamée par Dante ; que, depuis la fin du Grand Schisme, les conciles de Constance et de Bâle, elle reste à l'ordre du jour ; qu'à Florence, les membres de l'Académie platonicienne, Marsile Ficin et Pic de la Mirandole, sont des réformateurs qui, pour rendre au dogme ses prises sur les esprits, tentent de le rajeunir et de le concilier avec la plus haute sagesse des païens et de l'Orient; que Savonarole enfin est un réformateur qui fonde son effort et son œuvre sur la double tradition de la scolastique thomiste et de l'apocalypse mystique ; et qu'enfin, dans vingt ans, Luther viendra. Il faudra qu'un jour Machiavel lui-même, sur le problème de la Réforme, exprime son avis ${ }^{x l i}$. Mais on pourra comprendre alors que le catholicisme, la vie catholique, l'idéal catholique, ne l'ont jamais ému ni attiré. Non pas uniquement parce qu'il aime la vie facile, le divertissement et le plaisir. Machiavel, tout sensuel qu'il fût, n'était pas incapable d'ascétisme et de souffrir pour une idée. Mais l'idée à laquelle il pouvait se sacrifier ne se situait pas au delà de l'horizon humain. Construire, mainte- 
nir, agrandir la cité : mais nul renoncement à ce qui est gloire humaine, affirmation de la puissance du génie humain. Nul souci de la cité céleste. Machiavel, homme d'État, accusera la morale chrétienne d'avoir affaibli chez les modernes les vertus du citoyen ${ }^{\text {xlii }}$. p045

Aussi ne prend-il nul intérêt à l'effort des mystiques ou des ascètes qui, en cette fin du Quattrocento, se proposent de restaurer la vie chrétienne dans l'Église et dans le siècle. L'ascétisme monacal ne sera jamais à ses yeux que l'interprétation paresseuse et fausse d'une religion qui ne doit jamais contrarier ou retarder l'action du citoyen. Savonarole, sans doute, n'entendait pas conduire tous les Florentins au cloître réformé de Saint-Marc; il avait essayé d'accomplir en luimême l'union du citoyen et de l'ascète. Pour Machiavel une telle union demeure contradictoire et impossible, et c'est l'ascétisme chrétien qu'il condamne et rejette en entier. Non seulement une Florence dévote et pénitente où l'on brûlerait les œuvres d'art et les livres, ne conserverait pour lui nul attrait ; mais tant de dévotion, tant de pénitence n'accroîtrait en nulle manière, et risquerait au contraire d'affaiblir l'énergie de la cité. En fait, Florence, dévote et pénitente, ne sut pas ou n'osa pas, contre les agents masqués d'une restauration médicéenne, alliés avec la cour de Rome et Alexandre VI, défendre Savonarole.

Machiavel a donc refusé son consentement à la réforme civique et puritaine que tentait le grand dominicain. Florence se trouvait en pleine et violente réaction contre l'œuvre de Savonarole, quand, un mois après le bûcher de la place de la Seigneurie, Machiavel, élu en juin 1498 secrétaire de la seconde Chancellerie, entra dans la vie politique. Le seul fait qu'en un temps où n'était pas encore apaisée l'émotion de cette mort tragique, la Seigneurie, qui l'avait permise, appelât Machiavel à des fonctions de confiance et de responsabilité, démontre avec évidence qu'on ne lui savait nulle sympathie pour l'œuvre et nul regret pour l'homme. 
Deux chancelleries se partageaient la correspondance de la République florentine. La première assurait les rapports avec les pays étrangers. Elle avait pour chef le chancelier ou secrétaire de la République. Quelques hommes de haute valeur, et qui comptent dans l'histoire intellectuelle et politique de la cité, Coluccio Salutati, Lionardo Bruni, Poggio Bracciolini, Carlo Marsuppini, Benedetto Accolti, Barlolommeo Scala, Cristoforo ${ }_{\text {p046 }}$ Landino, avaient occupé ce poste, qui ne devait jamais être confié à Machiavel. La seconde Chancellerie assurait les relations administratives avec les officiers et magistrats établis dans les villes sujettes. Dès le 14 juillet 1498, Machiavel, sans quitter la seconde chancellerie, fut mis comme secrétaire à la disposition des Dix de la Liberté et de la Paix, appelés couramment les Dix de l'Autorité suprême, "Dieci di balìa ". Ces magistrats, renouvelés par élection tous les six mois, dirigeaient l'administration intérieure du domaine, organisaient la défense militaire, et, sous le contrôle de la Seigneurie et du chancelier, correspondaient au jour le jour avec les ambassadeurs et orateurs envoyés à l'étranger. Machiavel devait rester secrétaire de la seconde Chancellerie et des Dix jusqu'à la chute de la République et à la rentrée des Médicis en septembre 1512. Il ne reçut jamais ni très hautes charges, ni grands honneurs, et se vit toujours laissé au second rang, dans l'ombre d'hommes qui ne le valaient pas. Il ne fut jamais ambassadeur en titre et ne remplit que des légations : subordonné au chancelier de la République, Marcello Virgilio Adriani, bon humaniste, élève de Politien et de Landino, mais dont l'histoire n'a pas retenu le nom ${ }^{\text {xliii }}$. Ces années d'activité politique, diplomatique et militaire, d'études et de voyages, achevèrent de former son génie.

Florence était en guerre contre Pise, ville sujette, qui avait profité de la campagne de Charles VIII pour recouvrer sa liberté. Les opéra- 
tions, mal conduites, devaient se prolonger, avec peu d'honneur pour la République, jusqu'en 1509. Mais cette petite guerre devant Pise n'était qu'un épisode médiocre de l'histoire politique et militaire de ce temps. Les guerres d'Italie, commencées en 1494 avec la descente de Charles VIII , continuaient; elles allaient durer encore plus d'un demi-siècle, jusqu'en 1559 et au traité du Cateau-Cambrésis. Sans relâche se mêlaient aux actions militaires les jeux d'une politique de force et de ruse, et d'une diplomatie qui poussait déjà très loin l'art de dissimuler. p047

Charles VIII avait en un an tout conquis et tout perdu. Puis Louis XII avait revendiqué Naples, et prétendu de nouveaux droits sur Milan. Il avait en deux campagnes, d'août 1499 au printemps de 1500, occupé le Milanais ; le duc usurpateur Ludovic le More, trahi par ses mercenaires suisses, était maintenant prisonnier en Touraine, au château de Loches. Pour l'attaque de Naples, Louis XII s'était, en novembre 1500, allié à Ferdinand, roi d'Aragon; trahi à son tour par ses mercenaires aragonais, le dernier roi de Naples, Frédéric, alla vivre prisonnier au duché du Maine. Les deux vainqueurs se partagèrent le royaume et ne s'entendirent pas longtemps. Dès 1502, par la diplomatie et par les armes, ils se disputaient leur conquête ; elle finit par rester, en 1504, à Ferdinand. Naples fut espagnole ; Milan fut française ; à Gênes échut, en 1507, le même sort.

Jules II gouvernait, depuis 1504, l'Église catholique et l'État romain ; avec plus de zèle et de soin, étant avant tout guerrier et politique, l'État que l'Église. Les Borgia n'avaient fait que passer. Alexandre VI venait de mourir, et son fils César, après avoir presque réussi à créer en Romagne, avec l'appui de la royauté française, une monarchie vigoureuse, voyait du jour au lendemain la fortune lui échapper, et perdait en quelques semaines tous ses États. Le nouveau pape, âme tragique et violente, capable d'inspirer Michel-Ange et de le comprendre, n'avait que deux désirs : reconstituer et consolider le pouvoir temporel des papes en Italie; chasser d'Italie les étrangers qui y avaient établi des dominations barbares. La reconquête des territoires perdus par le Saint-Siège s'accomplit au moyen de petites guerres en Ombrie et en Romagne. On vit le pape entrer dans la Mirandole par la brèche, imiter à Bologne les triomphes païens de César. Contre Venise, usurpatrice de terres pontificales, détestée en Italie pour sa richesse et son esprit de conquête, Jules II sut se procurer l'alliance d'un de ces 
envahisseurs dont il souhaitait la ruine. Ce fut l'armée de Louis XII qui, le 14 mai 1509, près d'Agnadel, dispersa les mercenaires vénitiens. Aussitôt, contre Louis XII, le pape sut obtenir l'alliance de l'Espagne et des Cantons Suisses. Dès lors apparaissait l'essentielle faiblesse, dénoncée par Guichardin, de cette politique tumultueuse de libération. Pour chasser l'étranger d'Italie, Jules II, incapable de s'appuyer sur des forces italiennes, devait compter sur l'étranger. Mais le système qui consistait à faire chasser un barbare par un autre et le second par un troisième était sans p $048_{\text {issue }}{ }^{\text {xliv }}$. Fatalement, le dernier barbare victorieux, le plus fort, le plus tenace, le plus habile, le plus trompeur, le plus heureux, le mieux favorisé de la fortune, demeurerait. Les Espagnols restèrent, et pour deux siècles, à Naples et à Milan. Jules II coalisa Ferdinand, et Venise réconciliée, et les Suisses et jusqu'à l'Angleterre, en une ligue qui se déclara sainte. Maladroitement Louis XII recourut aux armes spirituelles; pour juger et déposer un pape qui provoquait la guerre entre des peuples chrétiens, il convoqua, d'accord avec l'empereur Maximilien, à Pise, puis à Milan, un concile universel qui fut peu fréquenté. Les armes temporelles, d'abord, lui réussirent mieux. Un jeune général de vingt-deux ans, dont une brève campagne révéla le génie, Gaston de Foix, chassa les Suisses du Milanais, délivra Bologne, prit Brescia, et, le jour de Pâques 1512, près de Ravenne, défit les Espagnols. Mais il avait trouvé la mort dans sa victoire ; et l'armée française, mal commandée, perdit aussitôt Milan. Rien ne subsista plus des conquêtes de Charles VIII et de Louis XII.

Florence, au milieu de ces événements tragiques, avait essayé de vivre et de se défendre. Elle s'y trouvait fatalement mêlée, p049 par une longue tradition d'alliance française. Mais incapable même de reconquérir Pise, elle laissait apparaître son évidente faiblesse ; en face des monarchies modernes qui se disputaient l'Italie, seules pouvaient compter Rome et Venise. Pour raffermir la conduite de sa politique, elle avait en 1502 introduit dans sa constitution une réforme qui resta vaine. On crut que la débilité florentine provenait des trop brefs pouvoirs confiés au chef responsable du gouvernement, ce gonfalonier de justice dont la charge ne durait que deux mois. On détestait Venise, mais on lui enviait la stabilité de ses institutions, à la fois républicai- 
nes et autoritaires. Le doge de Venise était élu à vie : le gonfalonier de Florence, désormais élu à vie, eut l'illusion d'un pouvoir accru sur des magistrats et des conseils fréquemment renouvelés. On désigna, le 22 septembre 1502, Piero Soderini, qui avait rempli de hautes fonctions et représenté Florence comme ambassadeur à Venise : sans talents supérieurs, honnête et libéral, incapable de susciter trop de haines ou d'amitiés. Machiavel du moins allait bientôt devenir le conseiller de Soderini, le guide et l'inspirateur de la politique florentine ${ }^{\text {xlv }}$.

Elle était vouée à l'humiliation et à la défaite. Florence, tenue en échec devant Pise, avait, en 1500, dû payer cher l'inutile envoi d'auxiliaires français. Quand, en 1503, César Borgia devint redoutable, et, à plusieurs reprises menaça de passer l'Apennin romagnol, l'amitié française, toujours chèrement payée, la protégea ; mais elle ne respira qu'à la mort d'Alexandre VI. Lorsque Louis XII, en 1504, abandonna le royaume de Naples à Ferdinand, et parut renoncer à toute idée de revanche, elle eut quelques années de répit. C'est alors que Machiavel tenta d'organiser, sur le modèle des Cantons Suisses, ces troupes citoyennes auxquelles, en vertu de l'ordonnance qui, le 6 décembre 1506, créait les Neuf de la Milice et l'en nommait secrétaire, il consacra tant de labeur et de passion. Florence, après avoir acheté la bonne volonté de la France et de l'Espagne, obtint finalement, en mai 1509, la capitulation de Pise. Elle ne désirait plus qu'observer, dans les conflits italiens, la neutralité. Elle se tint à l'écart des entreprises de Jules II contre la république vénitienne. Mais quand il forma contre Louis XII, son allié de la veille, une nouvelle ligue, le roi obligea les Florentins à prendre parti. Ce fut sur leurs domaines, à Pise, nouvellement ${ }_{p 050}$ réduite, que, malgré l'avis de Machiavel, s'ouvrit en novembre 1511 le concile qui entreprit de juger le pape et de le déposer. Florence, frappée d'interdit par Jules II, gravement menacée dans ses relations financières et commerciales avec les États pontificaux, subit de lourdes pertes ${ }^{x l v i}$. Marchands et banquiers souhaitèrent le retour des Médicis. Une fois le Milanais évacué par les armées françaises, les forces de la coalition papale dispersèrent aisément les milices de Machiavel et, le 29 août 1512, saccagèrent Prato. Les partisans de Médicis purent alors contraindre Soderini à l'exil, négocier avec l'ennemi, imposer la rentrée de la famille.

La carrière de Machiavel se trouva désormais achevée. On le priva, le 7 novembre, de tous ses emplois; quelques jours plus tard, on le 
bannit de Florence, et on lui assigna pour résidence le petit bourg de San Casciano, sur la route de Sienne, avec défense de s'en éloigner.

Table des matières

\section{III}

Tels furent les événements auxquels prit part Machiavel durant les quatorze années de sa vie active. Il put ainsi joindre, comme il l'écrivit plus tard dans la préface du Prince, à une lecture ininterrompue des choses antiques, une longue expérience des choses modernes ${ }^{\text {xlvii }}$. Il put, à cette double école, dégager, définir, analyser les éléments dont s'était composé, pendant ces quatorze années, le drame de l'histoire italienne.

$* * *$

Ce qui d'abord troublait et parfois accablait les esprits était le succès de l'invasion étrangère, trop facilement triomphante. $\mathrm{p}^{2} \mathrm{Il}$ Il posait la question de la débilité politique et militaire des États italiens. Les réflexions qu'un tel sujet inspirait à Machiavel devaient se retrouver, méthodiquement déduites, en ce chapitre XXIV du Prince, où il expose les raisons pour lesquelles les princes d'Italie perdirent leurs domaines. Faiblesse politique ; insuffisance de l'organisme constitutionnel, qui ne s'est pas trouvé assez vigoureux pour maintenir l'État en danger et pour en assurer la défense ; impopularité de gouvernements détestés du peuple, qui, pour s'en débarrasser, acceptait sans regret la domination étrangère; ou, lorsqu'ils s'appuyaient sur lui, trahis, au moment du danger, par les possesseurs des terres ou les détenteurs du capital. Faiblesse militaire enfin de ces États, qui n'avaient jamais su se donner aucune armée véritablement tirée du pays et au service du pays, et confiaient le soin de leur défense à des mercenaires ${ }^{\text {xlviii }}$.

Instruit par l'histoire des deux derniers siècles et par les événements contemporains, Machiavel assure que l'on ne peut compter ni sur ces troupes, ni sur leurs chefs, toujours prêts à se vendre, ou à préparer, par la force, le renversement de l'État et la fondation du despo- 
tisme. Machiavel, organisateur passionné des milices citadines, hait les soldats de métier et les méprise; sans nul souci d'impartialité ou de justice, il leur refuse d'emblée toute vertu militaire et toute loyauté. Au camp devant Pise, il a cru sans cesse constater le mauvais vouloir des officiers; chaque jour il a pressenti une trahison. A Milan, les Suisses, à Naples, les Aragonais avaient trahi Ludovic le More et Frédéric. A Agnadel, les mercenaires qui servaient la République vénitienne avaient plié. Peu à peu s'ébauchait, dans l'esprit de Machiavel, le douzième chapitre du Prince. Les armées mercenaires n'avaient pas su contenir l'invasion: "Quand vint l'ennemi, elles montrèrent ce qu'elles valaient. C'est ainsi que Charles VIII , roi de France, put occuper toute l'Italie sans autre peine que de marquer les logis à la craie... Et tout le talent des chefs de bande eut pour effet que l'Italie a été traversée à la course par Charles, rançonnée par Louis, a subi les violences de Ferdinand et les insultes des Suisses. Ils ont conduit l'Italie à l'esclavage et à la honte. » ${ }^{\text {xlix }}{ }_{\mathrm{p} 052}$

Cette faiblesse militaire avait été voulue, entretenue par les princes : "Qui disait que ces maux, poursuit-il, pensant à Savonarole, avaient nos péchés pour cause, disait vrai : mais ce n'étaient pas les péchés qu'il croyait: c'étaient les péchés des princes »" La libre commune avait, au Moyen Age, résisté vigoureusement aux empereurs, fait reculer Frédéric Barberousse. Henri VII, appelé par les gibelins et par Dante, avait, en 1313, dû lever le siège de Florence. La commune avait été forte parce qu'elle était libre, et que, pour défendre son indépendance et ses lois, elle armait des citoyens libres. Mais partout en Italie le premier soin des tyrans avait été de désarmer les peuples. Ainsi avaient agi, à Milan, les Visconti et les Sforza : ainsi, à Florence, les Médicis. Sur ce point, Machiavel se trouve d'accord avec Savonarole et Guichardin. Savonarole avait, le premier à Florence, compris la nécessité d'enrôler les citoyens pour la défense de leurs libertés. Guichardin, après que Machiavel eut écrit le Prince, l'Art de la Guerre et la plus grande partie des Discours sur la première Décade, composait entre 1524 et 1527, ce Dialogo del Reggimento di Firenze, où il expose, avec la clarté et la vigueur d'un Montesquieu, la philosophie de l'usurpation médicéenne: il accuse les Médicis d'avoir, de propos délibéré, fait tomber les armes des mains des citoyens li. Machiavel, au chapitre XII du Prince, affirme qu'une République munie d'armes qui lui appartiennent en propre, défend plus ai- 
sément que toute autre son indépendance contre l'étranger, sa liberté intérieure contre tout essai de coup d'État. Il citait l'exemple de Rome et de Sparte dans l'antiquité, des Cantons Suisses dans le monde moderne. Rome et Sparte restèrent, pendant de longs siècles, armées et libres : au contraire, Carthage fut trahie par ses mercenaires. Pareillement, dans le monde moderne, p053 il affirme que les mercenaires ont trahi tous les États italiens lii.

Ainsi l'étude du problème militaire le reconduisait au problème fondamental, le problème politique. Les princes italiens s'étaient trouvés incapables de résistance armée, parce que leurs États participaient de la faiblesse commune à toutes les tyrannies. De tels gouvernements n'osent pas armer les peuples; le despotisme a produit la faiblesse militaire des États italiens. Au contraire une cité libre, où tous portent les armes, devient nécessairement une puissance militaire ; puissance d'autant plus redoutable que les citoyens sont plus attachés à leurs lois et à leurs libertés. Il peut toutefois arriver qu'une république laisse corrompre en elle l'esprit républicain, et néglige d'assurer, par ses propres forces, la défense de son territoire. Ce fut, dans l'antiquité, le cas de Carthage ; c'est le cas de Venise, dont les institutions politiques sont bonnes au point que Florence lui emprunte le gonfaloniérat à vie ; mais où les citoyens, occupés uniquement d'intérêts mercantiles, ont négligé l'art militaire et le devoir militaire ; comme Carthage après Zama, Venise après Agnadel a payé son erreur ${ }^{\text {liii }}$. Ce fut le cas de Florence, aussi longtemps que les Médicis travaillèrent à corrompre les institutions de la République et l'esprit de ses lois. Machiavel put croire, jusqu'en août 1512, qu'il y avait restauré l'antique vigueur des milices citoyennes. Mais Naples et Milan, à jamais irréformables, lui paraissaient condamnées au despotisme, et, par là même à subir l'invasion et la servitude liv ${ }^{\text {p } 054}$

A la faiblesse politique et militaire des États italiens répondait la faiblesse de leur action extérieure.

Machiavel connaissait, conseillait, parfois dirigeait la politique étrangère de Florence. Il n'ignorait pas que Soderini manquait de décision, d'initiative et d'énergie. Longtemps après, dans une épitaphe ironique, il lui épargnait l'Enfer et lui assignait pour séjour éternel les 
Limbes des petits enfants ${ }^{\text {Iv }}$. Il avait pu espérer, jusqu'en septembre 1512, que cette politique d'hésitation, de réserve et de neutralité sans gloire, prendrait fin une fois la République rentrée en possession de ses forces militaires. Pourtant, quoique la ville fût riche et le domaine peuplé, elle restait la capitale d'un petit État, à la mesure des compétitions et des luttes médiévales. Dans un monde nouveau dont les découvertes maritimes élargissaient chaque jour l'horizon, la République de Florence ne comptait plus guère, en face des États modernes, doués de gouvernements vigoureux, comme la France et 1'Espagne, qui maintenant se disputaient la domination de l'Italie. Les événements de 1512 avaient démontré que le rôle historique de l'État florentin, comme puissance européenne, était fini.

Venise aurait pu parler plus haut. La ville également était riche et le domaine peuplé. Elle possédait de vastes territoires dans l'Italie du Nord, jusqu'au delà de Vérone, jusqu'aux environs de Ravenne et aux limites où s'arrêtait le pouvoir temporel du Saint-Siège. Elle exploitait, sur les côtes de la Dalmatie, dans le monde grec, jusqu'aux Échelles du Levant, tout un monde colonial. Elle continuait de trafiquer avec les Indes, par l'Égypte ou les ports du Levant, par les voies de la mer Rouge ou des caravanes. La découverte portugaise de la route du Cap n'avait pas encore causé à son commerce de dommages véritablement graves. Elle semblait si forte que toute l'Italie avait redouté son esprit de conquête. Pourtant les événements avaient mis en p055 lumière sa faiblesse. Elle avait mal résisté, en 1509, à la coalition formée contre elle par Jules II ; et Machiavel méprisait la politique mercantile et prudente de ces armateurs et de ces négociants, impropres à soutenir par les armes une grandeur qui lui semblait avoir trop longtemps fait illusion ${ }^{\text {lvi }}$.

En dehors des Républiques, faiblement dirigées par des assemblées et des conseils où prévalaient les intérêts bourgeois, les États princiers, soumis à l'autorité absolue de quelques hommes, qui, pour leur avantage et la grandeur de leur famille, avaient restauré le despotisme des Césars, laissaient voir même irrésolution, même impuissance. Au temps où Machiavel étudiait en Italie les gouvernements et les peuples, deux princes lui avaient seuls paru posséder à la fois la puissance matérielle et l'énergie : César Borgia et le pape Jules II. 
Orateur à plusieurs reprises, en 1502 et en 1503, auprès de César, il avait eu l'occasion d'étudier et de suivre son œuvre ${ }^{\text {lvii }}$. Il avait vu le fils du pape Alexandre VI, cardinal et archevêque de Valence à seize ans, renoncer presque aussitôt aux grandeurs d'Église, parce qu'un homme de talent et d'énergie n'y trouvait pas à satisfaire son orgueil et son désir de puissance autant que dans le gouvernement d'un État séculier. Le 13 août 1498, au consistoire, il déclarait que la vie ecclésiastique ne lui convenait pas, et déposait ses dignités ; Alexandre VI, le $1^{\mathrm{er}}$ octobre, l'autorisait à rentrer dans le siècle. Tout aussitôt, il entreprenait de fonder à son profit, en Romagne et dans les Marches, au détriment du Saint-Siège, mais avec l'approbation du pape, un nouvel État princier, une nouvelle tyrannie parmi les tyrannies italiennes. Tout aussitôt il s'était montré par l'audace, le manque de scrupules, l'art d'user, selon les circonstances, de la force ou de la ruse, le maître des princes de son temps. Machiavel l'avait vu, en quelques années, exploiter les ressources financières p056 et militaires de la papauté, cultiver l'alliance française, conquérir Imola, Faenza, Forlì, Rimini, Pesaro, et devenir, avec l'aveu d'Alexandre VI, duc de Romagne et seigneur d'un vaste domaine, destiné sans doute à s'annexer Bologne comme capitale, à s'étendre de l'Émilie aux approches de Rome et de l'Adriatique à la Méditerranée. Maître de la Romagne presque entière, des Marches et de l'Ombrie, il comptait sans doute y joindre, par la persuasion ou la force, Florence, Pise et Sienne, toute la Toscane, et créer ainsi, de l'une à l'autre mer, partie en Italie centrale, partie dans l'Italie du Nord, un vaste État où il eût pris le titre de prince ou peutêtre de roi. Projet toutefois irréalisable aussi longtemps que la France protégeait Florence et Sienne : César pensait dissimuler encore quelque temps, et profiter des querelles de Louis XII et de Ferdinand à propos de Naples. Cependant il imposait durement à ses sujets l'obéissance, l'ordre nouveau, la loi nouvelle.

La rencontre de César Borgia laissa dans l'esprit de Machiavel une ineffaçable impression. César était déjà souillé de divers crimes: l'assassinat de son beau-frère, le duc de Bisceglie, le meurtre d'Astorre Manfredi, seigneur de Faenza, étaient les plus éclatants ; on l'accusait d'avoir fait tuer son frère le duc de Gandia. On savait César menteur, traître et infâme ; nul n'ignorait qu'une fois son dessein arrêté, il ne reculait pas devant le parjure ou la violence. Le mélange de fourberie et de hardiesse insolente qui lui avait permis d'occuper vil- 
les et châteaux remplissait les contemporains de stupeur et d'émerveillement. On ne pouvait lui refuser certains dons de l'homme d'État. Les créateurs des plus puissantes dynasties de l'Italie du Nord, les premiers Visconti, François Sforza, revivaient en lui, avec une vue plus claire, plus positive des fins immédiates et des moyens ; avec un plus complet mépris des hommes, une plus cynique indifférence aux sentiments chrétiens et aux lois morales; avec une ambition plus dévorante, un désir plus passionné de prestige, de puissance, de luxe et de joie. Deux siècles de tyrannie italienne, l'exemple des Visconti et des Sforza, des Aragonais de Naples, des Malatesta de Rimini, des Este de Ferrare, l'exemple, plus humain en apparence, de Cosme et de Laurent, avaient créé toute une science du despotisme, dont il était l'élève et l'authentique héritier. Il savait comment on acquiert un État, comment on le développe, comment on le conserve. L'État, sans doute, restait dans sa pensée une forme vide. $\mathrm{Il}_{\mathrm{p} 057}$ ne paraît avoir désiré, comme les Visconti ou les Sforza, que la joie du prince qui impose sa volonté de force et de grandeur. Il n'a guère médité sur le rôle de l'État, guide et tuteur de l'activité des hommes. Pour le moment, il ne songeait qu'à maintenir et consolider son pouvoir en Romagne, par les moyens les plus atroces. Machiavel, de son côté, inquiet des signes trop certains qui révélaient la débilité florentine, limitait son attention au problème pratique du maintien de l'État : à cette œuvre César excellait. C'est pourquoi sa supériorité, d'ordre strictement pratique, bornée à la construction d'un édifice triomphal et inhumain, frappa singulièrement un observateur instruit par la politique et l'histoire lviii .

II se plut à noter chez César un talent de création, hardi et sans scrupule ; un mélange de réserve et de hâblerie, de courage et de cautèle, de valeur militaire et de traîtrise ; une volonté sans cesse tendue ; l'art de calculer, d'agir au moment opportun, sans hésitation ni retard, l'art de tromper, de paraître, d'en imposer aux hommes : "Ce seigneur, avait-il écrit aux Dix, est très splendide et magnifique ; animé d'une telle hardiesse militaire, que les plus grandes entreprises lui paraissent petites, et que, pour la gloire et pour agrandir son État, jamais il ne se repose ; il ignore fatigue et dangers ; il arrive avant qu'on ne le sache en route. Il se fait aimer des soldats ; il a choisi pour son service les meilleurs combattants d'Italie. Tout cela, joint à une perpétuelle fortune, le rend victorieux et redoutable. » lix. En décembre 1502, Machiavel prenait note des procédés infaillibles dont César avait usé pour 
attirer dans un guet-apens mortel, à Sinigaglia, plusieurs condottieri mal sûrs. Il avait, dans ses relations d'orateur, jugé durement César et son père ; de ${ }_{\mathrm{p} 058}$ retour à Florence, il rédigea pour lui-même, sans trop respecter l'exactitude des faits, mais avec le désir d'en tirer, en technicien d'une politique de force, le sens et la leçon, un mémoire sur cet épisode à la fois cauteleux et brutal, que, vers le milieu du siècle, Paul Jove, dans une Histoire de son temps destinée à retracer quelques portraits de grands hommes, devait appeler une très belle tromperie ${ }^{\mathrm{lx}}$.

Tout cet effort de César Borgia fut sans lendemain. Alexandre VI mourut subitement en août 1503. César avait depuis longtemps prévu sa disparition, et soigneusement arrêté la politique à suivre en cette occurrence. Comme il le dit plus tard à Machiavel, il n'avait commis aucune faute de calcul; il avait tout prévu, sauf que, lors de cette mort, il serait moribond lui-même ${ }^{\text {lxi }}$. Sans doute, il put saisir le trésor du pape ; mais, accablé par la fièvre, incapable de monter à cheval, il n'empêcha pas ses ennemis de soulever Rome, les cardinaux hostiles à sa famille de reprendre le gouvernement. Bientôt les populations, dans ses États, se soulevaient ; villes et châteaux rouvraient leurs portes aux seigneurs dépossédés. Après l'éphémère pontificat de Pie III, l'élection de Jules II, irréductible ennemi des Borgia, fut pour César, le 31 octobre, un dernier désastre. En quelques semaines, le duché de Romagne n'exista plus.

Machiavel fut témoin de cette débâcle. Il avait admiré le chef d'une armée redoutable, le maître d'un nouvel État qui déjà s'organisait; plein de projets de conquête et de grandeur. Il le retrouvait, abattu par la défaite, avili, prêt à rentrer dans le néant d'où la fortune et son génie insolent l'avaient tiré. Il le vit, dans l'antichambre de Jules II, s'humilier devant le duc Guidobaldo d'Urbino, qu'il avait dépouillé l'année précédente : «César, conte un témoin oculaire, entra dans la salle, le béret à la main; il s'avança, fit par deux fois une humble révérence, puis, se jetant à genoux, rampa jusqu'au duc d'Urbino, qui, ému de compassion, le releva et le fit asseoir à son côté. Alors p059 le duc lui demanda humblement pardon du passé ; il allégua sa jeunesse, les mauvais conseils qu'il avait reçus, le triste exemple d'Alexandre VI ; il insista longuement sur les torts du pontife, et maudit l'âme de son père lxii. " Machiavel ne reconnaissait plus le duc de Romagne ; César n'était plus le prince, maître des événements et des hommes : il n'était plus qu'un aventurier criminel et dégradé. Ma- 
chiavel, qui avait cru discerner en lui l'une des forces nouvelles de l'Italie, l'abandonnait à son destin. Jules II lui avait permis de partir pour la Romagne, afin de défendre contre Venise, déjà maîtresse de Faenza, bientôt de Rimini, les quelques places encore fidèles. Mais César ne put dépasser Ostie ; sommé d'ouvrir aux armées pontificales Cesena et Forlì, qu'il n'avait pas encore perdues, il refusa, fut reconduit et enfermé au château Saint-Ange. Il céda, chercha refuge à Naples, où la méfiance espagnole ne lui permit pas de rester longtemps. Gonzalve de Cordoue l'envoya, prisonnier, à Ferdinand, qui le détint quelques mois à Medina del Campo. Il finit par se mettre au service de son beau-frère, le roi de Navarre Jean d'Albret, et périt obscurément, en 1507, à l'assaut d'une petite place espagnole.

$* * *$

Ainsi la puissance de César Borgia n'était qu'illusion. Machiavel eut, en 1506, l'occasion d'étudier de près, orateur de la République, le pape Jules II. La politique des Borgia venait de démontrer la puissance matérielle dont le Saint-Siège disposait encore. Mais ils n'avaient travaillé que pour leur famille. Un autre allait reprendre, au service du pouvoir temporel du Saint-Siège, la tradition qu'ils laissaient, et, sur ce pouvoir consolidé, fonder une politique d'affranchissement italien. Jules II, violent, passionné, capable de haines tenaces, de longues rancunes et de folles colères, ne mit du moins son effort sans mesure qu'au service d'une idée. Son grand projet, qui consistait à diviser les barbares, à les armer les uns contre les autres pour les chasser d'Italie, était sans issue, parce qu'il y manquait l'appui d'une force nationale ; émouvant toutefois pour tous ceux qui, des Alpes à la Sicile, haïssaient la domination étrangère ${ }^{\text {lxiii }}$. p060

Mais le génie du pape n'étonna pas Machiavel. Il avait un moment admiré en César Borgia un chef et un politique, de conception hardie et lumineuse, d'action infaillible. Machiavel ne tint jamais le pape Jules II pour un homme d'État, à cause de « la fureur avec laquelle il menait toutes ses entreprises », et qui, en d'autres circonstances, l'aurait infailliblement conduit à la ruine ${ }^{\text {lxiv }}$. L'observateur florentin estimait peu les États d'Église, et ne pensait pas que la science politique trouvât profit à les étudier. L'autorité s'y fonde sur la religion ; l'art et le talent de gouverner y jouent un petit rôle. Si mal régis qu'ils soient, le scrupule religieux y tient les peuples dans l'obéissance, et 
les ennemis les plus acharnés conservent pour eux un respect qui leur épargne de trop graves désastres : "Ils ont des États et ne les défendent pas; des sujets et ne les gouvernent pas ; et ces États, bien que mal défendus, ne leur sont pas enlevés; leurs sujets, bien que mal gouvernés, ne songent pas à se détacher d'eux ${ }^{\mathrm{lxv}}$. " Du moins cet aveuglement fidèle pouvait-il leur offrir quelques garanties de stabilité. Mais Machiavel ne pensait pas que le Saint-Siège, dans l'Italie moderne, fût une force italienne, et capable de servir utilement une politique nationale. Florence, quoique cité guelfe, se méfiait du SaintSiège. Florentin, Machiavel s'en méfie ; Italien, il juge que la politique des papes a toujours été néfaste à l'Italie. Dans les Discours sur la première Décade de Tite-Live, il les accusera bientôt d'y avoir, pour la conservation de leurs domaines temporels, entretenu la division et la faiblesse, introduit l'étranger ${ }^{\text {lxvi }}$. Contre Venise, usurpatrice de quelques terres d'Église en Romagne, Jules II, qui disait ne vivre que pour libérer l'Italie des Barbares, appelait la France. Contre Louis XII, maître de Milan, il appelait les Suisses dans les plaines lombardes ${ }^{\text {lxvii }}$. Aussi lorsque Louis XII, en 1511, annonça p061 l'intention de rompre avec le pape et de l'attaquer par les armes spirituelles comme par les temporelles, le secrétaire florentin souhaita, sans beaucoup y compter, la défaite du Saint-Siège, "afin que ce gouvernement de prêtres eût l'occasion de goûter en ce monde quelques bouchées amères » lxviii

Machiavel ne trouvait donc en Italie que faiblesse, illusion, déception. La politique générale, depuis longtemps, dépendait de forces étrangères. Au cours de ses légations, il eut l'occasion d'en mesurer quelques-unes.

Il put, en 1507, voir l'empereur ${ }^{\text {lxix }}$. Devant l'Europe moderne, Maximilien survivait, non sans dignité, au Moyen Age. Respectueux lui-même de la magistrature chrétienne et romaine dont il était revêtu, il en eût volontiers imposé le respect aux princes et aux villes de cette Italie où Dante et Pétrarque avaient appelé Henri VII et Charles IV ${ }^{\text {lxx }}$. Il déniait à Louis XII la possession de Milan, fief de l'Empire. Il menaçait de passer les Alpes ; mais, comme à ses prédécesseurs du XIV et $\mathrm{du} \mathrm{XV} v^{\mathrm{e}}$ siècle, l'argent lui manquait, et il en demandait aux États fidèles. Machiavel escorta, de Trente à Bozen et à Innsbruck, cette majesté besogneuse: elle lui laissa faible impression. Il mena sur 
l'Empire une rapide enquête, dont il consigna les résultats, en 1508, dans sa Description des choses d'Allemagne ${ }^{\text {lxxi }}$. En réalité, il ne connut que le Tyrol et quelques Cantons Suisses; il crut y retrouver p062 la Germanie de Tacite. Il ignora la richesse et le luxe des grandes villes hanséates de la Mer du Nord et de la Baltique, Brème, Hambourg, Lübeck, Stralsund et Stettin. Il ignora la puissance marchande et la magnificence de Nuremberg, la puissance financière d'Augsbourg, l'opulence de cette banque des Fugger qui, onze ans plus tard, allait acheter pour Charles-Quint les voix électorales ${ }^{\text {lxxii }}$. Il ignora l'Allemagne mécontente et brutale des chevaliers franconiens et souabes, l'Allemagne éclatante et barbare des princes ; il ne connut pas le luxe des prélats, des grands abbés, des électeurs ecclésiastiques. Il ne sut rien du lent et vigoureux travail de réflexion, de préparation intellectuelle et morale, d'où allait naître, contre le Saint-Siège et les chefs italiens de l'Église catholique, la protestation de Luther et la Réforme luthérienne. Il vit le peu qu'il vit des pays germaniques avec les yeux d'un humaniste républicain, pour qui le faste anarchique du monde féodal n'était que faiblesse auprès du labeur librement administré des cités bourgeoises ${ }^{\text {lxxiii }}$. Pourtant, l'homme d'État sut étudier les causes qui produisaient l'actuelle débilité du corps impérial : particularisme, conflits des intérêts locaux, rivalité des provinces, des États princiers, des villes; confusion d'un vaste ensemble sans unité ${ }^{\text {lxxiv }}$. Au milieu de ce désordre, il sut reconnaître la force réelle et profonde d'une population nombreuse, robuste et sans grands besoins ${ }^{\text {lxxv }}$.

Mais les deux pays étrangers qui dominaient la politique italienne étaient les deux royaumes que Machiavel définit comme déjà unifiés sous le gouvernement de princes puissants: la France et l'Espagne lxxvi. Machiavel n'étudia jamais l'Espagne: ce fut p063 le partage de Guichardin : il avait, entre 1508 et 1509, dans son Histoire de Florence, exactement mesuré les forces et les faiblesses d'une cité républicaine; nommé, en 1512, ambassadeur auprès de Ferdinand le Catholique, il put inaugurer, en Aragon et en Castille, son enquête sur les grandes monarchies d'Occident. Machiavel n'a pas assez connu cette puissance espagnole, qui bientôt, démesurément agrandie par la double succession de Bourgogne et d'Autriche, allait permettre à Charles-Quint de revendiquer, avec le titre d'empereur, la monarchie universelle. Mais c'est en France qu'au cours de légations multiples, 
en 1500 , en 1504 , en 1510 , en 1511 , il a traité les affaires les plus délicates, le mieux regardé, le mieux compris ${ }^{\text {lxxvii }}$.

Il résuma rapidement en 1510, dans sa Description de choses de France, ses impressions sur le royaume ${ }^{\text {lxxviii }}$. Il n'aime ni la France ni les Français. La République n'avait pas à se louer d'une alliance qui risquait sans cesse de l'exposer aux pires dangers, sans lui apporter aucune garantie réelle. Il aborde l'étude des choses françaises avec certaines idées préconçues. Il n'avait pu, en pays germanique, se libérer du souvenir de Tacite ; il ne peut, en France, oublier les Commentaires de César. Les jugements de César éclairent à ses yeux l'expérience récente des guerres d'Italie. La puissance militaire de la France lui paraît plus brillante que solide. Les gens d'armes, les cavaliers, sont excellents, parce que la noblesse s'exerce aux armes, sans d'ailleurs connaitre aucune autre profession ${ }^{\text {lxxix }}$. L'infanterie, qui se recrute parmi les paysans, sans exercice, abaissés et dégradés par le régime seigneurial, vaut assez peu. Le roi se trouve ainsi obligé de composer son armée en partie de mercenaires ; ce qui est une erreur et une faiblesse. Il utilise de préférence, aux entreprises lointaines, ses sujets gascons: meilleurs soldats que les autres, mais enclins au vol lxxx . «Les Français, p064 dit-il encore, d'après César et l'expérience des guerres récentes, ont plus d'élan que d'endurance, et promptement se découragent. Ils supportent mal les privations et les incommodités ; ils se gardent mal et se laissent facilement surprendre lxxxi. \" Machiavel note, en revanche, la force politique du royaume. Elle résulte de la concentration de toute l'autorité aux mains du roi. Les provinces sont étroitement unies à la couronne. Les féodaux, qui autrefois pouvaient prendre les armes contre le roi, ne comptent plus. Le pays est riche de produits agricoles ; la main-d'œuvre à bon marché. L'argent, peu répandu, ne se trouve que chez les prélats et les seigneurs. Deux cinquièmes des revenus du royaume appartiennent au clergé. Il exerce une grande influence sur la conduite des affaires; le roi appelle de nombreux évêques aux conseils de la couronne. Les nobles reçoivent des commandements militaires, mais se mêlent moins à la politique ${ }^{\text {lxxxii }}$. Plus tard, après 1512, dans les Discours sur la première Décade de Tite-Live, dans le Discours sur la réforme de l'État florentin, Machiavel eut l'occasion de reparler du gouvernement français. Certaines pages qu'il écrivit alors semblent annoncer la théorie des puissances secondes, telle qu'elle se développe dans l'Esprit des Lois : 
pouvoirs subordonnés et dépendants, essentiels, d'après Montesquieu à la nature du gouvernement 065 monarchique, où un seul gouverne par des lois fondamentales ${ }^{\text {lxxiiii }}$. Machiavel semble encore entrevoir une idée chère à certains théoriciens qui, au XVIII siècle, essayèrent de définir la nature de la monarchie française : l'idée d'une constitution, jamais écrite, toujours respectée, où le rôle du clergé et de la noblesse est d'assurer, moyennant certains droits et privilèges, légalement reconnus aux deux premiers ordres, l'obéissance du peuple ${ }^{\text {lxxiv }}$. En 1510, Machiavel est surtout frappé de cette obéissance ${ }^{\operatorname{lxxv}}$. Ce peuple d'ailleurs vit à peu de frais, grâce à d'abondantes subsistances, et parce que chacun possède un morceau de terre. Machiavel a bien noté le réveil économique du royaume depuis les premières années du siècle. Il décrit en quelques lignes les revenus de l'État, les impôts, l'organisation du gouvernement et de l'Église, l'administration de la justice, le rôle et l'action des Parlements. Mais il insiste plus volontiers sur le pouvoir royal. Trois faits essentiels lui paraissent expliquer la France de ce siècle : la richesse agricole du pays ; la fidélité populaire ; l'autorité de l'État sans cesse renforcée lxxxvi.

On sent toutefois que le régime politique de la France lui paraît encore primitif, convenable à un pays dont la civilisation et l'économie conservent un type essentiellement agraire. Un jour que le cardinal Georges d'Amboise, archevêque de Rouen, p066 premier ministre de Louis XII, dit à Machiavel que les Italiens s'entendaient mal aux choses de la guerre, le secrétaire florentin répondit que les Français n'entendaient rien aux choses de l'État. Cette ignorance et cette maladresse lui apparaissaient, de façon plus frappante encore, dans la politique étrangère. Machiavel, en 1513, au troisième chapitre du Prince, devait analyser longuement la politique italienne de la France, en critiquer, avec une netteté lumineuse, les erreurs de calcul, l'imprévoyance, les fausses démarches. Au cardinal d'Amboise, il se contentait d'indiquer la plus grave et la plus insigne maladresse : avoir laissé le Saint-Siège acquérir en Italie une puissance démesurée, dangereuse à tous et d'abord aux intérêts français : "Car, poursuivait-il, si les Français entendaient la politique, ils ne laisseraient pas l'Église accroître à tel point sa grandeur lxxxvii. ${ }^{\text {. }}$ Machiavel n'est pas loin de considérer la monarchie française comme incapable de créer, à l'extérieur, œuvre qui dure. Républicain, nourri d'histoire romaine et de tradition guelfe, il s'accommoderait mal d'un gouvernement qui, à 
l'intérieur, ne connaît ni les libertés publiques, ni la représentation permanente des citoyens.

$$
\text { *** }
$$

Ainsi Machiavel, au contact des États italiens, du monde germanique et de la France, achevait de s'instruire. Il savait l'histoire; il connaissait à fond la politique italienne ; il connaissait l'Europe autant qu'aucun Italien de ce temps. Il avait, pendant quatorze ans, servi dans un poste de confiance, souvent inspiré, parfois dirigé la politique d'un État italien mêlé à toutes les affaires de la péninsule et à quelquesunes des principales affaires d'Europe. La chute de la République, la restauration médicéenne qui, à l'automne de 1512, écartèrent Machiavel de l'action et lui imposèrent les loisirs de la vie privée, allaient le transformer en un théoricien de la politique, en un historien et un philosophe de l'histoire. 


\section{Chapitre II}

\section{Le problème politique dans l'œuvre de Machiavel}

Tandis que Machiavel, privé de ses fonctions, se trouvait réduit à la solitude et à la gêne, le pape Jules II terminait à Rome, le 20 février 1513, sa vie agitée et violente. Pour reconstituer les domaines temporels de l'Église, il avait entretenu la guerre en Italie, travaillé avec acharnement à la ruine de Venise, l'un des rares États que la solidité de ses institutions et ses ressources rendaient capable d'imposer respect à l'étranger. Pour chasser les Français d'Italie il y avait appelé les envahisseurs allemands et suisses, encouragé les ambitions espagnoles. L'indifférence avec laquelle on le voyait subordonner l'administration spirituelle de l'Église à une politique de guerre et de force, avait aggravé la désaffection des peuples occidentaux, l'aversion croissante que, depuis la Captivité d'Avignon et le Grand Schisme, leur inspiraient les pratiques de la cour romaine. Le pontificat de Jules II, après celui d'Alexandre VI, appelait et provoquait la Réforme. Les politiques, comme Machiavel, refusaient de reconnaître un politique dans cet homme de colère et de violence. Les chrétiens, comme Érasme, dont l'Éloge de la Folie, publié depuis trois ans, était maintenant lu de tous, en Italie comme en France, en Allemagne ou en Angleterre, refusaient de reconnaître en lui un prêtre du Christ. Il était temps d'élever au trône de saint Pierre un pape de tempérament plus calme et d'esprit plus mesuré.

Le cardinal Jean de Médicis préparait depuis longtemps sa candidature. Prodigue, aussi habile que son père, Laurent le p068 Magnifique, à séduire les uns et les autres, protecteur comme lui des artistes et des écrivains, patient et persévérant, pourvu d'un tact assez fin pour 
éviter la violence et n'y recourir, comme Laurent, que dans les dernières extrémités; inégal du reste à Laurent pour le talent politique, la hardiesse et les dons de l'esprit, il semblait naturellement désigné pour succéder à Jules II. Ennemi de la monarchie française qui avait laissé les républicains renverser les Médicis et soutenu officiellement Soderini, la victoire de la Sainte Ligue, à laquelle il devait la rentrée de sa famille à Florence, lui imposait de continuer la politique étrangère du dernier pontificat. Le 11 mars, il fut élu par le conclave. Encore simple diacre, il dut, le 15, recevoir les ordres ; le 17, il devint le pape Léon X.

Les fêtes de son couronnement furent d'une incomparable splendeur. Florence manifestait une joie qui parut universelle. Les républicains vaincus et dispersés se taisaient. La ville espérait, de ce pape florentin, ami des arts et magnifiquement dépensier, un surcroît de prestige et de prospérité. Sans doute, les Médicis, quelques années affaiblis, retrouvaient des forces nouvelles; appuyés sur le SaintSiège dont Alexandre VI et Jules II avaient créé véritablement la puissance temporelle, il leur serait aisé désormais de renoncer à leur respect apparent de la constitution et des lois, et de fonder, à Florence et en Toscane, une seigneurie plus humaine à la fois et plus durable que la principauté romagnole de César Borgia. Mais seul un Génois, raconte l'historien Jacopo Nardi, sut avertir les Florentins du danger qui menaçait leurs libertés : "Vous vous réjouissez, leur dit-il, d'avoir un pape de votre ville ; mais avant d'en avoir eu autant que Gênes en a donné à l'Église, vous apprendrez à vos dépens combien coûte aux cités libres la grandeur des papes ${ }^{\text {Ixxxviii }}$. »

Quelques jours avant le départ du cardinal Jean pour le conclave, on avait recueilli les indices d'un complot contre la famille des Médicis. Les Huit de Garde avaient saisi un papier, égaré par un jeune homme, Pietro Paolo Boscoli, que l'on connaissait pour sa haine de la tyrannie. On y lut, parmi une vingtaine de noms, celui de Machiavel. Boscoli et son ami Agostino p069 Capponi, aussitôt arrêtés et mis à la torture, avouèrent le dessein d'affranchir Florence. Ils l'avaient tenu secret ; les noms étaient ceux de citoyens supposés favorables aux institutions libres, mais dont aucun n'avait été pressenti. On les arrêta ; on dut reconnaître qu'ils ignoraient tout du complot, dont la préparation n'avait même pas été sérieusement mise à l'étude. Le cardinal exigea la condamnation de Boscoli et de Capponi, qui moururent avec 
une fermeté antique. A dessein l'on exagéra la gravité de l'affaire, pour désarmer, selon la pratique constante des tyrannies, les citoyens que naguère Machiavel enrôlait dans ses milices républicaines. Toutes les armes durent être déposées aux mains des magistrats. Les Florentins obéirent sans résistance; ils acclamèrent, devant le Palais de la Via Larga, comme lors de la conjuration des Pazzi, la famille princière, le frère et représentant du pape, Julien, duc de Nemours, troisième fils du Magnifique.

Machiavel avait été, comme les autres suspects, emprisonné, et comme les autres mis à la torture. De ses déclarations, on ne put rien tirer contre lui. Si l'on avait découvert quelque indice de complicité, on ne l'aurait pas épargné. Bientôt Léon $\mathrm{X}$ voulut, par politique, se montrer clément. Le 4 avril, la commission qui gouvernait Florence en son nom publiait une amnistie générale ; et pour, rendre l'apaisement plus certain, on permit à tous les Soderini, même à l'ancien gonfalonier, de rentrer d'exil.

Le vide se faisait de plus en plus autour de Machiavel. La perte de son traitement médiocre de secrétaire, l'insuffisance de sa fortune personnelle, les dettes qu'il avait contractées, lui imposaient une gêne étroite. Il suivait, oisif et désœuvré, les événements dont la conduite lui échappait. Il tentait parfois comme un effort douloureux pour les oublier, oublier la politique, oublier son œuvre interrompue de citoyen, dans la vie obscure, insouciante et satisfaite des rustres. Mais l'homme d'État, nourri d'histoire et de pratique, de réflexion sur le présent et le passé, surmontait ces mornes épreuves qui ne parvenaient pas à le dégrader. ${ }^{x c}$ Quoi qu'il tentât pour ne plus être ${ }_{\mathrm{p} 070}$ qu'un banni paresseux, indolent, sans regrets ni désirs, Machiavel se retrouvait lui-même ; le savoir et la doctrine lentement élaborés dans son esprit au contact des hommes et des livres prenaient la forme de maximes, de sentences, de principes généraux, et formaient insensiblement l'ample et diverse matière d'un système contrôlé par l'expérience et la raison. Il s'essayait maintenant à écrire sur la politique. Il savait user d'une langue à la fois populaire et savante, propre aux discussions subtiles comme aux démonstrations rigoureuses. Mais sauf deux brèves relations sur les choses d'Allemagne et de France, quelques dissertations officielles sur des problèmes de gouvernement, et les rap- 
ports où il rendait compte aux Dix de ses missions auprès des États étrangers, il n'avait consacré aux affaires publiques, en 1504 et en 1508, que ses deux Decennali, annales versifiées en tierce rime, assez arides et prosaïques, des plus récents événements ${ }^{\text {xci }} 4$. Tout ce que l'histoire et la pratique lui avaient enseigné sur la fondation, le maintien, le progrès des gouvernements autoritaires ou libres, s'ordonnait en un vaste ouvrage, écrit en marge de Tite-Live, et qui reposait sur une méthode et sur une éthique.

La méthode est celle de l'historien. Si les hommes se laissent guider au hasard lorsqu'il s'agit de gouverner les États ou d'ordonner les armées, «c'est qu'ils n'ont pas la vraie connaissance de l'histoire, ne savent pas en dégager le sens ni en goûter la saveur profonde » xcii. Machiavel, historien, étudie l'apparition des formes politiques, recherche les causes internes ou extérieures qui en produisent la décadence, cherche à saisir les lois qui, à travers le monde antique et moderne, en déterminent la naissance et l'évolution. " J'ai posé des principes, écrit Montesquieu dans la préface de l'Esprit des Lois, et j'ai vu les faits particuliers s'y plier comme d'eux-mêmes, les histoires de toutes les nations n'en être que les suites... Je n'ai point tiré mes principes de mes préjugés, mais de la nature des choses. " Semblablement, Machiavel ne se soucie que de définir les principes en vertu desquels les faits particuliers s'éclairent au regard de l'intelligence qui cherche uniquement le vrai. Il voit ${ }_{\text {p071 }}$ républiques et monarchies naître, crô̂tre, grandir, dépérir et se restaurer, selon certaines lois historiques, de même que le naturaliste suit le développement de tels organes ou de telles fonctions selon les lois de la physiologie. Avec une égale objectivité, avec aussi peu d'émotion apparente, il examine les cas historiques présentés par la naissance, la création ou la réforme d'un État princier ou d'un État républicain. Cette étude critique des faits peut fonder une technique du gouvernement sûre au point d'atteindre un caractère de pérennité, en harmonie avec la pérennité des lois naturelles et des caractères essentiels de l'espèce humaine : «Ni le ciel, ni le soleil, ni les éléments, ni les hommes n'ont varié dans leurs mouvements, ou dans l'ordre qui les régit, depuis les temps anciens... Les hommes naquirent, vécurent et moururent toujours selon le même ordre. " ${ }^{x i i i}$ Ainsi la pensée et l'espoir de Machiavel, précurseur de Montesquieu, s'accordent avec la pensée et l'espoir de Thucydide. Notions acquises pour toujours : $\kappa \tau \mu \alpha \quad \varsigma \quad \varepsilon^{i i^{x i v}}$. 
Cette science de la politique, science neuve et que les humanistes du XIV et du XV siècle n'ont pas connue, strictement positive, indifférente au bien et au mal, se soumet à une éthique enthousiaste et passionnée. Éthique déduite par Machiavel de l'étude des anciens, mais également héritée des traditions communales. Éthique aussi dédaigneuse de l'intellectualisme humaniste qu'indifférente à la charité chrétienne ; éthique essentiellement active, subordonnée à la discipline de la loi, et qui tient pour essentielle vertu l'énergie capable d'entreprise périlleuse et de sacrifice. Elle se propose de servir, de défendre, de maintenir, et d'agrandir la cité. Elle exige de l'individu le renoncement à ses intérêts propres, à sa volonté personnelle, pour le bien de la cité. Elle y subordonne sans hésiter les lois de la morale commune ; elle oblige l'individu, s'il le faut, jusqu'au crime. Machiavel admire à la fois les dures vertus des Romains antiques, et les vieux

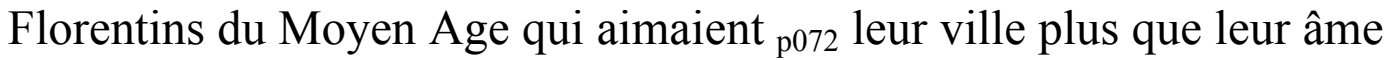
et leur salut éternel ${ }^{\mathrm{xcv}}$. De l'idée étroite, encore antique et médiévale de la cité, Machiavel, devant l'invasion étrangère, devait élever son culte à l'idée d'une nation qui restait à créer, mais exigeait même abnégation, même sacrifice. Éthique d'un poète et d'un voyant; par là Machiavel, si loin qu'il se tienne de Dante, reste de sa lignée, et peut s'entendre avec Michel-Ange.

Une lettre, qu'il adressait le 10 décembre 1513 à Francesco Vettori, son compagnon de légation auprès de l'empereur, et qui, rallié aux Médicis, ambassadeur à Rome, demeurait son confident, décrit ces alternatives de désœuvrement morose et d'exaltation; cette double vie, misérable et géniale, qui fut la sienne, lorsqu'il conçut la première ébauche de ses grands ouvrages. ${ }^{\text {xcvi }}$ Le matin, de bonne heure, dans un bois qu'il fait couper, il s'attarde en compagnie des bûcherons, qui ont toujours à conter quelque misère. Il guette et prend quelques oiseaux, tout en relisant Dante, Pétrarque ou Tibulle. Après le repas de midi, il s'établit à l'auberge, échange des propos avec ceux qui vont et viennent, et pendant plusieurs heures, joue au trictrac avec l'hôte, un meunier et deux boulangers. "Alors, dit-il, s'élèvent des contestations, des paroles de dépit, des injures; on se dispute pour un sou; on pousse des cris qui s'entendent jusqu'à San Casciano. Enveloppé de celte pouillerie, j'épuise à fond la malignité de mon destin. Mais le 
soir venu, je m'en retourne dans ma maison, et j'entre dans ma librairie. Je dépose sur le seuil mes vêtements boueux de tous les jours; je m'habille comme pour paraître dans les cours et devant les rois. Vêtu comme il convient, j'entre dans les cours antiques des hommes d'autrefois ; ils me reçoivent avec amitié ; auprès d'eux, je me nourris de l'aliment qui seul est le mien, et pour lequel je suis né. J'ose sans fausse honte converser avec eux, et leur demander les causes de leurs actions; et si grande est leur p $073_{3}$ humanité qu'ils me répondent. Et pendant quatre longues heures, je ne sens plus aucun ennui, j'oublie toute misère, je ne crains plus la pauvreté ; la mort ne m'effraie plus. Je passe tout entier en eux. " ${ }^{\text {xcvii }}$ Ainsi Machiavel s'exaltait à confronter «sa longue expérience du présent et sa lecture ininterrompue des choses passées. » ${ }^{\text {xcviii }}$

Auprès des philosophes et des historiens dont la parole, dans les veillées solitaires de San Casciano, consolait sa détresse, il cherchait le remède aux misères de l'Italie ${ }^{\text {xcix }}$. Elle conservait son orgueil, restait, selon le mot de Taine, " fille aînée de la civilisation moderne, imbue de son droit d'aînesse, obstinée dans sa rancune contre les transalpins, héritière de l'orgueil romain et du patriotisme antique ${ }^{c}$. » Elle regardait l'Europe avec les yeux de Dante et de Pétrarque, et jugeait barbares toutes les nations ultramontaines. Elle possédait la primauté de l'esprit; elle l'emportait par l'industrie, la richesse, l'inépuisable création des œuvres de l'art. Mais la force lui manquait. Elle s'était habituée depuis dix-neuf ans à voir les étrangers porter la guerre sur son sol et lui imposer leur domination : elle avait subi les Français, elle subissait les Espagnols et les Allemands. Les peuples regardaient avec admiration les palais et les églises de Florence, de Venise et de Rome ; leurs princes courtisaient ses lettrés et ses artistes; elle était fière d'imposer à ses envahisseurs les sentiments que la Grèce avait jadis inspirés à Rome. Tandis qu'ils foulaient son sol et rançonnaient ses villes, elle se divertissait aux récits merveilleux de ses poètes et de ses conteurs, aux fêtes éclatantes que donnaient ses princes et ses républiques, à l'inépuisable diversité du monde fantastique et réel que créait sans cesse le génie de ses artistes. Mais Machiavel, p074 citoyen, homme d'État, s'attristait et s'irritait de la résignation avec laquelle tant de cités et d'États subissaient leur destin. Il s'attristait et s'irritait 
au spectacle de ce qu'il appelait la corruption de l'Italie ; et c'était à la réforme de l'Italie corrompue qu'il travaillait maintenant par le livre, ne pouvant plus y travailler par l'action.

Il avait, secrétaire de la seconde Chancellerie florentine, orateur de Florence auprès des États italiens, pu constater leur faiblesse militaire ; expliqué cette faiblesse par l'inquiétude soupçonneuse des tyrannies, toujours tenues sous la crainte d'un complot ou d'un soulèvement, par la débilité politique des Républiques en décadence, qui avaient laissé corrompre l'esprit et la vigueur de leur institution primitive ${ }^{\text {ci }}$. Il avait aussi constaté, dans les gouvernements, l'absence de talents supérieurs. Parmi les hommes qui, en Italie, avaient sous ses yeux mené le jeu de la politique, il n'avait rencontré que des tyrans médiocres, à la fois violents et faibles, sans savoir réel ni expérience ni véritable énergie; des bourgeois prudents et calculateurs, uniquement soucieux de ne pas risquer, dans le hasard des entreprises, les intérêts de leur banque ou de leur négoce. Pas un homme dont la personne ou le génie eussent pu véritablement s'imposer. César Borgia, qui, trois ans, avait paru capable de créer et de construire un vigoureux État princier, avait tout perdu ou tout laissé perdre en quelques semaines. Jules II, violent, passionné, sans mesure ni calcul, menait, pour la ruine de l'Italie, une politique de colère et d'aveuglement. Mais, dans la solitude de San Casciano, l'attention de l'homme d'État et de l'historien se concentrait sur un autre fait, qu'il n'avait pas encore pris la peine d'étudier et d'analyser à loisir, et qui expliquait tout le reste : le manque, en Italie, de toute forme politique de caractère national, à quoi le sentiment national pût s'attacher. La cause dernière, profonde et véritable de la corruption politique de l'Italie, était la difficulté d'y créer un État capable de parler au nom de la nation italienne, et d'en assurer la défense.

Cette idée de la nation italienne et de la patrie italienne, Machiavel, sans doute, ne fut pas le premier à la concevoir. Il existait $\mathrm{p} 075$ un sentiment très fier de l'italianité, fait d'ailleurs en partie de souvenirs de la grandeur romaine, de la certitude d'une primauté dans l'ordre de l'esprit; fait essentiellement du mépris des Barbares. Ce sentiment avait été fort chez Dante; il s'exprime avec éloquence, au sixième chant du Purgatoire, dans l'invective de Sordello de Mantoue à 
l'Italie esclave. ${ }^{\text {cii }}$ Pétrarque l'avait magnifié dans ses lettres, dans la canzone Italia mia, dans la canzone Spirto gentil, dans l'Africa, cette épopée latine qu'il avait voulu consacrer au plus grand événement de la plus grande histoire, la défaite d'Hannibal par Scipion, la victoire de Rome sur Carthage. Les humanistes florentins et les humanistes du Nord avaient su découvrir, dans les historiens et les orateurs antiques, les titres de noblesse d'une Italie à jamais romaine. Dante, pourtant, restait universaliste, désireux avant tout de fonder l'ordre et la paix du monde chrétien sur l'équilibre temporel et spirituel de deux pouvoirs divinement institués; et s'il imposait au pape et à l'empereur le devoir de ne pas quitter le siège fatidique assigné par Dieu à l'un et à l'autre, il n'affirmait pas que l'empereur ni même le pape dussent être Italiens ; et l'Italie n'était à ses yeux que le jardin de l'Empire. ${ }^{\text {ciii }}$ Pétrarque, sauf cependant les quelques mois de son enthousiasme pour Cola di Rienzo, restaurateur éphémère de la république romaine, n'avait su que répéter à l'empereur Charles IV ce que Dante avait mieux dit à Henri VII de Luxembourg. Les humanistes s'étaient bornés à développer avec éloquence des lieux communs renouvelés de l'antique. Machiavel avait maintenant le loisir d'analyser plus exactement celle idée de la patrie italienne; son savoir d'historien et son expérience politique lui permettaient d'y introduire quelques éléments plus concrets.

Sans doute avait-il fallu un effort à ce fils de la libre commune, à ce magistrat de la libre commune, pour se détacher d'elle, de son horizon étroit et familier, et pour comprendre que, dans le monde moderne, parmi les grands États modernes en pleine croissance, la libre commune ne comptait plus. $\mathrm{Il}_{\mathrm{p} 076}$ avait fallu un effort à ce Florentin, qu'attachaient à Florence toutes ses traditions de famille, son passé, ses souvenirs, les quatorze ans de son activité politique et de sa vie officielle, pour conclure que dans le monde moderne Florence ne comptait plus. ${ }^{\text {civ }}$ Mais il avait vu, en France, une grande monarchie nationale poursuivre son travail de formation. Une grande monarchie nationale se formait en Espagne. Machiavel enviait, à la France et à l'Espagne, leur unité nationale. Inversement il avait vu, dans l'Empire, trop de ressources et d'énergies gaspillées et rendues vaines par l'égoïsme des petits États, le particularisme des villes et des princes. ${ }^{c v}$ Le cas de l'Italie était semblable et plus douloureux : car nul encore n'avait osé envahir l'Empire. Elle aussi souffrait du particula- 
risme des princes, des petits États princiers, des petites cités libres; elle avait vu ses princes, en lutte les uns contre les autres, faire habituellement appel à l'étranger. Il y avait pourtant cette différence entre l'Italie et 1'Empire, que l'Empire reconnaissait un empereur, si débile qu'il fût, tandis que l'Italie ne voulait reconnaître aucun chef. Ainsi peu à peu se développait et se précisait, dans l'esprit de Machiavel, l'idée de la patrie italienne. La patrie n'est plus, pour Machiavel, l'étroite commune de Florence, abritée au cœur de ses domaines toscans ; elle est l'Italie ; mais l'Italie n'est plus, pour Machiavel, le jardin impérial de Dante ; elle est une nation autonome et indépendante, soutenue par la forte armature d'un État national ${ }^{\text {cvi }}$.

Fonder un État national en Italie, au moment même où les Espagnols venaient de rétablir à Florence, par la force des armes, la tyrannie des Médicis, pouvait sembler une utopie dérisoire. Sans doute estce, pour parler comme Machiavel, une idée de prophète, par où se manifeste chez lui, sceptique et volontiers cynique, un tempérament de visionnaire, qui l'apparente à l'auteur du Paradis et de ce De Monarchia dont il rejette la doctrine. Car Machiavel admet, dans la pratique, $\mathrm{le}_{\mathrm{p} 077}$ rôle de ces prophètes qui travaillent à reconstituer l'État et la société selon certaines vues de l'esprit : à condition toutefois qu'ils ne se présentent pas désarmés pour imposer leur volonté aux hommes et aux événements ${ }^{\text {cvii }}$. Idée de prophète, mais longuement méditée par un réaliste, qui, pour servir une idée, cherche des armes.

Ce réaliste sait exactement ce qui devra disparaître, si l'on veut travailler à la fondation d'un État moderne et national d'Italie. Il sait que certaines institutions, leur rôle historique achevé, se survivent en dépit de la raison et gardent assez de force pour nuire. Le Moyen Age achevait de mourir en Italie, sans que, pour offrir à la société née de sa décomposition un abri durable, aucun ordre nouveau n'eût apparu. Il laissait des ruines assez vastes pour retarder la construction du monde moderne. De ces ruines médiévales, qu'il juge mortelles pour l'Italie, Machiavel fait table rase. ${ }^{\text {cviii }}$

La première est l'autorité impériale, qui prétend s'exercer encore en Italie, revendique ses droits féodaux sur Milan; autorité au nom de laquelle récemment encore, en 1508, en 1513, les lansquenets de 
Maximilien passaient les Alpes. ${ }^{\text {cix }}$ Dante avait admis, dans le temporel, la nécessité du pouvoir impérial, pour imposer aux princes et aux États l'ordre chrétien et la paix chrétienne. Machiavel, lecteur de TiteLive et de Tacite, déteste l'Empire romain, l'arbitraire et la violence des Césars, qui, finalement condamnés, comme tous les despotes, à la débilité militaire, n'ont pas su défendre l'Occident contre les Barbares. Nourri de tradition guelfe, il méprise le Saint-Empire romaingermanique, et connaît la faiblesse des Césars modernes. ${ }^{\mathrm{cx}}$ Sans doute ne comptaient-ils guère quand ils s'appelaient Frédéric III ou Maximilien. Pourtant un ensemble inouï de successions allait offrir à CharlesQuint assez de forces et de ressources 078 pour revendiquer pendant trente-sept ans une hégémonie chrétienne dont les plus grands empereurs du Moyen Age n'auraient osé rêver. Machiavel, qui, après 1519, put suivre d'année en année les progrès de cet empire rajeuni, et vécut assez pour apprendre, en mai 1527 , le sac de Rome, ne s'abusait pas lorsqu'il jugeait que l'autorité des empereurs avait été, dès l'origine, et toujours resterait néfaste à l'Italie, et que l'indépendance de la nation italienne serait en péril aussi longtemps que les nouveaux Césars persisteraient à réclamer leurs droits sur le jardin de l'Empire. Trois siècles en effet l'Italie devait subir les effets de la reconstitution par Charles-Quint d'une puissance qui semblait condamnée par l'histoire.

Une autre survivance médiévale, non moins malfaisante, est pour Machiavel le pouvoir temporel des papes. Si hostile à la politique de Dante, il s'accorde, sur ce point, avec lui. Dante refuse au pape le droit de posséder des domaines, des terres, des villes. En vain les canonistes allèguent que Constantin a donné Rome à Sylvestre $\mathrm{I}^{\mathrm{er}}$. Dante répond que l'empereur n'avait pas le droit de faire cette donation, le pape de l'accepter ${ }^{\text {cxi }}$. Dans l'intervalle entre Dante et Machiavel, était venu Laurent Valla, qui, par la critique des textes, avait démontré la fausseté de cette largesse prétendue. Machiavel ne se pose pas la question des origines du pouvoir temporel ; mais sans nul doute il le juge, comme Laurent Valla, fondé sur la fraude et l'usurpation. Il préfère en montrer, dans l'histoire médiévale et dans les temps modernes, la malfaisance. ${ }^{\text {cxii }}$ Une longue tradition guelfe, hostile à tout ce qui, de près ou de loin, pouvait favoriser les prétentions des empereurs, avait longtemps rendu Florence indulgente et consentante aux ambitions du Saint-Siège. p079 Machiavel dénonce énergiquement l'erreur de cette doctrine, que certains, de son temps, soutenaient encore. 
«Puisque l'on affirme souvent que les villes italiennes doivent attendre leur salut du Saint-Siège, je veux, contre cette opinion, développer les raisons qui se présentent à mon esprit... D'abord, les exemples criminels de la cour de Rome ont détruit en Italie toute piété et toute religion... Mais nous avons encore envers les prêtres un second sujet de reconnaissance, et j'y vois la seconde cause de notre ruine. C'est que l'Église a maintenu et maintient la division en Italie. Nul pays ne peut accomplir heureusement son unité, à moins de passer tout entier sous l'obéissance d'une seule république, ou d'un seul prince, comme il est advenu en France ou en Espagne. Or la raison pour laquelle l'Italie n'a pas atteint ce terme, et ne se trouve pas unie sous le gouvernement d'une seule république ou d'un seul prince, ne doit être cherchée que dans la politique de la papauté. Après y avoir établi son siège, et fondé sa puissance temporelle, elle n'a jamais eu assez de force et de génie pour conquérir la domination de toute l'Italie et pour s'en mettre à la tête. Mais d'autre part elle n'a jamais été faible au point de ne pouvoir, lorsqu'elle craignait la perte de ses domaines temporels, appeler à son secours une puissance étrangère contre qui lui semblait devenir trop fort en Italie. C'est ce qu'on a vu autrefois, quand elle a fait chasser par Charlemagne les Lombards déjà maîtres de l'Italie presque entière. De même, à notre époque, elle a fait appel à la France pour ruiner la puissance de Venise ; puis elle a chassé les Français avec l'aide des Suisses. Trop faible donc pour occuper toute l'Italie, elle n'a pas permis qu'un autre État s'en rendît maître, et par là elle a empêché l'union de l'Italie sous un seul chef, et nous a contraints à subir la domination de plusieurs princes, et seigneurs. D'où l'on a vu naître tant de divisions et tant de faiblesses, que l'Italie s'est trouvée réduite à devenir la proie non seulement des puissances barbares, mais du premier qui l'attaque. Voilà ce que nous autres Italiens devons au Saint-Siège, et à nul autre qu'à lui. »" ${ }^{\text {cxiii }}$

Le pouvoir temporel des papes est donc pour Machiavel la $\mathrm{p} 080_{\text {sur- }}$ vivance absurde et périlleuse d'un passé avec lequel doit rompre un homme d'État moderne. Mais reconstitué, restauré, renforcé par Alexandre VI et Jules II, menaçant et guerrier sous Jules II, diplomate, humaniste, artiste sous Léon X, et toujours aussi avide de force et de grandeur, il continuait de mener une politique néfaste à l'Italie. Pendant un demi-siècle encore il allait, par ses ententes et ses désaccords avec les États italiens, par ses alliances et ses conflits avec les étran- 
gers, entretenir en Italie, comme l'avait écrit Machiavel, la division et la faiblesse ; il allait finalement, tant par ses victoires que par ses défaites, contribuer à fonder en Italie, pour deux siècles, l'hégémonie barbare de l'Espagne. Informé du sac de Rome, l'historien crut peutêtre assister au déclin rapide, qu'il avait prévu, de la papauté temporelle. Du moins la juge-t-il aussi ruineuse pour l'Italie que l'autorité impériale, la politique guelfe aussi désastreuse que la gibeline; et si Dante s'est gravement trompé, s'il a péché contre l'Italie quand il appelait les armées d'Henri VII contre Florence, les Florentins qui l'exilèrent n'ont pas commis une moindre erreur et une faute moins grave, laissant grandir en Italie le pouvoir temporel du Saint-Siège. L'Italie ne sera sauvée que le jour où elle n'aura plus à craindre, dans le temporel, ni Pierre ni César.

D'autres également devront disparaître. Il faut simplifier la carte politique de l'Italie. Trop d'États particuliers dont l'existence ${ }_{p 081}$ ne se justifie pas, dont la multiplicité, les querelles vaines, les intrigues avec les plus puissants d'entre eux, avec l'empereur, avec le pape, entretiennent la division et la faiblesse. Des petites républiques, Machiavel, républicain, dit peu de chose, bien qu'au fond il sache leurs jours comptés. Mais il souhaite la ruine et la disparition des petits États princiers qui, depuis la fin du Moyen Age, ont pullulé dans l'Italie du Nord et du Centre. Il estime peu les tyrannies créées par des soldats heureux, qui, après avoir, sur les ruines des cités libres, fondé leur autorité absolue, n'ont su que plier les peuples à un despotisme souvent fantaisiste et sanglant. Machiavel a hérité de la doctrine des républicains florentins, et il la corrige. Il se résignerait peut-être à subir provisoirement la loi d'un despote éclairé, capable d'assurer aux hommes l'ordre et la paix dans le travail. Il se rallierait peut-être au gouvernement d'un César Borgia. Mais il hait le despotisme qui n'a d'autre but que le plaisir du prince. Or les tyrans italiens, qu'il s'agisse des Visconti ou des Sforza de Milan, des Aragonais de Naples, des Malatesta de Rimini, des Gonzague de Mantoue, des Este de Ferrare, n'ont su édifier aucune œuvre durable. Ils ont négligé l'art du gouvernement, la science de l'homme d'État et du chef d'armée. Seul César Borgia, parce qu'il savait la politique et la guerre, aurait été capable de travailler pour l'avenir: le destin l'a trahi, et, dans le malheur, la force du 
caractère lui a manqué. Les autres, des plus grands aux plus petits, ont montré que leur autorité n'était pas à l'épreuve de la mauvaise fortune. Quand vinrent les invasions et les temps douloureux, ils prirent la fuite, abandonnés par les condottieri auxquels ils accordaient leur confiance aveugle. Ainsi Milan et Naples sont tombées aux mains des barbares, et les moindres États sont entrés dans les clientèles étrangères. Les tyrans italiens, de tout temps malfaisants, ont trahi lors de l'invasion : ils doivent rentrer dans le néant.

Mais la création d'un État moderne en Italie condamne certaines formes sociales qui appartiennent au passé. Machiavel souhaite la destruction de tout ce qui garde le caractère féodal. Il n'est, à aucun degré, un historien de l'économie ou de la société : le caractère économique et social, autant que juridique et politique, de la seigneurie médiévale ne retient pas son attention. Mais il garde les préférences et les dédains de la classe ${ }_{\mathrm{p} 082}$ dont il est sorti ; bourgeois et citadin, fidèle à la tradition de la cité antique, qui, dans le gouvernement, voit une affaire citadine et le confie aux magistrats librement élus par les citoyens, aux libres assemblées des citoyens, propriétaires, commerçants, artisans urbains ; fidèle aux traditions de la commune florentine, qui, dès la fin du XIII siècle, a réservé l'autorité politique à la classe bourgeoise, aux maîtres des corporations industrielles et commerçantes. Il n'a que mépris pour les nobles, oisifs sur leurs terres lointaines, étrangers à la ville et à l'activité de la ville, et qui fondent leur orgueil de caste sur l'idée barbare et gothique de l'éminente dignité de l'homme qui ne travaille pas: "On appelle gentilshommes, dit-il, ceux qui vivent, dans la paresse et l'abondance, des revenus de leurs domaines, sans nul besoin de penser à la culture ou d'exercer une profession pour subsister. De tels individus sont pernicieux en tout État; mais les plus dangereux sont ceux qui, de plus, commandent des châteaux forts et ont des vassaux qui leur obéissent ». Les uns et les autres avaient depuis longtemps disparu de la Toscane; mais ils restaient nombreux et puissants dans quelques régions de la péninsule : «Le royaume de Naples, écrit Machiavel, la campagne de Rome, la Romagne et la Lombardie sont remplis de cette sorte d'hommes. Aussi, dans ces provinces, n'a-t-on jamais vu naître aucune république ni aucune forme de vie policée : car une telle engeance est l'ennemie de tout régime civil ${ }^{\mathrm{cxv}}$. » 
La noblesse offre au despotisme un appui naturel. Si les gouvernements tyranniques, dont les querelles divisent l'Italie, dont la faiblesse et la trahison livrent l'Italie en proie à l'étranger, doivent disparaître, il faut que cette classe rentre avec eux dans le néant. Par deux fois, dans les Discours sur la première Décade, et, avec plus de netteté, quand il écrivit pour Léon X, en p083 1519, son Discours sur la réforme du gouvernement florentin, Machiavel allait définir le rôle de la noblesse dans l'organisation sociale et politique des États. La monarchie s'appuie nécessairement sur une noblesse foncière. La république s'appuie nécessairement sur une bourgeoisie impatiente d'inégalité. Pour fonder une république à Milan, où les citoyens sont extrêmement inégaux, il faudrait y détruire la noblesse, ou la plier sous un niveau commun. Inversement, qui voudrait établir un principat à Florence, ville d'égalité, devrait y instituer d'abord l'inégalité : y créer une noblesse en possession de châteaux et de domaines, alliée naturelle du prince, et assez forte pour maîtriser, au moyen de ses armes et de sa clientèle, la ville et le pays. Sans la noblesse, le prince ne peut à lui seul soutenir le poids de l'État. Il faut entre le peuple et lui une force intermédiaire, une puissance seconde, qui l'aide à porter sa charge. Dans une monarchie bien ordonnée, et particulièrement dans le royaume de France, les gentilshommes règnent sur le peuple, les grands sur les gentilshommes, le roi sur les grands. En échange des privilèges que le roi leur accorde, les nobles assurent au roi la soumission des villes et des campagnes. ${ }^{\text {cxvi }}$ Ainsi Machiavel s'accorde avec Montesquieu, son lecteur attentif, qui, plus de deux siècles après lui, écrit dans 1'Esprit des Lois : "Le pouvoir intermédiaire subordonné le plus naturel est celui de la noblesse. Elle entre, en quelque sorte, dans l'essence de la monarchie, dont la maxime fondamentale est : point de monarchie, point de noblesse ; point de noblesse, point de monarque. " ${ }^{\text {cxvii }}$ C'est pourquoi Machiavel souhaite la ruine de la caste où les gouvernements princiers trouvent leur naturel et indispensable, appui.

Toutefois, comme il sait la faiblesse des républiques italiennes, p084 il ne peut exclure, et au contraire il s'attarde à discuter le cas où l'Italie accomplirait son unité sous la conduite d'un prince. Pas davantage il ne peut exclure le cas où l'Italie s'unifierait sous la forme d'une fédération de principautés et de républiques. Dans l'une et l'autre hypothèse, la noblesse terrienne conserverait un rôle nécessai- 
re, soit à l'intérieur d'une monarchie nationale, soit à l'intérieur des États princiers entrés dans la fédération nationale. Mais à coup sûr l'Italie nouvelle ne tolérerait pas une noblesse intraitable et brutale comme celle de Romagne et des États pontificaux. Elle n'admettrait qu'une noblesse exactement encadrée dans la constitution des États, et, comme dira Montesquieu, subordonnée ; une noblesse qui, dans la nouvelle Italie, jouerait le rôle attribué par Machiavel à la noblesse française, que les rois ont su contraindre à servir leur pouvoir dans les limites des lois.

Toutes ces destructions et ces transformations, toute cette réforme profonde de la politique italienne, ne pourront s'accomplir sans une réforme morale : car la corruption morale naît de la corruption politique et l'entretient. Or, pour Machiavel comme pour les hommes de son temps, il n'est pas de réforme morale sans réforme religieuse. Il se trouve ainsi conduit à l'étude du problème que Dante avait posé, dans le Purgatoire et le Paradis, et résolu par le franciscanisme. L'Église et la chrétienté ne seraient sauvées que si elles revenaient, sur les traces de saint François, au pur Évangile, à la charité chrétienne, au renoncement, au détachement des biens terrestres. Machiavel, une fois de plus, contredit le poète. Le christianisme ascétique de Dante, qu'il avait vu pendant trois ans et demi renaître à Florence, sous le gouvernement de Savonarole, est encore une de ces survivances médiévales qu'il a condamnées.

Il examine froidement l'héritage spirituel du catholicisme romain. Ou bien fidèles et prêtres ne prennent plus au sérieux leur religion, ce qui est le cas le plus fréquent; et tout le bénéfice qui doit en revenir à l'État fait défaut. ${ }^{\text {cxviii }}$ Ou bien les chrétiens ${ }_{\text {p } 085}$ ne savent tirer de leurs croyances qu'un idéal de perfection ascétique et de renoncement, tout impropre à former des citoyens libres. Machiavel estime peu la sainteté catholique : sa longue familiarité avec les anciens la lui rend inintelligible. Il entend le mot vertu au sens romain : la vertu consiste avant tout dans l'énergie, capable d'action périlleuse et de sacrifice. A la morale chrétienne, qui enseigne l'art de souffrir plutôt que d'agir, il préfère la morale païenne, qui place le souverain bien dans le plein et harmonieux développement des puissances humaines ; morale créatrice d'énergie et de gloire. C'est au christianisme médiéval que les mo- 
dernes doivent d'avoir, moins que les anciens, ressenti l'amour de la patrie et la passion de la liberté : " Notre religion nous fait moins estimer l'honneur du monde ; aussi les païens, qui l'estimaient très haut, et y reconnaissaient le bien suprême, étaient-ils plus hardis et plus fiers dans leur conduite... La religion antique n'exaltait au rang des bienheureux que des hommes comblés de gloire mondaine, comme les chefs d'armée ou les princes des États. La nôtre a glorifié les humbles et les contemplatifs plus volontiers que les hommes d'action. Elle a placé le souverain bien dans l'humilité, l'abjection, le mépris des choses humaines ; la religion païenne le plaçait dans la grandeur d'âme, dans la vigueur physique, dans tout ce qui contribue à renforcer l'énergie. Et si notre religion exige de nous la force de l'âme, c'est pour nous exercer à la souffrance plutôt qu'à l'action vigoureuse. Une telle morale a rendu le monde débile et l'a livré en proie aux scélérats. Ils peuvent le gouverner à leur aise, car ils voient que la plupart des hommes, pour aller en Paradis, songe à supporter les coups plutôt qu'à les venger. » Ainsi Machiavel déplore « la faiblesse où la présente religion a conduit le monde $\gg .{ }^{\text {cxix }}{ }_{\mathrm{p} 086}$

Ce christianisme ascétique et monacal n'est qu'une déformation du christianisme véritable ; la lâcheté des hommes en a interprété la doctrine selon un idéal de paresse et non de vertu. Machiavel affirme que le vrai christianisme, "tel qu'il fut ordonné par son fondateur », permet et veut que le citoyen travaille à l'exaltation de la patrie. Ce christianisme, authentique et véritable, mal compatible avec la religion des prêtres et des moines, répond aux besoins spirituels d'un homme d'État, qui, sans faire du Sermon sur la Montagne ou de l'Évangile selon saint Jean une méditation quotidienne, se flatte de lire la Bible judicieusement. ${ }^{\mathrm{cxx}}$ Christianisme patriote, civique et guerrier ; christianisme d'État, beaucoup moins proche du Nouveau Testament que de ce spiritualisme d'État, de ce stoïcisme d'État, dont les formules éloquentes suffisent à la religion d'un Cicéron. Machiavel souhaite une rénovation morale qui remette en honneur, chez les modernes chrétiens, la vertu antique.

Si contestables que soient son interprétation de l'Évangile et ses idées sur la politique présumée du Christ, il suffit de constater que Machiavel, comme tant d'autres, au cours des années qui précèdent immédiatement l'apparition de Luther, exige la réforme de l'enseignement chrétien, des « fausses interprétations » p087 tirées des 
croyances chrétiennes ${ }^{\text {cxxi }}$; qu'il affirme, comme tant d'autres, la nécessité d'un retour au christianisme primitif. Si rebelle au sentiment religieux, il ne peut esquiver le problème fondamental qui, dès le début du XIV ${ }^{\mathrm{e}}$ siècle, avait dominé la pensée de Dante, et qui, dans les premières décades du XIV ${ }^{\mathrm{e}}$, s'imposait aux plus hautes intelligences : le problème de la réforme de l'Église et de la société chrétienne.

Ainsi Machiavel poursuit l'analyse des questions posées par la nécessité de guérir les misères de l'Italie. Le problème militaire, le plus urgent à résoudre, l'a conduit au problème politique ; le problème politique au problème social, le problème social au problème moral et religieux. Un monde nouveau se reconstruit devant son esprit. Il sait ce qu'exige la création, en Italie, d'un État national, assez fort pour résister aux Barbares. Abolition ou affaiblissement définitif de l'autorité impériale ; abolition ou affaiblissement définitif du pouvoir temporel des papes ; disparition, suppression des petits États sans vigueur et sans avenir; de la plupart des cités républicaines et des seigneuries ; disparition, suppression, de tout reste du passé féodal, ou du moins obligation imposée aux nobles de se soumettre à la discipline d'un gouvernement civil et à l'autorité de l'État ; enfin réforme religieuse, retour au christianisme des origines ; ce qui, pour Machiavel, signifie désaveu de tout ascétisme, de tout idéal contemplatif ou monastique, réconciliation de l'Évangile avec les traditions les plus stoïquement actives de la philosophie païenne.

Restait à conclure. Pour accomplir les destructions nécessaires, les réformes nécessaires, qui mettre à la tête de l'entreprise ? A qui le soin d'unifier l'Italie ? César Borgia depuis longtemps avait disparu ; les Aragonais de Naples avaient disparu ; les Sforza n'étaient plus que les vassaux de l'empereur. Il ne restait que Venise, objet d'envie et de haine ; Florence, redevenue cité princière, dépouillée de ses vertus républicaines ; et le Saint-Siège, toujours malfaisant. Machiavel, arrivé à ce point, ${ }_{0} 08$ ne pouvait répondre. Et il était dit qu'il ne pourrait jamais répondre, et que ses efforts pour résoudre un problème insoluble l'entraîneraient et l'égareraient dans un dédale d'incertitudes, d'illusions et de contradictions. 


\section{Chapitre III}

\section{Illusions et incertitudes}

I

L'œuvre de réforme politique et morale dont Machiavel savait mesurer exactement l'ampleur eût exigé l'effort persévérant de plusieurs générations. Fallait-il donc se résigner à une longue patience ? Attendre que la nation eût pris conscience d'elle-même, et qu'à Florence, à Rome, à Venise, à Milan, se fussent lentement formées, lentement exercées, les forces nécessaires pour dominer tant de problèmes et les résoudre ? Attendre au milieu des dangers qui de toute part menaçaient jusqu'à l'existence de la nation, alors que les Espagnols occupaient Naples et Milan, que les rois de France n'avaient pas renoncé à Milan et peut-être à Naples; que l'Empereur persistait à revendiquer ses droits sur l'Italie du Nord, et que le Saint-Siège, avant tout soucieux de grandeur temporelle, poursuivait au hasard de ses alliances changeantes avec les États italiens ou étrangers, la même politique, dont l'effet constant était d'entretenir en Italie désunion et faiblesse ?

Une tradition italienne, vivante et singulièrement durable, conseillait de rejeter ces délais, et de s'en fier à l'intervention d'un homme providentiel. Tradition découragée, à la fois impatiente et paresseuse, d'un peuple qui renonce à compter sur le temps et sur lui-même, et place son espoir non dans sa conscience et dans sa force, mais dans l'aventure et le destin. p090

Deux siècles auparavant, Dante avait appelé de ses vœux un rédempteur envoyé de Dieu pour sauver l'Italie et la chrétienté. Le premier chant de la Divine Comédie annonce la venue du lévrier divin qui 
donnera la chasse à la louve, symbole de l'avidité des biens terrestres, symbole de la cour de Rome complice des rois capétiens, et la fera rentrer dans l'Enfer d'où elle est sortie ${ }^{\text {cxxii }}$. Au trente-troisième chant du Purgatoire, Dante prophétise l'apparition vengeresse d'un chef mystérieux qui détruira la fausse papauté et la monarchie usurpatrice $^{\text {cxxiii }}$. Il avait cru le reconnaître dans la personne de l'empereur Henri VII ; il compta peut-être, pendant les dernières années de sa vie, sur Louis de Bavière. L'enthousiasme de Pétrarque avait, quelques mois, salué Cola di Rienzo comme le libérateur prédestiné. Machiavel se laisse aller à ces espérances illusoires. Comme Dante, comme Pétrarque, il invoque à son tour le rédempteur, un Thésée, un Moïse ou un Cyrus ${ }^{\text {cxxiv }}$. Si le gouvernement de l'État doit être une œuvre républicaine et contrôlée par les citoyens, la fondation, et, plus encore, la réforme d'un État exigent l'action d'un seul ${ }^{\mathrm{cxxv}}$. Dans les dangers suprêmes, la république romaine élisait un dictateur. Machiavel, républicain, estime que l'extrême corruption où l'Italie est tombée ne lui permet d'attendre le salut que de l'action dictatoriale. Il attend le chef providentiel qui interdira désormais aux Barbares de saccager la p091 Lombardie, de rançonner la Toscane ou le royaume de Naples, et guérira les plaies douloureuses et invétérées du corps italien ${ }^{\text {cxxvi }}$. Déjà sans doute achevait de s'ébaucher dans son esprit cette théorie de la dictature qui se développe au premier livre des Discours sur la première Décade ${ }^{\text {cxxvii }}$. Le chef de génie dont il invoque le secours, recevra, sans nulle réserve, une autorité absolue cxxviii. Car une cité libre qui a laissé corrompre l'esprit de ses premières institutions permet difficilement qu'on la reconduise à la notion du bien public ; et la tâche est plus pénible encore chez un peuple accoutumé à la tyrannie ${ }^{\text {cxxix }}$. Mais le républicain Machiavel redoute les dangers de l'autorité personnelle et arbitraire. Le réformateur de l'État ne le gouvernera pas à vie. p092 Pas plus que le fondateur, il ne fera souche d'une famille régnante $^{\text {cxxx }}$. Les fonctions du dictateur, sous la République romaine, étaient temporaires. Également temporaires doivent être celles de l'homme chargé de restaurer un État ancien ou de créer un État nouveau. Son œuvre accomplie, il devra, par désintéressement civique, quitter ses pouvoirs. Il confiera à des magistrats et à des conseils librement élus le dépôt des lois. Dictature donc, mais provisoire et conditionnée. 
Il était permis de se demander si la pratique s'accommoderait à ces vues. Guichardin, qui, avec son expérience d'homme d'État et sa froide critique, rédigeait entre 1527 et 1530 ses Considérations au sujet des Discours de Machiavel sur la première Décade de Tite-Live, note que l'on peut imaginer de telles idées et leur consacrer des livres, plus aisément qu'elles ne se réalisent dans les faits ${ }^{\text {cxxxi }}$. Le désintéressement et l'abdication du fondateur ou du réformateur d'un État appartiennent au domaine du mythe. Les vieilles histoires citées par Machiavel à l'appui de sa thèse risquent de suggérer le doute. Plutarque affirme que Lycurgue et Solon se sont retirés de la vie publique : Guichardin souhaiterait que Machiavel eût relu, dans la Vie de Romulus, comment le fondateur de Rome prétendit garder une autorité sans limites, et comment les sénateurs, las de sa tyrannie, l'assassinèrent. Sans doute Guichardin, pas plus que Machiavel, n'écarte l'hypothèse d'une dictature salutaire. Il admet, comme Machiavel, qu'un seul peut, mieux que plusieurs, rétablir l'ordre social et politique. Il l'autorise, comme Machiavel, à ne pas s'embarrasser du droit et de la morale. Mais, à la réflexion, il préfère que le dictateur ne vienne pas. Il se méfie des hommes providentiels, rédempteurs et sauveurs de peuples, et de leurs ambitions personnelles, et du despotisme nouveau que fatalement ils instituent: "Prions donc, conclut-il, p093 que nous n'ayons pas besoin d'être réformés de cette manière. Car les hommes ne sont pas sincères, et le réformateur éprouve aisément la tentation de se faire tyran ${ }^{\text {cxxxii }}$. " Et Machiavel n'ignorait pas davantage que les dictateurs, depuis la mort de Cincinnatus, avaient oublié de retourner à la charrue.

Il cherchait cependant un candidat au pouvoir suprême, et, pour l'instruire, abandonnant les gloses qu'il écrivait en marge de son TiteLive, il achevait, dans les derniers jours de 1513, le traité du Prince. Il ne supportait plus l'éloignement de ces affaires qu'il se sentait capable de conduire. Principal conseiller de Soderini, prêt à définir dans ses Discours la liberté politique en termes inoubliables, il se rapprochait des Médicis, et pour rentrer en grâce auprès d'une famille de princes, composait un bréviaire de tyrannie. Qu'il pensât, de la sorte, servir l'Italie, travailler à une œuvre d'affranchissement national, on n'en peut douter, puisque ce fut la plus chère de ses illusions. Qu'il pensât que la fin justifie les moyens, on ne peut en douter, puisqu'il l'a plus d'une fois affirmé cxxxiii. Il voulait offrir son livre à Julien, frère de 
Léon X et troisième fils de Laurent le Magnifique. On parlait beaucoup, à Florence et à Rome, de réunir sous la domination de Julien, qui, âgé de trente-quatre ans, ne portait encore que le titre ducal de Nemours, quelques petits États de l'Italie du Nord, - Parme, Plaisance, Modène, Reggio d'Émilie —, déchirés par des querelles politiques et sociales, par les rivalités de tyrans médiocres et violents. On pensait encore à lui assurer la possession d'Urbino, dont le duc, Francesco Maria della Rovere, hésitant entre la France et l'Espagne, n'inspirait que méfiance au Saint-Siège. Un tel dessein ne différait guère de celui qu'Alexandre VI avait conçu pour César Borgia. Dans sa lettre du 10 décembre 1513, Machiavel, en termes émouvants, consultait Vettori sur l'opportunité de cette dédicace : ${ }_{\mathrm{p} 094}$ «Je m'use, écrivait-il, dans cette solitude, et ne puis rester ainsi longtemps sans tomber dans la misère et le mépris. Je désirerais donc que les seigneurs Médicis consentissent à m'employer, ne fût-ce qu'à rouler un rocher... ... Si l'on lisait ce livre, on verrait que, pendant les quinze années où j'ai eu l'occasion d'étudier l'art du gouvernement, je n'ai point passé mon temps à dormir ou à jouer; et chacun devrait tenir aux services d'un homme qui a su acquérir ainsi, aux dépens d'autrui, tant d'expérience.... Ma fidélité, concluait-il, ne devrait être mise en doute par personne : car, ayant toujours observé la foi, ce n'est pas maintenant que j'apprendrai à trahir. Qui est resté fidèle et loyal quarantetrois ans, - tel est mon âge - , ne pourrait changer de nature. En faveur de ma fidélité et de ma loyauté, ma pauvreté porte témoignage. " ${ }^{\text {cxxiv }}$ Il avait déjà sans doute écrit ce vingt-deuxième chapitre, où définissant les obligations réciproques du prince et du ministre détenteur des secrets d'État, il semble présenter, non sans une fierté discrète, sa candidature à une charge dont il se sait digne ${ }^{\text {cxxxv }}$. Mais le jeune Médicis, p095 que Michel-Ange, dans la Sacristie Nouvelle de SaintLaurent, a voulu transfigurer en un symbole de hardiesse agissante, ne s'imposait au choix de Machiavel par aucun don génial : lecteur frivole et distrait, l'appel désespéré du patriote ne l'aurait pas ému. Vettori préférait ne pas répondre à Machiavel. Une mort subite enleva, le 17 mars 1516, le prince auquel il réservait la dictature.

Il reporta ses espérances sur Laurent, petit-fils du Magnifique, fils de ce Pierre de Médicis qui, chassé par la révolution de 1494, avait mené neuf ans, à la cour de France et à la suite des armées françaises, la vie obscure d'un prétendant en exil, pour finir misérablement, le 28 
décembre 1503, à la journée du Garigliano, noyé dans le fleuve. Laurent, en 1516, avec l'autorisation de Léon X, conquit sans grand effort le duché d'Urbino ; le pape, l'année suivante, négocia, non sans peine et moyennant finance, la renonciation de Francesco Maria. C'est à Laurent, plus jeune que Julien, plus ardent et mieux doué pour l'action, que Machiavel finalement dédia son livre, et proposa de reprendre l'œuvre interrompue de César Borgia : "Jamais, conclut-il, les circonstances n'ont été plus favorables à un prince nouveau. $\mathrm{Si}$, pour qu'apparût le génie de Moïse, le peuple d'Israël devait être esclave en Égypte ; si, pour que pût se montrer la grande âme de Cyrus ou l'excellence de Thésée, il fallait que les Perses fussent opprimés par les Mèdes ou que les Athéniens fussent divisés ; pareillement aujourd'hui, pour faire éclater aux yeux le génie d'une grande âme italienne, il était nécessaire que l'Italie tombât dans la décadence où elle se trouve; qu'elle fût plus esclave que les Hébreux; plus assujettie que les Perses, plus divisée que les Athéniens ; sans chef, sans ordre ; battue, dépouillée, courue en tout sens par les ennemis ; et qu'elle eût éprouvé toute sorte de ruine... Elle attend l'homme qui viendra panser ses blessures, mettre fin au pillage de la Lombardie, au rançonnement du royaume de Naples et de la Toscane, et la guérira de ses plaies, depuis longtemps enracinées dans sa chair. On la voit prier Dieu qu'il lui envoie quelqu'un pour la délivrer de ces cruautés et de ces insolences barbares. On la voit toute prête à suivie un drapeau, pourvu qu'il y ait p096 un chef pour qu'il le saisisse... Ce sera une grande œuvre de justice ; car la force est juste quand elle est nécessaire, et les armes deviennent instruments de la piété, lorsqu'on ne peut espérer qu'en elles... La mer s'est ouverte, une nuée a montré le chemin ; une source d'eau vive a jailli du rocher... L'Italie est pleine de génie et de vigueur, si génie et vigueur ne manquent pas aux chefs... On ne doit donc pas laisser perdre cette occasion; il faut que l'Italie, après une longue attente, voie apparaître enfin son rédempteur. Et je ne puis dire avec quel amour il serait accueilli dans toutes les provinces qui ont subi les invasions étrangères; avec quelle soif de vengeance, avec quelle foi obstinée, avec quelle piété, avec quelles larmes. Quelle porte trouverait-il fermée? Quel peuple lui refuserait l'obéissance? Quelle rivalité rencontrerait-il ? Quel Italien lui refuserait le respect? Cette domination barbare est en dégoût à chacun... Que votre illustre maison accepte donc cette tâche avec le courage et l'espérance qui conviennent aux fortes entreprises, afin que, sous ses enseignes, notre 
patrie acquière une gloire nouvelle ; afin que, sous ses auspices, nous puissions voir se réaliser ce qu'annonça Pétrarque : «Le génie, contre la force barbare, prendra les armes, et le combat sera court: car l'antique valeur, dans les cœurs italiens, n'est pas encore morte ${ }^{\text {cxxxvi }}$. »

Laurent, le 4 mai 1519, suivit Julien, à l'âge de vingt-sept ans, sans avoir, à ses dernières heures, souhaité d'autre réconfort que les bons mots d'un bouffon. Le duc d'Urbino, que Michel-Ange, onze années plus tard, immortalisa sous les traits du Penseur, avait si vainement reçu la dédicace du Prince, qu'on ne sait même s'il l'a jamais lu. p097

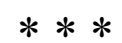

Mais quand bien même une mort prompte n'eût pas enlevé successivement les deux jeunes hommes auxquels le secrétaire florentin adressait un appel désespéré, ils n'avaient ni l'intelligence assez haute ni le cœur assez chaud pour y prêter attention. C'étaient de petits princes italiens parmi tant d'autres dont Machiavel avait dénoncé la faiblesse ; égoïstes et blasés, comme les autres, et dépourvus de génie. Julien et Laurent se seraient contentés de gouverner sans gloire, dans l'Italie du Nord ou du Centre, les États nouveaux qu'ils auraient dus à la bienveillance pontificale, sans beaucoup penser aux misères et à la détresse de l'Italie, et certainement sans nul souci de guérir une corruption dont ils n'étaient pas indemnes. Plutôt qu'à ces médiocres et douteuses figures, l'exhortation de Machiavel s'adresse au rédempteur mythique annoncé par de mystérieuses prédictions.

La poésie pouvait alors lui sembler plus vraie que l'histoire; elle lui permettait à la fois d'oublier et l'enseignement le plus certain des faits, et sa propre doctrine. Il ne pouvait douter que si quelque heureuse fortune permettait à Julien ou à Laurent de créer dans l'Italie centrale un État assez vigoureux pour grouper autour de lui la plupart des forces italiennes, leur premier soin serait de fonder une dynastie. Nul n'oserait leur demander sérieusement de redevenir simples citoyens. Machiavel connaissait assez les Médicis pour ne pas ignorer qu'après avoir, tenacement et sans renoncer même à l'appui de l'étranger, poursuivi la destruction de la République florentine, nul d'entre eux n'accepterait l'idée de fonder, au cœur de l'Italie, une principauté capable de dominer toute la politique italienne et d'imposer aux États 
italiens un ordre nouveau, pour rentrer ensuite dans la vie privée. Il savait bien que César Borgia, devenu roi dans l'Italie centrale, n'aurait jamais abdiqué par désintéressement civique. Il savait bien que si Julien ou Laurent pouvaient réussir dans l'entreprise à laquelle il les conviait, on devrait se résigner à les traiter en monarques. Il savait bien que ni l'un ni l'autre ne réalisait le type du dictateur républicain, soumis aux lois et à la constitution, et prêt, une fois l'État réformé, à rentrer dans le rang et le silence. Et d'ailleurs le livre dont il leur offrait la dédicace ne contenait aucune allusion à cette retraite, p098 aucun chapitre sur l'abdication du prince. Il n'y était question que de construire, sur des bases inébranlables, l'autorité absolue et perpétuelle d'un despote éclairé. C'était pour lui-même que, dans les Discours sur la première Décade, Machiavel écrivait alors le chapitre sur la dictature vertueuse, républicaine, constitutionnelle et soumise au consentement populaire. Mais ni Julien ni Laurent ne connurent cette théorie, qu'ils n'auraient pas prise au sérieux. De la sorte, Machiavel ne s'entendait avec eux qu'à force d'illusion volontaire, de réticences médiocrement franches, et à condition de ne leur livrer que la moitié de sa pensée. Dans la pratique, les contemporains qui ne connaissaient pas ses incertitudes et ses luttes intérieures, le voyaient offrir son concours aux Médicis, pour la fondation d'une monarchie dont nul n'aurait pu deviner qu'il ne la voulait pas éternelle.

$$
* * *
$$

Il se laissait aller encore à d'autres illusions, et, plus gravement encore, il contredisait sur un autre point sa propre doctrine. Il savait les ressources de Florence et de son domaine toscan, les ressources du pauvre duché d'Urbino, insuffisantes à soutenir l'effort qu'il demandait à Julien ou Laurent; et maintenant, pour le succès de leur œuvre, il comptait sur le Saint-Siège, dont leur famille, avec Léon X, avait pris possession. Si acharné à dénoncer, dans la politique des papes, la cause permanente des discordes et des faiblesses italiennes, il rêvait maintenant d'associer le pouvoir temporel du Saint-Siège non seulement à la fondation du nouvel État national, mais à la libération même de l'Italie : l'auteur du Prince offre à Julien ou à Laurent l'appui de l'Église, que gouverne l'un des leurs ${ }^{\text {cxxxvii }}$. Ainsi pour la première fois, - car il n'y a pas lieu de considérer l'accord d'Alexandre VI et de son fils César, qui n'étaient que deux complices, engagés dans une 
entreprise de rapine - , l'opposition traditionnelle, dénoncée par Machiavel, du Saint-Siège à l'effort de tout prince qui pourrait tenter l'unification ${ }_{\mathrm{p} 099}$ de l'Italie, va prendre fin. La grandeur italienne des Médicis pourra se concilier avec la grandeur italienne du Saint-Siège qu'ils occupent. Le Saint-Siège va, pour la première fois, mettre sa force politique et son prestige religieux au service de la cause nationale. Protecteur de Julien ou de Laurent, Léon X, pape italien, saura, mieux que Jules II, affranchir l'Italie des Barbares, assurer son indépendance avec son unité. Ainsi paraît s'ébaucher dans l'esprit de Machiavel une idée qui sera reprise, à la veille de 1848, par l'école néoguelfe, lorsque Vincenzo Gioberti, dès les premières années du pontificat de Pie IX, formera le projet d'une fédération nationale des États italiens, sous la présidence et le contrôle du Souverain Pontife. Ainsi Machiavel, qui certainement avait conçu déjà le dur chapitre XII du premier livre des Discours, qui certainement l'avait écrit sinon en 1513, du moins avant 1516 ou 1519, qui savait les méfaits du pouvoir temporel des papes en Italie, et qui en souhaitait la ruine, imaginait un biais pour l'utiliser à l'avantage des libertés italiennes ${ }^{\text {cxxxviii }}$. Et comme nul ne connaissait les pages redoutables et secrètes qui devaient survivre à de vaines combinaisons, Machiavel semblait se réconcilier avec cette papauté temporelle, dont il ne craignait plus d'affirmer publiquement la grandeur et la bienfaisance.

Mais ses calculs, où il associait, de façon inattendue, le pontificat d'un Médicis à une entreprise médicéenne de libération nationale, s'égaraient, comme cette entreprise même, dans le rêve et l'illusion. Appeler le Saint-Siège à soutenir, moralement et matériellement, l'effort de libération et d'unification de l'Italie, était un projet que rien ne pouvait encourager; aussi décevant, à l'automne de 1513, qu'il devait l'être au printemps de 1848. Comme Julien, comme Laurent, Léon X était de faible génie ; égoïste lui aussi, indifférent lui aussi et blasé. Plus volontiers il consacrait ses loisirs à converser avec les poètes et les artistes, à soigneusement examiner, loupe en main, médailles et miniatures de prix, qu'à préparer la restauration morale et religieuse de l'Église romaine ou ces entreprises hasardeuses d'affranchissement national que Jules II avait du moins conçues et tentées. Il vivait, en politique, au jour le jour. Il formait, en politique, des desseins limités aux intérêts de l'État pontifical et de la famille des Médicis. Il venait de réconcilier non sans ${ }_{\mathrm{p} 100}$ peine, après Marignan, le Saint-Siège avec 
François $\mathrm{I}^{\mathrm{er}}$; il travaillait à gouverner, sans trop de heurts et de conflits, une ville de tout temps mal gouvernable. Il ne voyait que Florence et Rome ; il ne voyait pas l'Italie. Il n'eût jamais permis à Laurent d'être autre chose que le docile instrument d'une politique étroitement florentine et familiale. Il ne se souciait pas de seconder Machiavel ou de le comprendre.

Si le secrétaire florentin s'était, un moment, laissé aller à l'illusion de réconcilier le Saint-Siège avec les intérêts et l'avenir de la nation italienne, les événements allaient bientôt lui démontrer que, sur la politique italienne des papes, le réquisitoire inscrit au premier livre des Discours, mieux que les lignes hasardées au dernier chapitre du Prin$c e$, exprimait la vérité. Comme Julien et comme Laurent, par l'effet de la fatalité qui poursuivait les Médicis, Léon X mourut prématurément, en décembre 1521. Le Hollandais Adrien VI ne fit que passer ; le cardinal Jules de Médicis fut élu, le 18 novembre 1523, par le conclave. Mais Clément VII, moins encore que Léon X, était capable de s'émouvoir aux rêves de Machiavel. Son pontificat, désastreux pour l'Église romaine, qui vit alors plus d'un tiers de l'Europe adhérer à la Réforme protestante, fut désastreux pour les libertés florentines et pour Florence, dont Clément VII, avec l'aide de Charles-Quint, put faire enfin la capitale d'un duché, bientôt grand-duché, où les Médicis devaient régner deux siècles; désastreux pour l'Italie, où les luttes malheureuses de Clément VII et sa réconciliation malheureuse avec Charles-Quint établirent, plus solidement que jamais, la domination espagnole dans le Nord et le Midi, et, plus solidement que jamais, soumirent les princes et les États à la politique de l'empereur.

Table des matières

\section{II}

Mais, depuis la mort du duc d'Urbino, Machiavel avait renoncé à 1'illusion qui, plusieurs années, lui avait fait rechercher, dans la famille des Médicis, l'artisan princier de la rédemption italienne. Il avait achevé, en décembre 1513, le traité du Prince, étude scientifique et durement positive d'une hypothèse désespérée. Mais il poursuivait la rédaction des Discours ${ }_{\text {p101 }}$ sur la première Décade. Il y exposait, en 
philosophe républicain de l'histoire, l'art de fonder, de gouverner, de maintenir, d'accroître et de réformer une république.

«Je désirerais voir trois choses avant de mourir, devait écrire, quelques années plus tard, Guichardin : une république bien ordonnée à Florence ; l'Italie affranchie de tous les barbares ; et le monde libéré de la tyrannie scélérate des prêtres. ${ }^{\text {cxxxix }}{ }^{\prime}$ Machiavel eût formé les mêmes vœux. Mais, instruit par les événements, il renonçait à la lutte contre l'étranger et le Saint-Siège. Il poursuivait la solution d'un problème posé en termes plus aisément saisissables; la réforme de ces républiques italiennes, qui, si jamais l'Italie délivrée se constituait en une fédération d'États, y représenteraient l'esprit à défaut de la force. Comme il aimait Florence par-dessus tout, c'était à la réforme de la république florentine qu'il consacrait l'effort ininterrompu de sa pensée.

Une fatalité pourtant condamnait ce réaliste, que sa passion transformait en visionnaire et en poète, à s'éprendre sans cesse de nouvelles chimères. Sitôt évanoui le fantôme du rédempteur génial qu'attendait l'Italie, Machiavel put croire venu le moment d'appliquer sa théorie la plus chère, celle de la réforme d'une cité libre par un dictateur citoyen et satisfait de rentrer, l'œuvre accomplie, dans la vie privée. Il crut le moment venu de renouveler et de rajeunir les lois constitutionnelles, par l'action dictatoriale, mais civique et républicaine, de deux autres Médicis, prêts au service du peuple et au renoncement.

C'était, pour parler la langue de Montesquieu, la corruption des lois républicaines qui, à Florence, par deux fois, avait provoqué l'établissement de la tyrannie. Mais la tyrannie médicéenne ne pouvait passer encore par un gouvernement stable et solide. Le régime, qui tendait insensiblement vers le principat, n'osait en adopter la forme. Ni Cosme ni Laurent le Magnifique, au siècle précédent, ni, plus récemment, Léon X, Julien de Nemours ou Laurent d'Urbino, n'avaient osé prendre ${ }_{\mathrm{p} 102}$ le titre de princes, ni fonder à Florence une monarchie que rien n'eût semblé soutenir. Dans la société bourgeoise, égalitaire de Florence, elle n'eût pas trouvé l'appui, indispensable à tout pouvoir monarchique, d'une noblesse foncière, maîtresse des campagnes, assez forte pour dominer la ville par sa clientèle. Une longue tradition de liberté n'avait jamais encore permis à la famille de revendiquer, 
devant les Florentins, une autorité absolue. De la sorte, ni républicain, ni monarchique, désormais étranger à l'esprit républicain, hésitant à rechercher, dans la monarchie, son achèvement, le régime offrait l'aspect de ces formes politiques mal définies, que Machiavel tenait pour vaines et de très brève durée. C'était pourquoi Cosme et Laurent, tous les dix ans, avaient craint de perdre le pouvoir ; c'était pourquoi Pierre, en 1494, avait été chassé par la révolution ; c'était pourquoi, en 1527 , les Médicis allaient être de nouveau expulsés ${ }^{\text {xxl }}$. Or Machiavel décrivait dans les Discours sur la première Décade le régime consulaire et sénatorial de la République romaine comme le type éternel d'un gouvernement mixte, où se tempère et s'accorde, parce qu'il est à la fois monarchique, aristocratique et démocratique, l'action des trois principes selon lesquels les hommes ont toujours été régis, et dont aucun ne suffit à fonder un État durable. Il songeait à réformer, sur le modèle romain, la constitution imparfaite de Florence. Et de nouveau il fondait son espoir sur les Médicis, et leur assignait comme rôle historique la révision des lois constitutionnelles. Le titre de réformateurs désintéressés d'une république devrait contenter leur ambition.

$* * *$

Machiavel avait fini par sortir de sa solitude. On l'avait introduit auprès des Médicis, qui, sans écouter ses exhortations, lui en savaient gré. Depuis la mort du duc d'Urbino, le cardinal Jules, neveu de Laurent le Magnifique et fils de Julien, la victime des Pazzi, gouvernait la ville, dont il était, depuis 1512, archevêque. Prudent, simple de manières, respectueux des apparences ${ }_{\mathrm{p} 103}$ de la liberté, le cardinal, qui bientôt allait recueillir la succession de Léon X et d'Adrien VI, entendait gouverner selon l'usage de Cosme et de Laurent, comme si Florence n'eût jamais cessé d'être une cité libre. Longtemps méfiant à l'égard de Machiavel, la politique lui conseillait de l'écouter, de l'interroger. Machiavel fut prié d'écrire sur la réforme du gouvernement florentin, et d'adresser l'ouvrage à Léon $X$, qui restait le véritable maître de l'État. Heureux de se voir pour la première fois consulté sur les affaires publiques, Machiavel rédigea, dans le courant de 1519, son Discorso sopra il riformar lo Stato di Firenze.

Au cardinal et au pape, il conseilla de rétablir définitivement la république de Florence ; mais ils garderaient, leur vie durant, le pouvoir 
souverain ; condition sans laquelle il savait bien que ses idées ne pourraient pas être accueillies. Il se posa donc un problème dont les termes contenaient une antinomie : restaurer, à Florence, la république; y laisser provisoirement aux Médicis la faculté de choisir les magistrats. Le cardinal et le pape auraient conservé une dictature à vie ; comme ils n'avaient pas d'héritiers, Florence, après eux, serait naturellement rentrée en possession de ses franchises. Machiavel leur suggère de simplifier le vieux mécanisme, artificiellement conservé, des magistratures et des conseils, et d'en renforcer les pouvoirs réels; de partager insensiblement avec les citoyens, sans cesser de les guider, la conduite de l'État; de les habituer à un plus large exercice de leurs droits ; d'instruire progressivement le peuple à user de cette liberté qui, un jour, lui sera rendue. Déjà sans doute étaient écrites les pages qui, dans les Discours, célébraient la retraite volontaire des réformateurs d'États; mais seuls encore quelques amis de Machiavel avaient pu les lire. Il préféra terminer son bref traité par une exhortation qui peut rappeler le dernier chapitre du Prince. Au lieu d'inviter les Médicis au commandement de l'Italie soulevée contre les Barbares, il ne leur offrait plus qu'une autorité viagère et la satisfaction d'un renoncement civique : "Ainsi, concluait-il, vous restez maîtres absolus; vous nommez les principaux magistrats ; votre vie durant, il n'y a pas de différence entre votre gouvernement et une monarchie. Vous laissez après vous une république; elle vous devra son existence... Le plus grand bien que l'on puisse faire, celui qui plaît le plus à Dieu, est celui que l'on fait à sa patrie. Les hommes dont on exalte ${ }_{\mathrm{p} 104}$ le plus la mémoire sont ceux qui ont réformé les républiques et les royaumes... Le ciel ne peut montrer à un homme aucune voie plus glorieuse. Parmi les félicités dont Dieu a comblé votre famille et votre personne, la plus grande est qu'il vous a donné l'occasion de vous rendre, par ce moyen, immortel, et de surpasser par là toute la gloire de vos aïeux ». cxli

Léon $\mathrm{X}$ et le cardinal Jules étaient bien décidés à ne prêter qu'une attention distraite aux conseils de Machiavel. Ils lui reconnaissaient un beau génie, tout chimérique, impropre à l'action pratique et réalisable. Ils le tenaient, à son tour, pour un de ces prophètes désarmés, objets de son ironie. Le pape et le cardinal n'avaient consulté Machiavel que pour l'entretenir dans ses illusions, le bercer de fausses espérances, apaiser sa perpétuelle inquiétude, pénétrer sa pensée secrète ; par là, 
connaître les espoirs des républicains, et, en même temps, le discréditer à leurs yeux.

Table des matières

\section{III}

Selon le calcul des Médicis, il se compromit avec eux. Sans prendre au sérieux sa doctrine et ses projets, ils finissaient par penser que les circonstances le destinaient peut-être à grandir ${ }^{\text {cxlii }}$. Ils s'efforçaient de le rendre prisonnier de leur cause et de leur famille. p105

Ils lui confièrent diverses missions médiocres, dérisoires pour l'homme qui, pendant quatorze ans, avait servi la cité, conseillé, parfois dirigé la politique florentine, et dont le labeur obscur renouvelait la science politique en Europe. En 1520, à Lucques, il allait régler de menus différends entre Florence et cette petite république, de tout temps malveillante. L'année suivante, à Carpi, devant le chapitre général de ces Frères Mineurs qu'il méprisait, il soutint les intérêts de quelques monastères florentins. Il sentait la mesquinerie des affaires qu'on lui réservait. Pour l'oublier, il défendait, en de nouveaux ouvrages, ses plus chères illusions.

A Lucques, son attention fut attirée sur l'histoire d'un aventurier local du XIV siècle, Castruccio Castracani, qui, d'abord chef de bandes au service des Visconti, s'était emparé de Pise, de Volterra, de Pistoia, de sa ville natale, et avait pu créer en Toscane un petit État militaire qui dura autant que sa vie. Machiavel, pendant les loisirs de sa légation, écrivit la Vita di Castruccio Castracani da Lucca. Il s'était peu soucié de vérité historique ; où la matière manquait, il avait enrichi la biographie du condottiere lucquois à l'aide de l'histoire d'Agathocle, tyran de Syracuse, telle que la conte Diodore de Sicile. Il se plut à reconnaître, en ce fondateur oublié d'une tyrannie éphémère, quelques traits de César Borgia. Il prit pour modèle la Cyropédie de Xénophon, et composa une sorte de roman politique et militaire ; il y 
voulut illustrer, par l'exemple d'un personnage à demi fictif, quelques-unes des théories que, dans le Prince, il avait soutenues sur la fondation d'un État monarchique ${ }^{\text {cxliii }}$.

Il achevait alors, il allait publier en 1521 ses trois dialogues De l'art de la guerre. Une fois de plus il s'appliquait à démontrer comment on doit armer un peuple pour défendre l'indépendance d'un État républicain ou monarchique. Une fois de plus, il dénonça l'erreur qui avait séparé, en Italie, la vie civile de la vie militaire, et fait des armes le métier d'hommes ignorants de toute autre besogne, étrangers à la vie de la cité. Il fallait revenir à l'usage de la République romaine, qui ne distinguait pas entre le soldat et le citoyen, enseignait au citoyen les vertus du soldat, mais voulait que le soldat conservât l'esprit du citoyen. Il fallait renoncer définitivement aux armées mercenaires, p106 créer, sur le modèle laissé par les anciens, ou qu'offraient, dans le monde moderne, les Cantons Suisses, des milices nationales ${ }^{\text {cxliv }}$.

Machiavel entreprit donc de défendre l'œuvre tentée en 1506 par la publication de l'Ordonnance sur la Milice florentine. L'armée de la république n'avait pas tenu tête à des forces inégales; et pourtant aucun législateur ne pouvait mettre en doute que la cité dût être défendue par les citoyens. Si les Vénitiens l'avaient compris, ils auraient fondé un Empire. Sur mer, où ils luttaient à l'aide de leurs propres armes, ils avaient toujours été vainqueurs. Leurs défaites sur la terre ferme provenaient du recours aux soldats de métier ${ }^{\text {cxlv }}$. Machiavel note que le roi de France néglige l'instruction militaire de ses sujets, et compose en partie ses armées de mercenaires : erreur qui l'affaiblit, et qui explique le succès, médiocre désormais, des armées françaises en Italie cxlvi . De nouveau, Machiavel flétrit la lâcheté des princes italiens, qui, faute de s'être préparés à la guerre, n'ont su, lors des invasions étrangères, que prendre la fuite ${ }^{\text {cxlvii }}$. Mais le secrétaire florentin, p107 qui n'avait jamais été que commissaire aux armées, sans commander en campagne, s'attribuait une compétence technique dont il manquait ; et Napoléon affirme qu'il a écrit sur la guerre comme un aveugle raisonne sur les couleurs ${ }^{\text {cxlviii }}$. Il put négliger les récents progrès de l'art militaire au point de méconnaître, après Ravenne, après Novare, après Marignan, le rôle et l'efficacité de l'artillerie cxlix. Cependant il conservait assez d'illusions politiques pour croire que les Médicis, à son appel, allaient armer le peuple, alors que, depuis le 
Moyen Age, le premier soin des gouvernements autoritaires avait été de désarmer les citoyens.

Mais déjà les Médicis, après l'avoir quelque temps mis à l'essai, ne souhaitaient plus de lui confier aucune fonction active ; sa personnalité trop forte les gênait. Pour le détourner de toute participation ou de tout désir de participer aux affaires de l'État, pour esquiver toute occasion de recevoir de lui des conseils qu'ils ne voulaient pas suivre, ils lui avaient fait confier par la Seigneurie, le 20 novembre 1520, le soin d'écrire, depuis les origines et à l'aide des archives publiques, l'histoire de Florence. Une pareille tâche pouvait le détourner longtemps de sa doctrine et de son œuvre. Le théoricien, souvent importun, de la politique et de la guerre, allait se transformer en un historiographe officiel, contraint à surveiller sa plume et à ne pas dire toute sa pensée.

Plusieurs années en effet, jusqu'au printemps de 1525, Machiavel dut s'occuper à la composition des Istorie fiorentine. Presque aussi longtemps, jusqu'à la fin de 1525 , il resta nécessairement éloigné de la vie politique, à laquelle de façon évidente, les maîtres de Florence ne voulaient plus qu'il se mêlât.

Éloigné aussi des républicains. Le calcul et la ruse des Médicis avaient réussi. Pendant l'absence du cardinal Jules, appelé à Rome, après la mort de Léon $X$, pour le conclave de 1522, où $p 108$ il se vit préférer Adrien d'Utrecht, les Soderini et quelques jeunes gens de leur clientèle préparaient à Florence un complot. D'accord avec quelques États, avec Pérouse et Urbino, ils espéraient l'appui français. Ces jeunes gens connaissaient Machiavel ; ils l'avaient entendu, chez Cosimo Rucellai, aux Orli Oricellari, lire ses Discours sur la première Décade; deux d'entre eux, Zanobi Buondelmonti et le poète Luigi Alamanni avaient reçu de lui la dédicace de la Vie de Castruccio Castracani $^{\mathrm{cl}}$. Ils s'étaient, à l'entendre et à le lire, passionnés pour la liberté. Ils le voyaient maintenant trop engagé avec les Médicis et ne lui révélèrent pas leur secret. Lorsque le complot eut échoué, que Buondelmonti eut cherché refuge dans l'Apennin toscan, Alamanni en France, Machiavel, cruellement poursuivi en 1513, ne fut pas cette fois inquiété. Les Médicis affectaient de ne plus le considérer comme républi- 
cain. Sans doute espéraient-ils que cette clémence achèverait de le discréditer devant son ancien parti.

Mais ils continuaient de décliner ses services. Le 19 novembre 1523, le cardinal Jules devint le pape Clément VII. Il quittait Florence, dont il laissa le gouvernement aux mains inexpertes et brutales du cardinal Silvio Passerini, bientôt détesté. Clément VII, inférieur à Léon X, timide, irrésolu, mal conseillé, commit l'erreur d'envoyer à Florence, pour assister le cardinal, deux jeunes bâtards que nul ne connaissait, Hippolyte, fils de Julien, à peine âgé de seize ans, et Alexandre, plus jeune encore, fils de Laurent et d'une esclave moresque, à laquelle il ressemblait par ses lèvres épaisses et ses cheveux crépus. Il devait, en 1530, après la ruine finale de la République, être le premier duc de Florence. En vain les citoyens les plus autorisés priaient le pape d'envoyer les deux adolescents à l'école. Il fallut les reconnaître, presque officiellement, comme chefs de l'État florentin. Machiavel devait renoncer à tout espoir d'améliorer un gouvernement de plus en plus impopulaire, et qui désormais, pas plus que celui de Soderini, n'était à l'épreuve des revers extérieurs. Ni le cardinal, ni les deux bâtards, ne se souciaient de lui. De nouveau, il s'était retiré à San Casciano. Il y poursuivait la rédaction de ses Istorie fiorentine, dans l'attente d'événements 109 dont il n'espérait rien d'heureux ni pour Florence, ni pour l'Italie ni pour lui-même. A ses moments perdus, il écrivait la Mandragola, comédie débridée et cynique, où parurent en scène, selon la fantaisie d'une intrigue bouffonne, l'hypocrisie papelarde de ces moines qu'il avait toujours exécrés, l'infinie crédulité des simples, la suffisance obtuse d'un docteur. Mais quelques vers du Prologue laissent sentir l'amertume dont Machiavel alors s'abreuvait: « Si cette matière, dit-il, vous semble trop légère pour un homme qui veut paraître sage et grave, excusez-le, et considérez qu'avec ces pensées frivoles, il s'efforce de rendre ses tristes années moins pénibles. Car il ne saurait tourner ailleurs les yeux : on lui a interdit de montrer, en d'autres entreprises, d'autres talents, et il n'est pas de récompense pour ses peines. » ${ }^{\text {cli }}$

Le désastre de Pavie, le 24 février 1525, la captivité de François I ${ }^{\mathrm{er}}$ à Madrid, firent courir en Italie un vent de panique. Tous les États s'y humilièrent devant la puissance espagnole et impériale de Charles- 
Quint. Elle leur fut si lourde que, dès l'automne, le gouvernement français pouvait, contre l'empereur, ébaucher l'organisation d'une ligue où entra le pape lui-même, bientôt suivi de Florence, qui n'avait d'autre politique étrangère que la sienne. C'est alors que les Médicis, obligés de faire appel, dans un danger pressant, à tous les concours, décidèrent enfin de confier à Machiavel des tâches dignes de lui. C'est alors qu'il rentra vraiment dans la vie publique. Sans doute jugeait-il le régime désormais inébranlable. Sans doute avait-il déjà composé p110 le dur chapitre où il conseille aux princes de ne pas prêter foi aux illusions des émigrés, à leurs promesses encore plus vaines clii. Il venait d'écrire que l'état des institutions florentines permettait à un sage législateur de les réformer à son gré, selon le principe de son

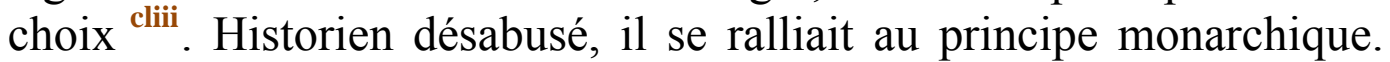
Mais, servant les Médicis, il jugeait servir les libertés de Florence et de l'Italie.

A Rome, en avril 1525, il fut reçu par Clément VII, et lui offrit les Istorie fiorentine, enfin achevées. Il affirma, dans une assez humble préface, que jamais Cosme ni Laurent n'avaient, malgré une légende hostile, nourri d'ambitions contraires aux intérêts de la cité cliv. Le pape le consulta sur la situation politique. Sa réponse fut telle qu'on pouvait l'attendre de l'homme qui, en 1506, avait armé le peuple florentin, en 1521 publié les Dialogues sur l'Art de la guerre. Il conseilla d'enrôler les populations ardentes et vigoureuses de Romagne. Clément VII l'y envoya, auprès de Guichardin, président pontifical. Mais p111 les difficultés étaient grandes, le pape hésitant; rien ne fut fait. Du moins Machiavel put-il s'employer à mettre, avec l'autorisation pontificale, les murailles de Florence en état de soutenir un siège. Il fit instituer, le 9 mai 1526, les cinq Procurateurs des Remparts ; il devint, neuf jours plus tard, chancelier de cette commission. La tâche fut rendue difficile par Clément VII qui, authentique descendant d'une famille de banquiers, voyait dans la réfection et le nouveau tracé des murailles l'occasion de spéculer sur les terrains. François $\mathrm{I}^{\mathrm{er}}$ quittait alors sa prison et l'Espagne, résolu à ne pas observer le traité qu'à Madrid il avait signé. Machiavel, au chapitre XVIII du Prince, lui avait d'avance accordé toute excuse ${ }^{\text {clv }}$. Le 22 mai 1526 fut conclue à Cognac la ligue où entrèrent le pape, Florence, Venise, Milan; elle prit les armes contre l'empereur. 
Machiavel voulut croire enfin les circonstances propices à l'affranchissement national; il venait d'écrire, le 17 mai à Guichardin : "Tout nous montre combien il serait facile de chasser d'Italie cette canaille. Pour l'amour de Dieu, ne perdons pas cette occasion... Délivrez l'Italie d'une inquiétude sans cesse renaissante. Détruisez ces brutes féroces qui n'ont de l'homme que l'aspect et la voix » ${ }^{\text {clvi }}$. Il passa quelques mois en campagne, au quartier général de la Ligue ; il y retrouva Guichardin. Mais les troupes coalisées cédaient sur tous les fronts. L'empereur réoccupait l'Italie du Nord; on ne pouvait attendre de Clément VII aucune énergie. La Toscane, au début de 1527, fut en danger. L'armée impériale du connétable de Bourbon avait alors hâte d'atteindre Rome: elle négligea Florence, et, par les Marches et l'Ombrie, poursuivit ses étapes vers la Ville Éternelle.

Le 11 mai 1527, on sut à Florence que Rome était tombée, p112 que les Impériaux la mettaient à sac. Il semblait que Charles-Quint allât maintenant se venger de Florence. Les républicains, du jour au lendemain, reprirent l'autorité ; on ne pensa plus qu'à rejeter le gouvernement que le pape vaincu ne pouvait plus défendre. La révolution, provoquée par les fautes du cardinal Passerini, éclata. Il ne comptait que soutenu par les forces du Saint-Siège ; il comprit que toute résistance était vaine, et prit la fuite avec Hippolyte et Alexandre. Le 16 mai 1527, la république était rétablie. On convoqua le Grand Conseil, et le gonfalonier Niccolò Capponi entra en fonctions le $1^{\text {er }}$ juin. On continuait de préparer hâtivement la défense ; on reparlait d'armer les citoyens valides, et Michel-Ange mettait son génie d'architecte au service de la commission chargée de restaurer les remparts. Mais on ne désespérait pas d'un accord entre la république et Charles-Quint, maintenant en rupture avec les Médicis. On ne prévoyait pas la réconciliation de Bologne et ses suites accablantes. On ne pensait pas que l'empereur et les Médicis étaient, d'instinct et par intérêt, alliés contre les peuples libres. Déjà pourtant s'annonçait le drame prochain du siège de Florence, dont la capitulation allait, en 1530, consommer la ruine des franchises italiennes.

$$
* * *
$$

Machiavel se trouvait dans une situation tragique. II s'était compromis avec les Médicis. Il apparaissait maintenant aux yeux des hommes qui venaient de les expulser, comme un ennemi de ces liber- 
tés qu'il avait tant chéries. Il revenait alors de Civitavecchia, où il avait conféré avec Andrea Doria, l'amiral génois des flottes pontificales, sur l'opportunité d'un coup de main pour la délivrance du pape. Il retrouvait les Florentins pénétrés de l'esprit qui avait animé les Discours sur la première Décade, l'Art de la Guerre, et ses lectures aux jeunes auditeurs des Orti Oricellari. On ne parlait que de fonder une liberté éternelle, d'instruire une armée de citoyens. Mais nul ne pensait à Machiavel : on le regardait avec méfiance, on l'évitait; il payait la préface de ses Istorie fiorentine. Le 10 juin, on rétablit, pour le contrôle de la politique extérieure et de la guerre, les Dix de la Liberté : Machiavel, quatorze ans leur secrétaire, aurait pu croire qu'on lui rendrait son poste. Il se le vit refuser, et comprit alors que tout était fini pour lui. p113

Il ne devait guère survivre à cette suprême déception, Bien qu'il n'eût pas encore atteint cinquante-huit ans, sa santé, depuis longtemps, était débile. Le 20 juin, il tomba gravement malade. Il mourut le 22 juin 1527. Un moine que l'on connaît sous le nom de fra Matteo, l'avait assisté à ses derniers moments. Il laissait les siens dans une grande pauvreté.

$\underline{\text { Table des matières }}$

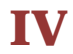

Ainsi, pendant ces quinze années, s'étaient succédé les inutiles projets que Machiavel avait successivement conçus, d'abord pour réaliser son plus grand rêve, la création d'un État national, et lui confier la défense de l'Italie contre les Barbares, pour satisfaire ensuite le désir plus modeste de fonder à Florence une république durable et bien ordonnée. Dans tous ses projets, l'examen positif des faits s'achevait en illusion. Illusion d'avoir espéré la venue de l'homme providentiel jadis prophétisé par Dante ; illusion d'avoir cru discerner le rédempteur italien dans les personnes médiocres de deux jeunes Médicis. Illusion d'avoir pu un instant imaginer que le Saint-Siège, occupé par un Médicis, renoncerait à cultiver les divisions et les faiblesses de l'Italie pour servir une politique d'union et de force nationale. Illusion d'avoir, pour restaurer à Florence l'esprit des lois républicaines, fait 
appel à deux autres Médicis, uniquement désireux d'y consolider la puissance princière de leur maison, le cardinal Jules et le pape Léon $\mathrm{X}$. Illusion d'avoir pu croire à la modestie civique d'un dictateur.

L'homme en qui la tradition a voulu reconnaître le plus authentique représentant de la politique la plus réaliste, apparaît donc, à suivre son action pratique et sa conduite, comme un illuminé, comme l'un de ces prophètes sans défense et sans armes sur lesquels s'exerçait son ironie ; le plus souvent égaré, dans les circonstances les plus graves, par ses visions; prompt à se tromper sur les hommes, à leur confier des missions historiques pour lesquelles ni leurs idées, ni leur tempérament, ni leurs plus certaines ambitions ne les désignaient. Au cours de ces quinze années où toutes les forces de son esprit se sont appliquées à fonder une politique positive, chaque fois qu'il a $\mathrm{a}_{114}$ voulu passer de la théorie à la pratique, intervenir dans le domaine des faits, conseiller ou guider ses contemporains, Machiavel s'est trompé.

Ses erreurs ne sont pas de celles dont on peut aisément excuser un homme d'État formé comme lui par la pratique et par l'histoire. On affirmerait vainement qu'elles ne le diminuent pas. Croire en 1513 à la possibilité de fonder en Italie un État national par l'action des Médicis et avec l'appui du Saint-Siège, n'était pas seulement s'aveugler sur la politique du Saint-Siège et des Médicis ; c'était oublier volontairement un fait pourtant essentiel, la force du particularisme italien, la diversité essentielle de l'Italie, la diversité des États italiens, de leurs institutions, de leur esprit ; la passion de l'indépendance locale ; passion jalouse, irrésistible, à laquelle chacun de ces États devait l'originalité de sa vie politique, sociale, souvent aussi de sa vie artistique et littéraire. Passion d'indépendance, esprit particulariste, dont Guichardin, relisant Machiavel, note le prix, la bienfaisance, et qu'il veut avec soin préserver. Une fois encore, Guichardin refuse de suivre Machiavel : «Je ne sais, écrit-il, si le fait que l'Italie n'ait pu se constituer sous la forme d'une monarchie unique a été pour elle bonheur ou malheur. Sans doute, ainsi divisée entre divers gouvernements, elle a subi bien des misères... Mais cette diversité a permis aussi le progrès d'un grand nombre de villes, prospères, éclatantes ; ce qui n'aurait pas été possible sous le gouvernement d'une seule république ; et, à mon avis, une monarchie unitaire aurait apporté à l'Italie plus d'inconvénients que d'avantages... Si donc le Saint-Siège s'est opposé 
aux efforts d'unification monarchique, je ne conclus pas que ç'ait été pour le malheur de ce pays ; il a de la sorte conservé une variété de vie qui répond mieux à ses habitudes et à ses tendances les plus anciennes » ${ }^{\text {clvii }}$. Ainsi Guichardin $p 115$ retrouve dans l'histoire et justifie par l'histoire, par tout un ensemble de créations éclatantes dans la politique, dans l'économie, dans l'art, ce particularisme italien dont Machiavel, trop aisément, fait abstraction, faute d'en avoir avec exactitude, en homme d'État et en historien, mesuré la vigueur. L'histoire de trois siècles allait démontrer combien, en Italie, les forces particularistes remportaient sur les forces d'unité nationale.

Il n'était pas moins surprenant, de la part d'un homme mêlé depuis sa jeunesse à la politique florentine, et qui savait assez bien l'histoire de Florence pour qu'on pût lui confier le soin de l'écrire, il n'était pas moins contraire à toutes les leçons qu'il pouvait tirer de cette histoire et des événements auxquels il avait participé, de croire que Léon X et le futur Clément VII, éloquemment exhortés, allaient rétablir à Florence les anciennes institutions, afin que la ville pût, après leur mort, se gouverner en cité libre. La famille ne poursuivait pas, avec une si heureuse ténacité, depuis plus d'un siècle, l'investissement de la république, pour qu'au moment où le principat était presque fondé, elle pût se contenter du rôle provisoire que la constitution romaine imposait au dictateur, rentrer civiquement dans cette classe de commerçants et de banquiers d'où elle était sortie. Machiavel savait bien que si Léon X et Clément VII n'avaient pas de postérité, la famille n'était pas éteinte ; et d'ailleurs Clément VII, dès son accession au pontificat, associait au gouvernement de Florence les deux bâtards de Laurent d'Urbino, dont le second, par la grâce du pape et de Charles-Quint, allait en 1530, devenir duc de Toscane. Machiavel savait bien qu'aucun Médicis n'avait été républicain. Et Guichardin, qui avait p116 accepté de les servir, tout en souhaitant lui aussi de voir s'établir à Florence un gouvernement bien ordonné, savait bien qu'il ne pouvait plus s'agir que d'une monarchie.

Enfin, si Machiavel s'était trompé sur la conduite des affaires italiennes ou florentines, il n'avait guère mieux conduit les siennes, ménagé son crédit moral ou politique. Républicain, destitué comme républicain en novembre 1512, poursuivi comme républicain lors du complot de Boscoli, théoricien des institutions et des vertus républicaines dans les gloses qu'il écrivait déjà en marge des Décades, il of- 
frait, dès la fin de 1513, ses services aux destructeurs de la République, et pour retrouver leur faveur, composait pour eux un manuel de tyrannie. Il risquait son honneur dans cette aventure. Il acheva de le compromettre lorsqu'il dédia publiquement le Prince au duc d'Urbino ; lorsque, en 1520, en 1521, et des derniers mois de 1525 au printemps de 1527, il accepta officiellement de servir les Médicis; lorsque, dans la préface des Istorie fiorentine, dédiée à Clément VII, il désavoua publiquement l'opinion des républicains sur la malfaisance de la tyrannie médicéenne clviii. Il eut le tort et la maladresse de paraître publiquement rallié à une politique dont le Discours sur la première Décade, qu'il continuait alors, était la négation. Il crut ainsi travailler pour la patrie et la liberté. Mais, après la révolution de mai 1527 , les républicains ne devaient pas lui pardonner l'équivoque de sa conduite, et ce qu'ils pouvaient appeler sa défection.

$$
\text { *** }
$$

Pareillement, il est bien certain que, dans ses écrits, sa pensée semblait se complaire à l'équivoque, ou du moins à poser des énigmes inquiétantes, dont il ne prenait aucun soin d'offrir la clef. Le Prince, pour ne rien dire de la Vie de Castruccio Castracani, était d'un théoricien de la monarchie ; d'un homme d'action qui offrait, à la monarchie, le concours de son expérience. Les Discours sur la première Décade étaient l'œuvre d'un théoricien de la république. Ainsi les avaient compris les jeunes gens enthousiastes qui, aux Orti Oricellari, chez Cosimo Rucellai, entendirent Machiavel en lire les principaux chapitres. Le Discours sur la Réforme de l'État florentin restait l'œuvre d'un théoricien $\mathrm{p}_{117}$ de la République, assez capable d'illusion pour en confier la restauration à deux Médicis. Mais on pouvait se demander quel était le véritable Machiavel : le conseiller de tyrannie, l'auteur du Prince, ou l'auteur républicain des Discours. En fait, on le voyait accepter les fonctions d'historiographe de l'État florentin, écrire une histoire officielle, exposer, sur les révolutions de Florence, la doctrine officielle du régime. Il inquiétait les uns et les autres, n'était aimé ni des uns ni des autres. Les républicains le tenaient à l'écart ; les Médicis suspectaient son attachement à une tradition qu'il persistait à croire vivante, ne cherchaient qu'à le compromettre et l'estimaient peu. 
Ainsi la grandeur de Machiavel n'est ni dans ce qu'il a fait, et qui reste médiocre, de faible succès, souvent discutable ; ni dans ce qu'il a voulu faire, puisque ses projets d'action, florentine ou italienne, furent également illusoires. Elle n'est pas dans son caractère, puisque, souvent cynique de manières et de paroles, il se montra peu sensible à certains scrupules. Elle n'est même pas dans son œuvre, que composent essentiellement un livre inachevé de philosophie historique, et un vigoureux traité de politique, mais discuté et discutable, et, à tout prendre, incomplet et sommaire. Euvre malgré tout énigmatique et de conclusion incertaine, puisque, républicain de sentiment et de doctrine, son livre le plus célèbre, le plus lu, et dont les conseils ont été le plus médités, définit la pratique d'une monarchie absolue. La grandeur de Machiavel est dans son analyse des faits qui forment la trame de la politique, dans son analyse des institutions et des lois, de l'esprit des lois et des institutions ; dans l'effort qu'il a tenté pour construire, selon une méthode strictement positive et sur des bases strictement positives, la science de la politique. C'est là que cesse l'incertitude et que Machiavel apparaît comme un maître. 


\section{Chapitre IV}

\section{Science positive ; enquête limitée}

Machiavel a pensé que la création d'un État unitaire et national en Italie, ou plus simplement la réforme de la constitution florentine, ne pouvaient se fonder que sur une politique positive. Dès le début des Discours sur la première Décade, il la définit comme une science nouvelle, avec l'orgueil de suivre une voie que nul encore n'a foulée ${ }^{\text {clix }}$.

Les hommes d'État qui, à Florence, avaient réfléchi sut l'art de gouverner les hommes, s'étaient bornés à des questions pratiques et n'avaient pensé qu'à leur cité. Ils avaient recherché les formes de gouvernement les mieux adaptées au caractère florentin, discuté sur les procédés d'élection, les pouvoirs des magistrats, les attributions des assemblées, l'art d'équilibrer l'autorité des conseils et des magistratures, de manière à éviter les conflits, à satisfaire les intérêts rivaux des classes et des clientèles. Savonarole lui-même, en dépit de la passion qui le portait à la recherche d'un régime capable de s'accorder avec ${ }_{\text {p119 }}$ l'Évangile, avait, dans son Traité du gouvernement de Florence, subordonné les vues idéales et abstraites aux combinaisons de pure opportunité ${ }^{\mathrm{clx}}$. Hors d'une pratique ingénieuse mais routinière, ils avaient peu à lui enseigner. Des humanistes il ne pouvait attendre aucune leçon vraiment utile. Sans doute ils ne négligeaient pas la politique; ils avaient, dès Pétrarque, aspiré à conduire les hommes d'État. Mais ils tentaient de résoudre une question trop vaste et trop abstraite, celle du gouvernement idéal ; faute d'une méthode propre à saisir le réel, ils avaient développé les lieux communs qu'ils empruntaient à 
Platon, Cicéron ou Sénèque. Florentins ou Lombards, ils avaient éloquemment soutenu la grandeur républicaine de Rome ou la majesté de l'Empire, mis leur savoir, leur talent et leur parole au service des cités libres ou des princes. Les humanistes républicains avaient approuvé la doctrine gréco-latine du tyrannicide légitime et glorieux ; leur enthousiasme, qui s'était exalté au récit des ides de mars, avait justifié, parfois encouragé certains attentats éclatants. On avait soupçonné les académiciens romains de souhaiter le meurtre de Paul II ; les assassins de Galéas-Marie Sforza, duc de Milan, étaient nourris de culture humaniste et de souvenirs antiques. Mais de cette tradition insurrectionnelle et déclamatoire, et qui n'aboutissait qu'à renforcer la servitude des peuples sous un despotisme plus soupçonneux, les maîtres de la culture nouvelle semblaient se détourner. A Florence, l'humanisme élégant, savant, helléniste, avait, par la plume d'Ange Politien, flétri la conjuration des Pazzi, l'assassinat de Julien, l'assassinat manqué de Laurent. Les platoniciens de Florence se ralliaient au despotisme civil des Médicis ; les cicéroniens de Rome allaient maudire le catilinarisme républicain. Le savoir politique des uns et des autres obéissait aux mêmes conventions. Giovanni Pontano, l'habile et délicat poète latin, mêlé, comme diplomate et homme d'État, au gouvernement du royaume de Naples, qu'il vit passer aux mains des Français, puis des Espagnols, n'avait su, dans son De principe, que tracer le portrait idéal d'un monarque fort différent de ceux qu'il avait servis ou rencontrés ${ }^{\text {clxi }}$. De la sorte, les leçons des humanistes italiens restaient assez faibles et confuses. Ni à Florence, ni à Rome, ni à Milan, ni à Naples, ils n'avaient rien dit qui pût ${ }_{\mathrm{p} 120}$ vraiment illuminer une intelligence appliquée à l'étude des problèmes politiques ou sociaux.

L'antiquité pouvait offrir à Machiavel des leçons plus solides. C'étaient les philosophes et les moralistes de la Grèce et de Rome qui avaient instruit l'humanisme à débattre la question du gouvernement parfait. Mais Machiavel n'avait pas de leurs œuvres une connaissance très approfondie. Par goût et par tempérament, il n'entendait pas suivre longtemps des hommes qui, pour la plupart, cherchaient avant tout à construire sur terre la cité des philosophes. Tels étaient Platon, Cicéron ou Sénèque. Platon lui aurait appris à dédaigner la société réelle, l'ordre apparent et provisoire d'où naissent le déséquilibre et la violence ; à rechercher la concorde et l'harmonie de ces forces de l'âme que libère et développe la vie de la cité. Mais Machiavel n'avait guère 
entretenu de contact avec les platoniciens de Careggi; attaché à Florence et à l'Italie par une passion trop ardente, il se plaisait à ce monde brutal et tragique où il menait son enquête désabusée ; il ne se souciait guère de fonder, sur l'idée du bien, une juste république. Dans les écrits politiques de Cicéron, improvisés, faiblement originaux, il eût trouvé du moins le souci d'accorder avec une doctrine conservatrice, le sens du juste et de la dignité civique. Les dissertations du traité des Lois sur le droit abstrait et les magistrations romaines, ne démontrèrent pas en vain à Machiavel comment la constitution républicaine et sénatoriale avait traduit et réalisé dans la pratique les plus hauts principes d'équité. Mais Cicéron, malgré son expérience de la vie active, écrivait en philosophe, curieux de théorie et d'idées pures. Sénèque enfin avait su négliger les fictions aristocratiques et sénatoriales de l'âge républicain ; il avait préféré, à la notion constitutionnelle et juridique du citoyen romain, la notion éthique et stoïcienne de citoyen du monde ; à la responsabilité de l'individu devant l'étroite loi de l'État, la responsabilité du vouloir humain devant la conscience et la loi morale. Mais le secrétaire florentin, serviteur d'une patrie vivante, n'en pouvait détacher son amour. Il n'était pas assez chrétien pour s'élever jusqu'à l'idéal du sage stoïque, affranchi en esprit des contraintes de la cité, et soumis uniquement au décret divin, de même que le fidèle, affranchi en esprit par l'Évangile de lois dont son humilité lui impose la discipline, sait qu'il n'est de perfection que dans la charité humaine et l'amour de Dieu. p121

Parmi tous les philosophes qui, dans l'antiquité, avaient traité de politique, Aristote, sans nul doute, était celui avec lequel il eût le plus aisément pu s'entendre. Il connaissait la Politique et ne pouvait l'ignorer. Certaines expressions, certains exemples historiques, certaines idées rappellent, dans l'œuvre de Machiavel, le grand ouvrage d'Aristote clxii. Il ne l'a probablement pas lu dans le texte, mais dans la traduction latine, d'ailleurs excellente, que Lionardo Bruni en avait donnée dès 1435, et dont les presses italiennes, depuis 1470, multipliaient les exemplaires. Il pouvait goûter, chez Aristote, une dialectique positive, enchaînée volontairement au réel, et qui n'entend le dépasser qu'en s'appuyant sur lui. Il voyait Aristote comparer les divers gouvernements de la Grèce, interroger l'histoire pour définir ces ré- 
gimes divers, en démêler l'esprit. Ces leçons ne devaient pas être perdues pour Machiavel. Mais Aristote raisonne en philosophe sur des questions philosophiques. Il s'efforce lui aussi de définir l'idéal d'un gouvernement parfait : autant qu'à l'histoire, il recourt à la raison pure. En même temps, sa conception de l'État est singulièrement vaste, synthétique, philosophique ; et Machiavel se trouve en désaccord avec lui à la fois sur les termes du problème à poser, et sur le rôle de l'État.

Machiavel ne cherche plus à résoudre, comme les philosophes antiques ou les humanistes italiens, le problème du bon gouvernement. Il a rompu avec cette tradition, recueillie par la scolastique et l'humanisme. Philosophes antiques, scolastiques et humanistes considèrent premièrement les hommes, leurs besoins, leurs revendications naturelles et légitimes, pour rechercher ensuite comment l'État peut assurer leurs droits, offrir un abri tutélaire à leur activité et à leur détresse. Machiavel, au centre de son système politique, établit non la nécessité de satisfaire les désirs naturels des hommes, mais la nécessité de les gouverner. Il affirme, d'abord, le fait du gouvernement, et ${ }_{\mathrm{p} 122}$ cherche à définir comment il s'impose le mieux et de la manière la plus durable, par la persuasion ou par la force. Il ne veut que définir les règles les plus commodes et les plus certaines d'un art de la politique. Rien de moins spéculatif. Machiavel ne considère ni le bien des hommes ni leurs droits, mais les moyens les plus sûrs de leur imposer un ordre et une autorité. Celle recherche, essentiellement technique, n'aboutit pas uniquement à une philosophie du succès politique, attentive à définir les causes psychologiques, morales, sociales, qui le déterminent. Si indifférent que soit Machiavel à l'idéal chrétien des humanistes, il ne peut éviter le problème moral ; ou du moins, le problème du succès politique se transforme pour lui en un problème moral. Car il n'estime le succès que dans la mesure où l'État en tire avantage pour son maintien, son renforcement ou sa défense ; et, de la sorte, l'art de la politique se laisse guider par une éthique, dont le rôle indispensable est de cultiver les vertus nécessaires à la conservation de l'État, et que déjà la cité antique exigeait des citoyens : obéissance aux lois, aux magistrats, respect des institutions civiles, religieuses, militaires. Vertus actives, que, d'un mot, Machiavel appelle la «virtù », et qui s'opposent au laisser-aller, à la négligence, à la paresse, à cet « ozio » qui a causé la faiblesse et la perte de la république florentine. Une cité où les individus les pratiquent, spontanément ou par 
contrainte, possède une vie politique. C'est pourquoi Machiavel les enseigne à ses jeunes auditeurs des Orti Oricellari : non par souci de leur perfection individuelle; l'individu et les vertus personnelles ne comptent à ses yeux que pour servir l'État ${ }^{\text {clxiii }}$. p123

La conception de l'État chez Machiavel est bien plus positive et plus étroite que chez Aristote. Le philosophe admet, pour point de départ, la société humaine, telle qu'elle est donnée par la nature, et ce qu'elle a le droit d'attendre de l'État. Machiavel pose d'abord le gouvernement, et les moyens qui lui permettent d'exiger l'obéissance des hommes et de les contraindre aux vertus nécessaires. Non qu'Aristote veuille diminuer l'autorité de l'État. Il le conçoit, pour emprunter un mot au parler de notre temps, sur le type totalitaire. L'action de l'État domine, règle, discipline la vie de la société tout entière. Aristote fait rentrer dans la politique non seulement la technique du gouvernement, la législation et la justice, mais l'ensemble des problèmes de l'économie, l'instruction publique et l'éducation physique, la gymnastique, la musique, la poésie et la religion : l'activité humaine tout entière. La cité ne peut laisser hors de son contrôle nulle des formes de cette activité, parce que nulle de ces formes ne lui reste indifférente. Le rôle de l'État est d'éduquer, de former, de cultiver le citoyen, d'assurer et d'organiser sa vie intellectuelle et artistique, son culte et ses relations avec le divin, de lui assigner sa place dans la hiérarchie des fonctions publiques et du travail. Ainsi l'État enveloppe de toute part l'individu et le discipline.

Pourtant la pensée d'Aristote n'est pas d'un politique, mais d'un moraliste. Le but suprême de cette intervention constante de l'État dans la vie des groupes sociaux et des individus, n'est pas l'intérêt de l'État, mais le bien de l'homme. Ce but n'est pas politique, mais éthique : il est, si l'on peut dire, humaniste au sens goethéen. Il s'agit d'assurer, au moyen des lois, des institutions, de la force contraignante de la cité, le plus heureux, le plus complet et harmonieux développement des facultés humaines, des puissances humaines, de l'esprit humain. Là réside véritablement la grandeur de la pensée politique d'Aristote : et Dante est capable de le suivre jusque-là. Mais le secrétaire florentin n'a pas accepté cet idéal, parce qu'il n'est pas humaniste, parce que son esprit est moins vaste que celui d'Aristote ou de Dante ; parce que l'homme, les puissances humaines, l'esprit humain et l'avenir de l'esprit humain lui importent moins qu'à Léonard de 
Vinci; parce qu'il lui importe uniquement ${ }_{\text {p124 }}$ non de satisfaire les désirs et d'assurer les droits des hommes, de les éduquer et de les élever à un niveau d'humanité toujours plus haut, mais de les gouverner. Le positivisme de Machiavel restreint volontairement le domaine de l'État, en exclut tout ce qui, de près ou de loin, ne se rattache pas à l'art d'obtenir l'obéissance des hommes et leur service.

Positivisme essentiellement romain. Rome avait affirmé très haut l'autorité de l'État sur l'individu. Mais elle avait, dans la pratique, limité l'action de l'État aux domaines des faits, politiques, juridiques, militaires et religieux; aux domaines des réalités où l'action de l'État cherche et trouve un appui. Elle avait plus ou moins abandonné le reste à l'initiative individuelle. Élève de Rome, beaucoup plus que de la Grèce, Machiavel contient lui aussi l'État dans les limites de ses fonctions politiques, juridiques, militaires et religieuses.

Conception étroite sans doute auprès du programme si vaste, si varié, si largement humain et philosophique d'Aristote. Mais conception plus pratique, plus immédiatement réalisable, plus facile à réduire en brèves formules, aussitôt applicables à l'action et dans le réel ; conception qui avait permis à Rome de subjuguer l'Italie, le monde, de fonder l'Empire, et, plus tard, de fonder l'Église. Or Machiavel, autant que de la sagesse romaine, prend conseil des circonstances; sa pensée est dominée par le sentiment d'une tâche immédiate, urgente, de salut public. Pour sauver l'Italie, ou seulement Florence, il faut d'abord construire l'armature de l'État; c'est-à-dire avant tout, le gouvernement et les fonctions essentielles qui s'y rattachent: politique d'abord. Ainsi Bismarck, en 1867, établissant la Confédération du Nord, pourra dire : « Mettez d'abord l'Allemagne en selle. » Fonder ou reconstituer, sur des bases strictement politiques, juridiques, militaires et religieuses, l'État, voilà pour le moment la seule chose nécessaire ; le reste sera donné par surcroît. Une fois l'État fondé, au besoin contre les hommes, et assuré, par une solide armature, contre ses ennemis de l'intérieur et de l'extérieur, il sera temps de penser aux hommes, à leurs besoins, à leurs désirs, à leurs droits.

Pourtant Machiavel n'est pas un pur technicien de la politique. Il s'élève à une vue générale de l'évolution humaine. Mais p125 il ne 
considère ni la succession de formes économiques ou sociales, ni le progrès de l'esprit. Homme d'État, politique, il ne veut être attentif qu'aux destinées des États, aux vicissitudes des formes politiques. Lorsqu'il tente ainsi de philosopher, ce n'est pas un philosophe qu'il suit ; c'est à un historien, le plus exact, le plus strictement politique des historiens de l'antiquité, c'est à Polybe qu'il emprunte la théorie classique du cercle éternel où se trouve fatalement enclose la succession des formes gouvernementales ${ }^{\text {clxiv }}$.

Les hommes vécurent d'abord dispersés à la manière des bêtes ${ }^{\text {clxv }}$. Puis, nécessairement réunis en groupes, ils firent choix de chefs pour se défendre. Le choix tomba sur les plus robustes et les plus courageux. Ainsi naquirent les premières sociétés ; avec elles apparut la notion du juste et de l'injuste, et l'on promulgua les premières lois. Dès lors, il ne suffisait plus de suivre le plus fort; on lui préféra le plus sage et le plus prudent ; la monarchie élective apparut. Mais bientôt, une première usurpation la rendit héréditaire. Le prince, oublieux des vertus qui avaient mérité au fondateur de sa maison les suffrages du peuple, ne pensa plus qu'à son intérêt, à son plaisir, devint tyran. Alors les chefs des plus puissantes familles, à l'aide du peuple soulevé, le renversèrent. On vit naître des républiques gouvernées par les premiers de la cité. Mais le régime aristocratique, une fois solidement établi, dégénère bientôt en oligarchie. Les aristocrates n'observent plus la loi, ni l'égalité civique ; le gouvernement des meilleurs devient domination arbitraire et désordonnée de quelques-uns, au mépris de l'intérêt public et des droits de tous. Nouvelle tyrannie, également condamnée à périr. Le peuple, à la voix du premier qui parle avec audace, se révolte, détruit l'oligarchie, s'empare du gouvernement. Il rejette à la fois l'autorité unique et personnelle du prince, l'autorité multiple des chefs des grandes familles, l'autorité restreinte de quelques hommes puissants. Mais le régime démocratique à son tour se corrompt ; le plus souvent très vite, dès qu'a disparu la génération des fondateurs. La démagogie triomphante ne respecte plus ni les droits des particuliers ni l'autorité des magistrats, ni la loi. Chacun règle sa conduite selon son intérêt. Le désordre devient bientôt si grave que pour y échapper on restaure la monarchie. p126 Et de nouveau la monarchie perd ses vertus, et la cité recommence les étapes qu'elle vient de fournir. Tel est le cercle que parcourent nécessairement tous les États. Ils y tourneraient à l'infini, si, le plus souvent, le désordre et la 
faiblesse qu'engendre cette perpétuelle inquiétude, ne les condamnaient à devenir la proie de quelque État voisin, alors mieux ordonné, plus vigoureux, mais destiné lui aussi aux mêmes révolutions, aux mêmes recommencements, à pareille fin. Ainsi se développe la thèse classique empruntée par Machiavel à l'antiquité, et reprise, deux siècles plus tard, par Montesquieu, lorsque, au huitième livre de l'Esprit des Lois, il étudia la corruption des principes des trois gouvernements ${ }^{\text {clxvi }}$.

Mais dans ce cercle éternel où les formes gouvernementales se trouvent indéfiniment entraînées, l'art et la science de l'homme d'État peuvent déterminer quelques temps d'arrêt ou d'équilibre, et d'ailleurs, - Machiavel ne l'ignore pas —, nécessairement limités. Pour éviter le danger de ces révolutions fatales, l'antiquité avait conçu et parfois réalisé une forme de gouvernement mixte, qui, participant du monarchique, de l'aristocratique et du populaire, possédait ainsi la stabilité qui manque à chacun des trois. Les trois éléments qui le constituent, exerçant l'un sur l'autre une action constante, assurent le maintien du pacte constitutionnel ${ }^{\text {clxvii }}$. Lorsque Lycurgue établit les lois de Sparte, il sut attribuer aux rois, aux nobles et au peuple, la $\mathrm{p}_{127}$ part de contrôle qui devait leur revenir dans les affaires publiques, et fonder un État qui dura plus de huit cents ans. Solon, au contraire, pour avoir institué un État purement populaire, laissa une œuvre si peu durable qu'Athènes, de son vivant, tomba sous la tyrannie de Pisistrate. Après la chute des tyrans, la démocratie athénienne, sans cesse menacée par les complots des grands et l'agitation des petits, ne se maintint guère plus d'un siècle, et, comparée au régime lacédémonien, n'eut qu'une vie brève. Mais Rome, mieux qu'Athènes, sut trouver son équilibre ; créer un État durable comme la cité Spartiate, et, plus que la cité Spartiate, capable de puissance et de conquête ${ }^{\text {clxviii }}$.

Les premiers fondateurs de Rome avaient eu le tort d'instituer d'abord une monarchie, trop indifférente aux droits et à la liberté des citoyens. La force naturelle des choses, la fortune de Rome, l'intelligence de ses législateurs, corrigèrent les défauts de la première institution. L'insolence des rois fit naître le gouvernement consulaire et sénatorial, où se retrouvent deux des trois éléments essentiels, l'autorité monarchique et l'autorité de l'aristocratie. Restait à introduire, dans ce régime, l'élément populaire. L'insolence de la noblesse offrit au peuple l'occasion de montrer sa force. Sans abattre l'autorité 
monarchique des consuls, l'autorité aristocratique de la noblesse représentée par le sénat, le peuple obtint de participer au gouvernement ; il élut ses tribuns, et reçut peu à peu accès aux magistratures. Le tribunat de la plèbe une fois établi, la République romaine atteignit son achèvement. Ainsi se constituait un gouvernement libre, où se perpétuait, avec les consuls, ce qu'il fallait conserver de pouvoir royal, où la noblesse et le peuple se tenaient mutuellement en respect ${ }^{\text {clxix }}$. Cette république parfaite, bien équilibrée, stable, dura jusqu'à César, qui la détruisit, et, sur ses ruines, édifia un despotisme, dont la tradition malfaisante survit dans l'Empire do Charles-Quint ${ }^{\text {clxx }} \cdot$ p128

$$
* * *
$$

Il existe donc, malgré l'écoulement universel et fatal des choses humaines, certaines règles où se résume l'art de créer un État assez longtemps durable, assez fort pour résister longtemps aux causes internes de dissolution, et se maintenir contre la concurrence et l'hostilité des États voisins. La forme idéale en est offerte par la République romaine, telle qu'elle a vécu, entre l'établissement du tribunat et les guerre civiles. Les règles essentielles qui permettent de fonder un tel gouvernement se déduisent aisément de l'histoire de la république romaine. Parmi tous les États que fondèrent les hommes, elle fut le plus robuste, le mieux équilibré, le plus capable de résistance, d'expansion et de conquête. L'histoire des premiers siècles romains est, pour le théoricien de la politique, une histoire privilégiée, plus riche d'enseignement que toute autre. C'est elle qu'il doit d'abord savoir à fond, et qui doit toujours éclairer sa pensée et sa pratique.

Machiavel se propose de l'étudier d'après Tite-Live ; il entreprend de commenter, en théoricien de la politique, l'œuvre complète de l'historien padouan. Mais la brièveté de la vie humaine ne lui a pas permis de dépasser les dix premiers livres. Sans doute sait-il aussi l'histoire grecque, et, mieux que la plupart de ses contemporains, l'histoire moderne de l'Europe depuis la chute de l'Empire d'Occident $^{\text {clxxi }}$; il sait, mieux que la plupart de ses contemporains, la politique européenne, à laquelle il fut mêlé. Mais ni l'histoire grecque, ni l'histoire moderne, ni la chronique récente ne contiennent un enseignement égal à celui qui, pour l'homme d'État, se dégage du passé romain. Pétrarque l'avait affirmé en poète. Les humanistes l'avaient répété en élèves de Pétrarque, avec une certitude que le spectacle de 
l'Italie vivante avait peu à peu affaiblie. Machiavel, qui a pris à considérer le monde moderne un singulier plaisir, mais qui ${ }_{\mathrm{p} 129}$ en sait les tares et les faiblesses, revient, après un long circuit à travers l'Italie et l'Europe, se mettre à l'école de la Rome consulaire et sénatoriale.

Ainsi se définit l'œuvre tentée par Machiavel. Le problème posé demeure strictement politique. La méthode est historique, comparative, expérimentale. Elle se fonde sur le fait tel qu'il est fourni par l'histoire. Peu importe que Machiavel attribue au récit de Tite-Live une autorité qu'il ne mérite pas ; la critique des légendes relatives aux premiers siècles de Rome n'était pas née. Partant de données qu'il juge incontestables, il cherche à suivre l'évolution des formes politiques, à discerner les causes qui déterminent leur apparition, leur progrès, leur décadence. Sous d'autres climats, en d'autres pays, dans d'autres temps et d'autres milieux, il étudie l'évolution de formes analogues ou différentes. L'histoire grecque et l'histoire moderne lui permettent d'établir, entre les institutions romaines, celles de la Grèce et des États récents, certaines comparaisons qui aident à comprendre l'esprit des unes et des autres. La méthode de Machiavel s'appuie enfin sur l'expérience. Ce qu'il a pu savoir, par la pratique, du gouvernement d'une cité libre et de ses rapports avec les États italiens ou européens, lui permet de vérifier sur le vif les conclusions que lui suggèrent les leçons du passé. C'est ainsi qu'il arrive, selon son expression, à dégager des faits historiques le goût et la saveur ${ }^{\text {clxxii }}$. C'est ainsi que peu à peu il s'élève jusqu'aux principes généraux selon lesquels se développe nécessairement la succession et l'évolution des formes politiques. "J'ai d'abord examiné les hommes, dira Montesquieu, lecteur de Machiavel; et j'ai cru que, dans cette infinie diversité de lois et de mœurs, ils n'étaient pas uniquement conduits par leur fantaisie. J'ai posé des principes, et j'ai vu les cas particuliers s'y plier comme d'eux-mêmes, les histoires de toutes les nations n'en être que la suite, et chaque loi dépendre d'une autre plus générale. » ${ }^{\text {clxxiii }}$. p130 
La méthode de Machiavel ressemble, par bien des aspects, à celle de Léonard de Vinci. Le peintre de la Cène de Sainte-Marie des Grâces réunissait alors, dans ses manuscrits échelonnés de 1489 à 1518, les éléments d'une immense encyclopédie. Léonard, comme Machiavel, n'est pas un pur humaniste. Plutôt que les philosophes, les orateurs et les poètes, il a fréquenté les savants de l'antiquité. L'expérience est à ses yeux la condition indispensable de toute science réelle et qui se veut efficace. Avec une aptitude admirable à l'observation et la longue patience du génie, il définit, classe et critique les faits, s'élève des constatations particulières aux lois générales, d'où il redescend à la pratique : «Étudie premièrement la science, ditil, puis la pratique née de cette science... La mécanique est le paradis des sciences mathématiques; avec elle on vient à leur fruit. " ${ }^{\text {clxxiv }}$. Aussi ne se lasse-t-il pas de travailler au perfectionnement des techniques, et d'inventer, pour les plus diverses industries, les machines les plus diverses. Mais en même temps ce savant universel s'élève sans peine à une vue générale du monde. L'élan de son esprit dépasse empirisme et positivisme : car la nature est pleine d'infinies raisons qui ne furent jamais dans l'expérience. L'univers est animé d'une vie mystérieuse; toutes ses parties sont agencées en vue d'une même fin. Le déterminisme physique traduit une nécessité interne et morale par où s'exprime un vouloir divin. De même, Machiavel poursuit, dans l'histoire romaine, dans la comparaison de l'histoire romaine avec l'histoire grecque et moderne, dans la confrontation des théories qu'il a pu tirer des faits avec les événements dont il a été spectateur, son enquête positive. Il s'élève aux principes généraux; il redescend ${ }_{\mathrm{p} 131}$ à la pratique. Il pourrait dire, transposant la parole de Léonard: " $\mathrm{La}$ politique est le paradis des sciences historiques; avec elle on vient à leur fruit. $"{ }^{\mathrm{clxxv}}$. Mais Léonard, qui pratique les sciences positives, et pressent que l'homme va saisir les lois de la nature et les plier à ses besoins, compte sur l'avenir, admet l'idée du progrès de l'esprit hu- 
main et de l'œuvre humaine. Au contraire, l'idée d'un progrès dans l'évolution des formes politiques reste étrangère à Machiavel. Il est trop convaincu, en historien, de la supériorité du monde antique sur le moderne ; il sait trop, en historien, la décadence de l'Europe après la chute de l'Empire romain. Plus volontiers il admet que les choses humaines tournent dans un cercle sans fin. La loi du retour éternel, qui conduit, à travers les révolutions de l'histoire, le jeu de la politique, exprime pour Machiavel, spectateur des choses humaines, cette vie mystérieuse qui, pour Léonard, anime le monde matériel. Tandis que Léonard veut reconnaître, dans l'harmonie de l'univers matériel, l'action ordonnatrice d'une intelligence divine, Machiavel, dans le mouvement circulaire qui entraîne sans fin les États et la société des hommes, semble concentrer tout ce que son intelligence, critique et négatrice, a pu garder de la notion du divin.

Cette idée du cercle que les choses humaines parcourent sans fin sert de base à l'éthique de Machiavel. Le but de l'activité humaine est de retrouver et de recréer, avec les rares améliorations qui peuvent sembler possibles, ce qui a déjà une fois prouvé son excellence. Le pessimisme de Machiavel ne semble concevoir d'autre avenir et d'autre idéal pour les modernes que de retrouver et ressusciter le génie politique d'Athènes et de Rome, et de subir à leur tour, après une période plus ou moins longue de grandeur et d'équilibre, la décadence des empires disparus. L'éthique de Léonard, qui compte sur l'avenir de l'esprit, entraîné de création en création, est plus confiante dans $\mathrm{p}_{132}$ la destinée humaine que l'éthique de Machiavel, où le rôle et le prix de la vertu agissante se trouvent subordonnés à la réalisation d'une œuvre politique qui n'est qu'un recommencement; œuvre de succès et de durée nécessairement précaires, et condamnée à dépérir en vertu de la loi même qui promet son succès. La pensée de Machiavel est triste, accablante, comme toute doctrine qui refuse d'ouvrir, devant l'âme humaine, un horizon illimité.

Pourtant le décret divin qui condamne la société des hommes à parcourir dans le même cercle sans issue la même course éternelle, ne le pousse pas à mettre en doute le prix de l'action. Au contraire, peu de doctrines ont, plus que la sienne, exalté le prix de l'effort individuel. Machiavel ne cherche pas à reconnaître, dans l'histoire, l'action 
collective des peuples, des sociétés, des classes, l'action mystérieuse du génie anonyme que les romantiques ont vu naître des foules. On chercherait inutilement chez lui un mot qui fasse pressentir les intuitions de Vico ou de Herder. Il est d'esprit trop positif pour s'arrêter, en histoire, devant le mystère des réalisations collectives. Le cheminement secret des idées, des théories, des doctrines, ne l'intéresse aucunement; pas davantage la lutte obscure des intérêts matériels. Il lui faut, pour comprendre les faits, citer des noms, voir lutter des hommes. Mais il croit à l'action décisive des individus qui savent répondre à l'appel du destin, seconder les intentions de la fortune, et, du moins, ne jamais perdre courage. De même qu'il explique volontiers la plus grande partie des événements par l'effet de textes législatifs, il attribue, en histoire, un rôle capital, et sans doute le premier, au législateur, qui impose à la société la discipline de lois durables. Vient aussitôt après l'homme d'État qui les applique, les adapte aux nécessités changeantes des lieux et des temps. Romulus et Numa, Lycurgue, Solon, Moïse, restent à ses yeux les plus hauts types d'humanité. Ils représentent l'intelligence, appliquée à saisir et à définir dans la loi les rapports nécessaires que la nature des choses établit entre les hommes; ils représentent la volonté qui impose la loi ${ }^{\text {clxxvi }}$. Sur un plan inférieur apparaît le ${ }_{\mathrm{p} 133}$ citoyen. Par la foi et l'enthousiasme avec lesquels il accepte la loi, lui obéit et, soldat, s'arme pour la défendre, il représente le sentiment, appliqué à l'œuvre humaine par excellence, la création et la conservation de l'État. L'action de l'homme inspiré qui conçoit et impose la loi, l'action du citoyen soldat qui en accepte et qui en aime la discipline jusqu'à la mort, sont les seules valeurs spirituelles que reconnaît le positivisme historique et politique de Machiavel. Mais il les exalte au point de reconnaître en ceux par qui elles s'expriment avec le plus de force, les saints ou les héros d'une religion toute civique et positive, et qui, dans le cercle morne et sans fin où tournent les choses humaines, réserve son culte et son amour à l'État ${ }^{\text {clxxvii }}$.

Déjà, d'ailleurs, le cours de l'histoire, — Machiavel n'en doute pas —, reconduit les hommes de la Renaissance aux plus sublimes espoirs. La loi du retour éternel détermine le renouveau de l'art et de la pensée, de la science politique, de l'action gouvernementale. Elle assure aux modernes la certitude de restaurer, pour quelques siècles, la grandeur romaine. L'Italie retrouve, dans ce passé où elle a inscrit les 
traces de son génie, ce que son génie a déjà une fois créé. Elle retrouve sa primauté intellectuelle; elle va retrouver sa force et sa maîtrise parmi les peuples. La loi du retour éternel lui garantit sa mission dans le monde moderne. Cette mission, Machiavel, précurseur de Mazzini, la définit, à la dernière page de l'Art de la guerre, en termes fatidiques: "Je ne veux pas que vous vous abandonniez ou perdiez confiance : car ce pays semble évidemment né pour ressusciter ${ }_{\mathrm{p} 134}$ les choses mortes, comme on l'a vu de la poésie, de la peinture et de la sculpture. ") clxxviii

Table des matières

\section{III}

Ainsi Machiavel s'exalte dans la solitude, au pressentiment d'une grandeur qui fut et qui va renaître. L'intuition du poète prolonge le calcul positif du savant. Mais le rêve de Léonard de Vinci embrasse tout l'avenir humain. Ses visions prodigieuses sont d'un homme dont le génie parcourt, avec la foi et l'espérance, tout le domaine des sciences, qu'à travers l'antiquité, le Moyen Age arabe et chrétien, l'effort incessant de l'esprit a lentement et sûrement constituées. Sa poésie est vérité, parce qu'elle se nourrit d'un savoir encyclopédique et positif. L'enquête du secrétaire florentin, contenue en de plus étroites limites, ne lui permet que le rêve d'un homme d'État.

Le problème que se pose Machiavel est volontairement borné à la politique. Il entreprend de définir les moyens les plus sûrs qui, dans l'universel écoulement des choses, dans le cercle où les formes politiques se succéderont sans fin, permettent de fonder un État solide, de le maintenir contre les menaces internes de dissolution, contre les dangers de l'extérieur; de le conserver, d'arrêter sa décadence, de le réformer. Problème d'art politique. C'est que Machiavel reste avant tout, comme les hommes d'État florentins, un technicien de la politique. C'est que la politique lui paraît dominer et commander l'économie et la vie sociale clxxix. C'est enfin que des raisons de salut public semblent lui imposer ${ }_{\mathrm{p} 135}$ ce parti pris. Qui veut sauver l'Italie, ou seulement Florence, doit avant tout construire ou reconstruire l'armature de l'État. Politique d'abord. 
Pareillement l'enquête scientifique de Machiavel s'impose de strictes limites. Elle porte à peu près uniquement sur l'ensemble des faits qui semblent concourir au maintien de l'État. Faits d'ordre politique, d'abord et avant tout : lois, institutions, constitutions, activité du législateur, de l'homme d'État, du citoyen ; faits d'ordre militaire, étudiés non pas sous leur aspect technique et spécial, - Machiavel s'impose cette tâche, sans la compétence requise, dans les Dialogues sur l'Art de la guerre -, mais dans les rapports qu'ils entretiennent avec les nécessités de la défense nationale et l'esprit des institutions; faits d'ordre diplomatique, étudiés non pas sous leur aspect technique et spécial, mais selon les rapports qui s'établissent naturellement entre les États, selon les nécessités de leur concurrence, de leur équilibre, et d'une lutte éternelle où la ruse vient aider la force. Les faits d'ordre religieux entrent enfin dans l'enquête de Machiavel. Mais, faiblement informé des religions antiques, mal accessible aux sentiments et aux idées qui constituent l'essence du christianisme, il ne considère les faits religieux que dans les rapports qu'ils entretiennent avec la politique, et la religion que comme un moyen subordonné aux fins de l'État.

En dehors de son enquête, il laisse tout ce qui constitue la vie sociale et la vie économique. Machiavel sait la politique, la législation, la diplomatie, et croit savoir la guerre; il connaît mal et dédaigne l'économie. Il affirme sommairement qu'il ne pourrait discourir sur l'art de la laine ou de la soie, sur les bénéfices des marchands ${ }^{\text {clxxx }}$. Dans cette Italie où, dès le XIII ${ }^{\mathrm{e}}$ siècle, ${ }_{\mathrm{p} 136}$ et notamment à Florence, l'essentielle industrie de la laine évoluait vers le type moderne de l'entreprise capitaliste, dans cette Europe où la même industrie, dès la même époque, avait pris à Bruges le même caractère, et maintenant, sous la direction du capitalisme commercial d'Anvers, créait au PaysBas un immense mouvement d'affaires et une immense richesse, le secrétaire florentin demeure volontairement étranger aux questions industrielles et refuse de s'y intéresser. L'Italie participait, dès le Moyen Age, aux grands échanges orientaux, par ses ports de la Méditerranée et par les échelles du Levant; elle avait créé les premières républiques marchandes, et la puissance encore à peine diminuée de Venise, malgré tant de causes intérieures et extérieures d'affaiblissement; la découverte de nouvelles voies vers les Indes, de 
nouveaux continents au delà de l'Atlantique, renouvelait dans toute l'Europe les entreprises et l'esprit du grand trafic; et pourtant Machiavel connaît mal les questions commerciales et n'en saisit pas l'intérêt. Florence, de bonne heure, avait été l'une des capitales de la banque italienne et internationale ; les Médicis dominaient la République parce qu'ils avaient été, avant les Fugger d'Augsbourg, les plus puissants banquiers d'Europe ; l'alliance de la banque et du SaintSiège était un fait historique dont l'évidence n'échappait à aucun observateur étranger, notamment à Érasme ${ }^{\text {clxxxi }}$. Et pourtant Machiavel ne s'intéresse pas aux questions de finance et au commerce de l'argent. Dès le XIV ${ }^{\mathrm{e}}$ siècle, le progrès du capitalisme industriel avait aggravé à Florence les difficultés sociales, la lutte des classes, le conflit de plus en plus violent du patronat avec les ateliers; les rancunes et les colères du «peuple maigre » contre le «peuple gras" avaient provoqué, en 1378, une première tentative de révolution sociale, conduite par le prolétariat des Ciompi. Machiavel néglige l'aspect social de la vie des peuples. La lutte obscure des intérêts matériels ne retient pas son attention. Homme d'État, politique, politicien de carrière et d'esprit, il ne considère, dans les conflits sociaux, que des épisodes secondaires de la lutte menée au premier plan par $_{\mathrm{p} 137}$ les partis politiques, les factions politiques et leurs chefs, et, derrière les factions et les partis, ne se donne pas grand effort pour découvrir la réalité économique ou sociale. Lorsqu'il essaie d'expliquer leurs luttes, il recourt à des formules classiques et vides, banal héritage des historiens romains : l'insolence des nobles, les mauvais traitements infligés à la plèbe ; l'impatience du peuple; les humeurs diverses du peuple et des grands.

Les chroniqueurs florentins du XIV ${ }^{\mathrm{e}}$ siècle, Dino Compagni, Giovanni et Matteo Villani, Donato Velluti, avaient mieux saisi l'influence prédominante des intérêts mercantiles dans les sociétés modernes. Machiavel reste l'élève de Lionardo Bruni, de Poggio Bracciolini, des historiens humanistes et dédaigneux des réalités matérielles que l'art de la chronique primitive savait décrire. Ils avaient affublé de masques romains les hommes des partis florentins ; méprisé leur temps au point de juger puérile et mesquine l'intelligente curiosité des vieux chroniqueurs pour la vie quotidienne des peuples modernes et le détail familier de leur labeur. En vertu d'une affinité profonde, effet de son tempérament et de son éducation classique, Machiavel 
a choisi, pour maîtres de ses études historiques, Tite-Live et Polybe. Aussi néglige-t-il, dans l'histoire, ce qu'ils ont négligé ; comme eux, ils ne s'attache qu'au drame des événements politiques, diplomatiques et militaires; à l'action du législateur; à l'évolution des principes, et des caractères qu'ils impriment aux institutions. Machiavel écarte enfin de son enquête, sinon la vie morale, qu'il réduit d'ailleurs a la pratique des vertus civiques, au respect de la loi, des traditions et des pratiques religieuses dont l'État juge le maintien nécessaire à son propre maintien, du moins toute la vie intellectuelle : l'effort des générations humaines pour comprendre le monde et se comprendre elles-mêmes ; pour exprimer ce qu'elles portent en elles de plus profond et de plus secret. Art et lettres, travail de l'esprit et de la pensée, restent, pour Machiavel, des domaines où personnellement, comme auteur de nouvelles et de comédies, comme poète, comme théoricien même des doctrines politiques et philosophe de l'histoire, il a pu rechercher et obtenir un rang éminent; domaines pourtant où la science historique n'a aucune raison de s'aventurer. Il a pu écrire une histoire de Florence sans parler de lettres ou d'art. p138

Si l'on veut mesurer exactement l'étroitesse de la question que Machiavel s'est posée, et l'étroitesse de l'enquête qu'il a instituée, il suffit de feuilleter l'Esprit des Lois. Le problème affronté par Montesquieu rappelle certainement celui que Machiavel a voulu résoudre : plus général toutefois, posé en termes plus philosophiques, par un homme de pensée plus vigoureuse et plus profonde. Machiavel étudie les moyens pratiques, immédiats, positifs, qui permettent de construire solidement, dans diverses circonstances précisément déterminées, un État ou princier ou républicain. En fait, il recherche et il définit les règles diverses de la technique gouvernementale. Montesquieu, historien comme Machiavel, instruit, comme Machiavel, des choses de l'État, informé du droit mieux que Machiavel et aussi bien de la politique, plus philosophe que Machiavel et d'un génie plus largement humain, étudie l'art de créer la loi, de l'adapter aux conditions les plus changeantes de la vie des États et des sociétés; de telle sorte qu'elle puisse servir de base à l'État, sous les diverses formes que produisent les diverses données de la nature et de l'histoire : État princier absolu, État princier constitutionnel, État républicain, aristocratique ou démo- 
cratique, ou de tel type encore inconnu dont l'évolution des choses humaines pourra déterminer l'apparition. Et de même, Montesquieu fait entrer dans son enquête tout ce que Machiavel a négligé.

Sans doute, lorsque, dans les douze premiers livres de l'Esprit des Lois, il étudie les principes des trois gouvernements, les rapports des lois avec ces principes, la corruption de ces principes, les lois dans leurs rapports avec la force défensive et offensive, les lois qui forment la liberté publique dans son rapport avec la constitution et dans son rapport avec le citoyen, la recherche qu'il entreprend et conduit méthodiquement, bien que beaucoup plus ample et complète, rappelle l'enquête de Machiavel ; et lui-même a reconnu ce qu'il doit à ce précurseur, et, comme il dit, à ce grand homme ${ }^{\text {clxxxii }}$. Mais les livres suivants élargissent ${ }_{\text {p139 }}$ bientôt cette analyse. Elle découvre des rapports entre finances publiques et liberté ; elle s'efforce de définir dans quelle mesure les institutions sont déterminées par le climat et la géographie physique; par l'évolution de l'économie, du commerce, de la monnaie et de la banque; par les conditions démographiques, la vie intellectuelle, morale et religieuse. De tous ces rapports, toutes ces influences, Machiavel n'a pas tenu compte ${ }^{\text {clxxxiii }}$.

Enfin, lorsque Montesquieu, celte enquête achevée, semble avoir déjà conclu, s'est élevé à une vue théorique et générale, a considéré les lois dans les rapports qu'elles doivent avoir avec l'ordre des choses sur lesquelles elles statuent, étudié la manière de composer les lois, et donné en exemple l'origine et la révolution des lois romaines sur les successions, il aborde le problème d'une action immédiate et pratique. Puisqu'il écrit en France et que son lecteur pense avant tout à la nécessité de réformer le gouvernement, le système des lois et la constitution du royaume, Montesquieu, dans ses deux derniers livres, cherche à définir l'évolution historique, et, partant, le sens des institutions françaises, afin de déterminer exactement les moyens et les chances qui s'offrent à tout effort de restauration ou de réforme. Il résume les travaux des juristes et des historiens qui se sont appliqués à l'étude des institutions nationales; il ébauche une théorie des lois féodales chez les Francs, dans la mesure qu'elles ont avec les révolutions de la monarchie ${ }^{\text {clxxxiv }}$. Mais Machiavel, écrivant pour des lecteurs italiens et florentins, qui, évidemment, en 1513, en 1519, pensaient avant tout à la réforme de leurs gouvernements affaiblis, et qu'il sollicitait d'y penser, n'a pas pris la peine de construire une théorie historique 
de ces institutions, florentines ou italiennes, qu'il fallait d'abord bien connaître avant d'y porter la main. Il n'a tenté cette entreprise que tardivement, lorsque, de 1520 à 1525, il a écrit ses Histoires florentines. Encore a-t-il dû recevoir des Médicis la charge de les écrire, en historiographe officiel, dont la plume n'était pas libre. La plus grande partie des Discours sur la première Décade était alors composée ; et si l'on peut découvrir, dans les Istorie, quelque influence des théories exposées dans les Discours, la réciproque n'est pas vraie, et l'étude des institutions florentines et de leur évolution, bien qu'elle ne soit pas absente des Discours, p140 ne paraît pas avoir exercé une influence sensible sur les théories générales qui en forment la trame ${ }^{\mathrm{clxxxv}}$.

Machiavel n'est pas Montesquieu; le Prince et les Discours sur la première Décade ne sont pas l'Esprit des Lois, bien que sans Machiavel, Montesquieu n'en eût pas conçu ni écrit certaines pages ${ }^{\text {clxxxvi }}$. Mais le simple rapprochement des deux œuvres aide à mesurer ce qui reste d'incomplet, de primitif, d'un peu archaïque, dans l'effort et la pensée du secrétaire florentin. Certaines écoles exaltent en lui un maître inégalé : il n'y a pas lieu d'accabler sa mémoire de tels honneurs. Malgré son génie, Machiavel n'est pas un guide infaillible; et si, pour la pénétration et la sûre clarté de l'esprit, on a pu difficilement le surpasser, la solution d'un problème posé en termes systématiquement étroits, les résultats d'une enquête systématiquement étroite, ne peuvent aboutir qu'à des conclusions limitées. La science de Machiavel ne peut dispenser que des enseignements dont il faut reconnaître les bornes. Il n'y a pas lieu de chercher, auprès de lui, réponse à des questions qu'il a négligées. Ces questions sont parfois plus intéressantes que celles qu'il a voulu résoudre ; il peut arriver qu'on se trouve empêché de résoudre celles qu'il se pose, avant d'avoir préalablement résolu celles qu'il ne se pose pas. Il a de la sorte, laissé beaucoup à dire à ses successeurs, et même à certains contemporains.

$$
* * *
$$

Il définit exactement l'armature de l'État. Il excelle à montrer comment on arme l'État par l'établissement d'un gouvernement fort. Il a étudié deux types essentiels d'État et de gouvernement ; État monarchique dans le livre du Prince, État républicain dans les Discours sur la première Décade. Il a recherché et défini les moyens les plus mathématiquement certains de fonder, de conserver, de renforcer un 
gouvernement princier. Dans le livre du ${ }_{\mathrm{p} 141}$ Prince, on peut juger sa démonstration parfaite, du point de vue technique. Il a, dans les Discours sur la première Décade, recherché et défini les moyens les plus mathématiquement assurés de fonder, de conserver, de renforcer un gouvernement républicain. Mais comme il n'a pu terminer ce livre, l'exposé n'y présente plus, comme dans le Prince, le caractère d'un enchaînement de conclusions. Le lecteur suit l'analyse que Machiavel a voulu, essentiellement d'après l'histoire de Rome, instituer des divers problèmes capitaux que pose toute politique républicaine. Cette analyse est d'un puissant esprit, qui, par la vigueur et la clarté des vues, la concision des formules, s'apparente à Montesquieu. Mais elle dédaigne le soin de tirer les conclusions et de construire la synthèse. On peut en dégager un certain nombre de règles, de maximes, de principes, sur les conditions qui seules assurent à l'État républicain la solide armature d'un gouvernement bien ordonné.

$$
* * *
$$

Cela sans doute est considérable : il faut pourtant constater que le reste manque. Machiavel s'est attaché à résoudre un problème d'algèbre appliquée à la technique gouvernementale. Mais il ne se demande pas quel asile l'édifice qu'il construit avec cet art infaillible peut assurer aux hommes et à leur labeur. Il s'y intéresse peu. La question des rapports juridiques et légaux entre les hommes passionne Montesquieu ; celle de l'organisation du travail, de la production et de la répartition des richesses a retenu longtemps les théologiens du Moyen Age : elles laissent Machiavel indifférent. Elles ont ému certains de ses contemporains.

II avait achevé depuis trois ans le Prince, il travaillait lentement à la composition des Discours, lorsque, en 1516, à quelques mois d'intervalle, sortirent des presses de Bâle et de Louvain l'Institutio principis christiani d'Érasme, et l'Utopie ou Traité de la meilleure forme de gouvernement, que Thomas More venait d'écrire en une sorte de collaboration amicale avec Érasme. Il serait évidemment facile et oiseux d'opposer, au dur réalisme et à l'immoralisme de Machiavel, la philanthropie fantaisiste de l'écrivain anglais, l'inspiration chrétienne d'Érasme et son évangélisme affectueux. Là n'est pas la question. Mais, dans l'Utopie, le grand avocat de Londres, le futur chancelier p142 d'Angleterre, a su, en homme de gouvernement et en économiste, 
juger la politique monétaire ou la législation agraire des deux premiers Tudors, écrire telle page restée classique chez les historiens de l'économie anglaise sur les effets des enclosures, de ce mouvement irrésistible qui aboutissait à transformer en vastes domaines clos, aux mains des grands propriétaires, les parcelles disséminées de la terre paysanne; sur la ruine des villages désertés d'où les moutons chassaient les hommes; sur le pullulement tragique des journaliers sans travail tombés dans la classe des pauvres. Et de même l'Institutio principis christiani d'Érasme n'est aucunement l'amplification trop facile d'un humaniste chrétien. Contre le mauvais gouvernement des princes, la critique érasmienne formule quelques griefs positifs et réels. Érasme sait assez bien la politique européenne et l'économie. Il n'a pas séjourné sans profit à Londres, auprès de Thomas More, ni vainement fréquenté, à Anvers, quelques-uns de ces grands bourgeois qui fondaient alors sur la banque, le commerce maritime et la libre industrie, le capitalisme moderne. Érasme et Thomas More sont mieux informés que Machiavel, parce qu'ils en sont moins dédaigneux, des humbles nécessités qui gouvernent l'existence quotidienne des hommes. Ils les ont vus vivre de plus près que n'a fait Machiavel, dans son bureau du Palais de la Seigneurie, au cours de ses missions diplomatiques auprès de César Borgia ou de Jules II, de Maximilien ou de Louis XII. Ils cachent, sous leur ironie, plus de compassion aux détresses humaines, plus de vraie amitié. L'Institutio principis christiani, et même l'Utopie de Thomas More, malgré la fantaisie qui s'y joue, développent un programme positif, concret, soigneusement élaboré de réforme législative, économique et sociale, que ni dans le livre du Prince, ni même dans les Discours sur la première Décade, Machiavel n'a pas pris soin d'ébaucher ${ }^{\text {clxxxvii } 29 .}$

Table des matières

\section{IV}

Si Machiavel a posé en termes assez étroits le problème qu'il a voulu résoudre, si l'enquête qu'il a menée reste fort incomplète, ${ }_{\mathrm{p} 143}$ et si les conclusions de son étude sont nécessairement limitées, il faut en même temps reconnaître que tout cet effort aboutit à un programme d'action assez décevant. Non pas seulement parce qu'il est double, et 
que Machiavel offre au choix du lecteur moderne une théorie du gouvernement républicain et une théorie du gouvernement personnel. Mais sa théorie républicaine reste composée d'éléments classiques et traditionnels, et, malgré le désir le plus profond de l'auteur, peu susceptible d'usage dans le monde moderne. Sa théorie monarchique est faite d'éléments qui appartiennent surtout à la pratique italienne du $\mathrm{XV}^{\mathrm{e}}$ et $\mathrm{du} \mathrm{XVI}^{\mathrm{e}}$ siècle, à la pratique des princes et tyrans italiens du temps de la Renaissance ; théorie adaptée à de petits États, à certaines circonstances historiques, à certaines formes de civilisation, à certaines conditions de temps et de lieu; difficilement applicable en d'autres temps et d'autres lieux; peu susceptible d'usage dans le monde moderne.

Le programme républicain de Machiavel est en effet emprunté, sans modification sensible, à la science politique des anciens. L'idéal qui se définit dans les Discours est ce gouvernement de type mixte qu'ils avaient maintes fois décrit; un gouvernement où se compense et s'équilibre l'action de trois principes apparus dès que les hommes ont fondé des cités. Le principe monarchique s'y affirmerait vigoureusement par l'autorité très forte et la pérennité de la magistrature suprême et responsable de la conduite de l'État. L'aristocratie constituerait, pour parler le langage de Montesquieu, une sorte de puissance seconde. Par le fait que son instinct conservateur et le souci de ses avantages sociaux la porteraient naturellement à maintenir l'équilibre et la solidité de l'État, ses assemblées et ses magistratures se trouveraient naturellement investies du rôle que les constitutions consulaires et impériales, de l'An VIII à 1814, attribuèrent au Sénat conservateur et au Conseil d'État. Enfin les classes populaires, dont le travail produit la richesse de l'État, dont la force et le nombre entretiennent la solidité de ses armées, seraient protégées par les lois constitutionnelles contre les violences et l'égoïsme de l'aristocratie. Elles participeraient aux assemblées; elles auraient, pour les représenter et les défendre, p144 des magistratures; elles pourraient accéder aux magistratures suprêmes ; elles interviendraient dans l'œuvre législative ; elles y imposeraient les modifications, les ménagements, les corrections et les réformes dont l'égoïsme aristocratique évite de reconnaître l'utilité. 
Ce régime idéal, Machiavel le trouvait mal réalisé à Florence, où le gonfalonier perpétuel Soderini n'avait pas su, beaucoup mieux que les anciens prieurs et le gonfalonier de justice trop souvent renouvelés, exercer l'autorité de qui commande au nom de l'État. En même temps, l'évolution de la cité florentine avait conduit à un affaiblissement excessif de la vieille aristocratie, de ces anciennes familles de propriétaires fonciers qui déjà, au temps de Dante, protestaient amèrement contre leur propre décadence. On n'avait vu se développer, de la sorte, qu'une fausse démocratie de marchands, de banquiers, d'hommes d'affaires ; oligarchie tumultueuse, divisée, soucieuse uniquement de richesse et de profits, devenue bientôt maîtresse d'une autorité publique sans cesse plus débile. De là tant de troubles, de désordres, de révolutions inachevées, que Dante, aristocrate et autoritaire, déjà déplorait. Tumultes, désordres, demi-révolutions, favorables au développement de l'activité factieuse, aux ambitions des individus sans scrupules et pressés de fonder, à l'aide des classes foulées et mécontentes, un pouvoir personnel. De là l'établissement et le maintien, pendant soixante années, de la tyrannie médicéenne ; de là le mauvais gouvernement de la république rétablie en 1494, régime de désordre et de paresse, propice à l'intrigue et à la brigue; de là encore la récente restauration des Médicis, avec l'appui des mécontents de l'intérieur, et des étrangers ennemis contre lesquels un gouvernement sans vertu n'avait pas su organiser la défense nationale clxxxviii.

Au contraire, cet idéal de république stable et bien équilibrée, Machiavel le voyait triompher à Rome, entre la fondation ${ }_{\mathrm{p} 145} \mathrm{du}$ tribunat et les guerres civiles ; à Rome sauvée après le désastre de Cannes, ainsi que Montesquieu devait le dire, par la force même de son institution ${ }^{\text {clxxxix }}$; et, par cette même force, victorieuse de Carthage et bientôt maîtresse du monde méditerranéen. Alors le génie romain, dans l'ordre de la politique, a donné toute la mesure de sa puissance et de sa grandeur. Alors l'autorité des consuls, au besoin suppléée par l'autorité provisoire du dictateur, maintient énergiquement l'action du principe monarchique. Le Sénat, gardien de la constitution, partage avec les consuls l'initiative des lois nouvelles, et joue pleinement le rôle essentiel que la science politique assigne à l'aristocratie. Le peuple, dont les tribuns défendent les droits et les libertés, participe, dans une juste mesure, à l'action des magistrats et à l'œuvre législative. La vivacité même et la violence des luttes qui mettent aux prises le peu- 
ple et le Sénat, a pour effet salutaire de réfréner, de part et d'autre, tout effort d'empiétement et d'usurpation, de contraindre les uns et les autres au respect du pacte constitutionnel.

Tel est le gouvernement que décrivent Polybe, Cicéron et TiteLive. Tel est sans nul doute le gouvernement le plus sage qu'ait jamais conçu l'esprit humain ${ }^{\mathrm{cxc}}$. Or l'œuvre de l'homme d'État, dans le cercle éternel où tourne l'histoire des cités et des institutions, consiste à retrouver, recréer, ressusciter ce qui une fois se démontra parfait. C'est donc à une forme de gouvernement renouvelé des temps héroïques de la République romaine, qu'il conviendrait de reconduire les cités et les États d'Italie, et même, s'il était possible, les autres États modernes, encore barbares.

On doit se demander ce que vaut pareil programme. On ne peut blâmer l'auteur de l'avoir presque entièrement emprunté à l'antiquité, puisque sa conception de l'histoire universelle et ${ }_{\mathrm{p} 146}$ de la supériorité du monde antique sur le monde moderne, sa conception de la science politique et de la modestie nécessaire qui en limite l'effort à une œuvre de restauration, justifient cet emprunt. Mais il apparait bien qu'un tel programme est à la mesure de la cité antique ou de la commune médiévale, et non pas du grand État moderne, dont pourtant Machiavel eût souhaité la naissance en Italie.

On pourrait objecter qu'un tel régime a subsisté à Rome pendant la conquête de l'Italie, de la Méditerranée, de l'Orient, de l'Espagne. Il est facile de répondre que cette conquête l'a détruit, qu'il n'y a pas survécu et n'y pouvait survivre, parce qu'il n'y était pas adapté. Les invectives de Machiavel contre les auteurs des guerres civiles, contre les Gracques, Marius, Sylla, contre César, ne peuvent supprimer ce fait élémentaire : la vieille constitution sénatoriale ne convenait pas au gouvernement d'un empire. De même, ce programme pouvait se trouver à la mesure de la commune médiévale ; à la mesure de Florence, telle que Dante regrettait déjà qu'elle ne fût plus de son temps ; établie au centre d'un petit domaine circonscrit par un étroit horizon. Mais Florence maîtresse de la Toscane, une question nouvelle s'était posée, celle de ses rapports avec les villes sujettes; et la vieille constitution communale n'avait pas su la résoudre. Sans doute Machiavel répond 
que Florence aurait dû suivre l'exemple de la République romaine. Elle avait admis les cités italiennes au partage de ses droits souverains et les avait associées à sa politique : de même Florence pouvait, avec les villes toscanes, créer une confédération analogue à celle des cités étrusques. Mais les accords de Rome avec les cités italiennes, que l'aristocratie sénatoriale continuait de dominer et d'exploiter durement, n'avaient empêché ni guerres sociales ni guerres civiles. Quand même Florence eût créé une confédération des villes toscanes, et se fût, de la sorte renforcée en face des autres États italiens, l'égoïsme des classes qui dirigeaient sa politique n'eût accordé aux bourgs du domaine, comme le Sénat aux municipes d'Italie, qu'une autonomie illusoire ; et le type constitutionnel ainsi réalisé serait resté singulièrement provincial, étroit, et d'un faible exemple pour le grand État moderne que Machiavel eût aimé fonder. Il fallait trouver autre chose. Le programme de politique républicaine, ébauché par Machiavel d'après le modèle de Rome consulaire et sénatoriale, programme a la mesure de la cité antique ou de la commune p147 médiévale, ne s'adapte guère à ce qu'on peut appeler le rêve de Machiavel, la création en Italie d'un État unitaire. Il ne s'adapte même pas très bien à une réforme durable de la République florentine, souveraine des villes de Toscane.

Sans doute, si l'on tentait de définir, dans la pratique, le caractère que pourrait prendre un État national d'Italie, l'idée d'une fédération, comme au temps de Laurent le Magnifique, s'imposait. La variété des États italiens, les traditions, souvent précieuses, du particularisme italien, ne permettaient d'unir les peuples d'Italie qu'au moyen d'un pacte très large ${ }^{\text {cxii }}$. Il n'existait à peu près rien de commun entre les traditions politiques de Florence et de Venise, rien de commun entre les deux grandes républiques et les tyrannies du Nord ou le royaume de Naples, pour ne rien dire du Saint-Siège. A l'intérieur même de certains États, duché de Milan, royaume de Naples, persistaient quelques survivances féodales : et par là ces États, selon Machiavel, n'étaient pas mûrs pour la vie civile ; on n'y pourrait entreprendre une réforme politique avant d'avoir établi l'autorité absolue d'un prince assez fort pour réduire une classe malfaisante ${ }^{\text {cxcii }}$. Un État national d'Italie ne 
pouvait donc se concevoir que sous l'aspect d'une fédération de républiques et d'États princiers.

Or Machiavel a connu, en Europe, des États de type fédératif. Il sait la force du lien fédéral qui unit les Cantons Suisses. La constitution même de l'Empire, qui admet à la fois des villes libres et des États princiers, pourrait offrir un modèle, si l'autorité de l'Empereur se montrait capable de conduire tant de forces latentes et dispersées ${ }^{\text {cxciii }}$. Mais du texte de Machiavel on ne ${ }_{\mathrm{p} 148}$ peut tirer plus qu'il ne contient. Il serait arbitraire de définir sa pensée quand elle reste vague, et de lui prêter, au sujet de l'État unitaire d'Italie, des vues systématiques et complètes, alors que nulle part sa doctrine, sur ce point, n'est arrivée à se préciser. Il aurait, pour le fonder, fallu d'abord chasser les Barbares, et les Espagnols semblaient décidés à rester; il aurait fallu abaisser le pouvoir temporel des papes, qui demeurait solide et bien vivant, même après le sac de Rome ; ruiner en Italie l'autorité de l'empereur, plus puissant alors qu'il n'avait été depuis trois siècles. C'est pourquoi Machiavel ne conclut pas ; c'est pourquoi des Discours sur la première Décade ne se dégage aucune leçon vraiment utilisable, pas plus pour la fondation d'un gouvernement moderne de type fédératif que pour la fondation d'un gouvernement moderne de type républicain.

$$
* * *
$$

Mais le secrétaire florentin avait été frappé, et ne pouvait pas ne pas l'être, par le progrès des grandes monarchies d'Occident. Pour sauver l'Italie, il admettait d'en simplifier la carte ; il admettait la disparition de la plupart des petites cités républicaines, ou des petites seigneuries, débiles et violentes. Il était, par la logique de sa pensée, conduit à l'étude de l'hypothèse monarchique. Le problème de la création, en Italie, d'un État national, le conduisait nécessairement à dépasser les conceptions républicaines empruntées à l'histoire consulaire de Rome, à l'histoire communale de Florence, à l'histoire des cités d'Italie.

Il semble que Machiavel, étudiant la politique romaine, aurait dû être naturellement conduit, du moment qu'il se posait des questions que la pratique sénatoriale et consulaire ne pouvait plus résoudre, à descendre le cours de l'histoire, à s'engager résolument dans la pério- 
de impériale, à questionner César, véritable fondateur d'une monarchie italienne et méditerranéenne ordonnée et dominée par Rome ; Auguste, organisateur et législateur de celle monarchie. Ce procédé eût été conforme à ses vues générales sur l'histoire universelle : l'antiquité seule enseigne ; elle enseigne la république idéale ; elle enseigne la monarchie parfaite. Machiavel s'y est refusé. Il exècre l'empire, et n'y veut reconnaître que la république dégénérée et corrompue; 149 il hait César, son exemple, ses leçons ${ }^{\text {cxciv }}$. La passion anti-césarienne, la passion guelfe, n'ont pas permis à Machiavel de se comporter en historien, en savant libre de préjugés. D'abord, en vertu d'un postulat d'ordre sentimental, il a décidé qu'il ne demanderait à l'Empire romain ni exemples ni conseils. Il a, de la sorte, étudié l'hypothèse monarchique, sans considérer un instant la plus puissante monarchie que l'histoire offrit à son examen, la monarchie impériale de Rome.

Il en résulte que son programme de gouvernement, princier, pas beaucoup plus que son programme républicain, ne se prête à une application pratique. Il refusait d'interroger les empereurs, héritiers de César et de son œuvre néfaste. Il avait, non sans quelque intérêt, lors de ses légations en France, considéré la monarchie française ; il ne l'admirait guère, la jugeait primitive, mal agencée, fondée sur l'obéissance résignée des peuples ${ }^{\text {cxcv }}$. Il ne connaissait pas les royaumes espagnols ni le royaume d'Angleterre. Il ne pensait pas que l'on pût demander aux Barbares des leçons de gouvernement. Il avait dit un jour au cardinal d'Amboise que les Français n'entendaient rien aux choses de l'État ${ }^{\text {cxcvi }}$. Mais ce dédain, justifié ou non, des grandes monarchies d'Occident, de leurs principes de gouvernement, de leurs constitutions (car Machiavel discerne l'existence d'une constitution française), cette haine partisane de l'Empire romain, de l'œuvre immense accomplie par ses magistrats et ses jurisconsultes, ont eu naturellement pour effet de clore, devant l'esprit de Machiavel, les plus larges avenues, et de le reconduire à l'étude de la pratique élémentaire des petits tyrans du monde gréco-romain, telle que nous la connaissons par Plutarque ou les écrivains antiques; plus volontiers encore, à l'étude de la politique, nullement compliquée, faiblement instructive, des princes italiens ses contemporains, et, particulièrement, de celui qui, entre tous, lui avait paru savoir le mieux son métier de prince, César Borgia. Mais le programme monarchique élaboré par Machiavel à 
l'aide de tels exemples restait, comme son programme républicain, de faible portée, à la mesure de la tyrannie antique, ou de la petite seigneurie italienne, ou de l'éphémère duché de Romagne créé par le bâ$\operatorname{tard}_{\mathrm{p} 150}$ d'Alexandre VI. La plupart des questions que pose la vie des grandes monarchies modernes ne s'y trouvent ni résolues, ni véritablement discutées. Ce n'est pas impunément qu'un théoricien de la politique dédaigne Jules César pour César Borgia.

Ainsi deux programmes, qui, ni l'un ni l'autre, ne satisfont pleinement l'esprit, et n'apportent ni l'un ni l'autre, une solution véritable aux questions posées. Un effort de science positive ; une méthode historique, comparative, expérimentale, qui est une méthode de science positive. Mais une enquête insuffisante, et des conclusions peu certaines.

On peut dire que la pensée politique de Machiavel se meut sur deux plans différents. C'est le secrétaire florentin, guide d'une république florentine et d'une confédération toscane présidée par Florence, qui définit le programme d'une république, réformée selon l'idéal de la Rome consulaire et sénatoriale. C'est le grand Italien qui rêve d'un État fédératif d'Italie, mi-princier, mi-républicain, ou même, par instant, d'un État monarchique d'Italie. Le secrétaire florentin est positif, réaliste, souvent dur et cynique. Le grand Italien parle en poète et en visionnaire. Sa pensée aisément s'évade hors du réel, en néglige les données et les avertissements. Elle se tourne vers la légende, elle accueille le mythe; mythe gréco-romain, mais biblique également, du législateur qui apparait, dans la suprême détresse des peuples, - Thésée, Lycurgue, Romulus ou Moïse - et qui impose aux sociétés le cadre où leur vie, pendant plusieurs siècles, s'inscrira. Mythe romain du dictateur génial et désintéressé ; qui, au moment où des institutions corrompues mènent un État à la ruine, le réforme, le rétablit, et, son œuvre accomplie, l'État sauvé, la société guérie, rentre dans la modestie de la vie privée ; mythe médiéval, dantesque, cher également à Pétrarque, et qu'un instant le fol enthousiasme de Cola di Rienzo crut réaliser, de l'envoyé providentiel, annoncé par Dante, du lévrier divin qui pourchasse et détruit le mal sur la terre, du rédempteur envoyé de Dieu pour redresser l'Italie. 
Par là Machiavel diffère de Guichardin, étonne Guichardin, qui le regarde avec surprise et ne le comprend plus. Machiavel alors cesse d'être réaliste, ironique et cynique. Il devient capable d'étranges illusions. Dante avait cru reconnaître, dans la p151 $_{1}$ personne de l'empereur Henri VII de Luxembourg, le sauveur de l'Italie, et ne s'était jamais résigné à l'échec de l'homme trop tôt venu ; Pétrarque avait salué le rédempteur dans la personne emphatique et médiocre de Cola di Rienzo, et plus tard, dans celle de Charles IV, empereur sans prestige ; de même Machiavel essaya de le reconnaître dans les deux jeunes Médicis, égoïstes et médiocres, auxquels successivement il dédia le livre du Prince. Pour comprendre la pensée et l'œuvre de Machiavel, il ne faut jamais oublier cette étrange dualité, cette antinomie interne où s'opposent sans cesse le théoricien positif et réaliste de la politique, le philosophe positif et réaliste, l'historien qui annonce Montesquieu et souvent l'instruit, et le grand Italien visionnaire, riche d'enthousiasme et d'illusion, en qui revit quelque chose des espérances apocalyptiques de Dante. 


\section{Chapitre V}

\section{Machiavel historien}

Machiavel avait déjà conduit son enquête, défini l'objet de son étude, construit sa doctrine, écrit le Prince et la plus grande partie des Discours sur la première Décade de Tite-Live. Il savait l'histoire ancienne, connaissait le monde moderne et l'interprétait en historien. Dans les sept livres de l'Art de la guerre, ses vues théoriques et son expérience se fondaient sur des faits empruntés à l'histoire récente ou gréco-romaine. La Vie de Castruccio Castracani était un roman historique à la manière de Xénophon, où l'histoire italienne du $\mathrm{XIV}^{\mathrm{e}}$ siècle offrait à la fantaisie de l'homme d'État philosophe quelques thèmes politiques et militaires. Sa nomination d'historiographe officiel, le 20 novembre 1520 , le transforma, pendant les cinq années que lui demanda la composition des Istorie fiorentine, en historien de métier. Il serait malaisé de retrouver, dans les Discours désormais interrompus, la trace des réflexions que purent lui suggérer les annales dramatiques de sa ville. Plutôt que d'élargir une enquête désormais close, ce nouveau travail allait lui permettre de vérifier, à l'aide de nouvelles données, ses conclusions et les lois qu'il avait pensé découvrir ${ }^{\text {cxcvii }} \cdot{ }_{\text {p153 }}$

Table des matières

\section{I}

Il lui fallait apprendre une nouvelle technique. Pour la première fois, il devait non plus disserter et philosopher sur les événements choisis qui attiraient son attention et prouvaient sa doctrine, mais exposer avec une longue patience, et sans rien négliger de vraiment né- 
cessaire à l'intelligence de l'ensemble et du détail, toute une histoire, qui, dépassant l'horizon de la Toscane, s'élargissait à la mesure de l'Italie entière et parfois de l'Europe. La nécessité du sujet à traiter lui imposait la stricte discipline de l'historien.

Un homme nourri comme lui d'antiquité, un lecteur passionné des historiens grecs et romains, et qui venait d'occuper la plus grande partie de ses loisirs à commenter Tite-Live, ne pouvait songer à suivre le modèle des vieux chroniqueurs florentins. Pourtant Dino Compagni, Giovanni et Matteo Villani, Donato Velluti, s'étaient montrés singulièrement habiles à saisir les traits du monde moderne, à suivre les luttes des partis, l'action des groupes religieux, l'influence des commerçants et des chefs de l'industrie, le jeu de ces intérêts industriels et mercantiles que Dante avait haïs. Mais si curieux qu'ils fussent des détails matériels dont se compose la vie des peuples, ils restaient des annalistes ; bien que fort capables de comprendre la grande politique italienne et européenne, ils ne savaient pas bien encore montrer avec art l'enchaînement des faits, définir les idées, le caractère, la personne des chefs. Pétrarque et les humanistes $d u X V^{e}$ siècle, ses élèves, avaient méprisé leurs chroniques, indignes de la majesté de l'histoire ; Machiavel ne pensa guère à les réhabiliter ${ }^{\text {cxcviii }}$.

L'idéal historique de Pétrarque et des humanistes italiens du $\mathrm{XV}^{\mathrm{e}}$ siècle venait en droite ligne de la préface où Tite-Live avait défini son intention et son désir ; texte capital, qu'ils avaient longuement étudié ; texte familier à Machiavel, lecteur et commentateur des Décades. Cette préface est d'un moraliste plus que d'un historien. Tite-Live entend présenter aux contemporains 154 un tableau des mœurs antiques de Rome, évoquer les grands ancêtres qui leur enseigneront l'art oublié de vivre pour servir : "Je veux que chacun s'efforce vigoureusement à comprendre les hommes et les moyens qui, dans la paix et dans la guerre, ont fondé cet empire et l'ont accru. Je veux que l'on suive le progrès insensible par lequel, une fois la discipline relâchée, on a vu les mœurs s'affaiblir, puis tomber chaque jour plus bas, enfin entraînées à une telle décadence, que nous vivons en un temps où nous ne pouvons plus supporter nos vices ni leurs remèdes... Si la connaissance de l'histoire peut se montrer utile et bienfaisante, c'est qu'elle enseigne avec éclat par l'événement et par l'exemple. C'est qu'on y découvre, pour soi et pour l'État, et les modèles à suivre, et les fautes à éviter, lorsque l'entreprise et l'issue apparaissent également douteu- 
ses. Au reste, si l'amour de mon sujet ne m'abuse pas, il ne fut jamais de république aussi puissante, aussi religieuse, aussi riche en nobles exemples; jamais de cité où la débauche et l'avidité aient pénétré si tard; où l'on ait autant et si longtemps honoré la pauvreté et l'épargne. Tant il est vrai que moins on possède et moins on désire. C'est tout récemment que la richesse et l'abondance des plaisirs ont introduit chez nous cette passion désastreuse, ruineuse pour l'État, du luxe et de la débauche ${ }^{\text {cxcix }}$. " L'ambition de Tite-Live est de ressusciter, $\mathrm{p} 155$ dans son livre, Rome tout entière et son génie ; d'évoquer, pour l'éducation des modernes, pour leur réforme intellectuelle et morale, l'image d'une cité conduite par les meilleurs et les plus sages. Euvre où la passion du moraliste anime l'enthousiasme du poète : «A conter ainsi l'histoire de cette antiquité, je m'en fais, je ne sais comment, le contemporain ${ }^{\text {cc }}$. »

Ainsi Tite-Live enseignait aux humanistes ce qu'il tenait pour le but le plus haut du travail historique. Quelques textes de Cicéron, également classiques, résumaient pour eux l'art d'écrire l'histoire, en quelques règles que Tite-Live d'ailleurs avait suivies. Cet art, pour Cicéron, procède de la rhétorique, indispensable à qui se prétend historien : "Existe-t-il pour l'orateur un usage plus digne de son talent que d'écrire l'histoire? Je ne connais aucun genre littéraire qui demande une manière plus large, plus abondante et plus variée. » $\mathrm{Du}$ moins ne veut-il pas négliger la technique de la recherche; mais il la définit en moraliste plutôt qu'en homme du métier: "Personne n'ignore que l'historien s'impose, comme première règle, de ne rien dire de faux, et de dire hardiment toute la vérité ; de fuir tout soupçon de faveur ou de malveillance partisane. » Cicéron exige la précision chronologique, une description vivante des lieux ; le talent de démêler et de mettre en lumière les motifs et les raisons diverses des actions humaines, et d'exposer ces actions et leurs résultats; la clarté d'esprit qui juge les faits, saisit les causes variées qui en ont déterminé le caractère et les conséquences, et sait discerner la part du hasard, du calcul et de l'imprudence. Il veut encore que l'historien soit psychologue et peintre de portraits. Il définit enfin le style historique : «Une manière douce, égale, quelque chose de coulant, d'abondant, de facile ; sans ce ton âpre de dispute qui convient au barreau; sans les traits passionnés qui conviennent à l'éloquence politique ${ }^{\text {cci }}$. " p156 
Cette conception romaine de l'histoire et de la manière historique diffère sensiblement de celle qui soutint, en Grèce, l'effort d'un Thucydide ou d'un Polybe. C'est chez eux, et non chez les Romains, que s'affirme véritablement l'esprit historique. Cet esprit exclut toute préoccupation morale, politique, ou nationale. Il s'impose, comme tâche essentielle, unique, la recherche de la vérité ; il exige une documentation scrupuleuse et une critique sévère. Il essaie de construire un système de connaissances exactes, rigoureusement fondées, strictement vérifiées, établies; acquises, dit Thucydide, pour toujours ${ }^{\text {ccii }}$. L'histoire, chez eux, est science, philosophie, sociologie. Rien de tel à Rome : l'histoire n'y a d'autre but que de glorifier un idéal de caractère national et civique. Sans doute ne doit-elle dire que la vérité ; mais elle s'en sert pour démontrer une doctrine. Cicéron ne le dit pas en propres termes ; lorsqu'il invite l'historien à sans cesse intervenir pour juger, il le suggère. Tite-Live écrit à la gloire de sa patrie. Comme l'histoire désormais enseigne et veut prouver, il ne suffit pas qu'elle expose avec la netteté froidement objective d'un Thucydide ou d'un Polybe ; il faut qu'elle soit éloquente et pittoresque. Cicéron rattache l'histoire à la rhétorique, et Tite-Live est évidemment, comme Taine l'assure, un historien orateur ${ }^{\text {cciii }}$. p157

$* * *$

Les humanistes italiens ont suivi la leçon de Rome bien plus que de la Grèce. Cette préface, éloquente et grave, de Tite-Live, ce bel exposé, éthique et technique à la fois, de Cicéron, avaient enseigné aux humanistes la manière de concevoir et d'écrire l'histoire. Ils lui avaient, dès Pétrarque, assigné pour but un enseignement moral et civique; avec cette différence toutefois que Pétrarque visait surtout à former, par la méditation de l'histoire antique, un type supérieur d'humanité, et que les humanistes florentins du Xv siècle cherchaient davantage à former des citoyens. Ils s'efforcèrent de l'écrire comme Cicéron voulait qu'on l'écrivit, comme Tite-Live l'avait écrite. Ils avaient professé le respect et le culte de la vérité, et s'étaient vantés de la dire. Ils s'étaient appliqués à l'exactitude chronologique. Ils avaient recherché les causes et les effets; ils avaient jugé ; ils avaient tracé des portraits. Ils s'étaient proposé pour modèle le style de Tite-Live. Mais ils négligeaient ce que Tite-Live avait négligé, ce que les vieux chroniqueurs avaient su observer, la vie matérielle des peuples, les 
conflits d'intérêts, les luttes de classe. Le mépris où ils tenaient leur temps, quand ils le comparaient à l'antiquité romaine, l'imitation de Tite-Live, les conduisirent à négliger les détails, qu'à tort ils jugeaient médiocres, de la réalité florentine. Les luttes des classes et des partis à Florence, étudiées avec tant de soin par les Villani, revêtent, dans l'œuvre de Lionardo Bruni ou de Poggio Bracciolini un aspect faussement romain. Ils prêtent aux hommes d'État modernes des discours imités des harangues que prononcent, chez Tite-Live, les magistrats, les consuls, les généraux au Sénat, au Forum ou dans les camps. Selon l'exemple de Tite-Live et des historiens antiques, ces discours servent parfois à développer une philosophie de l'histoire, ou simplement un commentaire des faits. La narration recherche l'effet oratoire et dramatique plus que l'exactitude et la couleur vraie ${ }^{\text {cciv }}$.

Machiavel était nécessairement l'héritier de cette école. Il ne pouvait revenir à la manière encore primitive des anciens chroniqueurs. Il était lui aussi lecteur et admirateur de Tite-Live. p158 Il avait tiré du texte de la première Décade les faits sur lesquels il fondait les maximes qu'il proposait à la méditation des hommes d'État. Il admettait qu'on dût écrire l'histoire comme Tite-Live plutôt que comme Thucydide ou Polybe. Mais il pensait, en histoire, comme Thucydide ou Polybe. Par une anticipation de génie, il avait, dans la pratique, dépassé les timidités humanistes. Sans s'attarder au détail des faits, il avait usé de l'histoire en savant, exercé comme Léonard de Vinci, aux méthodes de l'expérience et de la comparaison. Il avait demandé à l'histoire des notions positives et les avait confrontées avec d'autres notions, acquises au spectacle du monde contemporain. Alors, glossateur de Tite-Live, il s'était libéré de son modèle classique ; il avait repris un effort abandonné depuis la Politique d'Aristote, et, malgré d'évidentes lacunes et l'insuffisante documentation, ébauché une œuvre de savant, par où il dépassait, de toute la force et la hauteur de son esprit, l'école humaniste. Mais, chargé à Florence d'une tâche officielle et quelque peu ingrate, la loi du genre le condamnait à n'écrire l'histoire qu'en héritier de cette école et en élève des Romains.

Machiavel, depuis trop longtemps, avait pris l'habitude de travailler, méditant les Décades, sur une histoire qu'il croyait faite : il ne se donna pas la peine d'établir, en érudit, les annales de sa ville. Nulle recherche dans les Archives de l'État; il accorda toute confiance à ses divers prédécesseurs et les suivit : chroniqueurs comme Giovanni Vil- 
lani, Marchionne di Coppo Stefani, Piero Minerbetti ; mémorialistes comme Gino Capponi ; historiens humanistes comme Flavio Biondo, Lionardo Bruni, Giovanni Cavalcanti, Giovanni Simonetta. Les uns et les autres lui fournirent le canevas de sa narration. Il ne lui restait plus qu'à la mener selon les préceptes de Cicéron et l'exemple de TiteLive, avec le désir de ressusciter les choses mortes, le souci de comprendre les raisons qui ont déterminé les actes des hommes et des partis ; le besoin passionné de juger leur action, de saisir les causes des succès ou des échecs; avec un effort constant pour analyser en psychologue la pensée de ceux qui ont conduit les affaires humaines. Exposé vivant, persuasif, où la démonstration se fait éloquente; où l'art de l'avocat et de l'orateur politique intervient pleinement, lorsque Machiavel donne la parole aux acteurs de l'histoire, pour attaquer leurs adversaires, défendre leur doctrine, dicter leurs volontés.

Mais dans cet effort pour se conformer à des modèles classiques, p159 il introduit heureusement tout son génie, toute l'originalité et toute la vigueur de sa pensée. Commentateur de Tite-Live, il vient d'étudier les causes de la grandeur et de la décadence républicaine; et de cette étude, il a essayé de dégager quelques-unes des lois qui régissent l'histoire des peuples et des États. Il a, dans le Prince, étudié, à travers l'antiquité et les temps modernes, les gouvernements monarchiques et les tyrannies, les secrets de leur solidité, les causes de leur décadence. Il peut maintenant appliquer, à l'évolution de la politique florentine, à l'histoire des origines et des transformations du régime qu'il a servi quatorze ans, les méthodes d'analyse sur lesquelles se fondent les théories des Discours et du Prince. Sa connaissance de l'histoire générale des temps anciens, sa connaissance des États modernes, lui permettent une vue d'ensemble sur les luttes de partis et les révolutions; et pour la première fois, d'introduire un ordre scientifique et rationnel dans le chaos où la curiosité intelligente des chroniqueurs n'avait pas su discerner de lois directrices, et où les humanistes n'avaient introduit qu'un ordre littéraire et artificiel. Les harangues même que, trop fidèle peut-être à une convention classique, il prête aux politiques et aux chefs de parti, rappellent, à force de plénitude et d'intelligence, Thucydide plutôt que Tite-Live.

A la différence de ses précurseurs humanistes, il possède une doctrine : Poggio, Bruni, bons praticiens des affaires quotidiennes, ne savaient pas dominer les grandes questions de la politique. Les Histoires 
florentines permettent à Machiavel de défendre et d'illustrer les thèses générales que développent le Prince, les Discours sur la première Décade et l'Art de la Guerre. Il écrit l'histoire sinon pour démontrer, du moins avec le désir secret de justifier certaines idées. Tite-Live aussi avait écrit afin de soutenir une doctrine. Mais elle se réduisait à l'idéal de grandeur civique et militaire sur lequel les Romains conservateurs et instruits souhaitaient de reconstituer l'union d'une patrie déchirée ; idéal en somme élémentaire et sentimental. Chez Machiavel, il s'agit véritablement d'une doctrine politique, scientifiquement fondée, rationnellement élaborée. Par là, son œuvre risque de perdre en objectivité ; Machiavel ne recherche pas toujours l'exactitude avec un soin minutieux ; il lui arrive d'imposer aux faits un ordre arbitraire ou factice, d'en forcer l'interprétation, de les contraindre à prouver ses 160 propres thèses ${ }^{\text {ccv }}$. Une passion secrète anime son récit: elle s'exprime, dès la préface, par le reproche qu'il adresse à Lionardo Bruni et à Poggio Bracciolini de n'avoir pas avec assez de soin étudié les discordes civiles et l'effet des querelles intérieures ${ }^{\text {ccvi }}$. On retrouve, dans les Istorie fiorentine, l'homme politique, le théoricien de la monarchie et de la république, le républicain fidèle aux traditions d'un peuple laborieux; on retrouve le patriote italien. L'œuvre historique de Machiavel reste vivante parce que Machiavel y survit.

Table des matières

\section{II}

Le premier livre introduit à l'histoire de Florence. L'auteur y retrace à grands traits les vicissitudes italiennes depuis la chute de l'Empire romain, à travers le Moyen Age, et jusqu'à la troisième décade $d u X V^{e}$ siècle. Vaste synthèse que seul à pareille date un esprit aussi curieux du détail, aussi capable de saisir les ensembles, pouvait tenter. L'auteur du Prince et des Discours y montre toute la force et aussi les limites de son génie. Son histoire, comme sa politique, ne se soucie que de l'État, de la formation et de la conservation de l'État, par la force des lois et des armes. Assez peu lui importent les questions d'ordre économique ou social, la production ou l'échange, p161 
l'agriculture, l'industrie ou le commerce, les rivalités matérielles des classes. La vie religieuse et la pensée religieuse ne l'intéressent que dans la mesure où l'État peut s'en prévaloir; pas davantage la vie intellectuelle, le développement des lettres et des arts. Mais plutôt que par ce qu'il néglige, l'auteur du Prince ou des Discours sur la première Décade se reconnaît, dès ce premier livre, à certains partis pris.

Le premier personnage qui retient assez longtemps son attention est Théodoric, roi des Ostrogoths, qui, de 493 à 526, porta le litre de roi d'Italie, et s'efforça de restaurer l'ordre légal et l'autorité de quelques traditions romaines. Machiavel retrouve en lui comme une première ébauche du prince de génie dont il a rêvé. Pour établir une correspondance plus exacte entre le personnage réel dont il résume l'œuvre et le personnage idéal dont l'image entrevue ne cesse d'animer son enthousiasme, il atténue les détails qui rappelleraient trop évidemment le caractère barbare du réformateur. Il conclut sur Théodoric, à peu de chose près, comme sur César Borgia : « Si tant de vertus n'avaient pas été, dans les dernières années de sa vie, souillées par quelques cruautés que le soupçon lui fit commettre contre Symmaque et Boèce, véritables saints, sa mémoire mériterait d'être pleinement glorifiée. Grâce à ses talents et à ses vertus, Rome et l'Italie, et toutes les autres parties de l'Empire d'Occident, libérées enfin de toutes les misères qui les accablaient depuis les invasions barbares, respirèrent, et connurent enfin un gouvernement bien ordonné ccvii . »

Le progrès de la puissance pontificale lui offre l'occasion de vérifier les griefs que, dans les Discours sur la première Décade, il a déjà développés contre la politique italienne du Saint-Siège. Il lui reprochait d'avoir sans cesse appelé au secours de ses ambitions temporelles, et contre quiconque prenait trop de place ${ }_{\mathrm{p} 162}$ en Italie, la force des étrangers et des Barbares: "Les papes, répète Machiavel, voyant grandir l'autorité des Lombards, appelèrent contre eux le secours de la France et de ses rois. Ainsi désormais, chaque fois que les Barbares vinrent porter la guerre en Italie, ils y furent provoqués par le SaintSiège... Ces pratiques durent encore de notre temps : c'est là ce qui a maintenu et maintient encore la désunion et la faiblesse de 1'Italie ${ }^{\text {ccviii. } . ~ » ~ L e ~ c o n t r a s t e ~ d e ~ d e u x ~ p o l i t i q u e s, ~ c e l l e ~ d e s ~ g r a n d s ~ E ́ t a t s ~ e t ~}$ des princes, qui hâtait, consciemment ou non, l'unification de l'Italie, celle des papes qui, pour conserver leur domaine temporel, travaillaient avec ténacité à une œuvre de désunion, domine désormais, jus- 
qu'aux premières décades $\mathrm{du} \mathrm{XVI}^{\mathrm{e}}$ siècle, l'histoire générale de l'Italie : «On verra, conclut Machiavel, comment ils ont su, d'abord au moyen des censures ecclésiastiques et des armes spirituelles, puis par l'action combinée des armes spirituelles et temporelles, se faire craindre et respecter; et comment, pour avoir abusé des unes et des autres, ils sont arrivés maintenant à un tel point qu'ils ont perdu complètement leur autorité spirituelle, et, pour la temporelle, se trouvent à la discrétion d'autrui. »" ${ }^{c c i x}$ Ainsi Machiavel, qui n'a pas daigné rappeler l'humiliation de l'empereur Henri IV à Canossa, ni même cité le nom de Grégoire VII, semble, comme Guichardin, constater avec un secret plaisir les effets de la Réforme, qui, en 1525, a déjà soustrait à l'obédience du Saint-Siège un tiers du monde germanique, pénètre en France et aux Pays-Bas ; il semble prévoir le sac de Rome et la capitulation de Clément VII devant Charles-Quint ${ }^{\mathrm{ccx}}$. ${ }_{\mathrm{p} 163}$

Machiavel expose brièvement la lente décadence de l'Empire. Autant que la puissance temporelle des papes, il hait l'autorité anachronique des Césars modernes. Il a depuis longtemps rejeté l'idéal dantesque d'un monde chrétien guidé, par l'accord de Pierre et de César, vers la paix et la connaissance. Rien n'est plus étranger à son esprit d'homme politique et d'historien que ce discours sur l'histoire universelle, que l'on peut aisément tirer de quelques chants du Purgatoire et du Paradis, et de quelques chapitres du traité De Monarchia. Les papes ont humilié la puissance impériale, qu'un Henri VII n'a pu relever; ils ont voulu, dans un monde sans loi et sans règle, usurper la force temporelle que Dieu leur avait refusée ; depuis leur asservissement à la maison de France, une ombre mortelle attriste la terre chrétienne ; il est temps que Dieu vienne au secours des hommes ${ }^{\text {ccxi }}$. Cette philosophie de l'histoire demeure étrangère à Machiavel, trop peu chrétien pour rechercher, à travers les fastes de l'humanité, les vestiges perdus d'un ordre divin. Il ne connaît que le cercle éternel où s'inscrivent sans fin la grandeur, la décadence, la renaissance des États. Dans la lutte du sacerdoce et de l'Empire, il ne considère que la formation de partis italiens, les guerres incessantes des gibelins et des guelfes, le déchirement de l'Italie.

Il suit, sans nulle amitié, le progrès des gouvernements princiers, des tyrannies fondées sur les ruines des libres communes; tandis que grandit l'audace des compagnies d'aventure et de leurs chefs, que républiques et monarchies s'abandonnent à p164 leur sauvegarde, et res- 
tent à la merci des usurpations militaires ou des attaques de l'étranger. Même dédain systématique et partial, même dénigrement volontaire des condottieri. Même pensée, même langage que dans les Discours et dans le Prince : «Tous les États, écrit-il, faute d'armes qui leur eussent appartenu, étaient désarmés. Venise, devenue puissance continentale, déposait les armes qui sur mer avaient assuré sa grandeur; et, suivant l'usage commun, abandonnait à des mercenaires la conduite de ses troupes. Le pape, étant empêché de porter les armes, faisait par nécessité ce que les autres faisaient par erreur. Florence obéissait à la même fatalité. Les luttes civiles y avaient détruit la noblesse ; la république, aux mains d'hommes de négoce, suivait l'exemple des autres États, et s'acheminait aux mêmes désastres. De la sorte, la seule force militaire qui pût compter en Italie, se trouvait aux mains de quelques petits princes ou de quelques aventuriers sans terres. Les petits princes, pour leur défense ou leur agrandissement, apprenaient le métier des armes ; les capitaines d'aventure, n'en sachant pas d'autre, demandaient aux armes richesse, puissance, honneurs... Tous ces hommes de guerre se concertaient pour que nul des États qui les prendrait à sa solde n'obtînt jamais victoire complète. Ils finirent par abaisser à tel point l'art militaire, que le plus médiocre capitaine en qui l'on eût vu renaître quelque ombre de valeur antique les aurait honteusement mis en déroute, à l'émerveillement de l'Italie imprudente qui les honorait. Or toute mon histoire sera désormais pleine de ces princes sans courage et de ces armes avilies. \> ${ }^{\text {cxii }}{ }_{\text {p165 }}$

Les livres II, III et IV racontent l'histoire de Florence jusqu'au rappel de Cosme, triomphal retour d'un bref exil. Machiavel y étudie, en homme d'État plus qu'en historien, le mécanisme de la constitution florentine. Il admire les vieilles générations du XIII ${ }^{\mathrm{e}}$ siècle, les républicains auxquels la commune, en 1265, dut, avec ses institutions militaires et civiles, sa liberté. Dans le conflit des Arts mineurs et majeurs, qui, après le triomphe définitif du parti guelfe, anti-impérial, favorable à la politique du Saint-Siège, agite l'histoire de Florence, Machiavel ne prend guère la peine de dégager l'action des intérêts économiques et les effets de la lutte des classes. Il ne connaît que la politique. Trop aisément il explique ces conflits, selon l'habitude des historiens humanistes, au moyen d'une comparaison avec cette histoire romaine 
que lui-même, commentateur de Tite-Live, connaît beaucoup mieux qu'eux, et que pourtant, faute de tenir un compte suffisant de l'économie, il interprète exclusivement en politique ${ }^{\text {ccxiii }}$. p166

Mais dans ce long récit des luttes qui pendant deux siècles ont troublé la vie florentine, l'attention de Machiavel retient, avec le jeu des partis et la lente dégradation des formes politiques, l'œuvre de quelques personnages dominateurs. L'auteur du Prince et des Discours sur la première Décade admettait volontiers l'action décisive et capitale de quelques volontés, assez fortes pour guider l'évolution des sociétés ou le développement des États. Il s'est plu à considérer le rôle des aventuriers de la politique ou de la guerre; il a étudié les créations de leur audace et de leur talent, les causes de leur succès éphémère ou durable. De tels individus apparaissent également, triomphateurs d'un jour ou d'un siècle, dans les Istorie fiorentine. C'est Gautier de Brienne, duc d'Athènes, qui, en 1342, appelé par Florence afin de conduire la lutte contre les gibelins de Toscane, put fonder, avec l'appui de la plèbe, une tyrannie démagogique et militaire, vite brisée par la résistance de la légalité républicaine. C'est, en 1378, Michele di Lando, le contre-maitre venu des ateliers de l'Arte delle Lana, lors du tumulte des Ciompi; chef pendant quelques jours des hommes des métiers contre la tyrannie des classes possédantes. C'est Salvestro de' Medici, le grand bourgeois qui, à la faveur des mouvements populaires, travaille à la grandeur de sa famille. C'est Cosme l'Ancien, dont Machiavel loue la manière civile, la prudence consommée, la libéralité envers ses amis, et dont il décrit avec une force et une netteté singulières les menées politiques, depuis ses premiers conflits avec l'oligarchie des Albizzi jusqu'à son exil padouan et jusqu'aux acclamations qui saluèrent la rentrée du maître de Florence ${ }^{\text {ccxiv }}$. Ainsi se dégage de ces trois livres une vue générale, qui reste purement politique, mais que l'histoire de l'économie et de la société permet de compléter aisément, sur l'évolution fatale qui entraînait Florence à la monarchie.

Les derniers livres, consacrés au gouvernement de Cosme et de Laurent, auraient dû montrer comment ils tinrent la gageure ${ }_{\mathrm{p} 167}$ difficile de gouverner, bourgeois parmi les bourgeois, serviteurs comme les autres de l'État, soumis à la commune discipline de civisme et 
d'humanité, une ville soupçonneuse, et peu indulgente à quiconque prenait les allures d'un maître. Il appartenait à Machiavel de montrer par quels procédés et par quelles manœuvres, sans jamais revêtir aucun titre princier, ils créèrent à leur profit ce gouvernement personnel dont ils fuyaient les apparences. Mais la plume de Machiavel n'était plus libre. Il écrivait, annaliste officiel, historien d'une cité dominée par les Médicis ; son ouvrage devait être dédié à un Médicis, le pape Clément VII ; il ne pouvait tout dévoiler. Il s'en ouvrit à Guichardin, président pontifical en Romagne, le 30 août 1524: «Je paierais dix sous, pour ne pas dire davantage, afin de vous avoir près de moi... Car je suis arrivé à un point où j'aurais besoin d'entendre de vous si j'offense, pour trop exalter ou trop abaisser... J'imaginerai quelque moyen de dire la vérité sans que nul ne puisse se plaindre ${ }^{\text {ccxv }}$. » Il allait affirmer, dans la Préface à Clément VII, que jamais Cosme ni Laurent n'avaient nourri d'ambitions contraire aux intérêts de la cité ${ }^{\text {ccxvi }}$.

Aussi, après avoir, à la fin du quatrième livre, conté les débuts de Cosme, son exil et son retour, traite-t-il plus volontiers, dans les deux suivants, de politique étrangère. Il raconte les guerres florentines, les guerres italiennes ; il y trouve une nouvelle occasion de flétrir les capitaines d'aventure et de condamner les armées mercenaires. Il parvient ainsi, à la date de 1464 et à la mort de Cosme, sans avoir tenté grand effort pour analyser ses méthodes de gouvernement. Cosme a démontré comment on peut acquérir le pouvoir dans une cité libre, en captant la bienveillance des citoyens, sans recourir aux armes, par le seul moyen de la prudence et de la ruse. Sans dépasser les bornes de ce que Machiavel nomme la modestie civile, il a pu, homme désarmé, gouverner trente et un ans la République ${ }_{\mathrm{p} 168}$ florentine. Il a su constamment se prévaloir du jeu des partis et des entreprises de la politique étrangère. Machiavel ajoute quelques mots sur ce gouvernement des esprits qui contribuait à renforcer le régime, sur la protection accordée par système autant que par goût aux lettres et aux arts, dont, historien politique, il néglige de montrer la vigueur multiple et créatrice. Trop peu libre pour analyser à son gré le caractère de Cosme, son intelligence robuste, mais âpre et cauteleuse, son amour du pouvoir et sa dureté réelle, il se borne à rapporter de lui un certain nombre de mots, dont quelques-uns, passablement cyniques, laissent assez bien entendre ce qu'il préfère ne pas dire : «Plutôt ville ruinée que ville 
perdue... Quelques aunes de drap rosé suffisent à faire un honnête homme... Les régimes ne se défendent pas avec des patenôtres ${ }^{\text {ccxvii }}$. »

Après la mort de Cosme, l'historien de Florence aurait dû étudier le resserrement de plus en plus étroit du régime médicéen, les retouches insensibles mais ininterrompues que Laurent sut apporter à la constitution, le progrès d'un pouvoir personnel, appuyé sur un nombre de plus en plus restreint de citoyens qui devaient tout au régime, et soutenu par un système de police, d'espionnage et de délation. Il a préféré s'abstenir, et, plus volontiers, il élargit son sujet à la mesure de l'Italie. Il y voit le despotisme partout triomphant, la corruption sans cesse aggravée de la société. Les guerres, qui, au temps de Cosme, méritaient encore de retenir l'attention de l'historien, sont conduites avec une mollesse et une indifférence croissantes. Du moins la politique ingénieuse et habile de Laurent réussit-elle à établir, entre les divers États italiens, un équilibre qui, durant quelques années, maintint la paix, et, par la même occasion, enleva tout prétexte aux interventions étrangères, déjà menaçantes. Mais la vie politique partout décline. p169 L'amour de la liberté, l'énergie individuelle, ne se manifestent plus que dans les conspirations multipliées. Machiavel s'applique à raconter ces conflits tragiques des tyrans et de leurs sujets. Peu de pages dans son œuvre et dans la prose italienne ont un caractère plus dramatique et un relief plus saisissant que le récit du meurtre de Galeas-Marie Sforza, duc de Milan, en 1476, ou de la conjuration des Pazzi, dont, à Florence, deux ans plus tard, Julien, frère de Laurent, fut victime. Machiavel, comme il l'affirmait déjà dans les Discours sur la première Décade, montre comment ces tentatives désespérées de la violence n'ont jamais réussi qu'à renforcer la tyrannie ${ }^{\text {ccxviii. }}$. En vain les Pazzi appelèrent Florence à la liberté. Les succès et les largesses des Médicis avaient rendu le peuple sourd, et le nom de la liberté ne semblait plus l'émouvoir.

L'œuvre se termine à la mort de Laurent, le 8 avril 1492. Machiavel discerne en lui le contraste et l'accord du génie et du laisseraller $^{\text {ccxix }}$. Tous les talents nécessaires à la conduite d'une cité libre ou à la fondation d'une tyrannie ; une éloquence persuasive et troublante devant les conseils, et, dans les entretiens particuliers, une parole spirituelle et péremptoire ; la réflexion prudente et la décision prompte ; la hardiesse de l'exécution; p170 l'aptitude à maîtriser et conduire l'opinion ; l'art de la satisfaire par une habile réclame, par l'activité 
des travaux publics, la magnificence des constructions qui proclament la solidité du régime ; l'art de faire oublier des citoyens, par la facilité de la vie matérielle, au milieu des réjouissances et des fêtes publiques, la liberté perdue ; les dons les plus précieux de l'intelligence, le sens le plus fin de la beauté, le goût de la pensée pure ; les faveurs multipliées à qui excellait dans la pratique d'un art; les secours libéralement accordés aux écrivains et aux philosophes; le tact délicat avec lequel il savait traiter en égaux, étant artiste, penseur et poète luimême, les artistes, les philosophes et les écrivains ; et, à côté de ces qualités qui relevaient au-dessus des hommes, un tempérament brutal et sensuel, des passions violentes et tenaces, dont il choisissait mal l'objet; une recherche presque puérile de l'amusement et du jeu; le goût des propos bouffons, des plaisanteries mordantes et cruelles: "Qui le voyait mener ainsi, conclut Machiavel, une double existence, austère et folle, eût pensé que deux hommes divers, unis de force, luttaient en lui ${ }^{c c x x}$. » L'historien ajoute que la fortune, en toute chose, le favorisa, sauf dans ses entreprises financières : Laurent, dépensier autant que Cosme était économe, ruina la banque d'où était sortie la grandeur de sa famille. Il fallut que l'État, par divers moyens obscurs sur lesquels Machiavel ne peut insister, l'aidât à rétablir sa fortune compromise. Mais Guichardin et Jacopo Nardi nous ont conté comment les magistrats asservis le laissaient puiser dans les fonds publics, mettre la main sur les fortunes confisquées, les gabelles, les capitaux de la Dette ; comment il ne regardait guère aux moyens qui le sauvaient de la ruine ; comment ses fidèles, avec sa complicité, pillaient les deniers de la commune ${ }^{\text {ccxxi }} 25$. Machiavel indique seulement que, las de la finance, p171 il préférait maintenant acquérir immeubles et domaines. Il n'était plus un bourgeois enrichi par le négoce ; il dirigeait l'exploitation de ses terres; il y oubliait la banque et les affaires ; il y vivait en grand propriétaire foncier, comme les princes ${ }^{\text {ccxxii }}$.

Machiavel aurait voulu poursuivre le récit de l'histoire florentine à travers les guerres d'Italie. Quelques fragments et quelques notes conduisent jusqu'à l'avant-dernière année du siècle. Mais les événements politiques ne lui permirent pas d'achever son œuvre. Elle se termine brusquement, à la mort prématurée de Laurent, parmi les tristes présages qui l'accompagnèrent, et qui, au moment où allait man- 
quer à l'Italie l'homme assez habile depuis vingt ans pour assurer l'équilibre des États, apaiser leurs rivalités et leurs haines, contenir l'étranger aux frontières, semblaient annoncer et annonçaient en effet la fin d'un monde ${ }^{\text {ccxxiiii. }}$. 


\section{SECONDE PARTIE}

\section{LA DOCTRINE DE MACHIAVEL}

Table des matières

\section{Chapitre premier}

\section{Le gouvernement légal}

On a, jusqu'ici, tenté de suivre Machiavel au cours de ses années d'étude, de voyage, d'activité politique; essayé de comprendre la formation de son esprit; essayé de définir les termes dans lesquels se posait pour lui la question inévitable et dominante, celle de la réforme des gouvernements d'Italie et de la fondation, dans l'Italie unifiée, d'une autorité assez forte pour la défendre contre l'étranger. On a tenté de comprendre ses illusions, marqué le contraste qui existe entre ses incertitudes pratiques et le caractère scientifique et positif de sa méthode, constaté l'étroitesse des problèmes qu'il a tenté de résoudre, l'étroitesse de son enquête scientifique, la portée nécessairement restreinte de ses conclusions. On a enfin noté chez lui le dualisme d'une intelligence durement positive et d'une imagination de visionnaire et de poète.

Il est possible désormais d'entreprendre l'étude de sa doctrine. Machiavel, commentant la première Décade de Tite-Live, formule un certain nombre de sentences, de maximes, d'où se dégage la théorie d'un régime constitutionnel, soit républicain, soit monarchique, d'un État libre, ou, comme il dit, civilement gouverné. Dans le livre du 
Prince, qui semble écrit en marge des Discours, il construit la théorie d'une monarchie absolue, d'un despotisme qu'il veut toutefois éclairé. Le Prince, dans sa carrière d'écrivain et d'homme politique, ne représente que l'occupation de quelques mois, consacrés à l'étude d'une hypothèse illusoire. Les Discours sur la première Décade, p176 sans cesse retouchés et complétés, expriment la pensée qui l'a véritablement soutenu jusqu'à la mort.

$\underline{\text { Table des matières }}$

\section{I}

A la base de tout gouvernement qui s'interdit l'arbitraire et les procédés tyranniques, Machiavel semble affirmer la nécessité d'un pacte. Sans doute, la notion du contrat passé entre ceux qui gouvernent et ceux qui sont gouvernés, en vertu duquel ceux-ci accordent confiance et obéissance à ceux-là, tandis que ceux-là s'engagent à n'user de leur pouvoir qu'afin de maintenir les droits et de défendre les intérêts de ceux-ci, n'est pas analysée dans les Discours. Machiavel n'a pas lu les théologiens du Moyen Age qui, à cet égard, auraient pu l'instruire. Il vit plus d'un siècle et demi avant Locke. Pour que la notion contractuelle du gouvernement puisse se développer et se définir dans le monde moderne, il faudra le soulèvement des Pays-Bas contre Philippe II, les guerres françaises de religion, la fondation du régime républicain aux Provinces-Unies et particulièrement en Hollande, près de deux siècles d'histoire anglaise et deux révolutions anglaises. Pourtant l'idée d'un accord entre gouvernants et gouvernés s'impose, par la force des choses, à l'esprit de Machiavel ; l'idée d'une monarchie de droit divin lui est absolument étrangère. On a souvent, à propos de Machiavel, l'occasion de citer Montesquieu ; on n'a jamais l'occasion de citer Bossuet. Républicain ou monarchique, tout gouvernement civil repose sur un pacte, soit exprimé dans un texte constitutionnel, soit sous-entendu.

C'est d'après l'exemple de la monarchie française que Machiavel définit cette notion du pacte. Les théoriciens français de la politique se sont, pendant tout le XVIII ${ }^{\mathrm{e}}$ siècle, évertués à découvrir la constitution du royaume ${ }^{\text {ccxxiv }}$. Dès la seconde décade du XVI ${ }^{\mathrm{e}}$, Machiavel en avait 
affirmé l'existence : "Le royaume de France, écrit-il, possède la paix et la sûreté à l'intérieur; et ${ }_{\mathrm{p} 177}$ cela essentiellement est dû à une infinité de lois, par lesquelles l'autorité royale se reconnaît liée... Ce royaume est plus soumis à la discipline des lois que nul autre État contemporain... Les princes y naissent sous la règle de la constitution... Celui qui ordonna cet État (et ici apparaît le mythe, cher à Machiavel, et recueilli au XVIII siècle par les philosophes, du législateur qui, à l'origine de l'histoire, trace le cadre où se développe la vie des sociétés) voulut que les rois pussent, à leur gré, disposer de la force militaire et de l'argent; mais il leur interdit de disposer du reste autrement que selon l'ordre défini par les lois ${ }^{\text {ccxxv }}$. »

Machiavel poursuit cette analyse de la constitution française. Elle a prévu la création d'un corps chargé de maintenir le contrat passé entre le gouvernement et la nation: "Ces lois, sur lesquelles se fonde l'ordre de l'État, sont confiées à la garde des Parlements, et surtout du Parlement de Paris. Il les rappelle et les remet en vigueur, chaque fois qu'il a l'occasion de prononcer une sentence contre quelque grand, ou même contre les excès de l'autorité royale. » Et Machiavel note que, par cette résistance à l'arbitraire, le Parlement préserve les libertés essentielles de la nation. Si les Parlements cessaient de remplir leur devoir, l'ordre tout entier du royaume se dissoudrait ${ }^{{ }^{c} \text { cxxvi }} \cdot$ p178

Ainsi apparaît chez Machiavel une des idées que les théoriciens parlementaires du XVIII ${ }^{\mathrm{e}}$ siècle, et Montesquieu dans l'Esprit des Lois, ont conçue au terme de leurs études sur la monarchie française, ses origines et son évolution; l'idée d'un dépôt de lois, au maintien duquel se trouvent liées et la sécurité des individus et la solidité de l'État. Dépôt de lois confié à la garde d'un corps de magistrats, qui savent le code et rendent la justice, mais sont en même temps investis de la plus haute fonction politique, parce qu'ils forment une sorte de sénat conservateur, gardien du pacte constitutionnel : « Il faut encore, dit Montesquieu, un dépôt de lois. Ce dépôt ne peut être que dans le corps politique qui annonce les lois lorsqu'elles sont faites et les rappelle lorsqu'on les oublie... Un corps qui fasse sans cesse sortir les lois de la poussière où elles seraient ensevelies... Dans les États despotiques, où il n'y a pas de lois fondamentales, il n'y a pas non plus de dépôt de lois ${ }^{\text {cxxvvii } . » ~}$ 
Machiavel établit donc, à la base de tout État civil et policé, un pacte qui, une fois agréé, ne doit pas être rompu arbitrairement. Le respect du pacte constitutionnel peut seul assurer au gouvernement, qu'il soit aux mains d'un monarque ou de magistrats républicains, l'équilibre et la stabilité : "Quand un prince observera ces accords, écrit Machiavel, et que le peuple verra qu'en aucun cas il n'interrompt le cours des lois fondamentales, le peuple s'accoutumera bientôt à vivre satisfait et sans inquiétude ccxxviii. . Rien n'affaiblit un gouvernement comme l'infidélité à de telles promesses; et Machiavel cite, en exemple, une erreur de Savonarole : «Florence, dit-il, s'était, après 1494, donné une nouvelle constitution, avec l'aide de frère Jérôme Savonarole, dont les écrits démontrent le savoir, la prudence, la vertu qui l'animait. Une loi dont il avait, à très grand-peine, obtenu l'approbation, établissait le droit d'appeler devant le peuple de toutes les sentences rendues par les Seigneurs ${ }_{\mathrm{p} 179}$ ou par les Huit en matière politique, et garantissait ainsi la sécurité des citoyens. Or il arriva que cinq d'entre eux, en août 1497, accusés de complot contre la République, furent condamnés à mort par la Seigneurie. Mais lorsqu'ils voulurent faire appel, Savonarole, en dépit de la constitution, ne le permit pas. Cette illégalité diminua le crédit du moine plus qu'aucun événement. Il ne pouvait ni la désavouer, au risque de se désavouer luimême, ni la justifier, car elle était injustifiable. Une telle violation de la loi avait révélé son caractère intraitable, son orgueil de partisan; elle abaissa son autorité, et créa contre lui de redoutables griefs ${ }^{\text {cxxix }}$.»

***

Machiavel souhaite que le pacte constitutionnel puisse s'appuyer sur la religion. Ainsi se trouve posée la question moderne des rapports de l'Église et de l'État.

Ni le fondateur, ni le réformateur d'un État, ne peuvent faire abstraction des croyances religieuses d'un peuple. Autant que les hommes de génie qui ont créé les républiques et les royaumes, Machiavel respecte et admire les hommes de génie qui ont, comme Moïse ou Numa, établi des croyances, un culte, des lois religieuses. La religion, qui réfrène les mauvais instincts des hommes, est indispensable au maintien d'un ordre policé. La fortune de Rome lui donna, après Romulus, roi guerrier, Numa qui sut, législateur religieux, assurer la co- 
hésion de l'État et de la société chez un peuple travaillé de passions violentes ${ }^{\text {ccxxx }}$. Malgré quelques restrictions de pure forme et de prudence en faveur de la vérité romaine, Machiavel reconnaît, à l'origine de toute croyance confessionnelle, la débilité de l'esprit humain et son éternelle détresse. Il admet aisément que, à l'origine de tous les cultes, l'imposture ne fut jamais absente ; mais les peuples sont ainsi trompés pour leur bien. Peu importent les mensonges et les prestiges auxquels Numa recourut pour convaincre $\mathrm{p} 180$ les Romains : les fondateurs de religions ont toujours abusé leurs fidèles, et il est bon que leurs fidèles se soient laissé abuser. A la politique d'utiliser ce moyen d'action que lui offre la psychologie des peuples. L'histoire antique et moderne enseigne que les plus incrédules n'y sont pas le moins sensibles: «Les Florentins, écrit Machiavel, ne sauraient passer pour ignorants ou grossiers. Et pourtant frère Jérôme Savonarole les persuada qu'il s'entretenait directement avec Dieu... Je ne veux pas juger si c'était à tort ou à raison, car d'un si grand homme on ne doit parler qu'avec révérence. Mais je puis dire que la foule y croyait, sans en avoir jamais vu aucune preuve extraordinaire ${ }^{\text {ccxxxi }} »$. - « Ne combattez jamais la religion, écrira bientôt plus résolument, mais en secret et pour lui-même, Guichardin ; ni rien de ce qui semble en rapport avec Dieu : car de tels objets ont trop de force sur l'esprit des sots ${ }^{\text {ccxxxii }}$. » Il sera donc toujours possible de provoquer et d'obtenir ces actes de foi collective. Beaucoup les ont obtenus, beaucoup les obtiendront encore, et personne ne doit désespérer d'imposer aux hommes des illusions contre lesquelles ils ne se défendent jamais bien. Inhumanité demeure à ce qu'elle fut dès les origines : " les hommes naquirent, vécurent et moururent toujours selon le même ordre et les mêmes lois éternelles ${ }^{\text {cxxxxiii }}$.

La solidité du pacte gouvernemental exige donc le maintien de la religion. Le moyen le plus sûr d'y pourvoir est de conserver intacts le culte et les pratiques: «Les États princiers ou républicains, s'ils ne veulent voir leurs institutions se corrompre, doivent avant tout garder de toute corruption les cérémonies ${ }_{\mathrm{p} 181}$ religieuses ${ }^{\text {ccxxxiv }}$. » Il faut protéger avec le plus de soin tout ce qui émeut le plus sûrement l'âme des peuples: le reste suivra naturellement. Dans l'antiquité grécoromaine, il se fût agi des sacrifices, de la divination, des oracles, des augures. Chez les peuples modernes et chrétiens, Machiavel entend la liturgie, les cérémonies, les observances pieuses, tout ce que la Ré- 
forme essaiera bientôt d'abolir ou de corriger. Tout ce qui saisit l'homme par les sens et l'imagination, le détourne de la réflexion critique ; tout ce qui encourage la foi au surnaturel, à la vertu des formules et des rites, l'attente du miracle, et l'invincible besoin de croire sans preuves. Augures et oracles, prophéties juives et chrétiennes, sacrifices païens et messe catholique, ont imposé aux hommes et leur imposeront longtemps un prestige qui s'explique par des lois constantes. Elles dispensent le politique d'entrer dans le détail des dogmes, qui appartient aux prêtres et aux théologiens. Mais il respectera toujours la religion, il affectera de la respecter, même sans y croire, parce que l'on peut seulement au nom de la religion contraindre les hommes aux sacrifices nécessaires, les plier sous une discipline de concorde et de vertu. Il ne reculera même pas, au besoin, devant l'imposture. Il devra d'autant mieux observer cette conduite qu'il sera plus prudent et mieux instruit des lois naturelles ${ }^{{ }^{c x x x x v}}$.

Machiavel n'admet donc et ne conçoit qu'une religion d'État, simple moyen de gouvernement, subordonné aux fins de l'État. Mais il a perdu le véritable sens de la vie religieuse. Il ne saurait admettre un instant qu'elle puisse avoir pour objet premier la perfection spirituelle de l'individu. Car l'individu ne compte à ses yeux que dans la mesure où il peut servir l'État, p182 comme législateur, comme magistrat, comme citoyen ou soldat. La religion à laquelle croit peut-être le secrétaire florentin, ne retient son attention que dans la mesure où elle plie l'individu à la discipline de l'État. Il ne la considère que de l'extérieur, et pour l'usage ; l'essence intime et profonde du christianisme, ou de toute religion, lui échappe, lui reste étrangère, ne l'intéresse pas. Il est bien l'élève des politiques et des juristes romains, qui, dans la diversité des formes religieuses, ont avant tout considéré l'avantage qu'en peut tirer l'art de gouverner les hommes : il est l'élève de Polybe, et, comme lui, s'applique à montrer l'usage que les Romains ont su faire, pour maintenir l'État, de la crédulité des foules. Il suffira de rappeler, dans les Discours, le titre du treizième chapitre du premier livre : «Comment les Romains se servaient de la religion pour rétablir l'ordre dans la cité, conduire leurs entreprises, mettre fin aux tumultes intérieurs ${ }^{\text {ccxxxvi }}$. " L'homme d'État se sert de la religion; il n'est pas nécessaire qu'il y croie ; mieux vaut même qu'il n'y croie pas. Et le chapitre XIV démontre comment les hommes de qui dépendait la politique de Rome savaient trouver des accommo- 
dements avec les auspices, même défavorables. Quand la raison leur démontrait la nécessité d'une entreprise, ils s'y engageaient sans hésitation, au besoin malgré les auspices. Mais ils savaient, en pareil cas, passer outre aux interdictions religieuses sans avoir l'air de négliger la religion; et ils ne manquaient pas de punir sévèrement quiconque en eût publiquement professé le mépris ${ }^{\text {ccxxxvii }}$.

Ainsi se développe la doctrine de Machiavel sur les rapports de l'État et de la religion. L'État a besoin de la religion et l'utilise pour assurer son propre maintien. Il en résulte que Machiavel ne consentirait jamais à séparer l'Église de l'État, qui a besoin d'elle parce qu'il ne peut se passer des services que lui rend la religion. Machiavel conserve l'Église traditionnelle; 183 assure aux prêtres le respect dû par les citoyens à leurs fonctions religieuses et à leur rôle social, les honneurs que l'État leur réserve parce qu'il veut être soutenu par un corps de prêtres. Machiavel garde intactes les croyances et les pratiques d'une religion d'État dont le sort est lié au sort de l'État. Conseiller de Trajan ou de Marc-Aurèle, il aurait approuvé les mesures de rigueur et de répression contre les chrétiens, dont la propagande religieuse et morale risquait d'affaiblir l'Empire. Il n'est pas loin de tenir, comme les politiques de la Contre-Réforme, l'unité religieuse pour un bien suprême, et de penser que la diversité de foi défigure et affaiblit un État. Dans les États modernes où le catholicisme, à la date où il écrit, conserve encore le privilège d'une religion professée par les détenteurs de l'autorité publique, Machiavel est partisan de maintenir le catholicisme, l'accord étroit et la collaboration étroite entre l'Église catholique et l'État. On ne concevrait pas à Florence une République hostile ou indifférente au culte romain; nul État italien ne pourrait ignorer le catholicisme et négliger le concours de l'Église catholique.

Mais de cet accord entre l'Église et l'État, il reste évident que l'Église doit faire les frais. Machiavel méprise la théologie ; il ne demande à l'Église que de renforcer la discipline morale, indispensable pour plier les individus au service de l'État. Il n'entend aucunement soumettre les intelligences à un régime de compression et de contrainte. L'Inquisition n'existe plus depuis longtemps en Italie, et la liberté de penser et d'écrire y est, pratiquement, très large. Il n'imaginerait pas volontiers une renaissance du Saint-Office, et de nouveaux procès d'hérésie. Rien ne lui eût aussi profondément déplu que la ContreRéforme catholique, telle qu'on la vit se développer en Italie après le 
rétablissement de l'Inquisition romaine, dans la seconde moitié du $\mathrm{XVI}^{\mathrm{e}}$ siècle. Sous un tel régime, il n'eût pu écrire ni le Prince, ni les Discours sur la première Décade de Tite-Live. Il se sert des prêtres, mais il ne les aime pas ; il méprise leur gouvernement, et ne leur permettrait pas volontiers de régenter la vie des esprits ${ }^{\text {ccxxxviii }}$. Il entend conserver intacte sa liberté intérieure. II reste fidèle aux traditions du gouvernement florentin, qui, très peu dévot, honorait la religion, s'appliquait 184 à la maintenir dans le peuple, mais exigeait du clergé la stricte obéissance aux lois, lui détendait au besoin d'obéir au pape lors des conflits du Saint-Siège avec la République, et, s'il arrivait que Rome l'eût frappée d'interdit, ordonnait aux prêtres de continuer le culte $^{\text {ccxxxix }}$. Si Machiavel ne veut pas que l'Église et l'État s'ignorent, c'est pour contraindre l'Église à le servir. L'État serait même en droit de marquer sa défaveur à certaines formes ascétiques et monacales du christianisme, et d'encourager une interprétation civique et stoïque de l'Évangile. Mais nul texte ne permet de préciser dans quelle mesure Machiavel autorise l'État à surveiller et contrôler l'enseignement moral et pratique de l'Église.

Si l'on veut définir la doctrine de Machiavel sur les rapports indispensables de l'Église et de l'État, elle se réduit aisément à l'idée d'une Église nationale, dépendante de l'État, liée à l'État, subordonnée aux fins de la politique nationale et à la défense des intérêts nationaux. Cette doctrine toute romaine et antique du rôle de la religion et du corps sacerdotal, de la collaboration de l'Église avec l'État, a joué un rôle capital dans l'histoire moderne. Elle se présentait si naturellement à l'esprit des législateurs que bien des gouvernements l'ont retrouvée sans s'être mis à l'école de Machiavel. Les juristes gallicans de la monarchie française l'ont conseillée aux rois, qui l'ont en somme le plus souvent pratiquée. Les États protestants, au XVI ${ }^{\mathrm{e}}$ siècle, l'ont suivie. Elle est devenue, dans le royaume de Prusse, un élément essentiel de la tradition politique des Hohenzollern. La plupart des États catholiques, au XVIII ${ }^{\mathrm{e}}$ siècle, l'ont trouvée commode, et s'y sont conformés. Le despotisme éclairé l'a fait entrer dans son système. Elle inspire en Autriche la politique religieuse de Joseph II, et cette subordination de l'Église à l'État qui porte dans l'histoire le nom de joséphisme. C'est d'elle ${ }_{\text {p185 }}$ également que Bonaparte s'inspire lorsqu'il conclut avec Pie VII une entente politique en vue d'une affaire politique: l'utilisation par l'État des forces de discipline dont dispose l'Église 
romaine, transformée, avec l'aveu du Saint-Siège, en un service administratif: "On dira que je suis papiste, déclare-t-il; je ne suis rien; j'ai été mahométan en Égypte ; je serai catholique ici pour le bien du peuple. Je ne crois pas aux religions ${ }^{c c x l}$. $\gg$ Ainsi Bonaparte retrouve naturellement, pour régler les rapports de l'Église et de l'État, la doctrine de Machiavel ; et suivant jusqu'au bout la pensée du Florentin, il dicte à l'Église gallicane le catéchisme civique et national qu'elle doit enseigner à ses fidèles. Mais il serait hasardeux de lire, entre les lignes des Discours sur la première Décade, les ordonnances religieuses de Joseph II ou le catéchisme impérial de 1806.

Table des matières

\section{II}

Telles sont, pour Machiavel, les bases essentielles d'un gouvernement civil. Un pacte constitutionnel, conservé dans un dépôt de lois, par un corps de magistrats investis en même temps de la mission politique d'un sénat conservateur; pacte dont l'appui le plus solide est la religion, et, qui, par suite, exige la présence et l'action d'un corps sacerdotal placé sous la tutelle et la surveillance de l'État. Ces données élémentaires, traduites clans le vocabulaire de l'histoire française, pourraient s'exprimer ainsi : Constitution, Parlements, Église gallicane, Concordat, Articles organiques. Il reste à définir ce que Machiavel entend par gouvernement civil.

Le caractère essentiel d'un tel gouvernement est d'assurer aux citoyens ce que Machiavel appelle la liberté ${ }^{\text {cxli }}$. Montesquieu affirme qu'aucun mot n'a reçu plus de différentes significations ${ }_{\mathrm{p} 186}$ ni frappé les esprits de tant de manières. Il y veut pourtant reconnaitre le pouvoir de faire tout ce que l'on doit vouloir, le droit de faire tout ce que les lois permettent, et de n'être pas contraint à faire ce que l'on ne doit pas vouloir ccxlii. Machiavel emploie ce mot sans se donner la peine de disserter sur une notion pour lui tout évidente. De préférence, il définit la liberté par ses effets. Le plus précieux est la sûreté ccxliii ; mais il n'a pas pris soin d'analyser un droit que les Constituants de 1789 ont déclaré naturel et imprescriptible ${ }^{\text {ccxliv }}$. Dominé par le souvenir des tyrannies antiques et modernes, il pense avant tout à la sécurité des per- 
sonnes et des biens, à la protection contre la violence et les confiscations ${ }^{c c x l v}$. Montesquieu et les Constituants ont, de préférence, recherché les garanties de l'individu contre les arrestations et les détentions arbitraires, la mise en pratique du principe anglais de " habeas corpus », formulé par la loi de $1679^{\text {cxxlvi }}$. La sûreté peut encore signifier le droit que la Déclaration ${ }_{\mathrm{p} 187}$ reconnaît au citoyen de n'être pas inquiété pour ses opinions, tant qu'à les manifester il ne trouble pas l'ordre public: d'où résulte le droit de communiquer librement sa pensée, de parler, écrire, imprimer librement, sauf à répondre de l'abus de cette liberté dans les cas prévus par la loi ${ }^{\text {ccxlvii. }}$. Machiavel n'a pas analysé ces notions juridiques, lentement élaborées au cours de deux révolutions anglaises, de la révolution américaine, de la révolution française. Il ne s'applique guère à défendre cette liberté de pensée et de parole qui pourtant lui est chère, et à la concilier avec les exigences d'une religion d'État, ou de la défense de l'État.

Mais la liberté n'est pas seulement la sûreté de l'individu et de ses biens matériels ou moraux. Elle est encore liberté politique. La plupart des hommes n'en portent nul souci, et ne souhaitent que sécurité ; seul un petit nombre aspire à la liberté politique, parce qu'il aspire à commander $^{\text {cxxlviii, }}$, entend contrôler le gouvernement, y participer. Reste à définir dans quelle mesure ce désir est légitime et mérite d'être satisfait ; à définir ce contrôle et cette participation, et dans quelle mesure on y peut admettre les citoyens. Machiavel n'a pas abordé ce problème. Il emploie volontiers le terme de liberté romaine ; il montre comment les luttes des plébéiens et des patriciens assurèrent à Rome une liberté qu'il définit surtout comme résistance à l'oppression ${ }^{\text {ccxlix }}$; il énumère les moyens qui, dans un ${ }_{\mathrm{p} 188}$ État républicain, permettent de maîtriser les ennemis de la liberté politique ${ }^{\text {ccl }}$. Mais il ne s'attarde guère à une analyse abstraite dont l'étude de l'histoire romaine l'a dispensé. Il conçoit cette liberté comme la pratiquait, entre la défaite d'Hannibal et les Gracques, la république romaine ccli. Il exigerait, comme les citoyens ou villes antiques, le droit de n'obéir qu'à des magistrats librement élus, et à des lois librement discutées et votées dans de libres assemblées, selon les termes de la constitution. Il s'en tient à la notion antique, gréco-romaine, telle que Fustel de Coulanges la formule : jouir de droits politiques, voter aux assemblées, élire des magistrats, pouvoir être élu magistrat ${ }^{\text {clii }}$; ou telle encore qu'Aristote, en quatre mots, l'avait résumée : participer au droit de juger et de 
commander $^{\text {ccliii }}$. Il y ajouterait probablement celui de consentir l'impôt. Mais il n'a jamais fait le départ entre la franchise, accordée par la constitution à tel ou tel groupe de citoyens, et les droits qui naturellement doivent appartenir à tous. Sa religion de l'État souverain ne lui permet ni d'exprimer ni même de concevoir l'idée de souveraineté du peuple : comme le citoyen antique, le citoyen selon Machiavel demeure asservi à l'État ${ }^{\text {clliv }}$. Aussi ne prend-il pas la peine d'examiner dans quelles limites le peuple peut contribuer à la création de la loi. On chercherait en vain chez lui une critique des subterfuges qui, dans le p189 monde antique ou les démocraties modernes d'Italie, réduisaient en pratique, pour les hommes des classes inférieures, le droit d'élire et de voter. Au fond, il reste un aristocrate, ou du moins persuadé que tous ne sont pas également capables de comprendre et de défendre au besoin les intérêts de l'État, qui seuls importent. La liberté politique n'est et ne peut être qu'une liberté inégale.

Machiavel s'entendrait avec les Constituants pour reconnaître dans la propriété un droit inviolable et sacré ${ }^{\text {cclv }}$. Il n'a rien de commun avec les Franciscains spirituels ni avec les Taborites. La critique socialiste, dans la mesure où quelques pages de l'Utopie en offrent l'ébauche, lui demeure absolument étrangère. Tout régime civil repose nécessairement sur le respect de la propriété. Sous la République, sous les empereurs fidèles au pacte constitutionnel, les citoyens romains ne furent pas troublés dans la possession de leurs biens ${ }^{\text {cclvi }}$. Dans une monarchie moderne qui a, comme la française, une constitution, si le roi dispose à sa guise de la force armée et des impôts, la fortune des sujets reste sous la garantie des lois ${ }^{\text {cclvii }}$.

Mais le secrétaire florentin ne s'attarde guère à discuter des principes. Il pense en historien plutôt qu'en juriste, et plus volontiers cite des faits concrets. C'est par opposition à certains procédés de tyrannie qu'il définit l'indispensable sûreté. Quand, au chapitre X du livre I, il condamne en quelques lignes le mauvais gouvernement des Césars, il montre par contraste les biens dont Rome a joui sous la République sénatoriale et consulaire, ou sous les empereurs qui, de Nerva à MarcAurèle, ont respecté les principes républicains. Ces biens, qui se résument en un mot, la sûreté des citoyens, sont essentiellement des libertés : liberté individuelle, libre disposition laissée à chacun de sa fortune ${ }^{\text {cclviii. }}$. Maintenues aussi longtemps que les assemblées et les magistratures conservèrent leur pouvoir légal, ces libertés et les garan- 
ties constitutionnelles de ces libertés ont été détruites par César ${ }^{\text {cclix }}$. Dans les temps modernes, ces libertés et ces p190 garanties sont ignorées des tyrans qui règnent à Milan ou à Naples; aussi ces pays ne se prêtèrent jamais â la création d'un régime civil. La noblesse féodale méprise ces libertés; partout où elle existe, on ne pourra créer ou maintenir un régime civil ${ }^{\mathrm{cclx}}$.

Il serait vain de décrire un idéal de gouvernement sans poser certaines questions de caractère social. Machiavel ne demande jamais à l'économie, qu'il dédaigne et qu'il ignore, une interprétation de la politique. Il ne saurait « discourir ni de l'art de la laine, ni de l'art de la soie, ni des gains ou des pertes des marchands ${ }^{\text {cclxi }}$ ». Il ne connaît pas les questions de prix ou de salaires; les luttes des classes florentines lui échappent; il sait mal les questions de finance ou de banque, si importantes dans l'histoire des villes italiennes, de Gênes, de Florence. Théoricien et praticien de la politique, son information médiocre en économie ne lui permet pas de démêler exactement le jeu des forces occultes qui interviennent de façon obscure et souvent décisive dans l'histoire politique des États. Pourtant, il discerne, entre les formes politiques et les caractères de la société, quelques rapports nécessaires.

Un régime civil, et plus particulièrement un État républicain, exige une certaine égalité sociale ${ }^{\text {cclxii }}$. Montesquieu pareillement démontrera que la vertu sur laquelle repose une démocratie est l'amour de l'égalité et de la frugalité : "L'amour de la frugalité, dit-il, borne le désir d'avoir à l'attention que demande le nécessaire pour sa famille, et même le superflu pour sa patrie ${ }^{\text {cclxiii }} \gg$. Il montre comment les lois doivent entretenir la ${ }_{\mathrm{p} 191}$ frugalité dans la démocratie par l'égalité et la médiocrité des fortunes. Pourtant il admet comme compatible avec la démocratie l'existence d'une classe commerçante, même riche, à condition qu'elle reste laborieuse et ordonnée. Machiavel, sur ce point, annonce Montesquieu, et les chapitres III-VI du livre V de l'Esprit des Lois offrent le commentaire exact de sa pensée. Sans doute l'existence d'un État libre n'est pas compatible avec celle d'une classe de gentilshommes possesseurs de seigneuries et de droits féodaux. Sans doute serait-il à souhaiter que, dans une république bien ordonnée, l'État fut riche et le citoyen pauvre ${ }^{\text {cclxiv }}$. Machiavel ne 
s'arrête pas à cet idéal primitif et lacédémonien, qui ne s'accorde ni avec le progrès de l'économie ni avec l'évolution sociale. Pratiquement, il admet l'inégalité, créée par l'histoire, du peuple gras et du peuple maigre, de la bourgeoisie industrielle et commerciale et des petits artisans. L'égalité qui lui importe, et qui reste essentielle à un gouvernement libre, est cette égalité bourgeoise qu'il faut maintenir à l'intérieur de la classe dirigeante. Égalité qui n'exclut pas la différence des fortunes, créées avec un succès différent dans l'industrie, le commerce ou la finance, comme à Florence, Venise ou Gênes ${ }^{\text {cclxv }}$. Mais ces fortunes sont de même origine ; elles appartiennent à un patriciat bourgeois dont les membres se surveillent les uns les autres et ne permettent pas volontiers que l'un s'élève au-dessus des autres; l'habitude du travail y entretient un certain esprit de modération et de simplicité. Une république bourgeoise risque de se perdre, quand une de ces familles patriciennes, élevée au-dessus de sa classe par l'acquisition d'une fortune princière, conçoit un esprit nouveau d'ambition p192 princière. Tel fut le cas des Médicis. Et Montesquieu devine et dégage la pensée que Machiavel lui suggéra : "Lorsque la démocratie est fondée sur le commerce, il peut fort bien arriver que des particuliers y aient de grandes richesses, et que les mœurs n'y soient pas corrompues. C'est que l'esprit de commerce entraîne avec soi celui de frugalité, d'économie, de modération, de travail, de sagesse, de tranquillité, d'ordre et de règle. Ainsi, tandis que cet esprit subsiste, les richesses qu'il produit n'ont aucun mauvais effet. Le mal arrive lorsque l'excès des richesses détruit cet esprit de commerce. On voit tout à coup naître les désordres de l'inégalité, qui ne s'était pas encore fait sentir ${ }^{\text {clkvi }}$.»

Montesquieu, poursuivant l'analyse de Machiavel, a mieux défini la mesure d'égalité sociale que le secrétaire florentin juge nécessaire dans un État librement gouverné. Le problème est d'empêcher l'apparition d'une classe d'hommes élevés par leur opulence audessus de la loi. Mais la notion d'égalité républicaine et civile reste chez lui très élastique, et, dans la pratique, il n'est pas partisan d'un effort pour réduire au même niveau toutes les fortunes.

Telle serait, sans doute, la base idéale d'une république stable et d'un État bien ordonné. Mais si cette base manque depuis l'origine, on 
ne doit pas en tenter une restauration artificielle. Car on ne peut remonter le cours de l'histoire. Machiavel consacre un long chapitre à démontrer que si, dans une république, une loi tend à rétablir un passé trop lointain, et contredit un état de choses établi par un trop ancien usage, il n'en peut résulter que trouble et scandale ${ }^{\text {cclxvii }}$. La loi agraire, à Rome, n'était pas injuste en soi. Mais elle rompait une sorte de prescription depuis toujours admise. Elle offensait une classe puissante qui, défendant ses avantages, pouvait se donner l'apparence de défendre l'intérêt public. Les hommes tiennent plus aux biens p193 qu'aux honneurs ${ }^{\text {cclxviii }}$. La noblesse avait cédé, devant les revendications plébéiennes, sur le partage des magistratures. Lorsqu'il s'agit des terres, elle refusa tout partage avec une obstination acharnée. La loi agraire créa donc à Rome un état permanent de guerre civile. Elle provoqua le soulèvement de la plèbe, le triomphe plébéien de Marius, la réaction aristocratique de Sylla; Pompée continua Sylla, César continua Marius ; et, vainqueur, fut le premier tyran de Rome : ainsi périt la république ${ }^{\text {cclxix }}$. Machiavel n'a pas voulu recueillir, contre les Gracques, la tradition d'insulte qui remonte à Cicéron. Responsables, sans doute, du siècle de troubles qui naquit de la loi agraire et aboutit à la ruine de la liberté ; mais leurs intentions étaient pures. Ils manquèrent de prudence : car nul projet n'est plus dangereux que d'entreprendre la correction d'abus invétérés ${ }^{\text {cclxx }}$. On risque d'aggraver les effets du mal que l'on voulait combattre; et, comme les Gracques pour la crise agraire, de le rendre irrémédiable. Ainsi Machiavel se montre singulièrement prudent, conservateur en matière sociale, ennemi des révolutions, convaincu, par l'exemple de l'histoire grecque et romaine, par l'exemple des cités médiévales, qu'elles aboutissent le plus souvent à la tyrannie et à la ruine des libertés.

$\underline{\text { Table des matières }}$

\section{III}

Machiavel ne place pourtant pas l'idéal d'un gouvernement civil dans l'immobilité et la quiétude. Une cité qui vit politiquement, où les citoyens maintiennent et cultivent, toujours agissantes, les vertus civiques, ne s'accommode pas du silence ${ }_{\mathrm{p} 194}$ où s'endorment les cités corrompues ${ }^{\text {cclxxi }}$. C'est pourquoi Machiavel préfère, à l'ordre muet 
qu'imposent les monarchies, le régime populaire avec ses risques de tumulte. Comme toujours, la république romaine lui offre l'image idéale et pourtant vraie d'un peuple soumis librement à la loi, éloigné de l'orgueil insolent et de l'obéissance servile ${ }^{\text {cclxxii }}$, maître de ses destinées, apte à décider et à commander, toujours respectueux du pacte constitutionnel ${ }^{\text {clxxiii }}$. A un gouvernement populaire du type romain, il attribue plus de stabilité politique, plus de constance, plus de sagesse prudente qu'à une monarchie ${ }^{\text {ccxxiv }}$. Il voit le peuple affranchi des passions qui égarent soudain la conduite des despotes : capable d'élire ses magistrats avec plus de soin et de jugement que les princes ne choisissent leurs conseillers et leurs ministres ${ }^{\text {cclxxv }}$. Une république ordonnée selon le modèle romain grandit plus vite qu'un État princier ${ }^{\text {cllxxvi }}$; si un prince peut mieux achever l'organisation d'un État, un gouvernement démocratique saura la conserver plus longtemps ${ }^{\text {cclxxvii }}$. Car il échappe ${ }_{\mathrm{p} 195}$ aux causes de ruine qui menacent les régimes personnels. Ses pires violences n'atteignent que des ennemis présumés du public; celles d'un prince ont pour objet de satisfaire ses haines privées ${ }^{\text {cclxxviii }}$. On peut trouver des remèdes à la licence populaire ; contre un prince criminel il n'existe d'autre recours que le poignard ${ }^{\text {cclxxix }}$. Ainsi l'exemple de Rome démontre que la liberté politique n'exclut ni la grandeur ni la puissance ${ }^{\text {cclxxx }}$.

Il démontre également la nécessité et la bienfaisance des luttes politiques, qui mettent aux prises de grands partis, organisés pour la défense de certains principes de droit et de certains intérêts de classe. Les conflits de la plèbe et du Sénat eurent cet effet salutaire de couper court, de part et d'autre, à tout effort d'empiétement et d'usurpation, de contraindre plèbe et Sénat au respect du pacte constitutionnel, d'assurer le triomphe de la liberté cclxxxi. Quand une république aspire à la grandeur et à la puissance, et que, pour fonder son empire il lui faut entretenir un peuple nombreux et habitué aux armes, elle doit se résigner, comme la République romaine, à une vie tumultueuse, et s'en accommoder ${ }^{\text {cclxxxii }}$. Seul un État sans force intérieure et sans ambition peut se promettre un calme que rien ne trouble. Mais les agitations d'un peuple libre portent rarement préjudice à la liberté : elles naissent du fait ou de la seule crainte de l'oppression ${ }^{\text {cllxxxiii }}$.p196

Ainsi les partis sont indispensables à la vie et même au salut de l'État. Mais le secrétaire florentin condamne la faction, créée par un homme et pour un homme, et dont le but unique est de porter un 
homme au pouvoir et de partager avec lui les avantages du pouvoir. Dans l'histoire romaine, l'usurpation de César, comme celle de Sylla, est le triomphe de la faction ${ }^{\text {cllxxxiv }}$. Dans l'histoire récente de Florence, l'usurpation médicéenne est le triomphe d'une faction. Or tout ce qui se fait par voie illégale, en dehors du pacte constitutionnel, contre le pacte constitutionnel, détruit l'esprit d'un régime civil.

$* * *$

Il faut que tout gouvernement légal, soucieux de son maintien, de son prestige et de sa grandeur, sache utiliser et susciter l'effort et le dévouement des citoyens. Machiavel veut que l'État provoque l'émulation à l'aide de récompenses, mais sans jamais négliger de punir les manquements au devoir. Moins ingrats que les Athéniens envers les bons serviteurs de l'État, les Romains nous offrent l'exemple à suivre. Les gouvernements populaires en général pratiquent mieux la reconnaissance que les gouvernements princiers. Les citoyens, de leur côté, dans leurs efforts pour le service de l'État, doivent s'imposer une discipline d'obéissance et d'effacement volontaire. Qui a rempli les plus hautes charges ne doit pas se croire humilié si l'État, par la suite, lui en confère de plus modestes. La république de Venise et les royaumes modernes ont tort de tenir compte de cette vanité. Si, à Rome, les anciens consuls n'avaient accepté de servir l'État qu'à titre de consuls, si la cité ne leur avait imposé l'obligation de rentrer dans le rang et d'accepter les fonctions plus modestes qu'elle leur confiait, elle aurait supprima l'une des plus essentielles garanties de la liberté ${ }^{\text {cllxxxv }}$.

Plus activement encore, l'État doit pourvoir à sa défense contre les ennemis intérieurs. Instruit par la faiblesse de Soderini, qui croyait, à force de patience et de mansuétude, réconcilier ${ }_{\mathrm{p} 197}$ les partisans des Médicis avec la république, Machiavel refuse d'épargner les fils de Brutus ${ }^{\text {cclxxxvi }}$. Mais plus que les complots à main armée, il redoute les lents progrès d'une usurpation pacifique et masquée. Il sait que sous le couvert d'œuvres entreprises dans l'intérêt commun se cachent souvent les premières démarches d'un candidat à la tyrannie ${ }^{\text {cclxxxvii }}$. Il sait que pour réfréner, comme il dit, l'insolence d'un homme puissant, le moyen le plus sûr consiste à lui enlever sans bruit sa clientèle et par là ses moyens de nuire cclxxxviii. Si les adversaires de Cosme, en 1434, avaient imité sa manière et capté comme lui la bienveillance du peu- 
ple, ils seraient arrivés sans violence à paralyser son intrigue. Mais lorsqu'un citoyen devient évidemment dangereux, Machiavel pose en principe que l'État ne doit pas rester désarmé. La constitution doit prévoir le moyen d'agir pour le défendre; elle doit prévoir la mise en accusation des citoyens trop ambitieux ou mal respectueux de la loi. Machiavel consacre tout un chapitre à démontrer combien sont nécessaires, dans une république, les mises en accusation pour maintenir la liberté. Il cite l'exemple de l'histoire romaine, et du rôle joué, à cet égard, par les tribuns cclxxxix. Il affirme, de la sorte, la nécessité d'une juridiction spéciale chargée d'enquête sur les délits d'ordre politique, les attentats commis ou simplement préparés contre les libertés publiques ou les lois constitutionnelles. Juridiction qu'il ne définit pas, et qui peut correspondre à une Haute Cour, ou, en cas de danger suprême, à un Tribunal révolutionnaire. Dans les États où cette institution manque ou se montre inefficace, il ne reste, pour arrêter les entreprises des aventuriers de la politique, que ${ }_{\mathrm{p} 198}$ le soulèvement populaire. Or il ne faut rien éviter avec plus de soin que l'intervention armée du peuple en un domaine qui appartient à la loi ${ }^{\text {ccxc }}$.

Toutefois, avant de conseiller le recours à ces juridictions suprêmes, Machiavel hésite. Car rien ne serait désastreux pour l'État comme de voir leurs sentences méprisées. Or il arrive souvent qu'on invoque trop tard leur intervention, et lorsque le mal est déjà sans remède. Cosme était déjà trop puissant lorsque ses adversaires obtinrent contre lui une sentence d'exil pourtant justifiée. Cette sentence ne fit qu'exaspérer son parti, qui bientôt reprit assez d'audace pour en imposer l'annulation, et lui réserver un retour triomphal. Degré de puissance où il ne serait jamais monté, sans l'inopportunité d'une accusation tardive. De même tous les efforts tentés pour défendre légalement contre César la constitution et la liberté ne firent que hâter la ruine de la république. Et Machiavel, comme toujours, conseille la prudence. Il faut bien considérer la puissance du mal qui menace l'État. Si les manœuvres d'un aventurier ne sont pas assez redoutables pour mettre en échec la loi et la constitution, il faut, sur-le-champ, agir. Sinon, plutôt que de s'exposer à voir la loi méprisée, ou de risquer le hasard d'une intervention illégale des forces populaires, mieux vaut temporiser. Souvent, si l'on peut gagner du temps, le mal, de lui-même, se détruit, ou du moins retarde longtemps ses effets, par là même affaiblis ${ }^{\text {ccxci }}$. Ainsi se développe l'opportunisme de Machiavel. 
$\underline{\text { Table des matières }}$

IV

Pour résister à toutes les causes de corruption qui le menacent, un gouvernement libre a souvent besoin de se réformer. Machiavel avait l'intention de consacrer à cette question de la réforme des États, en prenant pour type la république romaine, ${ }_{\text {p199 }}$ le troisième livre de ses Discours ; il ne l'y traita qu'en passant ${ }^{\text {cxxcii }}$. Réforme, mais non révolution: le secrétaire florentin est essentiellement modéré, conservateur, ennemi de tout appel à des forces mal disciplinées. Cette réforme est le chef-d'œuvre de l'art politique ; elle exige une longue étude. On peut introduire, dans le corps des lois constitutionnelles, quelques éléments nouveaux, mieux adaptés aux circonstances, aux conditions nouvelles de l'État et de la société : Machiavel n'écarte pas et ne peut pas écarter cet enrichissement. Les politiques florentins ont, à mainte reprise, jugé utile, pour réformer la république, d'emprunter quelques idées à la constitution de Venise, et Machiavel ne les en a pas désapprouvés ${ }^{\text {cxciii }}$. De préférence, il veut qu'on supprime plutôt que d'ajouter, qu'on élague plutôt que de greffer, et que l'on conserve, au moins en apparence, l'esprit des institutions anciennes ${ }^{\text {ccxciv }}$. Car la réforme de l'État, comme la réforme de l'Église, exige le retour à la pureté des institutions primitives ${ }^{\text {ccxcv }}$ : «Si notre religion, dit-il, n'avait pas été ramenée à son principe par les deux fondateurs des ordres mendiants, saint François et saint Dominique, elle serait complètement éteinte. C'est grâce à eux que la malhonnêteté des prélats et des chefs de la religion ne l'ont pas ruinée. ${ }^{\text {ccxcvi }}$. De même convientil d'agir dans le temporel. p200

On entrevoit ici l'ébauche d'une politique traditionaliste. Chaque État s'est constitué selon un certain nombre de principes, qui forment l'esprit de ses lois. Cet esprit, lente création de l'histoire, exprime sans doute la nature profonde de cet État et ses tendances essentielles. Les hommes responsables de son gouvernement doivent ne rien laisser 
perdre de cet esprit, ne rien introduire dans le corps des lois qui ne soit accordé à cet esprit, amender et corriger tout ce qui est venu l'y fausser. Cette conception et cette règle, Montesquieu les a retenues, et les résume en une formule qui, très exactement, rappelle le texte de Machiavel : "Quand une république est corrompue, on ne peut remédier à aucun des maux qui naissent qu'en ôtant la corruption et en rappelant les principes. Tout autre correction est ou inutile, ou un nouveau mal. » ${ }^{\text {cxxcvii }}$.

Le soin nécessaire de veiller sur la constitution et de la réformer selon l'esprit de ses principes était confié, par la loi romaine, aux tribuns et aux censeurs. Les modernes peuvent l'attribuer à certains magistrats, ou à certains corps à la fois judiciaires et politiques, comme sont en France les Parlements : le secrétaire florentin s'entendrait aisément sur ce point avec toute une école française et avec Montesquieu. Mais il admet aussi, conformément à l'exemple classique de Rome, l'action d'un dictateur. Machiavel, qui étudie en historien le rôle de la dictature, constate qu'elle rendit à la république romaine les plus grands services : "Quand une république, dit-il, est menacée de corruption, il faut que, par respect de la légalité, elle coure à sa ruine, ou que, pour se sauver, elle rompe l'ordre légal. Je conclus que les républiques, qui, dans des périls urgents, n'ont pas recours à la dictature ou à quelque autorité du même genre, se perdent infailliblement. » ${ }^{\text {ccxcviii }}$.p201

$$
* * *
$$

Le dictateur, à qui Machiavel confie volontiers la réforme d'un gouvernement républicain, n'a rien de commun avec le tyran. La dictature est une magistrature républicaine, prévue par la constitution, inscrite dans la constitution. Le dictateur ne se nomme pas lui-même : il est désigné régulièrement par les autorités régulières. Sans doute, le pouvoir dont il se trouve revêtu, pendant la durée de sa charge, est absolu, et l'exercice de ce pouvoir suspend ce que les modernes nommeront les garanties constitutionnelles. Mais cette suspension est légale ; elle a été prévue ; elle est autorisée par la constitution. Les magistratures et les assemblées subsistent, quoique inactives ; et leur permanence oblige le dictateur au respect des lois. Enfin, il ne dispose que d'une autorité provisoire, limitée à l'accomplissement d'une tâche définie, qui, dans la pensée de Machiavel, doit être avant tout la restau- 
ration de l'État. Son œuvre terminée, le dictateur rétablit les libertés politiques et rentre dans les rangs des citoyens ${ }^{\text {cxcix }}$.

Ainsi Machiavel, toujours instruit par l'histoire romaine, conçoit la dictature comme la permettait et la pratiquait la République sénatoriale et consulaire. Le dictateur, pour Machiavel, est Camille, Cincinnatus, Q. Fabius Maximus. Ce n'est pas Sylla ; ce n'est pas César. Machiavel ne reconnaît pas le dictateur, magistrat régulier de la République, dans le partisan venu du monde politique ou des armées, qui, par la force d'une faction victorieuse, s'empare et s'investit d'une mission de salut ${ }_{\mathrm{p} 202}$ public. Même si les intentions sont bonnes, le moyen reste condamnable et d'effet pernicieux : car le pouvoir personnel suffirait à gâter un État sain ${ }^{\text {ccc }}$. Contre les entreprises de cette sorte d'hommes, une juridiction supérieure, Haute Cour ou Tribunal révolutionnaire, doit protéger la liberté ${ }^{\text {ccci }}$.

Table des matières

Le gouvernement civil, dont les Discours ont défini l'idéal, présente le caractère d'une république, sur le type de la Rome consulaire et sénatoriale ou de la cité florentine. Pourtant Machiavel n'écarte pas l'idée de ce que Montesquieu appellera une monarchie bien réglée ${ }^{\text {cccii }}$. Au cœur même du livre du Prince, après deux chapitres consacrés à la théorie des usurpations violentes, se développe un chapitre sur la fondation d'un principat civil ${ }^{\text {cciiii }}$.

Machiavel entreprend l'étude d'un fait capital. Il a déjà laissé entendre que, dans une république menacée d'une crise mortelle par des conflits sociaux, la seule réforme efficace doit consister non pas à satisfaire davantage la passion populaire, mais à corriger les lois selon le type monarchique ${ }^{\text {cciv }}$; il a reconnu qu'un tel effort semble exiger le plus souvent l'action extraordinaire ${ }_{\mathrm{p} 203}$ et violente d'un homme ${ }^{\mathrm{cccv}}$. Pourtant, il persiste à la vouloir écarter. Il recherche comment un État républicain, sans violence ni recours aux armes, sans l'intervention illégale et brutale d'une faction, mais avec le consentement général, peut réviser sa constitution en faveur d'un citoyen qui reçoit légale- 
ment le titre de prince. Un problème politique et historique se trouve ainsi posé : celui du passage légal de la république à la monarchie, dans un pays qui n'a jamais connu que la forme républicaine; ou, dans un pays qui, après avoir été constitué en monarchie, s'est donné un régime républicain, le problème de la restauration légale de la monarchie. Si l'on cherche des exemples dans l'histoire, il n'est pas fort aisé d'en trouver du premier cas, et tous les faits qu'on pourrait alléguer, soit dans l'antiquité classique, soit dans l'antiquité juive, appartiennent plus ou moins à la légende. En revanche les exemples du second cas se présentent en foule à l'esprit. Il suffit de citer la restauration des Stuarts deux ans après la mort de Cromwell, ou les diverses tentatives légales de restauration qui se sont produites en France, soit à l'époque du Directoire, après les élections de 1797, soit dans les premiers temps de la troisième République. Encore faut-il, pour se placer dans l'hypothèse étudiée par Machiavel, éliminer tous les cas de restauration monarchique réalisée par d'autres moyens que le suffrage des assemblées, soit avec le concours d'une faction disposant de la force militaire, soit avec l'appui militaire de l'étranger. Ce qui écarte, dans l'histoire ancienne, la restauration de la monarchie à Rome en faveur de César, et, dans les temps modernes, le 18 Brumaire, ou le 2 décembre, ou les deux restaurations des Bourbons en 1814 et en 1815.

Telle est la question à étudier. Machiavel en définit correctement les termes. Il commence par décrire les conditions dans lesquelles peut se produire soit un passage légal de la République ${ }_{\mathrm{p} 204}$ à la monarchie, soit une restauration de la monarchie. Il énonce le fait de la lutte des classes, évident même pour un historien de formation spiritualiste et classique. Il ne les formule naturellement pas dans ce langage marxiste que Thomas More, un jour, a semblé pressentir, pour donner de l'État une définition ironique et négative, mais à l'aide du vocabulaire banal et imprécis que l'humanisme a hérité de Tite-Live : «Dans toute cité, dit-il, le peuple désire n'être ni commandé ni opprimé par les grands, et les grands désirent commander au peuple et l'opprimer. " ${ }^{\text {ccvi }}$. Puisque ce fait essentiel domine toute l'histoire politique, Machiavel ne voit que trois solutions possibles : ou un gouvernement libéral, qui accorde en un heureux équilibre les intérêts et les aspirations des deux classes rivales; ou un gouvernement auprès duquel prévalent les intérêts et les passions populaires, et qui prend fatalement un caractère démagogique ; ou une monarchie autoritaire, 
alors instituée ou restaurée, et capable de tenir en respect l'une et l'autre classes ${ }^{\text {cccvii. }}$.

Cette fondation ou cette restauration ne peuvent pourtant se faire qu'avec l'appui de l'une ou de l'autre. Le nouveau prince s'élève au pouvoir suprême par la force du peuple ou des grands. Ou bien l'aristocratie, menacée par le progrès des éléments populaires, s'adresse à l'un des siens, et, pour défendre ses intérêts de classe, le porte au principat. Ou bien le peuple, opprimé par l'aristocratie, se donne un prince afin d'être défendu. Dans l'un et l'autre cas, tout se passe légalement, en vertu d'un vote régulier des assemblées, que la majorité y appartienne à l'aristocratie ou aux éléments populaires. Le candidat au pouvoir, en pareil cas, n'a nul besoin de génie ; la chance et l'habileté politicienne suffisent ${ }^{\text {cccviii }}$. p205

Mais l'étude de Machiavel reste toute scolastique. Ici encore son enquête est sommaire à l'excès. Il a été visiblement embarrassé pour trouver, dans le passé comme dans les temps modernes, des exemples historiques. Un seul cas est retenu : il manque d'éclat, et Machiavel n'insiste guère. Il rappelle comment Nabis, roi de Sparte au début du second siècle, put obtenir, avec l'aide du parti populaire et sans violence, que la constitution révisée lui accordât une autorité absolue ; il assura de la sorte, pendant quelques années, la défense de la Grèce contre Rome ${ }^{\text {cccix }}$. Cet exemple, encore une fois tiré de Tite-Live, ne répond à l'hypothèse examinée que si l'on assimile les deux rois de Sparte, contrôlés par les éphores et les assemblées, à des magistrats républicains ; le problème constitutionnel posé par l'aventure de $\mathrm{Na}$ bis reste celui du passage d'une dyarchie impuissante à une monarchie autoritaire. En fait, il ne dut pas son pouvoir à la seule persuasion, au seul consentement des assemblées; il avait fait appel à la force des éléments prolétariens et même serviles ; à la force militaire d'une petite troupe d'aventuriers fanatisés. Enfin la violence révolutionnaire de l'œuvre qu'il accomplit, une fois maître de Sparte, l'apparente beaucoup moins aux fondateurs ou aux restaurateurs de monarchies régulières et civiles, qu'à ces dictateurs révolutionnaires qui, en possession des pleins pouvoirs, renouvellent tout l'ancien ordre politique et social, et font table rase du passé. On le vit abolir les dettes, redistribuer les terres, confisquer les capitaux, affranchir les esclaves, entreprendre et réaliser tout un programme de révolution sociale. Par là Nabis, roi de Sparte, apparaît comme un aventurier de la politique et de la guer- 
re, élevé à l'autorité suprême grâce aux factions populaires et par la force des armes, et qui, sûr de ces appuis, s'engage dans une politique d'action hardie et violente. Son cas, malgré la supériorité présumée de son talent, reste banal. Il suffit de rouvrir Fustel de Coulanges: « Lorsque l'aristocratie devint maîtresse, le peuple ne se borna pas à regretter la monarchie ; il aspira à la ${ }_{\mathrm{p} 206}$ restaurer sous une forme nouvelle... Il réussit généralement à se donner des chefs. Ne pouvant les appeler rois, ... il les appela tyrans... Partout ces tyrans, avec plus ou moins de violence, avaient la même politique... Leur règle de conduite était de frapper l'aristocratie en s'appuyant sur le peuple. » ${ }^{\text {cccx }}$. Mais par là, Nabis, roi ou plutôt tyran de Sparte, aurait plus exactement trouvé son rang parmi les factieux et les usurpateurs.

Machiavel n'emprunte aucun exemple à l'histoire récente de 1'Italie. Partout, en effet, où la vieille commune avait cédé la place à un gouvernement personnel, le passage d'un régime à l'autre avait été violent ; les factions et la force armée avaient joué un rôle capital. Il semble toutefois que, par moment, tandis qu'il écrivait ce chapitre, Machiavel ait pensé aux Médicis, dont pourtant il s'interdisait de citer les noms, dont il ne pouvait citer les noms. L'habileté politicienne et fortunée peut assez bien définir la politique de Cosme ou de Laurent. Mais en réalité, les Médicis n'avaient pas davantage à intervenir dans ce débat. En apparence, ils avaient respecté les formes extérieures de la légalité. Mais ils n'avaient grandi qu'avec l'aide d'une faction, qui, riche de toutes les ressources d'une des plus puissantes banques de l'Europe, s'était installée à tous les postes d'où elle pouvait commander les assemblées et les magistratures. Faction populaire, démagogique, hostile à l'étroite aristocratie qui, légalement, gouvernait la cité. Et la force n'était jamais loin, toujours prête à menacer ou à punir. Toutes les retouches apportées par Laurent à la constitution, et qui, de plus en plus, resserraient le pouvoir en un petit nombre de mains, n'avaient jamais été obtenues que sous la pression de la force, dissimulée, toujours présente. De la sorte, l'étude de l'œuvre politique des Médicis, étude que Machiavel n'a d'ailleurs pas voulu esquisser, trouvait naturellement place non au chapitre de la fondation ou de la restauration légale de la monarchie, mais au chapitre des usurpations.

$$
* * *
$$


On peut donc passer assez vite sur les réflexions et maximes que l'étude, en réalité tout abstraite et scolastique de la question posée, inspire à Machiavel. Comme il a distingué les deux cas où le nouveau prince doit son élévation à l'aristocratie ou p207 au peuple, il se demande dans lequel l'œuvre de fondation ou de restauration est la plus solide, et comment, dans l'un et dans l'autre, le nouveau prince doit se comporter.

Bien qu'il n'en donne pas d'exemple historique, il juge qu'une restauration ou une fondation accomplie avec l'aide de l'aristocratie a peu de chance de durée : "Celui qui s'élève au principat avec l'aide des grands, se maintient plus difficilement que celui qui s'y élève au moyen du peuple. » ${ }^{\text {cccxi }}$. On peut en déduire que les restaurations conservatrices, accomplies à l'aide des notables, ont moins de chances de succès et de durée que les tyrannies démagogiques. Toute restauration de caractère conservateur est nécessairement précaire. Le prince, en pareil cas, se maintient avec peine ; il a contre lui toute la masse du peuple, et les grands qui l'ont porté au pouvoir prétendent être ses égaux et lui imposer leurs conditions ; il lui est difficile de les commander et de les manier à sa guise. Au contraire, l'histoire démontre qu'un prince, arrivé au pouvoir par le suffrage du peuple, se maintient longtemps et crée un État durable. Il est seul ; il n'a pas, autour de lui, un groupe de puissants personnages, prêts à lui reprocher les services rendus et à le trahir. Appuyé sur la force plébéienne, il réduit sans peine un petit nombre d'aristocrates malveillants. Il satisfait plus aisément ceux qui l'ont porté au pouvoir. Car le peuple est moins exigeant qu'une aristocratie : il se contente de peu, tandis qu'elle n'est jamais satisfaite. Enfin, on peut le satisfaire en commettant moins d'injustices. Machiavel, peu favorable à la noblesse, reste fidèle aux traditions démocratiques et républicaines de Florence. Dans le conflit qui met aux prises le peuple et les aristocrates, dans cette lutte de classes qu'il a sommairement définie, Machiavel, qui est de la bourgeoisie, prend parti pour le peuple : «Les revendications populaires, dit-il, sont plus honnêtes que les ambitions des grands. Ils veulent opprimer, et le peuple veut échapper à l'oppression. »" ${ }^{\text {cccxii }}$.

Des faits ainsi constatés Machiavel dégage quelques règles de conduite. Un prince qui obtient le pouvoir avec l'appui du peuple doit naturellement en cultiver l'amitié : ce qui lui sera p208 facile, puisque les classes inférieures ne cherchent qu'à ne pas subir de violences. 
Mais un prince qui obtient le pouvoir avec l'appui de l'aristocratie se charge d'une tâche plus lourde. Son soin le plus pressant doit être sa réconciliation avec le peuple. En d'autres termes, une monarchie fondée ou restaurée avec l'appui des notables se ruine rapidement par une politique de réaction. Il est indispensable qu'elle emprunte à la démocratie une part de son esprit, de ses programmes et de ses méthodes. Même établi ou restauré par les aristocrates, un prince ne servira pas leurs intérêts, leurs rancunes ou leurs passions. Au contraire il doit avant tout prendre le peuple sous sa tutelle, et au besoin le protéger contre eux : " Jamais les hommes, dit Machiavel, ne sont plus agréablement surpris que par les bienfaits de qui ils attendent du mal. Le prince, en pareil cas, peut devenir plus populaire que si le peuple même l'avait élevé au pouvoir. Mais, incapable de se réconcilier avec le

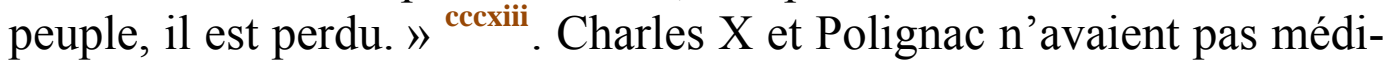
té ces quelques lignes.

Machiavel comprend qu'un prince, restauré par les notables et qui se rapproche hâtivement de la foule, les déçoit, les déconcerte, les scandalise. Il sait le dédain des aristocrates pour le populaire. Les réacteurs s'écrient que leur protégé fait fausse route, et que fonder un État sur le peuple est le fonder sur la boue. Erreur vulgaire, répond Machiavel. La science politique ne peut, au contraire, qu'approuver un prince qui, dût-il son pouvoir aux aristocrates, recherche un plus solide appui. S'il sait commander, tenir tête à la mauvaise fortune, s'il sait enthousiasmer, par la supériorité de son génie, la masse des citoyens, il ne sera jamais déçu par le peuple; et, dans le péril, il s'apercevra qu'il avait bien placé sa confiance ${ }^{\text {cccxiv }}$. C'est pourquoi Napoléon voudra se proclamer l'élu du peuple français; mais il n'osera pas, en 1815, user d'un appui librement offert.

Toutefois, une monarchie régulière et civile, fondée ou restaurée soit avec l'appui du peuple, soit avec l'appui des grands, mais nécessairement et sous peine de ruine réconciliée avec le p209 peuple, doit s'imposer dans la pratique une très grande prudence. Elle doit observer à tout prix la légalité. Un tel gouvernement ne peut se maintenir qu'à condition de respecter la loi et de ne pas porter atteinte aux libertés publiques. Plus que tout autre, le prince qui a reçu le pouvoir dans de telles conditions doit maintenir le pacte constitutionnel. Dès qu'il le viole, et tente de s'élever, comme dit Machiavel, du système de gouvernement civil au système de gouvernement absolu, son pouvoir 
est en péril ${ }^{\text {cccxv }}$. Car les magistratures dont il a dû nécessairement, au début de son règne, maintenir l'autorité, conservent un prestige qu'il ne saurait détruire du jour au lendemain ; elles restent, en cas de crise grave provoquée par des revers extérieurs, assez fortes pour lui refuser l'obéissance et organiser contre lui la résistance légale. Et Machiavel, qui, théoricien d'un principat civil, a pensé à Laurent ou à Cosme, se souvient sans doute ici des maladresses brutales commises par Pierre de Médicis : oublieux des leçons et des exemples de son père et de son arrière-grand-père, il s'était cru assez fort pour braver ces magistrats citoyens auxquels Laurent et Cosme n'avaient jamais refusé la déférence. Au jour du danger, quand l'armée de Charles VIII eut dépassé Pise, il se vit abandonné de tous; son mépris de la loi détruisit, en deux ans, l'œuvre de soixante années, et provoqua le rétablissement imprévu de l'ordre républicain. Un prince sage, conclut Machiavel, évitera ces maladresses et ces excès, maintiendra la constitution et les garanties qu'elle offre aux citoyens. Ils comprendront que leur intérêt est lié au maintien de son pouvoir et du régime.

Machiavel n'estime pas que la tâche d'un prince, établi ou restauré par voie légale, exige un savoir, un esprit ou des talents exceptionnels. La tâche de l'usurpateur, qui crée tout de rien, qui impose son nom, sa personne, l'ordre qu'il a conçu, est le véritable chef-d'œuvre de l'art et de la science. Ni l'obscur roi Spartiate Nabis, dont il a brièvement parlé, ni Cosme et Laurent, dont il semble se souvenir sans les nommer, n'intéressent le théoricien de la science politique autant qu'un César Borgia. Pour Machiavel, le fils d'Alexandre VI est évidemment supérieur aux Médicis, comme à tous les princes qui ont eu la chance d'obtenir le pouvoir sans se trouver contraints à le conquérir. p210 Ils ont eu surtout besoin d'habileté ; ils ont dû évaluer exactement les forces des partis, le concours ou la mauvaise volonté qu'ils peuvent attendre des uns et des autres; gouverner avec l'aide des plus forts et des plus fidèles ; la plus difficile de leur tâche a été, s'ils devaient leur autorité à l'aristocratie, de manœuvrer pour se rapprocher du peuple, lui donner satisfaction, lui rendre confiance, obtenir et cultiver son amitié. Mais tout cela n'est pas très difficile; il y suffit, comme dit Machiavel, d'une astuce heureuse ${ }^{\text {cccxvi }}$. 
Après les gouvernements républicains fondés sur la loi et l'égalité civique, après les gouvernements princiers fondés sur le consentement populaire ou sur un désir de restauration monarchique, se présente à l'esprit un autre type de gouvernement légal, qui, dans ces premières décades $\mathrm{du} \mathrm{XVI}$ siècle, tenait encore une place considérable en Europe : le gouvernement des prêtres. Machiavel, au cours de ses légations dans l'Empire, avait pu s'informer de la puissance territoriale des trois électeurs ecclésiastiques de Mayence, Trêves et Cologne, des évêques rhénans ou des pays du Main, ou des plaines de Westphalie. Il avait sous les yeux les vastes domaines du Saint-Siège, étendus de la Méditerranée à l'Adriatique, de La Romagne à la Campanie et à la Pouille. Ces gouvernements sacerdotaux exigeaient des peuples une obéissance passive et ne condescendaient pas à discuter avec leurs représentants. Mais un tel absolutisme pouvait alléguer un contrat tacite, au nom duquel le sujet chrétien acceptait sans nulle réserve la conduite d'un chef éclairé par Dieu.

Machiavel n'aime pas le Saint-Siège, qu'il rend responsable de la démoralisation, de la division, des faiblesses de l'Italie. Il sait que les domaines pontificaux sont mal gouvernés. Mal gouvernés sous Alexandre VI, qui, cyniquement, les a laissé mettre au pillage par son fils César; follement gouvernés par Jules II, p211 tout occupé de conquêtes, de guerres, de prestige extérieur et de grandeur, et qui, par l'emportement furieux avec lequel il menait ses entreprises, ne fut jamais un homme d'État. Machiavel écrit dans les premiers temps du pontificat de Léon X; il lui accorde plus de confiance; mais il l'attend à l'œuvre. Dans l'Empire, il a pu connaître le désordre administratif, les dépenses folles, le néant politique des États administrés par les prélats, grands et petits. Il conclut, avec une froide ironie, en termes qui semblent rappeler à dessein le texte classique d'un psaume : «Les princes d'Église sont les seuls qui aient des États et ne les 
défendent pas, des sujets et ne les gouvernent pas. Cependant, leurs États, bien que sans défense, ne leur sont pas enlevés; et les sujets, bien que non gouvernés, n'en prennent pas souci, ne cherchent pas à se détacher d'eux, et n'y pensent même pas. Voilà donc les seuls États heureux et bien assurés. ॥ cccxvii.

Il n'étudie pas les causes de cette stabilité qui déroute l'entendement humain. L'art de régir les peuples, le talent, la raison, la science politique, n'entrent ici pour rien. La force de ces États se fonde sur une tradition d'obéissance qu'impose le scrupule religieux : elle seule contraint les sujets à respecter des princes revêtus du caractère sacerdotal. Avec un mélange de dédain et de respect moqueur, Machiavel se borne à dire qu'il ne parlera pas de tels régimes : leur conservation est un mystère qui échappe à l'intelligence; Dieu se charge d'assurer leur grandeur et leur maintien; il serait présomptueux d'en vouloir disputer cccxviii. Lorsque, dans l'été de 1510, Louis XII et Maximilien projetaient, contre Jules II et le Saint-Siège, la convocation du Concile œcuménique, Machiavel avait souhaité, sans trop l'espérer, l'humiliation de ce gouvernement de prêtres ${ }^{\text {ccxix }}$. Deux ans plus tard, il avait assisté au triomphe de la Sainte-Ligue ; il en restait victime. Parmi les tyrans italiens, les plus résolus, les plus violents, les plus criminels, n'osaient porter la main sur ${ }_{\mathrm{p} 212}$ le pape et sa cour. En 1505, Jules II, avec sa témérité coutumière, s'était jeté, sans attendre le gros de l'armée pontificale, dans Pérouse. Gianpaolo Baglioni, l'un de ses pires adversaires, put tenir à merci le pape, les cardinaux, toutes leurs richesses; il céda la ville. On savait qu'il avait pris sa sœur pour concubine, fait assassiner, pour saisir le pouvoir, ses cousins et ses neveux : "Il n'osa pas, bien qu'il en eût juste occasion, écrit Machiavel, risquer une entreprise où l'on aurait admiré sa hardiesse, et qui aurait montré aux prélats combien mérite peu d'estime qui vit et règne comme eux. " ${ }^{\text {cccxx }}$.

Mais la restauration politique de l'Italie, la concentration de toutes les forces italiennes contre l'étranger, supposent nécessairement l'abaissement, l'affaiblissement et au besoin l'abolition du pouvoir temporel des papes. De même, dans l'Empire, les chefs de la Réforme luthérienne, restaurateurs du christianisme primitif, souhaiteront encore une Allemagne définitivement maîtresse de ses destinées, et l'abaissement ou la suppression des États ecclésiastiques, débiles et prêts à subir les influences étrangères. En Italie, Machiavel doit cons- 
tater que le Saint-Siège, encore faible dans les vingt dernières années $\mathrm{du} \mathrm{XV}^{\mathrm{e}}$ siècle, est devenu, depuis moins d'une génération, redoutable. Sixte IV et Innocent VIII n'étaient même pas les maîtres de Rome, où ils voyaient leur autorité sans cesse contrariée et tenue en échec par les factions rivales des Orsini et des Colonna. Tous les princes italiens, jusqu'aux moindres barons, méprisaient la débilité de l'État pontifical. Renforcé par Alexandre, il a pu, sous Jules II, ruiner l'impérialisme vénitien et chasser les Français d'Italie ${ }^{\text {cccxxi. De cette }}$ grandeur nouvelle qui l'inquiète, de ce fait nouveau qui contrarie toutes ses espérances, Machiavel, bien qu'il ne veuille pas prendre la peine d'étudier les secrets ressorts d'un gouvernement de prêtres, doit, comme malgré lui, rechercher les causes. Ce prestige diplomatique et guerrier du Saint-Siège, État italien, pose un problème que l'on ne peut esquiver. p213

Il apparaît aussitôt que si, à l'intérieur, la cohésion des domaines pontificaux et la fidélité des peuples sont dues à des causes religieuses, les progrès du Saint-Siège parmi les États d'Italie et d'Europe sont dus à des causes toutes profanes, et qui n'ont rien de commun avec l'Évangile. Cette grandeur nouvelle repose sur la puissance de l'argent, la force des armes, la diplomatie. Cette grandeur nouvelle a été fondée par Alexandre VI. Il a le premier montré ce que peut faire un pape au moyen de la finance et par la guerre. Peu soucieux de l'Église, il ne travaillait qu'à l'exaltation de sa famille et de César Borgia. Son œuvre fut aussi égoïste que violente, et il eût volontiers sacrifié, à l'avenir des siens, l'avenir du Saint-Siège. Il mit sans hésiter à la disposition de César les trésors et les domaines dont il était le gardien et le défenseur. Alexandre mort et César rentré dans le néant, l'État pontifical recueillit les fruits de leurs efforts. Jules II le trouva puissant, maître de la Romagne, délivré des menaces des barons romains, en possession des richesses d'Alexandre. Il poursuivit, dans l'intérêt du Saint-Siège, l'œuvre familiale et dynastique de son prédécesseur $^{\text {ccxxii }}$. Il eut la chance de réussir avec éclat des entreprises violentes et mal conduites. Sans doute, s'il avait plus longtemps vécu, aurait-il à son tour connu la mauvaise fortune. En des temps où la diplomatie et le calcul eussent été plus nécessaires que la force, Jules II, incapable de renoncer aux procédés que lui imposait son tempérament, eût couru le risque fatal de se ruiner ${ }^{\text {ccxxiii }}$. Du moins a-t-il élevé l'Église à un haut degré de puissance temporelle. Enfin est venu 
Léon X, de nature plus calme ; fils de l'homme habile qui, pendant une dizaine d'années, a véritablement dirigé toute la politique des États italiens, assuré l'équilibre des forces italiennes, tenu à l'écart les étrangers ; fils de diplomate et diplomate lui-même. C'est à lui qu'il appartiendra d'achever, par des procédés plus doux, l'œuvre d'Alexandre, de César et de Jules II ${ }^{\text {cccxxiv }}$. p214

Cette œuvre, en effet, cachait en elle, une cause grave de faiblesse que Machiavel n'ignorait pas. Cause toute morale, mais dont la politique réaliste devait tenir compte, et que Machiavel n'a pas négligée : le contraste entre le caractère violent et séculier du gouvernement pontifical, et la doctrine dont les papes étaient les pontifes et les gardiens. Ce contraste, nécessairement, troublait les consciences. Il suffit de rappeler l'inquiétude récemment éprouvée à Rome, en présence de la cour mondaine et guerrière de Jules II et de ses triomphes païens, par deux voyageurs étrangers, l'un déjà connu de quelques lettrés et savants, l'autre totalement obscur, qui se nommaient Érasme et Luther. L'opinion du monde chrétien était une force morale que le Saint-Siège ne pouvait braver impunément. Machiavel, d'avance, l'a mesurée. Dans les Discours sur la première Décade, il écrivait, pressentant la désaffection des peuples, cette phrase prophétique : «A considérer les principes de l'Église et l'oubli où elle en est tombée, on jugerait que, sans nul doute, elle est, à bref délai, menacée de ruine ou de châtiment. ${ }^{\text {cccxxv }}$.

Le réalisme de Machiavel sait toutefois utiliser les forces morales. Le moment est venu où, dans l'intérêt même de la puissance temporelle et matérielle du Saint-Siège, il faut qu'elles interviennent, avec l'apparition d'un pape vertueux et chrétien. Machiavel souhaite, sans trop l'espérer probablement, qu'on le trouve en Léon X. Et il conclut, avec une flatterie à l'égard du pape Médicis que, pendant quelques années, il a voulu intéresser à son rêve de rédemption italienne : " On espère de lui que, si ses prédécesseurs ont rendu le Saint-Siège grand par la force des armes, il saura, par sa bonté et ses autres vertus infinies, lui conférer une grandeur plus haute et l'imposer à la vénération. ${ }^{\text {cccxxvi }}$. 


\section{Chapitre II}

\section{Les créations de la force}

Machiavel, théoricien du gouvernement civil, républicain ou monarchique, mais fondé sur la loi, s'est fait aussi théoricien de l'usurpation princière et d'un pouvoir princier fondé sur la force. Méthodiquement, scientifiquement, il s'était appliqué à définir le type le plus parfait et le plus humain d'un régime qui repose sur le respect du droit ; avec la même méthode, le même souci d'exactitude objective, il recherche les moyens qui permettent d'établir et de conserver par la force une autorité de fait. Il essaie de définir le type le plus accompli d'un régime de violence et l'esprit de ce régime. Telle est l'autre face de sa doctrine.

Par là il fait rentrer dans son étude tout ce que, théoricien du gouvernement civil, il a d'abord écarté. D'abord la conquête à main armée par une puissance étrangère. Puis la violence interne, l'action factieuse, l'action démagogique, et l'art de les exploiter. Machiavel, théoricien du gouvernement civil, a décrit les recours d'un État bien ordonné contre les tentatives des aventuriers et des factieux. Théoricien de la force et des réalisations de la force, il montre avec une égale objectivité comment un aventurier conquiert, à l'aide d'une faction, le gouvernement d'un État. Il a, théoricien du régime civil, défini la dictature légale et constitutionnelle, républicaine et temporaire. Théoricien des réalisations de la force, il doit considérer objectivement le progrès et le succès de la dictature illégale, factieuse, despotique, p216 sans limites de durée. César, objet d'exécration pour le théoricien du gouvernement civil, devient nécessairement objet d'étude. Les tyrannies 
antiques, les tyrannies italiennes, que le théoricien du gouvernement civil repousse et condamne, deviennent objet d'étude.

Ici encore apparaît l'étroitesse de l'enquête menée par Machiavel. Il s'attarde auprès de quelques petits tyrans dont il lisait les faits et gestes dans Tite-Live et les historiens anciens. Il considère quelques tyrans italiens qu'il a vus agir, de son temps et sous ses yeux. Il consacre surtout quelques pages vigoureuses, et qui comptent parmi les chefs-d'œuvre de la littérature politique italienne, à César Borgia et à la création de son État romagnol. Mais, dans le monde antique, il a volontairement négligé la personne et l'œuvre dont l'étude aurait été la plus riche d'enseignement: César et sa dictature. Dans le monde moderne, il n'a pas étudié l'usurpation sur laquelle un Florentin, mêlé à la vie florentine, instruit de l'histoire florentine, était le mieux renseigné : l'usurpation médicéenne. Écrivant sous la domination des Médicis le livre du Prince, et résolu à le leur dédier, il ne pouvait guère se risquer à cette analyse. C'est chez Guichardin, dans cette Histoire de Florence terminée avant la restauration de 1512, quatre ans avant que Machiavel ne composât le Prince, c'est dans les deux dialogues, écrits entre 1524 et 1527, du Gouvernement de Florence, qu'il faut chercher et l'histoire et la philosophie de la dictature médicéenne.

Malgré ces réserves et cette étroitesse de documentation, le Prince reste avant tout un livre de science. Il est l'étude d'une série de faits auxquels nécessairement la science politique doit s'arrêter : les fondations et les réalisations de la force. Machiavel retient un certain nombre de cas donnés par l'histoire, et dont le plus éclatant lui paraît celui de César Borgia. La méthode reste strictement objective. Il décrit la création et la croissance d'un État princier, comme un physicien ou un biologiste expose un ensemble de faits régis par les lois de la nature. C'est pourquoi, comme il l'annonce dans la préface, le livre du Prince écarte toute rhétorique, tout ornement littéraire, et pourquoi l'auteur, volontairement, n'y a recherché que l'exactitude et la vérité ${ }^{\text {cccxxvii'. }}$ Euvre de science pure; effort pour dégager de faits bien connus et compris des lois indéfiniment stables. p217

Machiavel n'aime pas ces gouvernements princiers dont il dresse la théorie. Toute sa vie politique le prouve, malgré quelques faiblesses, puisque, dans le temps même où il acceptait de servir les Médicis et de se compromettre avec eux, il gardait l'espoir, qui fut sa plus 
grande illusion, de les voir sur ses conseils rétablir, dans cette ville où ils n'osaient encore prendre le titre de princes, les libertés républicaines et la constitution républicaine. L'ouvrage nous livre une part capitale de son savoir politique, mais non ses espérances ni sa pensée profonde. La dédicace à Laurent, duc d'Urbino, la péroraison même du livre, l'appel au prince envoyé de Dieu qui libérera l'Italie des Barbares, ne sauraient donner le change. Machiavel, l'esprit quelque temps dominé par le mythe dantesque du rédempteur qui viendra, a pu, un moment, penser que l'affranchissement de l'Italie exigeait l'intervention énergique et froide d'un prince dont nul pacte constitutionnel ne retarderait les décisions. Mais ni Julien ni Laurent ne l'avaient écouté. Lui-même tenait trop aux formes républicaines, aux traditions républicaines, aux libertés républicaines, pour s'arrêter longtemps à cette idée. Lui-même d'ailleurs a trop exactement défini les causes d'ordre social qui ne permettaient pas d'établir à Florence une monarchie, quand même une robuste tradition de liberté républicaine ne s'y fût pas opposée ${ }^{\text {cccxxviii }}$; et l'on peut imaginer aisément que, sous l'autorité arbitraire d'un prince, Machiavel, indépendant de manières et d'esprit, eût amèrement regretté la liberté perdue. Si l'on conservait des doutes à cet égard, il suffirait de relire, dans les Discours, le chapitre LVIII du livre I. Il y décrit les causes en vertu desquelles le gouvernement populaire est supérieur à celui d'un prince, et conclut que les États n'ont jamais augmenté leur vraie puissance et leur vraie richesse que sous un gouvernement libre, parce qu'un tel gouvernement cherche l'utilité commune, tandis que le prince ne pense qu'à son intérêt particulier ${ }^{\text {cccxxix }} \cdot$ p218

Il n'y a donc à chercher, dans le livre du Prince, que l'étude objective et scientifique de ce qu'on peut appeler l'hypothèse princière et le cas princier, et qui complète l'étude objective et scientifique, développée au long des Discours sur la première Décade, de l'hypothèse républicaine et du cas républicain.

Comme la question posée est celle des réalisations de la force, Machiavel ne s'attarde pas aux monarchies héréditaires, anciennement établies, et qui se transmettent de père en fils. Les peuples y sont habitués à la famille régnante; le prince s'y maintient, sans grand effort et sans grand talent, à moins d'un concours inouï de circonstances défa- 
vorables. Rien ne s'y perd, mais rien ne s'y crée. Ce n'est pas là qu'on peut étudier ce que peut la force, unie à la science politique et au génie ${ }^{\text {cccxxx }}$. Machiavel, de préférence, considère la fondation d'un État complètement nouveau, par un prince à qui nul prédécesseur n'a ouvert la voie. Une telle création apparaît comme le chef-d'œuvre de la science politique. La science même n'y suffit pas : il faut que la fortune offre l'occasion. Mais les occasions les plus propices restent vaines où manque le savoir.

Ainsi Machiavel étudie le cas des aventuriers heureux, qui, à force d'audace et de talent, ont pu, dans un pays déterminé, contre les lois et la constitution, conquérir l'autorité suprême. De même qu'il sait les moyens de briser leurs entreprises, il sait les moyens d'en assurer le succès.

L'homme hardi qui, au mépris de l'ordre établi et légal, tente de s'imposer comme maître, a pour ennemis tous ceux qui tirent avantage du régime qu'il veut détruire. Il est le plus souvent ${ }_{2219}$ mal soutenu, sans beaucoup de confiance et de courage, par les mécontents qui profiteront de son œuvre, mais en attendent le succès pour se prononcer. Nul ne doit compter plus exclusivement sur ses propres forces, et se méfier davantage de la lâcheté humaine ${ }^{\text {cccxxxi }}$.

Deux cas se présentent. Le chef nouveau peut être obligé de s'entendre avec autrui, de s'appuyer sur des partis déjà constitués, des groupes déjà organisés ; de prendre, avec les uns et les autres, des engagements, et, dans une certaine mesure, de payer leur concours ou leur silence en acceptant leur contrôle. Il lui est alors difficile d'obtenir un succès décisif, de rien fonder qui dure. Ou bien la force dont il dispose lui permet de se soustraire à tout accord et à tout contrôle. Il se trouve à la tête d'une faction assez puissante pour briser tout obstacle, et rompue à l'obéissance passive. Il peut, en pareil cas, mener jusqu'au bout son combat, réaliser son plan, imposer un régime stable ${ }^{\text {cccxxxii }}$.

Dans l'une et l'autre hypothèse, la création du nouveau gouvernement exige science, talent et force. Mais toute la science qui détermine les plans d'action et les programmes de gouvernement, tout le talent qui seul permet d'exécuter les uns et de réaliser les autres, demeu- 
rent vains sans la force. A elle seule, en pareil cas, appartient le dernier mot. Une fois passée la borne des conventions légales, sans la force il ne se crée rien. Les prophètes désarmés ont péri ${ }^{\text {cccxxxiii }}$.

De même que seule elle permet de fonder, seule elle permet de maintenir. La persuasion ne suffit pas à conserver ce qui, en politique, est création violente : "La nature des peuples est changeante, dit Machiavel ; on les convainc assez facilement ; il est malaisé de maintenir en eux la conviction $»$. Il faut donc les soumettre à une telle discipline, qu'au moment ${ }_{\text {p220 }}$ où ils sont tentés de ne plus croire, on puisse les faire croire de force. Moïse, Cyrus, Thésée, Romulus, n'auraient longtemps imposé le respect de leurs institutions, s'ils n'avaient usé de contrainte. Plus récemment, frère Jérôme Savonarole périt avec ses lois nouvelles, quand la multitude cessa de croire en lui : «car le moyen lui manquait de maintenir dans la foi ceux qui avaient cru, et d'obliger ceux qui ne croyaient pas à faire comme s'ils croyaient. » ${ }^{\text {cccxxxiv }}$.

Il ne s'agit pas ici de morale. Machiavel n'examine pas si l'usage de la force est licite à l'homme d'État : son ironie envers les prophètes désarmés indiquerait suffisamment sa réponse. Il étudie, en savant, une hypothèse politique selon laquelle l'usage de la force est nécessaire. Plutôt que de mesurer, en termes abstraits, la part qui revient à la science, la part qui revient à la force, il préfère étudier certaines données concrètes que lui offre l'histoire. Ainsi se présente d'abord à son esprit la tragique et récente aventure de César Borgia.

Le duc de Romagne appartient au nombre de ces princes qui, favorisés de la fortune, surent aussitôt appliquer tout leur génie à multiplier ce qu'ils avaient reçu d'elle ${ }^{\text {cccxxxv }}$. La fortune fit naître l'occasion de sa grandeur. S'il n'eût été fils de pape, César ne serait jamais sorti de son néant. Mais dès qu'il eut acquis, grâce à l'appui matériel et à la complicité de son père, ses premiers domaines, on lui vit faire, pour assurer sa grandeur naissante, tout ce qui appartenait à un homme prudent et valeureux : "C'est pourquoi, déclare Machiavel, je ne saurais proposer à un prince nouveau venu de meilleurs préceptes que l'exemple de sa conduite. » S'il dut abandonner son œuvre interrompue, ce ne fut pas l'effet de fautes ou de mauvais calculs, 
mais d'une extraordinaire p221 malignité du destin ${ }^{\text {cccxxxvi }}$. Machiavel entreprend donc un exposé systématique et rigoureux de la politique suivie par César. Il conclut que le duc de Romagne ne commit aucune erreur, aucune fausse démarche, jusqu'au jour fatal où, accablé par la maladie, il laissa élire pape, après la mort d'Alexandre VI et l'éphémère pontificat de Pie III, Jules II, qu'il aurait pu écarter.

Alexandre VI n'ignorait pas les difficultés qui, dans l'avenir et le présent, s'opposaient à la grandeur de son fils. Il ne pouvait le faire seigneur d'un État qu'au détriment des domaines de l'Église, qu'il devait maintenir intacts. Il n'hésita pas : à l'origine de la carrière de César se place une usurpation résolue et violente. L'entreprise rencontrait aussitôt des adversaires; le duc d'Urbino, Venise, maîtresse d'une partie de la Romagne, les seigneurs de Rimini et de Faenza refusaient d'admettre l'établissement de César sur le versant adriatique de l'Apennin. Les principaux chefs de bande, auxquels, faute d'une armée propre, il devait s'adresser, étaient d'accord avec les ennemis romains du pape, les Orsini et les Colonna. Alexandre appela donc en Italie, contre le duc de Milan, le roi de France, dont l'imprudente Venise sollicitait déjà la venue. Louis XII reçut de lui faveurs et avantages ; en échange, aussitôt maître de Milan, il accordait à César assez de soldats et de subsides pour conquérir la plus grande partie de la Romagne. Mais, à peine établi, César allait comprendre le danger que l'on court à dépendre d'autrui. Il voulait attaquer Bologne : Louis XII l'arrêta; envahir la Toscane: Louis XII l'interdit. Il n'avait pas d'armée qui lui appartînt ; il savait la médiocre fidélité de ses mercenaires. Il prit, dès lors, la résolution de ne compter, pour la politique et la guerre, que sur lui-même. Il trouva en Romagne de nouvelles troupes, débaucha les meilleurs officiers des chefs de bande suspects, leur donna des terres, des châteaux, en fit des gentilshommes, entièrement dévoués à sa cause. Les circonstances allaient lui permettre d'en finir d'un coup avec les capitaines d'aventures, complices et instruments de ses premières entreprises, et désormais prêts à une trahison. Inquiets eux-mêmes, ils p222 complotent contre lui à Pérouse, tentent de soulever la Romagne. Mais César, encore allié de Louis XII, est le plus fort. La simple promesse d'un secours français décourage les conjurés. Maître de la situation à force d'audace, il la résout par la perfidie. Il feint une réconciliation ; il les comble de prévenances, de cadeaux, 
de marques d'amitié ; tant et si bien que leur simplicité les conduit au guet-apens de Sinigaglia.

Seigneur de la Romagne, des Marches, du duché d'Urbino, César organise sa conquête. Il fonde, sur la force, un gouvernement régulier, qui, par les avantages assurés aux populations, va obtenir, non plus leur obéissance, car la crainte y a pourvu, mais leur respect et leur dévouement. Nouvelle œuvre, aussi digne d'étude et d'imitation que la première. Dans ces pays, jusque-là mal gouvernés par de petits tyrans avides et brutaux, il établit une administration régulière. On n'y avait connu que brigandage, factions et violences; César y envoie l'un de ses plus durs lieutenants, Remirro de Orco; il donne, à cet homme

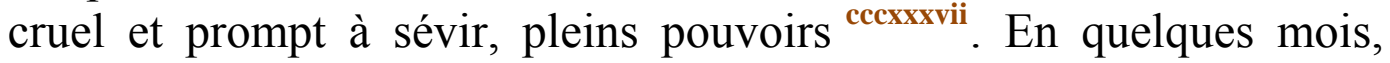
l'ordre est rétabli, l'autorité publique vigoureusement maintenue. Alors, au régime de dictature et de terreur le duc substitue un gouvernement civil; il accorde au peuple une manière de constitution; il crée, au cœur de la province, un tribunal d'État, auprès duquel les villes peuvent se faire représenter chacune par un avocat, chargé de défendre leurs intérêts et leurs droits. César désavoue l'agent le plus exécré de sa dictature ; il rejette sur Remirro de Orco la responsabilité des violences commises. Un matin, les gens de Cesena voient sur la Grand-Place, avec stupeur et satisfaction, un billot de bois, un coutelas sanglant, un cadavre taillé en deux morceaux ${ }^{\text {cccxxxviii }}$ p223

Désormais César n'avait plus qu'à poursuivre ses agrandissements. Il rencontrait maintenant l'obstacle de la France. Louis XII s'était aperçu trop tard de l'avoir fait trop grand. César pensait à secouer la tutelle, désormais pesante, de la monarchie française. Il se rapprochait des Espagnols, qui disputaient aux Français le royaume de Naples, et, dès mai 1503, s'emparaient des principales forteresses et de la capitale. En même temps il prévoyait la mort d'Alexandre VI, et se mettait en garde. Un pape hostile encouragerait contre lui les familles qu'il avait dépouillées. En hâte, il en faisait assassiner les derniers survivants. Il acquérait l'amitié des gentilshommes romains, afin de tenir le Saint-Siège en respect; enfin, il travaillait à rendre sa domination territoriale assez forte, lors de la mort d'Alexandre, pour résister aux efforts éventuels d'ennemis coalisés. La possession de la Romagne, des Marches et de l'Ombrie, ne le mettait pas à l'abri de toute atteinte. Il fallait y ajouter la Toscane. Déjà, par Pérouse, par Piombino, où il s'était établi, par Pise, qui avait réclamé sa protection, il cernait la 
province de toute part. La France, qui venait de perdre Naples, était trop ébranlée pour s'opposer à ses projets. César une fois dans Pise, Lucques et Sienne se donnaient à lui, et Florence était perdue. Le plan de campagne était prêt; César l'eût infailliblement exécuté avant la fin de 1503. Dès lors, maître de l'Italie centrale, régnant de la Méditerranée à l'Adriatique, des approches de Rome aux approches de Bologne, il eût été assez fort pour ne plus craindre personne et ne plus dépendre que de son génie.

Ces projets, bien combinés, et qui, selon toute apparence, devaient réussir, échouèrent du fait d'une de ces circonstances que le plus habile ne peut prévoir. Alexandre mourut trop tôt, avant que César eût commencé l'expédition de Toscane, et tandis qu'il se trouvait entre deux armées, la française et l'espagnole, qui du jour au lendemain pouvaient se tourner contre lui. Mais son génie eût aisément, contre ces dangers nouveaux, trouvé une parade nouvelle. Le fait imprévu, de conséquence incalculable, fut que César, lors de la mort d'Alexandre, pensa mourir lui-même des fièvres romaines. Il n'avait jamais imaginé un tel hasard ${ }^{\text {cccxxxix }}$. Pourtant, son autorité était déjà si fortement ${ }_{\text {p224 }}$ assise que la Romagne attendit plus d'un mois pour s'émouvoir. A Rome, bien qu'on le crût à l'agonie, on n'osa rien contre lui. Il fallut une coalition, et l'entrée en ligne des Vénitiens, pour ébranler son État, auquel manquait pourtant l'appui du SaintSiège. Mais ce fut alors qu'il commit la seule faute politique de sa carrière. Malade et accablé, il n'avait pu s'opposer à l'élection de Pie III, qui mourut presque aussitôt. Au conclave d'octobre, il laissa ses partisans voter pour le cardinal Della Rovere. Il aurait pu l'empêcher d'être pape; il devait l'en empêcher, l'ayant offensé. L'appui de l'Espagne lui était nécessaire ; il gardait des obligations envers la France : il devait faire élire un Espagnol, ou consentir à l'élection d'un Français. Il ne devait jamais permettre l'élection de celui qui fut Jules II. Car on a tort de croire que, chez les grands personnages, les bienfaits nouveaux font oublier d'anciennes injures. Cette erreur et cette fausse manœuvre causèrent sa ruine ${ }^{\text {cccxl }}$.

Ainsi Machiavel résume, en un dur langage, admirable de vigueur, de netteté, d'objectivité scientifique, la carrière de César Borgia, fondateur d'État. A ne considérer que le but poursuivi, l'art de choisir et de mettre en œuvre les moyens, l'importance des résultats, ce cas historique permet de dégager, par-delà le bien et le mal, quelques règles 
infaillibles de méthode : "Après avoir résumé toutes les actions du duc de Romagne, écrit Machiavel, je ne saurais le reprendre ; il me semble juste, au contraire, de le proposer en exemple à tous ceux qui sont arrivés au pouvoir par la faveur de la fortune, et avec l'appui d'armes étrangères. Comme il avait l'âme grande, et que ses intentions étaient hautes, il ne pouvait conduire autrement son œuvre. Un seul obstacle vint traverser son dessein : Alexandre mourut trop tôt, et lui-même alors tomba malade. " ${ }^{\text {cccxli }}$. p225

Voici donc très exactement quelles règles d'art politique l'exemple de César Borgia peut enseigner à tout fondateur d'un État nouveau : réduire ses ennemis à sa discrétion; se procurer une clientèle; n'hésiter jamais sur le choix des moyens; vaincre par la force ou par la fraude ; se rendre populaire, et en tout cas se faire craindre ; se procurer une force militaire habituée à l'obéissance passive, et, pour cela, se débarrasser des troupes insuffisamment sûres; anéantir d'avance toute opposition dès qu'on la prévoit; rénover et rajeunir la constitution de l'État; se montrer inflexible justicier, mais prêt à récompenser les services rendus ; donner l'impression d'un chef qui voit grand, sait dépenser et faire largesse ; diriger avec soin sa politique extérieure, maintenir et cultiver les amitiés et les alliances, de telle sorte que l'étranger comprenne l'avantage de rendre service au nouvel État, et regarde à deux fois avant de l'attaquer. Pour la pratique de toutes ces règles, conclut Machiavel, on ne peut trouver d'exemples plus éloquents et plus neufs que dans la vie de César Borgia ${ }^{\text {ccxlii }}$.

$$
* * *
$$

Machiavel l'absout aisément de tous ses crimes. La fin seule compte en politique, et l'utilité de l'État. Dans l'établissement et l'accroissement du duché romagnol, il faut reconnaître une grande création de l'intelligence; non pas seulement le chef-d'œuvre d'un homme d'État qui sait fonder et construire, mais un bienfait pour les peuples de Romagne, qui alors seulement connurent la tutelle d'un pouvoir fort. Peu importe donc que César ait usé de violence et n'ait jamais hésité devant un crime utile. Machiavel pourtant n'esquive pas le problème que pose, si l'on étudie les réalisations de la force, l'emploi des moyens contraires à la morale et au droit. Mais pas davantage il n'entend ${ }_{\text {p226 }}$ le discuter en philosophe, à la manière de Platon ou d'Aristote, de Cicéron, de saint Augustin ou des scolastiques. 
Une fois encore il ne veut considérer que les données de l'histoire. Elle a retenu les noms de certains tyrans dont l'œuvre entière fut entachée d'infamie; de certains hommes qui, par simple scélératesse et pour satisfaire leur scélératesse, ont fondé des États. Machiavel étudie ces cas extrêmes, afin de marquer plus exactement les bornes où doit se contenir, dans l'effort d'un homme d'État, l'usage du crime ${ }^{\text {ccxliiii }}$.

Deux exemples, empruntés, l'un à l'histoire ancienne, l'autre à la contemporaine: Agathocle, tyran de Syracuse; Oliverotto, tyran de Fermo dans la Marche. Le premier fut un criminel brave et rusé. Préteur de Syracuse, sûr de l'appui de Carthage, il fit massacrer par ses soldats les sénateurs et les chefs du peuple; devenu seul maître de l'État, il en sut organiser la défense, et rejeta les Carthaginois en Afrique. Mais il commit des atrocités, ne sut pas créer un gouvernement régulier et durable ; son œuvre périt avec lui. Oliverotto fit massacrer son oncle Giovanni Fogliani et les premiers citoyens de Fermo, put y créer à son profit un État nouveau, réforma les institutions militaires et civiles, et, en moins d'un an, organisa une tyrannie active et redoutable, qui dura jusqu'au jour où lui-même, à Sinigaglia, resta victime de la trahison d'un plus habile que lui, César Borgia. Machiavel hésite à considérer Agathocle et Oliverotto comme de véritables hommes d'État. Ce furent deux scélérats de talent, qui ne cherchèrent dans le pouvoir qu'une satisfaction égoïste ; leur œuvre, à la mesure de leur âme criminelle, reste mesquine, subordonnée au désir de satisfaire une ambition brutale et sans idées.

Machiavel peut désormais conclure sur la question des excès qu'une science positive de la politique permet à la force, ou, selon son expression, sur l'art d'user bien ou mal de la cruauté. Elle ne peut être qu'un moyen. En bien user, c'est, pour un prince, ne commettre d'actes cruels qu'à certains moments critiques, lorsqu'il lui faut nécessairement consolider son pouvoir. Mais il ne doit pas s'y complaire ; le peuple doit en tirer avantage. Mal user de la cruauté, c'est, pour un prince, y eût-il modérément recouru au début de son règne, multiplier sans p227 règle ni mesure les violences inutiles. Au moment de fonder un Etat, il faut donc très exactement calculer tous les actes impitoyables qu'il sera nécessaire d'ordonner, et les ordonner d'un seul coup, afin de ne pas avoir à recommencer tous les jours, de rassurer bientôt les peuples, de les réconcilier aisément avec une autorité bientôt redevenue plus humaine. Qui se comporte autrement, par hésita- 
tion ou faux calcul, devra tenir sans cesse le couteau à la main. Les actes de violence doivent être commis en un même temps; de la sorte, l'injure en est moins prolongée, et l'offense paraît moindre. Mais les bienfaits doivent être accordés peu à peu, et goûtés à loisir ${ }^{\text {ccxliv }}$. De tels préceptes, bien que Machiavel ne le dise pas et ne veuille pas le dire, rappellent nécessairement le souvenir et l'exemple d'Auguste.

Table des matières

\section{II}

L'étude scientifique des créations de la force aboutit nécessairement à poser le problème de la conquête, des procédés, des résultats de la conquête. Machiavel n'en discute nullement la légitimité : ce qui est obtenu par la force est légitimement obtenu. Il se borne à considérer, en historien, le fait de la conquête, l'existence de certains États agrandis par l'annexion de provinces différentes d'eux-mêmes. Tels furent, dans l'antiquité, l'empire macédonien ou l'empire romain. Tels sont les grands États européens dont Machiavel a pu étudier, hors d'Italie, la formation. Telle est la monarchie française elle-même, peu à peu constituée, depuis des siècles, par l'accession de provinces diverses au domaine royal, par l'absorption, dans le premier État capétien, des petits États féodaux et provinciaux. A ce type ${ }_{\text {p228 }}$ répond mieux encore cet Empire franco-italien dont rêvent les Valois depuis Charles VIII , et qu'ils cherchent à constituer par l'acquisition de Naples ou de Milan. L'établissement de tels États, faits d'éléments anciens et nouveaux, souvent étrangers, pose, devant l'esprit de Machiavel, un certain nombre de problèmes d'agencement et d'organisation. Problèmes importants, et relatifs à l'art de fonder, sur la conquête, un empire $^{\text {cccxlv }}$.

Deux cas se présentent. Ou bien les provinces annexées appartiennent à la même région géographique, parlent la même langue ; ou bien elles appartiennent à d'autres régions et parlent des langues différentes. Dans le premier cas, les difficultés sont médiocres, surtout si ces populations ne sont pas habituées à un gouvernement libre. Il suffit d'assurer la disparition de la famille régnante. Il suffit de ne pas altérer les lois et de ne pas aggraver les impôts. Si les coutumes des pays 
annexés ressemblent à celles de l'État auquel on les rattache, si le langage présente peu de différences, l'annexion, à la lumière de l'histoire, apparaît aisée et durable. Ainsi la Bourgogne, la Bretagne, la Gascogne, la Normandie, ont accepté la réunion à la France ; malgré quelques différences de langage, elles sont entrées aisément dans l'unité française, parce qu'il n'existe pas d'opposition entre leurs coutumes et celles du royaume ${ }^{\text {cccxlvi }}$. Au contraire, quand un prince acquiert un pays où la langue, les usages, l'ordre politique tout entier diffèrent de ce qui existe dans ses anciens États, l'œuvre d'annexion et de fusion est difficile, et réclame une grande science du gouvernement. Le prince doit y résider en personne, établir dans les villes principales, dans les régions les plus importantes, des colonies civiles, selon l'usage de Rome, au risque de déposséder quelques propriétaires. Ces colonies d'habitants civils travaillent, produisent, et se fixent au sol ; elles dispensent d'entretenir dans le pays de nombreuses garnisons, oisives et malfaisantes ; elles coûtent moins cher, et leur établissement offense moins les anciennes populations. Une telle œuvre exige en même temps une diplomatie, qui a pour ${ }_{\text {p229 }}$ but de ne pas permettre aux États voisins d'intervenir dans les affaires des provinces annexées ; elle affaiblit les uns, et cultive l'amitié des autres ${ }^{\text {ccxlviii. }}$

Ces principes posés, Machiavel ébauche en quelques lignes une critique, singulièrement pénétrante et forte, de la politique maladroite, faite de violence et de faiblesse, que les rois de France avaient suivie sous ses yeux en Italie cccxlviii. Si Louis XII n'a pas su instituer, dans la péninsule, une domination durable, c'est qu'il a mal observé ces diverses règles. Il avait conquis la Lombardie ; Florence, Mantoue, Bologne, Forlì, Faenza, Rimini, Piombino, Pise, Sienne, sollicitaient son amitié. Mais il ne vint pas résider à Milan; il n'établit pas de colonies françaises dans ses nouveaux domaines ; il ne tenta rien pour les assimiler. Il dédaigna d'organiser autour d'eux une clientèle de petits États amis ; au contraire il favorisa les entreprises du Saint-Siège, voisin redoutable. A peine maître de Milan, il commit la faute de soutenir Alexandre VI, et d'aider son fils César à conquérir la Romagne. Première erreur, qui l'engagea dans une suite de fausses démarches : si bien qu'à la fin, quand Alexandre et César devinrent dangereux et menacèrent la Toscane, Louis XII se trouva dans l'obligation de les arrêter, au risque de se brouiller avec le Saint-Siège, après leur avoir sacrifié ses alliés naturels. Nouvelle faute, et plus grave encore : dans 
son désir de reconquérir Naples, et son incertitude de mener à bien cette entreprise avec les seules forces de la France, il eut l'imprudence de s'y engager avec l'aide d'un autre, aussi puissant que lui, le roi d'Espagne. Il pouvait laisser à Naples un roi vaincu, désormais soumis à sa volonté ; il le détrôna, et vit bientôt le roi d'Espagne seul maître du royaume conquis à deux. Enfin, et par une erreur suprême, sans s'apercevoir qu'il réduisait son rôle à servir la politique pontificale, il travailla, de concert avec Jules II, en réalité pour le compte de Jules II, à ruiner la république de Venise. Faute qu'il ne devait pas commettre, après avoir agrandi à son désavantage l'Espagne et le Saint-Siège. S'il s'était engagé à soutenir le pape contre Venise, il devait se dégager d'une promesse nuisible à son intérêt ${ }^{\text {ccxlix }}$. Louis XII a p230 donc été incapable de fonder en Italie un empire français, parce qu'il n'a pas suivi les règles selon lesquelles on fonde un empire en pays étranger. Il n'y eut là aucun miracle, mais l'effet naturel d'une ignorance de l'art politique. Machiavel avait un jour déclaré au cardinal d'Amboise que si les Français s'y étaient entendus, ils n'auraient pas laissé le Saint-Siège acquérir une telle puissance ${ }^{\text {cccl }}$. L'expérience démontre que la grandeur du Saint-Siège et de l'Espagne en Italie a été l'œuvre de la politique française, et que la puissance française en Italie a été ruinée par le Saint-Siège et l'Espagne ${ }^{\text {cclii }}$.

Dans le livre du Prince, l'action gouvernementale de César Borgia, une fois maître incontesté de son domaine romagnol, semble s'achever en une œuvre de réparation politique et de conservation sociale. Pareillement, le secrétaire florentin semble y enseigner aux fondateurs d'empire une politique modérée, de prudence, d'équilibre, qui respecte les traditions, les coutumes, les droits établis. Au premier livre des Discours, les tumultes provoqués en Italie et en Occident par les querelles franco-espagnoles, - peut-être, si ces pages datent des dernières années de sa carrière, par la rivalité des Valois et des Habsbourg, peut-être enfin les bouleversements causés en Europe orientale par le fait de la conquête turque, dont la menace grandissait aux frontières et sur les côtes de l'Italie, - induisirent Machiavel à conclure, sur le problème des créations de la force, en termes plus brutaux, avec un pessimisme amer, à un immense mépris des hommes. Sa pensée, généralement traditionaliste et conservatrice, admet encore, lorsqu'il 
s'agit de fonder sur la violence interne ou la conquête un État nouveau, l'action la plus résolue à détruire tout l'héritage du passé. Par là, et pour quelques instants, Machiavel semble s'accorder avec les plus grands révolutionnaires de l'histoire. p231

Machiavel admet que le créateur d'un État ou d'un empire sache, au besoin, renouveler de fond en comble l'ancien ordre politique et social. Établir, dans les villes, de nouvelles magistratures, sous de nouveaux noms, avec de nouveaux pouvoirs; y appeler des hommes nouveaux. Enrichir les pauvres et appauvrir les riches, selon le texte biblique ; ainsi agit David quand il devint roi. Bâtir des villes nouvelles, ruiner les villes anciennes, transplanter les peuples d'une région dans une autre : ainsi Philippe de Macédoine les transplantait de province à province comme des troupeaux. Ne rien laisser d'intact : il ne doit subsister aucune autorité, aucune dignité, aucune richesse, qui ne dépende du nouveau prince et ne sache en dépendre ${ }^{\text {cclii }}$.

«Ces moyens, ajoute-t-il, par une concession tardive à l'humanisme érasmien, sont cruels et destructifs, je ne dis pas seulement du christianisme, mais de l'humanité. Chacun doit les abhorrer et préférer une condition privée au titre de roi, s'il faut l'acquérir au prix de tels désastres. Néanmoins, quiconque veut établir et maintenir son autorité doit au besoin admettre ces violences. » Mais Machiavel sait que rarement les fondateurs poussent jusqu'à l'extrême l'audace révolutionnaire. Au regard de la science politique, ce n'est qu'erreur et faiblesse. Erreur commune aux particuliers comme aux chefs d'État: les hommes se décident ordinairement à suivre les voies moyennes, qui sont encore bien plus nuisibles, parce qu'ils ne savent être ni entièrement bons ni mauvais entièrement ${ }^{\text {cccliii }^{2}}$ p232

Contre les gouvernements imposés par la force, Machiavel cherche, non plus dans le livre du Prince, où ce n'eût pas été le lieu, mais dans les Discours, des garanties pour les hommes. Le plus long chapitre de tout l'ouvrage est réservé à l'étude des conjurations ${ }^{\text {cccliv. Il }}$ n'avait déjà reconnu, contre un prince criminel, d'autre recours que le poignard $^{\text {cclv }}$. Jamais peut-être aucun écrivain n'a plus savamment, avec plus de netteté froide, exposé l'art de l'assassinat politique. Il divise les attentats selon leur objet, en plusieurs genres; en plusieurs 
catégories les individus qui peuvent s'y risquer ; il suit le développement de leurs entreprises ; il définit les moyens qui permettent de les découvrir, les dangers qui en peuvent contrarier l'exécution. L'histoire antique, l'histoire de l'Italie moderne, lui ont fourni les éléments d'une érudition où il semble prendre un singulier plaisir. Mais il a voulu, d'avance, exprimer les conclusions d'une sagesse prudente et désabusée : «Je traiterai longuement ce sujet, dit-il, afin que les princes apprennent à se mettre en garde contre de tels dangers, et que les citoyens hésitent avant de s'aventurer dans de telles affaires. Je souhaite qu'ils apprennent à supporter avec résignation le gouvernement que le sort leur a donné... Tacite a eu raison d'écrire que les hommes doivent honorer le passé, mais obéir aux choses présentes; désirer de bons princes, et les tolérer quels qu'ils soient. Qui se comporte autrement, le plus souvent se ruine et ruine, avec soi, sa patrie. »" ${ }^{\text {cclvi }} \cdot$ p233

Table des matières

\section{III}

Les conclusions pratiques auxquelles il aboutit, et qu'il résume en quelques chapitres, brefs et denses, reposent sur une enquête scientifique mais limitée. Par suite, ces maximes de science politique ne sont que les réflexions d'un puissant esprit, nourri d'histoire, apte à comprendre et à comparer, mais qui n'a retenu, pour en tenter l'analyse, qu'un petit nombre de faits choisis dans le passé ou d'épisodes contemporains. Même complété par les Discours sur la première Décade, le Prince ne constitue pas un traité complet, et l'on ne doit pas demander à Machiavel ce qu'il n'a pas voulu donner. Mais il a su retenir, pour y attacher sa pensée, quelques problèmes capitaux.

$$
\text { *** }
$$

Tel est, par exemple, celui des États princiers peu à peu agrandis par la conquête, ou par un ensemble d'annexions accomplies de gré ou de force. A ce type, du vivant de Machiavel, appartenait un très grand nombre d'États européens. Il ne faut jamais regarder de trop près comment s'est forgée l'unité des nations : les provinces qui, au temps de Machiavel, formaient le royaume des Valois, n'étaient pas toutes 
entrées par la seule persuasion dans l'unité française. Les cas les plus récents étaient alors celui de la Bourgogne, à laquelle il fait allusion, et de la Picardie, conquises par Louis XI après la mort de Charles le Téméraire. Plus tard, les Trois Évêchés, le Roussillon, l'Alsace, la Franche-Comté, et, dans une certaine mesure, la Lorraine, devaient être annexées après des guerres heureuses. L'unité espagnole qu'avaient tenté d'achever les rois catholiques se fondait en partie sur la force. Mieux encore que les États où s'abritait déjà une vie nationale, certaines dominations européennes, faites de pièces que seule tenait ensemble l'unité du souverain, comme les États de la Maison d'Autriche, comme l'immense et disparate royaume de Pologne, répondaient au type considéré par Machiavel. Au même modèle se rattachaient les grands empires constitués dans le passé, l'empire assyrien, p234 l'empire macédonien, l'empire romain, ou, création de l'histoire la plus récente, l'empire turc. Au même modèle le chancelier florentin ramenait les empires que les puissances étrangères s'efforçaient de créer en Italie. Selon ce type devait se fonder et se développer l'empire napoléonien. Pouvaient s'y rapporter encore les empires coloniaux jadis créés par les Républiques marchandes d'Italie; l'empire que Venise avait créé, sur les côtes dalmates, en Grèce, dans les îles de l'Archipel et au Levant; les empires qu'au temps de Machiavel, Portugais et Espagnols créaient, par les moyens les plus cruels, aux Indes, à Ceylan, au Brésil, au Mexique, bientôt au Pérou. Enfin devaient s'y rapporter les grands empires fondés, dans le monde moderne, par les peuples colonisateurs, Hollandais, Anglais ou Français.

Machiavel aborde ainsi, au troisième chapitre du Prince, une question vaste et complexe, qui, sous ses divers aspects, domine l'histoire antique et moderne. On ne saurait dire qu'il l'ait étudiée à fond ou qu'il en ait véritablement montré l'importance. Sans doute, sa critique des maladresses commises par les rois français en Italie garde pour l'historien un très grand prix, et il est difficile de juger avec plus d'intelligente perspicacité la politique italienne suivie de Charles VIII à François $\mathrm{I}^{\text {er }}$. Mais il reste que Machiavel n'a étudié que de façon superficielle l'ensemble des problèmes que ce chapitre suggère à l'esprit. Quelques considérations sommaires sur l'empire turc; quelques considérations sommaires sur le royaume de France; mais l'essentiel de sa documentation est, comme toujours emprunté à 
l'histoire ancienne, et de préférence à l'histoire de Rome. Encore semblerait-il nécessaire qu'il se fût particulièrement appliqué à l'époque impériale, et qu'il eût, en historien, en juriste, en homme d'État, examiné les méthodes suivies par Rome, maîtresse du monde méditerranéen, pour organiser, administrer et gouverner son empire, et y imposer, pendant quatre siècles, l'ordre et la paix. Mais le préjugé républicain de Machiavel, la haine qu'il porte à César et à ses héritiers, à son œuvre et aux défenseurs de sa tradition, l'ont détourné de cette étude, pourtant capitale et indispensable. Il ne considère que la Rome sénatoriale et consulaire, ses méthodes de conquête et de gouvernement; il énonce les maximes qui s'en dégagent. Il n'a emprunté ni une idée, ni un principe quelconque d'administration ou de gouvernement, à la pratique tenue par César, par ${ }_{\text {p235 }}$ Auguste, par les Antonins, pour conserver et pour régir les peuples que Rome avait soumis. Dans le monde moderne, on ne peut le blâmer de ne pas avoir pressenti l'importance de la conquête coloniale ; car, à la date où il écrivait le Prince, nul ne pouvait encore prévoir l'immensité de l'empire que le Portugal fondait en Afrique, en Amérique et aux Indes ; les Espagnols ne possédaient encore que la Floride et quelques Antilles; ils ne commencèrent pas la conquête du Mexique avant 1519. Mais il n'a pas pris la peine d'étudier cet empire colonial vénitien dont l'existence, vieille de plusieurs siècles, était l'un des faits qui dominaient la politique et l'économie des pays méditerranéens. En réalité, son attention a été retenue, dans le présent, par les événements dont il avait été spectateur et victime : les efforts de la France et de l'Espagne pour conquérir l'Italie. Son attention a été retenue, dans le passé, par la première conquête romaine. Ce sont là, essentiellement, les deux groupes de faits sur lesquels il fonde ses conclusions. Aussi se réduisent-elles à un petit nombre de règles pratiques, empruntées de préférence aux méthodes de la république romaine, et dont la valeur se trouve confirmée par les insuccès du gouvernement français, qui, en Italie, n'a pas su les suivre ; mais règles sommaires, générales, élémentaires : nécessité pour le prince conquérant de résider en personne dans la province conquise ; d'y créer des colonies civiles plutôt que d'y entretenir des garnisons ; nécessité d'une diplomatie capable de se concilier les États voisins et d'empêcher leur intervention en pays annexé. On peut, sur ces principes, développer une théorie des fondations impériales; mais Machiavel ne s'en est pas donné la peine. 
L'étude des empires de Rome et de Venise lui aurait suggéré plus de comparaisons et d'idées pour préciser sa doctrine.

$$
* * *
$$

De même, lorsqu'il étudie les créations des aventuriers de la politique et de la guerre, il pose un problème capital. Certains hommes, par la puissance des partis ou des factions, par la puissance également de la personnalité, de l'intelligence ou du talent, mais, en dernière analyse, par la force, ont imposé leur vouloir aux peuples, transformés des États anciens, créé, de toutes pièces ou à peu près, des États nouveaux. Ils ont joué, dans p236 l'histoire universelle, un rôle souvent redoutable; et la liste en est longue.

Mais le secrétaire florentin n'a pourtant pas épuisé la question. Sans doute, à la critique, objective et scientifique des erreurs françaises en Italie, répond l'étude, objective et scientifique, de l'œuvre entreprise et conduite, avec une maîtrise consommée, par César Borgia. Un tel cas lui permettait de suivre et d'analyser l'action de l'aventurier qui fonde un État où il n'y avait rien. Mais l'histoire romaine offrait à Machiavel le type le plus accompli des conquérants et fondateurs de génie, venus de la guerre ou de la politique : César, le maître dont ils ont, à tout propos et hors de propos, invoqué le nom. Machiavel n'a pas voulu étudier César, parce qu'il l'exècre et le met au niveau de Catilina. Bien qu'il veuille, dans le Prince, faire œuvre scientifique, il s'est laissé dominer par la passion. Cette négligence et cette exclusion s'expliquent peut-être par un respect superstitieux de Tite-Live ; les livres conservés de ses Histoires n'atteignent pas les guerres civiles et la fin de la république. Machiavel aurait dû lire les Commentaires de César, les lettres et les discours de Cicéron, Suétone, Plutarque, Dion Cassius. Il n'était pas historien de métier; il n'était pas philologue; le goût lui manquait d'entreprendre de telles recherches ; il n'y était pas préparé. Il ne connaissait, du passé romain, que la vulgate de Tite-Live, et son savoir s'arrêtait où elle s'arrête. C'est pourquoi il semble n'avoir jamais eu, sur César et son œuvre, que des notions sommaires et conventionnelles. Mais cette lacune, dans un traité des créations princières, est grave.

De même le monde moderne lui offrait, sous ses yeux mêmes, à Florence, le cas de l'usurpation médicéenne. Sans doute, les Médicis 
n'appartenaient pas à la classe des aventuriers venus des armées : le goût des armes, le talent militaire, manquaient à ces banquiers. Mais c'était bien par la politique, par le jeu des partis, grâce à l'appui d'une faction, qu'ils avaient imposé leur autorité. Sans doute encore leur succès, en apparence, n'était pas fondé sur la force. Ils avaient évité d'user de la violence, car l'humanité florentine se révoltait contre la barbarie des tyrans lombards. Cosme et Laurent avaient affecté de n'être que de simples citoyens, respectueux des lois républicaines. Mais leur grandeur reposait sur la secrète menace d'une force masquée. Cosme avait exigé l'exil de tous ses adversaires. Un système d'impôts arbitrairement progressifs détruisait ${ }_{\mathrm{p} 237}$ lentement la richesse de la bourgeoisie républicaine : "Mieux vaut, disait-il, ville ruinée que ville perdue ${ }^{\text {ccclvii }} \gg$. S'il respectait en général la vie des personnes, il n'écartait pas l'idée d'un meurtre utile. Sous Laurent, plus hautain, plus impatient, les vengeances et les représailles qui avaient suivi le complot des Pazzi, la révision méthodiquement poursuivie des lois fondamentales, avaient hâté les progrès du pouvoir personnel et d'un régime chaque jour plus étroit, plus dur, qui n'usait pas de la terreur parce que l'espionnage et la délation suffisaient, mais, au fond, restait essentiellement violent.

Tel était le type nouveau d'établissement princier qu'offrait à Machiavel la politique menée pendant soixante ans par les Médicis. Ils l'avaient reprise depuis 1512 ; et maintenant, le rôle de la force était évident. C'était bien à la force, à la force étrangère des Espagnols et des Impériaux, que les Médicis avaient dû leur restauration. Mais, pas plus que l'action et l'œuvre de César, Machiavel n'a voulu étudier l'action et l'œuvre des Médicis. Le livre qu'il leur offrait ne pouvait parler d'eux. Cette seconde lacune, dans une œuvre destinée à établir la théorie scientifique des usurpations et des réalisations princières, reste aussi grave que l'absence d'une étude sur César.

Il en résulte que, par compensation, Machiavel a sans nul doute, exagéré l'importance historique de César Borgia et de son œuvre; exagéré l'importance des leçons qui peuvent s'en dégager pour la science politique. D'abord parce que, comme il le reconnaît lui-même, il y eut, à l'origine de la carrière de César, une part de hasard heureux ${ }^{\text {cclviii }}$. La fortune le fit naître fils de pape, et d'un pape qui, sans hésiter, lui permit de grandir au détriment des domaines du SaintSiège. Hasard qui rend son cas trop singulier. César ayant ainsi débu- 
té, n'a rien de commun avec les aventuriers de la guerre et de la politique, qui véritablement ne sont fils de personne, et ont eu tout à créer. En second lieu, il dut ses progrès à la complaisante maladresse de la politique française ; sans les ressources financières et militaires mises à sa disposition par Louis XII, le fils d'Alexandre VI n'aurait pu conquérir la Romagne, et serait resté le seigneur sans gloire de quelques petits domaines d'Émilie. p238 Ainsi favorisée de la fortune, ainsi aidée de l'étranger, l'action de César fut sans doute conduite avec une parfaite clarté d'esprit, une parfaite indifférence au choix des moyens. Malgré tout, à considérer la ruine si brusque de sa grandeur trop rapide, on est tenté de penser que Machiavel, peut-être, se tire trop aisément d'affaire en accusant l'extraordinaire malignité du destin. S'il a suffi, pour ruiner César, qu'il tombât gravement malade à la mort de son père, mort dont il avait pourtant calculé depuis longtemps les conséquences, c'est que la fondation du duché de Romagne n'était qu'une œuvre artificielle et sans avenir.

Humilié de cet effondrement rapide, César allégua la maladie, qui pendant quelques jours ne lui permit pas de monter à cheval. Mais il était guéri dès le début de septembre; et l'homme qui, tremblant de fièvre, avait conservé assez d'énergie et de lucidité pour se faire livrer de force l'argenterie, les bijoux, le trésor du pape défunt, pouvait donner ordre à la défense de son État. En fait, ce fut dans le courant de septembre, César guéri, capable de tenir la campagne, de courir de Rome à Nepi et de Nepi à Rome, que Guidobaldo de Montefeltro recouvra, sans coup férir, Urbino; que la sœur de Guidobaldo reprit possession de Sinigaglia; que les Appiani de Piombino rentrèrent dans leur ville, les Vitelli à Città di Castello, que Gianpaolo Baglioni reprit Pérouse, tandis que les troupes vénitiennes paraissaient aux frontières de Romagne. Dès la fin du mois, César avait perdu la plus grande partie de ses domaines.

Trop prompt à recevoir l'explication qu'il donna de son désastre, trop prompt à lui accorder confiance et à lui attribuer du génie, Machiavel exagère le rôle qu'il pouvait jouer au conclave d'octobre, et la faute qu'il aurait commise en laissant élire Jules II. Les Vénitiens avaient alors envahi la Romagne ; ils occupaient Faenza ; ils allaient prendre Rimini. César n'était plus capable d'imposer au conclave le candidat qui lui plaisait. Les cardinaux espagnols, liés d'intérêt à sa famille, avaient perdu toute confiance, et ne pensèrent qu'à 
l'abandonner. Le cardinal Della Rovere put aisément, par divers moyens dont tous ne furent pas honorables, obtenir leurs voix. Une candidature française, au lendemain de la perte de Naples, enlevée à Louis XII par les Espagnols, n'avait aucune chance de succès. Jules II fut élu sans peine, le $1^{\text {er }}$ novembre 1503, et ${ }_{\text {p239 }}$ César n'aurait pu s'y opposer. Sa faiblesse apparut tout entière, moins d'un mois plus tard, quand le pape le somma de restituer Cesena et Forlì ; le fit, sur son refus, arrêter à Ostie le 29 novembre et conduire à Rome, tandis que les derniers seigneurs dépossédés rentraient sur leurs domaines; que Giovanni Sforza reprenait Pesaro, que les Ordelaffi reprenaient Forlì, que les Vénitiens occupaient le reste de la Romagne. Quand César, étroitement surveillé à Rome, eut rendu ses dernières places au SaintSiège, rien ne subsista d'une seigneurie qui ne méritait pas de vivre.

Le développement qu'on en aurait pu attendre, si le pape Borgia n'était pas mort trop tôt, reste, malgré l'optimisme de Machiavel, assez douteux. César aurait, en 1503, attaqué la Toscane, et Florence courait un danger évident. Mais la complexité de la politique italienne et des intérêts étrangers mêlés aux affaires italiennes était telle, que Florence, alliée de la France et de la clientèle française, eût trouvé des défenseurs ; le duc de Romagne, qui avait provoqué tant de rancunes et de haines, comme l'événement le démontra, s'engageait dans une aventure périlleuse, et probablement aurait vu se former en face de lui, du jour au lendemain, une coalition contre laquelle il n'eût pas obtenu facilement le concours avare de l'Espagne.

Machiavel a dédaigné d'étudier les finances de César. Mais il n'avait pu concevoir et tenter ses diverses entreprises qu'avec les subsides de la France, et les trésors du Saint-Siège, mis à sa disposition par la complicité de son père. Ce qu'il pouvait tirer de ses États, généralement pauvres, se réduisait à peu de chose. Quand les ressources financières du Saint-Siège vinrent à lui manquer, tout lui manqua. Machiavel, absorbé par l'analyse du problème abstrait de construction politique qu'il s'est posé, néglige ces réalités humbles et pressantes. Il y aurait aperçu l'une des causes qui devaient conduire César à la ruine, quand même il aurait eu du génie.

Or Machiavel semble avoir volontairement exagéré la grandeur du personnage. Il établit une différence entre César Borgia d'une part, et, de l'autre, les hommes qui, par simple scélératesse et pour satisfaire 
leur scélératesse, se sont élevés au pouvoir. César avait l'âme grande et ses intentions étaient hautes; il avait formé le dessein de créer, dans l'Italie centrale, un grand État; et Machiavel imagine peut-être que ce grand État eût pu servir de base à quelque fédération nationale assez p240 forte pour tenir en respect les Barbares. Peut-être, si César avait réussi à fonder, de l'une à l'autre mer, un royaume d'Italie centrale, Machiavel lui eût-il, neuf ans plus tôt, adressé la péroraison du Prince. Considérant les fins qu'il lui attribue, Machiavel l'absout de n'avoir jamais hésité sur le choix des moyens. Au contraire, Agathocle de Syracuse et Oliverotto de Fermo ne furent pas de véritables hommes d'État ; leur œuvre reste mesquine, à la mesure de leurs âmes criminelles.

Mais il semble bien que, Machiavel écrivant le Prince dix ans après la chute de César, son imagination de poète et de visionnaire, prompte à créer des mythes, ait, démesurément et pour la démonstration d'une thèse, grandi l'œuvre et l'homme. Il avait vu de ses yeux l'œuvre tomber en ruine et l'homme s'avilir. Machiavel était à Rome en 1503 lors de l'élection de Jules II : il y accomplissait une de ses légations; les Dix l'avaient chargé d'assurer le nouveau pontife du dévouement florentin, et de le mettre en garde contre l'impérialisme de Venise, encouragé par la débâcle romagnole. César, dans l'antichambre du pape, demandait humblement pardon à Guidobaldo d'Urbino. Quand rien ne subsista plus de l'État qu'il avait fondé, il lui fallut rechercher la protection de Louis XII, et se mettre au service de son beau-frère, le roi de Navarre Jean d'Albret. Il rentrait dans le néant, d'où le hasard de sa naissance et une insolente fortune, secondée par un génie malfaisant, l'avaient fait sortir. L'histoire de sa grandeur et de sa décadence se réduisait à un épisode violent et tragique de l'histoire du népotisme pontifical. Lorsque Machiavel écrivit le septième chapitre de son livre, César était, depuis six ans, mort obscurément au siège d'une petite place de Navarre. Pourtant, le secrétaire florentin a voulu glorifier en lui le Prince, maître des hommes et des événements, soucieux uniquement de réaliser, par delà le bien et le mal, un idéal surhumain de grandeur tragique.

Cette transfiguration permet de constater la dualité de plan sur lequel se développe la pensée de Machiavel, politique positif et poète visionnaire. Le politique vit dans le domaine des faits, les note froidement, les examine et les juge, ne s'embarrasse d'aucun souci de 
morale ou de droit. Il porte cette impartialité, cette froide objectivité dans l'étude de l'histoire. Instruit par l'histoire et la pratique des affaires, il étudie en théoricien les problèmes les plus émouvants de la politique, la défense ${ }_{\mathrm{p} 241}$ des républiques contre les tyrans, la conquête des républiques par les tyrans, avec l'indifférence du naturaliste ou du physicien qui décrivent des faits régis par les lois naturelles. Mais le poète s'évade hors du réel et son imagination accueille le mythe et la légende. Le mythe dantesque du rédempteur qui un jour viendra sauver l'Italie se fond, dans la pensée de Machiavel, avec le mythe romain du dictateur génial qui sauve un peuple du désastre. Peu à peu l'image de César Borgia, dépouillée par le temps de ses faiblesses et de ses misères, purifiée de ses hontes, s'embellit pour l'éternité ; ainsi apparaît celle du prince de génie prêt à sauver l'Italie en ruine; du prince de génie prêt à l'action éclairée par la pensée ; du prince de génie en qui semblent déjà vivre et s'accorder les deux figures tragiques de Michel-Ange qui s'affrontent à Florence dans la Nouvelle Sacristie de Saint-Laurent, l'homme d'action et le penseur; effigies des deux jeunes Médicis auxquels successivement Machiavel dédia son ouvrage, et qui sans doute, ni l'un ni l'autre, ne prirent la peine de l'étudier.

$* * *$

Ainsi vérité et poésie s'unissent dans ce qu'on peut appeler le mythe de César Borgia, parce que vérité et poésie s'unissent dans le mythe du prince. Si l'histoire contemporaine a fourni les indispensables données du réel, l'idée appartient à la tradition, qui, héritée de Pétrarque et de Dante, annonçait un rédempteur. Et de là le caractère révolutionnaire de l'œuvre que, sinon dans le livre destiné à un auditoire princier, mais dans les pages que, glossateur inspiré de Tite-Live, il écrivait pour lui-même, le secrétaire florentin attend de l'homme qui un jour viendra et qui créera, au besoin par la force, un monde nouveau. Car la tradition politique du rédempteur est chez Dante, essentiellement révolutionnaire, comme est révolutionnaire le symbole du Lévrier divin, qui traquera, jusqu'à l'abîme d'où elle est issue, la Louve, toujours plus avide de richesse et de puissance. L'idée d'une régénération violente du monde circule à travers tout le Moyen Age italien ; elle anime l'enthousiasme de Cola di Rienzo ; Pétrarque l'a volontiers accueillie; l'humanisme lui-même l'a faite sienne, dans l'espoir de trouver, auprès de l'antiquité classique, des leçons assez 
ardentes pour relever les modernes de leur abaissement. Idée religieuse autant que p242 politique ou sociale; aussi Machiavel, si étranger pourtant au christianisme, retrouve-t-il naturellement, pour définir l'action de l'homme qui devra rénover toute chose, un texte biblique : «Esurientes implevit bonis, et divites dimisit inanes ${ }^{\text {cclix. }}$. Unies clans le mythe du prince, il est naturel que vérité et poésie s'unissent dans l'exhortation à libérer l'Italie des Barbares. Bien plutôt qu'aux médiocres et douteuses figures de Julien et de Laurent, le réaliste visionnaire s'adresse au rédempteur prédestiné par de mystérieuses prophéties. 


\section{Chapitre III}

\section{La paix, la guerre, les traités}

Machiavel, théoricien du gouvernement légal ou du gouvernement fondé sur la force, laisse apparaître aisément sa préférence pour les États où les citoyens élisent librement leurs magistrats, délibèrent et votent librement dans les assemblées. Il se méfie des États princiers, à moins que l'autorité n'y soit, comme en France, modérée par un ensemble de lois constitutionnelles, et par la présence de corps intermédiaires qui assurent le maintien de la constitution. Les États despotiques lui paraissent offrir un objet intéressant d'étude, lorsqu'ils doivent leur création à quelque tyran de génie. Mais, dans la pratique, il s'entendrait avec Guichardin pour préférer un régime capable d'accorder moins durement discipline et liberté. Enfin les gouvernements d'Église ne sont à ses yeux que survivances paradoxales, et souvent absurdes et malfaisantes, d'un passé que l'histoire condamne. Il n'éprouve nulle amitié pour le gouvernement temporel des papes. II s'inquiète à la fois de ses progrès trop rapides et des symptômes de décadence et de ruine qu'il y découvre ${ }^{\text {ccclx }} \cdot$ p244

$$
* * *
$$

Quels que soient ces divers États, quelles qu'en soient la forme, la constitution politique et les lois fondamentales, la menace à laquelle n'échappe aucune des créations du génie humain plane également sur eux. Ils sont tous périssables, tous exposés à la ruine et à la mort. Tout État, du fait qu'il existe, cherche donc avant tout à se conserver; il ne fait ainsi que suivre la loi dictée par la nature à tous les êtres vivants. 
Ce besoin de conservation perd, quand l'État y obéit, le caractère d'égoïsme qu'il garde le plus souvent lorsqu'il règle la conduite des individus. A la conservation de l'État s'attache un intérêt collectif, qui se décompose en une extrême variété d'intérêts individuels. Comme d'autre part l'État offre à l'esprit humain l'abri qui lui permet d'accomplir son œuvre, cette conservation importe nécessairement à la vie même et à l'avenir de l'intelligence. La loi égoïste qui s'impose à l'État comme à tous les êtres vivants s'élargit et revêt un caractère presque sacré ; s'il doit veiller avant tout à se défendre et à se maintenir, c'est dans l'intérêt des hommes et dans l'intérêt de l'esprit.

La nécessité de cette défense prescrit à l'État un certain nombre de règles, qu'il ne peut éluder sans péril. L'ensemble de ces règles forme, pour soutenir les États dans la concurrence qui sans cesse les met aux prises, comme une éthique de la force guidée par l'intelligence ; éthique hors de laquelle il n'y a pour eux aucun salut.

Elle permet à chacun d'atteindre une plénitude de développement et de stabilité. Elle permettrait à tous de réaliser une sorte d'équilibre où la puissance des uns serait contrebalancée par la puissance des autres. Mais, bien que la pratique vénitienne et florentine puisse l'instruire, et que Laurent le Magnifique ait réussi à maintenir une balance exacte des forces italiennes, Machiavel ne cherche guère à définir la théorie de cet équilibre des États en perpétuelle compétition. Il ne montre pas comment les États peuvent s'accorder entre eux sur le respect mutuel de leur droit à la vie. Il n'a pas étudié, de façon théorique et générale, selon les principes de la morale et du p245 droit, la question des rapports entre les États, ni celle des sacrifices et des renonciations consenties que la fondation d'une harmonie durable exigerait de tous et de chacun. Il n'a pas étudié les conditions de cette harmonie, parce qu'il ne la croit ni possible ni désirable. Il abandonne au libre jeu des lois naturelles la concurrence qui nécessairement s'institue entre les États. A elles seules appartient d'assurer un équilibre, qui, fatalement, puisque tous les États, pour les raisons les plus diverses, ne sont pas également capables de pratiquer l'éthique de la force guidée par l'esprit, ou de la pratiquer avec un égal succès, finit par se rompre au bénéfice du plus vigoureux, du plus habile, du mieux favorisé de la fortune. 
$\mathrm{Si}$, des maximes brièvement énoncées par Machiavel, se dégage une vue générale des relations entre États, elle est et veut être strictement réaliste. Il se borne à constater le fait des luttes qui les mettent aux prises, comme il a constaté le fait de la lutte des classes. Il est ainsi conduit à formuler un certain nombre de règles, que tout État, dans cette concurrence, dit suivre avec soin, s'il ne veut pas être dévoré par un plus fort. Machiavel admet, comme son maitre Polybe, que les affaires humaines parcourent nécessairement, sans progrès et à l'infini, la même suite de révolutions; de la monarchie à la tyrannie, de la tyrannie à l'aristocratie, qui cède la place à la démocratie, condamnée à dégénérer en démagogie ; après quoi, fatalement survient une restauration monarchique, et l'État recommence dès le début la carrière qu'il vient de parcourir. Tel est le cercle où s'inscrit nécessairement l'histoire des peuples. Ils y tourneraient sans fin, si, le plus fréquemment, victimes du désordre et de la faiblesse que provoquent ces variations incessantes, ils ne tombaient sous la loi de quelque voisin, alors mieux discipliné, plus vigoureux, mais destiné lui aussi aux mêmes révolutions, aux mêmes recommencements, à la même ruine ${ }^{\text {ccclxi }}$. C'est pourquoi Machiavel, théoricien de la politique intérieure, cherche désespérément le moyen d'arrêter, le plus longtemps possible, par l'institution d'un régime bien équilibré, le progrès fatal de ces révolutions, sans compter jamais au fond sur une longue période d'ordre et de stabilité. C'est pourquoi Machiavel, théoricien de la politique extérieure, cherche désespérément les moyens de prévenir les dangers p246 auxquels l'assaut livré aux faibles par les forts expose inévitablement l'avenir des États.

Cette vue de l'histoire et de la politique est brutale et triste. Elle est triste comme toute doctrine qui n'ouvre pas, devant l'esprit humain, un avenir infini. Les sociétés humaines, pour Machiavel, ne peuvent aspirer qu'à restaurer ou ranimer ce qui, dans le passé, a déjà démontré son excellence : ressusciter des choses mortes ${ }^{\text {ccclxii }}$. Elle est brutale parce que, tout compte fait, si elle admet, dans la lutte incessante des États, l'action nécessaire de l'intelligence, de l'habileté, du calcul, elle la subordonne en dernière analyse à la force, toujours capable de détruire, mais sans laquelle l'esprit ne peut rien créer. Les prophètes armés ont vaincu; les prophètes désarmés ont subi le discrédit et la défaite. 
Celte vue de l'histoire et de la politique est, de la sorte, essentiellement matérialiste. Machiavel ne pense pas que les idées, à elles seules, aient la puissance de conduire les sociétés humaines : il la dénie aux idées religieuses comme aux idées philosophiques. Les religions ne triomphent point par la seule persuasion; il faut encore que la force et la contrainte les aident à s'imposer ${ }^{\text {cclxiii }}$. Cela est vrai de l'Islam et de l'antique judaïsme. Le christianisme n'a pas échappé à cette règle. Il n'a pu s'imposer qu'à partir du moment où les dirigeants de l'Empire romain l'ont accepté, où Constantin et ses successeurs ont mis officiellement au service de la nouvelle religion les forces matérielles et politiques de l'Empire. Machiavel a vu succomber Savonarole, prophète désarmé ; un siècle plus tôt Jean Hus, prophète sans armes, avait péri. Mais, sous les yeux de Machiavel, Luther, prophète armé, tenait en échec, à l'aide de la force des princes allemands, l'empereur et le pape. La dialectique des idées pures ne suffit pas à conduire le monde; et Machiavel ne croit guère aux victoires de l'esprit que la force ne seconde pas.

Ainsi très sommairement s'ébauche une sorte de matérialisme historique, où manque naturellement, Machiavel n'étant point un économiste, la base économique sur laquelle Marx et Engels fondèrent leur doctrine. Du moins serait-il aisé d'amener ${ }_{\text {p247 }}$ Machiavel à conclure que l'idée ne s'impose qu'une fois incorporée à la force matérielle, et que la force ne sert l'idée que dans la mesure où les hommes sont portés par leur intérêt, par la représentation juste ou fausse, raisonnée ou passionnée qu'ils s'en font, à suivre l'idée. Le dernier mot de la politique serait donc, pour reprendre une formule de Pascal, d'apprendre aux hommes l'art de bien penser; c'est-à-dire d'acquérir une notion juste, exacte, scientifique, de leurs véritables intérêts, d'en dégager une idée d'action, et d'armer ensuite cette idée.

\section{$* * *$}

La politique de Machiavel, toute positive, admet la guerre comme un fait naturel, normal et nécessaire. Toutes les fois qu'un État se juge menacé dans sa sécurité ou dans ses intérêts, ou revendique un avantage qu'on lui dispute, la guerre est pour lui le seul et suprême recours. Il n'en existe pas d'autre. L'équilibre, d'ailleurs toujours précaire, qui s'établit entre les nations, ne s'établit qu'au moyen des luttes, des victoires et des désastres des nations. Machiavel admettrait 
aisément que, dans la concurrence qui s'institue entre les peuples, la guerre aboutît à réaliser une sélection naturelle en faveur des plus intelligents et des plus courageux, et, en dernière analyse, des plus forts, de ceux qui ont le plus vigoureusement armé l'idée qu'ils représentent parmi les peuples. Inutile d'insister sur les doctrines modernes auxquelles s'apparente celle théorie de la guerre; ni sur les rapports qu'elle offre avec telle doctrine darwinienne, de caractère purement naturaliste et positif; ni sur l'accord élémentaire de cette théorie avec la philosophie hégélienne de l'histoire; ni sur le prolongement qu'elle a pu trouver chez les disciples de Hegel.

$$
\text { *** }
$$

Dante avait eu l'occasion de se poser le même problème, de le résoudre dans un autre esprit. Le contraste où, sur la question des rapports entre les États, la pensée de Machiavel s'oppose à la pensée de Dante, aide à comprendre et à saisir ce que signifie, dans l'histoire générale des doctrines politiques depuis p248 la fin du Moyen Age, l'apparition de la politique positive et réaliste de Machiavel.

Le poète gibelin n'écarte pas l'ambition de réformer le monde chrétien tout entier. Il lui voudrait imposer un ordre tout idéal, fondé sur certaines conceptions, théoriques, de caractère moral et religieux. Ordre dont il n'emprunte et ne peut emprunter aucun élément au réel, à la réalité politique, ou même religieuse et morale, que, dans les premières décades du XIV siècle, l'Occident chrétien offrait à son étude. Car les deux institutions qui lui servent de base pour reconstruire le monde, sont l'une et l'autre, empire et papauté, dégradées et déchues ; et l'éthique chrétienne qui devra soutenir l'effort de restauration aura besoin elle-même d'être reconduite à l'esprit de ses origines. Mais, armé d'une vérité qui possède un avenir éternel, il décrit les étapes d'une réforme intellectuelle et morale de l'individu; il trace le plan d'une rénovation du monde chrétien, par la restauration de l'Empire et la réforme de l'Église ${ }^{\text {ccclxiv }}$.

La différence essentielle qui oppose Machiavel à Dante ne consiste pas seulement dans l'abandon d'un programme où le réalisme du secrétaire florentin ne reconnaît qu'illusion. Dante veut organiser la société chrétienne selon certaines exigences de l'esprit. Machiavel y renonce, et la laisse trouver d'elle-même son équilibre, par le simple jeu 
des forces qu'elle porte en elle. Jeu que l'esprit, au besoin, peut seconder, mais qu'il ne se hasarde pas à contrarier et à conduire. Dante pose en principe que les conflits des groupes humains doivent se résoudre en un apaisement et une harmonie suprêmes, conformes à certains postulats du sentiment, à certaines affirmations de l'intelligence. Machiavel n'aperçoit et ne veut apercevoir à ces conflits aucune fin. Il admet que la lutte, la rivalité, la concurrence, la guerre, constituent la norme selon laquelle se développe la destinée de l'espèce. Il admet cette lutte comme un fait, donné par la nature, fatal, inéluctable ; il juge totalement vain d'y chercher un remède. Le seul ordre qui puisse s'établir entre les États perpétuellement et fatalement en lutte, est l'ordre de hiérarchie que la force peut imposer au bénéfice du plus fort. Ordre qui d'ailleurs ne peut, comme toute chose humaine, être que provisoire. Il en résulte que Dante, lorsqu'il songe à l'avenir des sociétés humaines, pense d'abord et avant ${ }_{\text {p } 249}$ tout à organiser la paix. Machiavel ne pense qu'à préparer et déchaîner la guerre.

$$
* * *
$$

La condamnation de la guerre, chez Dante, ne procède pas d'une simple répugnance du sentiment. Elle ne procède même pas uniquement de la morale de l'Évangile. Dante s'attarde peu à protester contre le caractère antichrétien de conflits sanglants entre les hommes dont le sacrifice du Rédempteur a fait des frères. Elle ne s'inspire pas uniquement des doctrines religieuses et des croyances religieuses dont vit l'âme passionnée du poète. Elle se fonde aussi sur la raison : « Il nous faut voir, écrit-il, vers quelle fin tend la civilisation humaine tout entière : car Dieu et la nature ne font rien qui reste inopérant. Il existe donc une œuvre en vue de laquelle tout le genre humain est ordonné. » Celte œuvre, par définition, dépasse et l'individu, et la famille, et le clan, et la cité, et l'État. Elle est le terme fatal de l'effort collectif des hommes ${ }^{\text {ccclxv }}$. Cette œuvre, nécessairement proportionnée et coordonnée à la puissance de l'humanité prise dans son ensemble, Dante la définit à l'aide d'éliminations successives. Poète intellectualiste, il la conçoit comme purement intellectuelle : «L'œuvre propre du genre humain, à le considérer tout entier, est de faire passer à l'acte toutes les puissances qui se trouvent contenues virtuellement dans l'esprit. » Il commente cette formule d'un humanisme essentiel : «L'intelligence humaine doit se porter d'abord à la spéculation ; puis, 
appliquant la théorie à la pratique, elle travaille à guider l'action selon ses vues ${ }^{\text {ccllxvi }}$. » Ainsi l'humanité ne ${ }_{\mathrm{p} 250}$ remplit son destin que par le progrès de l'intelligence, qui sans cesse éclaire et conduit la charité agissante. Qu'un tel effort soit œuvre presque divine, le psalmiste luimême en témoigne, qui écrit: «Tu n'as abaissé l'homme que d'un degré au-dessous des anges ${ }^{\text {cclxvii }}$. » Cette œuvre ne peut s'accomplir véritablement que sous le règne de la paix universelle. Il en résulte avec évidence que la paix universelle est le plus haut des biens dispensés aux fins de la béatitude humaine : «Et c'est pourquoi, — ajoute Dante, qui, après avoir établi sa démonstration en philosophe, conclut en chrétien - , les anges, dans la nuit de Noël, n'annoncèrent aux bergers ni la richesse, ni les honneurs, ni la longévité, ni la santé, ni la force, ni la beauté, mais la paix : "Gloire à Dieu au plus haut des cieux et paix sur la terre aux hommes de bonne volonté ccclxviii. »

Mais Dante n'est, pour Machiavel, qu'un prophète désarmé et vaincu. Pour la politique réaliste de Machiavel, la défaite de Dante est le signe et la preuve de son erreur. Pourtant, le désaccord entre les deux penseurs ne porte pas seulement sur la conception que l'un et l'autre se font de l'avenir humain, alors que l'un veut l'ordonner selon l'esprit, et que l'autre l'abandonne aux triomphes de la force. La table des valeurs ne s'établit pas, chez l'un et chez l'autre, selon les mêmes principes ou les mêmes préférences. Dante est avant tout philosophe et théologien. Il vit avant tout par l'esprit, et c'est à la vie de l'esprit que, parmi les formes d'action que crée la société humaine, il attribue une dignité éminente et une éclatante primauté. Il est un clerc, riche de tout le savoir encyclopédique des Universités; il a étudié Aristote et les philosophes, saint Thomas et les théologiens ${ }^{\text {ccclxix }}$. Machiavel n'a rien d'un clerc. $\mathrm{Il}_{\mathrm{p} 251}$ ignore et dédaigne la théologie ; il ne sait pas philosopher selon les règles. Le système d'idées abstraites où les philosophes essaient de captiver et d'enfermer la réalité ne l'attire pas. Il n'en éprouve pas la curiosité. Il n'a pris nul intérêt dans sa jeunesse aux travaux de l'Académie florentine ; il a vu avec indifférence Marsile Ficin ou Pic de la Mirandole reconstruire et moderniser le vieux néoplatonisme, et l'accorder avec un catholicisme modernisé. Il n'est même pas un véritable humaniste ; sa culture antique et classique reste bornée ; il ne sait guère le grec. Il pense en homme d'action, formé essentiellement par la pratique, par l'expérience du gouvernement intérieur de Florence, par l'expérience de la politique italienne et euro- 
péenne, par l'observation des gouvernements italiens ou étrangers et de leurs lois. Homme d'action qui, pour contrôler et compléter ce qu'il a pu ainsi apprendre, a lu, de près, quelques historiens et quelques théoriciens de la politique. Homme d'action qui, d'Aristote, n'a lu que la Politique, et n'a pas lu, vraisemblablement, la République de Platon; et qui, aux traités politiques de Cicéron, préfère Tite-Live. Aussi, lorsque Dante propose, comme but suprême à l'activité des sociétés humaines, de « faire passer à l'acte toutes les puissances contenues virtuellement dans l'esprit », Machiavel ne comprend pas, ou cesse d'écouter. Car il n'assigne d'autre but à l'activité des sociétés humaines que le développement de la force et la conquête de la puissance ; alors que le poète, menant son analyse, a successivement éliminé tout ce qui se rapporte à la force et à la puissance, refusé de trouver, dans la force et la puissance, autre chose que des moyens subordonnés au progrès de l'esprit, et qui, pour permettre à l'esprit d'accomplir sa tâche, doivent se plier à une discipline de paix universelle. Sans doute Machiavel n'ignore pas que la conservation de l'État est nécessaire à l'œuvre de l'esprit. Mais, s'il le reconnaît, il n'y voit pas l'essentiel. Et jamais il n'a pensé un instant d'imposer à une politique réaliste et positive, comme norme à laquelle tout dût se réduire, l'accomplissement de l'œuvre collective de l'esprit humain.

Machiavel avait achevé le Prince depuis la fin de 1513, il travaillait à composer les Discours sur la première Décade de Tite-Live, quand, à Bâle, en 1515, Érasme donna une nouvelle édition, p252 singulièrement accrue, des Adages, déjà publiés à Venise sept ans plus tôt. Pour la première fois, certaines pièces, comme Dulce bellum inexpertis, apparaissent à la fois comme des essais familiers et comme les manifestes d'un programme politique et religieux, aussitôt multipliés comme tels par les presses de Bâle, de Strasbourg, de Mayence, de Cologne, de Leipzig, de Louvain, d'Anvers et de Paris. L'année suivante, l'édition princeps du Nouveau Testament grec, publiée à Bâle en février 1516, lui offrait l'occasion de définir, commentateur de l'Évangile, son idéal de paix chrétienne. A Louvain, avant la fin de la même année, Thomas More, qu'une étroite amitié unissait depuis la fin du siècle précédent à Érasme, publiait son Utopie ou traité de la meilleure forme de gouvernement. La même année, sortait des mêmes 
presses l'Institutio principis christiani d'Érasme. L'année suivante, à Bâle, chez Froben, Érasme publiait la Querimonia pacis undique profligatae : plainte de la paix chassée de tout lieu ${ }^{\text {ccclxx }}$.

Érasme et Thomas More s'accordent à condamner le recours à la guerre pour trancher les querelles pendantes entre les États : « Les habitants de l'île d'Utopie, écrit Thomas More, détestent la guerre comme une chose bestiale ; encore n'existe-t-il pas d'espèce animale qui s'y livre de façon aussi permanente que l'homme. Ils la détestent au suprême degré, et, contrairement à l'opinion de presque tous les peuples, ils considèrent que rien n'est plus inglorieux que la gloire recherchée à la guerre. Toutefois ils se plient régulièrement à la discipline militaire, les femmes comme les hommes, afin d'éviter d'être inhabiles aux armes s'il fallait s'en servir. Mais ils déclarent la guerre à contrecœur, et seulement pour défendre leur territoire, ou repousser des ennemis qui auraient envahi un pays allié, ou par sympathie envers un peuple accablé sous un régime tyrannique. En pareil cas, ils agissent par humanité, afin de l'affranchir du despotisme et de la servitude, ils prêtent secours à leurs amis, non pas seulement pour les défendre, mais parfois aussi pour les venger des injures subies. Toutefois une victoire sanglante leur inspire de la tristesse et même de la honte ; car ils estiment folie de payer d'un prix trop cher le bien même le plus précieux. " ${ }^{\text {ccllxxi }}$. Ainsi se développe l'humaine fantaisie de Thomas ${ }_{\mathrm{p} 253}$ More. Mais la critique d'Érasme est plus résolument hardie et révolutionnaire.

Il voit l'Europe divisée, depuis la première descente de Charles VIII en Italie, par des coalitions qui ne cessent de tenter, sans succès durable, la fortune des armes. Les princes temporels s'y décident pour la vengeance d'injures imaginaires ou pour la défense de droits prétendus. Ils cherchent dans la guerre une diversion aux querelles de la politique intérieure. Les papes entrent dans les alliances des princes et se compromettent dans leurs aventures. Théologiens et moines trouvent des arguments pour justifier le recours à la force. Mais un prince chrétien ne doit jamais entreprendre la guerre s'il peut l'éviter. Il doit la conduire en ménageant des vies humaines, et la terminer au plus tôt. L'auteur de l'Institutio conseille donc aux princes de bien gouverner leurs domaines plutôt que de les agrandir. Les affaires de la France, si riche de tous biens, iraient mieux si ses rois n'avaient pas tenté la conquête de l'Italie. Pour fonder une paix durable, Érasme 
propose que l'on fixe en termes clairs les frontières des États; puisque les successions princières mettent si souvent les peuples aux prises, il demande que les fils des rois s'interdisent tout projet d'établissement hors de leur domaine, et que, pour les couronnes vacantes, on consulte au besoin le suffrage populaire. Mais la guerre sans cesse renaissait de la guerre, et les violences déchaînées poursuivaient leur cours. François $\mathrm{I}^{\mathrm{er}}$, vaincu à Pavie et prisonnier à Madrid, y acceptait un traité de démembrement que, rentré dans son royaume, il désavouait pour reprendre les armes; et bientôt les lansquenets de Charles-Quint venaient démontrer au pape, dans Rome saccagée, le péril où se risquait le Saint-Siège, à conclure, avec les princes temporels, des accords particuliers ${ }^{\text {ccclxxii }}$.

Érasme, comme Dante, constate et mesure le désordre d'un monde sans loi et sans règle, abandonné à la violence et à l'oppression. Il pense, comme Dante, que toutes ces misères ont pour source profonde l'affaiblissement de l'esprit chrétien. Comme Dante, il pense que les œuvres de l'intelligence et de la charité postulent la paix universelle ; que la paix universelle peut seule permettre à l'humanité de remplir son destin. Il sait ${ }_{\mathrm{p} 254}$ que tant de misères ne peuvent trouver de remèdes que dans un retour à l'Évangile. Mais, guère plus que Machiavel, il n'accorde confiance au siège romain, et ne croit la papauté réformable. Également, il dénie à l'empereur la mission de pacificateur suprême. Il sait les Habsbourg avides uniquement de domination territoriale, de force matérielle, de puissance. L'idée d'Empire, que Dante exalte, lui paraît aussi dérisoire et vide qu'à Machiavel, aussi malfaisante, propre à entretenir en Europe des querelles sans fin; et quand, au printemps de 1527, la chancellerie impériale lui offre le soin de publier le De Monarchia dantesque, il se dérobe ${ }^{\text {ccclxxiii }}$.

Si Machiavel, quelques années après l'achèvement du Prince, et tandis qu'il continuait d'écrire les Discours sur la première Décade, eut la vraisemblable curiosité de lire l'Institutio ou le Querela, le mâ̂tre de l'humanisme européen dut lui apparaitre comme un de ces prophètes désarmés dont son ironie dédaignait la faiblesse. Érasme, prophète désarmé, n'obtenait pas l'audience des maîtres de la terre. A leur prêcher la paix, il se rendait importun. Il s'attristait et s'indignait d'entendre, dans la chaire chrétienne, la parole du Christ publique- 
ment trahie. Machiavel, offrant aux princes une doctrine de conquête et de guerre, répondait mieux qu'Érasme à leurs instincts profonds et à leurs désirs de force et de puissance.

$\underline{\text { Table des matières }}$

\section{II}

Les relations naturelles qui s'établissent entre les États, fatalement engagés dans une concurrence mortelle aux faibles, imposent à tous une éthique de force et de raison.

Elle se fait stricte et impérative pour un État civilement gouverné, dent la forme peut être monarchique ou républicaine, mais dont la conduite exige l'approbation des citoyens ou de leurs représentants. Un tel État devrait puiser sa vigueur dans le dévouement des individus à l'intérêt commun. Le sentiment ${ }_{\mathrm{p} 255}$ national y devrait atteindre le plus haut degré de vigueur. Et pourtant il arrive que de tels États ne sachent pas montrer, dans leurs rapports avec l'étranger, fierté et résolution. Machiavel a souffert de la lenteur avec laquelle, sous le gouvernement de Soderini, la république florentine décidait et agissait. Or la lenteur à résoudre accuse la faiblesse d'un État; les décisions hâtivement prises, au dernier moment, ont causé des désastres. Il cite, comme d'habitude, Tite-Live; il rappelle aussi quelques épisodes d'une récente histoire. Mais rien n'est pire que de pratiquer entre deux adversaires une neutralité fatalement suspecte à l'un et à l'autre ; neutralité que Florence avait sans cesse tenté d'observer entre Louis XII et Ferdinand, Louis XII et Maximilien, Louis XII et Jules II, entre César Borgia et ses adversaires, et que la diplomatie de Machiavel avait dû trop souvent défendre pour n'en ignorer ni les dangers ni les humiliations ${ }^{\text {ccclxxiv }}$.

État civilement gouverné, comme Florence, plus puissant que Florence, Venise avait plus mal encore pratiqué l'éthique de la force. Sa politique arrogante apparut, lors des revers, incapable de fierté et de dignité : «Dans la bonne fortune, écrit-il, les Vénitiens, persuadés de l'avoir obtenue par des vertus qu'ils n'avaient pas, montrèrent un orgueil insolent; ils appelaient le roi de France fils de saint Marc; ils 
n'estimaient pas la force du Saint-Siège ; l'Italie leur semblait trop étroite pour les contenir; ils s'étaient mis en tête d'égaler Rome par la grandeur de leur empire. Mais quand Louis XII, à Agnadel, leur infligea une défaite qui n'était pourtant pas sans remède, ils perdirent, par le soulèvement des populations sujettes, leurs domaines ; ils en abandonnèrent, par lâcheté et bassesse de cœur, une partie au pape et au roi d'Espagne; ils s'avilirent au point d'envoyer une ambassade à l'empereur pour lui payer tribut; ils adressèrent au pape une lettre pleine de lâcheté et de soumission. Et quelques jours leur suffirent pour tomber à ce dernier abaissement. » ${ }^{\text {ccllxxv }} \cdot$ p256

Mais ces défaillances s'expliquent, en dernière analyse, par la mauvaise qualité des lois. Le fait, pour les Vénitiens, est évident. Si leur constitution avait été vraiment vigoureuse, ils auraient pu reprendre courage, et, du moins, perdre plus glorieusement la partie. Leur lâcheté, effet de la faiblesse de leurs institutions militaires, leur fit perdre à la fois terres et courage : et il arrivera de même à quiconque

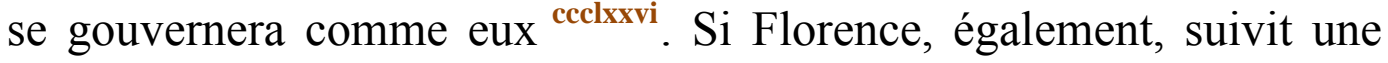
politique débile, on en doit accuser certains défauts de la constitution. «Tous les États reposent sur deux bases essentielles, les bonnes lois et les bonnes armes. » En dernière analyse, le premier principe se réduit au second : il ne peut y avoir de bonnes lois où il n'y a pas de bonnes armes ${ }^{\text {ccllxxvii }}$. Les institutions politiques et sociales d'un État ne sont ni complètes ni bien assurées, s'il ne possède pas une solide armature militaire. Non pas seulement en raison du danger extérieur; mais un tel État néglige de cultiver chez le citoyen certaines vertus, créatrices de résolution et de fierté. Quand le gouvernement, pour assurer la défense publique, fait appel à des mercenaires, le peuple, inhabile aux armes et incapable de constance et de sacrifice, accepte aisément, à l'intérieur, le despotisme, à l'extérieur, de lâches accommodements et la défaite. Inversement, où les institutions militaires sont bonnes, les lois ne peuvent être que bonnes. Les lois que se donnent ou qu'acceptent des citoyens régulièrement armés pour la défense de la cité, ne peuvent, même sous un gouvernement monarchique, présenter un caractère de servitude et de tyrannie ${ }^{\text {ccclxxviii }}$. p257 Il n'est donc pas de bonnes institutions civiles sans bonnes institutions militaires; et des citoyens soldats ne tolèrent pas aisément, à l'extérieur, une politique de faiblesse. Ainsi la véritable base de tout État est la bonne milice. La République florentine se montra faible, parce que les Médicis 
avaient désarmé le peuple, et que Machiavel n'eut pas le temps d'ordonner et d'exercer les milices citoyennes, ni d'habituer les citoyens à penser en soldats. A Venise, une oligarchie de marchands qui, désarmant le peuple, avait fondé sur la constitution d'une cité libre en apparence la plus jalouse tyrannie, paya sa mauvaise politique d'une accablante défaite.

L'éthique de la force guidée par la raison s'impose naturellement, par la nécessité même de leur conservation, aux États despotiques. Mais ici le problème se définit en termes nouveaux. Il ne s'agit plus des vertus collectives qui conviennent à un peuple libre et à un gouvernement de citoyens. Il s'agit des vertus d'un homme, responsable à lui seul du gouvernement d'un État. La force et la dignité s'inscrivent de la sorte au nombre des vertus sans lesquelles un prince ne peut remplir ses devoirs envers lui-même, ses peuples et son État. Elles exigent de lui le cœur d'un soldat, le talent militaire, la hardiesse qui appelle et reçoit la confiance des hommes. Pareilles vertus, familières à César Borgia, manquèrent singulièrement aux tyrans de l'Italie du Nord, éperdus devant l'invasion.

Machiavel a négligé de dire comment, dans une république, doit s'effectuer le partage des pouvoirs entre les magistrats civils et les généraux. Son idéal, sans doute, serait celui de la république romaine, où consuls et préteurs, magistrats civils, savaient aussi commander les armées ${ }^{\text {ccllxxix }}$. Machiavel définit avec ${ }_{\mathrm{p} 258}$ plus de soin le rôle militaire d'un prince constitutionnel ou d'un despote ${ }^{\text {cclxxx }}$. Il doit, d'abord et avant tout, être un soldat. Il doit se réserver tout ce qui concerne la guerre et la milice. La cause essentielle qui l'ait acquérir ou perdre un État est le talent militaire ou la négligence de l'art militaire. Francesco Sforza, parce qu'il excellait dans le métier des armes, devint, de simple particulier, duc de Milan. Ses fils, impropres à la vie des camps, redevinrent simples particuliers. Pendant la plus grande partie du $\mathrm{XV}^{\mathrm{e}}$ siècle, les petits États de la péninsule n'avaient cessé de se déchirer; depuis 1494, l'Italie était devenue le champ de bataille où les coalitions européennes tranchaient par la force des armes leurs querelles. Machiavel avait vu grandir César Borgia par la force de ses armes. Un 
an avant d'écrire le Prince, il avait vu la République de Florence, faute d'esprit guerrier, et pour avoir voulu conserver, entre les grands États en guerre, les avantages douteux de sa neutralité, tomber en ruine. Instruit par les événements, il impose au prince les devoirs du soldat.

Tout gouvernement, républicain ou monarchique, ne recrutera ses troupes que parmi les citoyens. Les mercenaires ne conviennent ni aux États princiers, ni aux cités libres. Ce principe, que Machiavel a conçu dès son entrée dans la vie active, s'impose à la fois par les nécessités de la défense contre les ennemis du dehors et les convenances de la politique intérieure. Machiavel a pu constater de ses yeux, au camp devant Pise, la trahison des chefs de bande. Les troupes mercenaires sont indisciplinées, infidèles et lâches. La solde seule les retient sous les drapeaux ; mais elle ne saurait garantir le dévouement d'hommes qui se vendent à qui les paie. La ruine de l'Italie a pour cause première leur trahison. Elles semblaient vaillantes lorsqu'elles combattaient entre elles; une fois l'étranger venu, elles montrèrent ce qu'elles étaient: et Charles VIII put occuper l'Italie sans autre peine que de marquer à la craie les logements. p259 Carthage, après la première guerre punique, faillit succomber à la révolte de ses mercenaires. Venise, qui fit de grandes choses tant qu'elle recruta ses armées dans sa noblesse et dans son peuple, a récemment, par la faute des mercenaires, perdu en un jour ce qu'elle avait acquis en plusieurs siècles. Tout le génie des chefs de bande, dont villes et princes s'étaient disputé les services, n'a pu empêcher les campagnes de Charles VIII et de Louis XII, les violences de Ferdinand et des Suisses. Machiavel, à Florence, avait tenté la reconstitution des vieilles milices citadines, qui, tardivement organisées par des hommes de médiocre compétence, n'avaient pu, en 1512, sauver la République. Mais le principe de l'armée nationale subsiste indiscutable: Machiavel voudrait la voir s'ordonner selon le modèle macédonien ou romain, ou sur le type qu'offrent, dans le monde moderne, les Cantons Suisses ${ }^{\text {ccclxxxi }}$.

Tout gouvernement, despotique ou civil, évitera de solliciter le concours militaire d'une puissance alliée. Florence, qui, en guerre contre Pise, recourut à l'aide de Louis XII, n'en tira nul avantage. Un prince habile aime mieux être vaincu à la tête de ses troupes, que devoir une victoire, aux forces d'autrui : «Je n'hésiterai jamais, écrit Machiavel, à rappeler l'exemple de César Borgia. Il entra en guerre et 
conquit la Romagne avec l'aide des troupes françaises. Il prit, grâce à elles, Imola et Forlì. Puis, comme elles ne lui paraissaient pas suffisamment sûres, il chercha des mercenaires, prit à sa solde les Orsini et les Vitelli. Bientôt, à l'usage, il les trouva douteux, infidèles, dangereux. Il s'en débarrassa, et ne fit plus la guerre qu'au moyen de ses propres soldats; et l'on peut constater que sa réputation s'accrut singulièrement dès qu'il fut seul maître de son armée. ${ }^{\text {ccclxxxii }}$. Et Machiavel, qui sait l'histoire de la France, et qui a eu l'occasion d'étudier sur place, à plusieurs reprises, les ressources du gouvernement français, cite un autre exemple. Charles VII, une fois son royaume reconquis sur les Anglais, comprit la nécessité de se procurer une armée qui fût à lui ; il ordonna la levée régulière des gens d'armes et de l'infanterie. Mais Louis XI renonça bientôt à équiper des fantassins, et commença ${ }_{\text {p260 }}$ de prendre à sa solde des mercenaires suisses. Cette faute, où tombèrent également ses successeurs, fut cause des dangers que la France a courus. Elle a de la sorte laissé croître la réputation des Suisses, et abaissé la valeur de ses propres forces. Elle n'a plus d'infanterie, et ses gens d'armes ont tellement pris l'habitude de faire campagne avec les Suisses, qu'ils ne se croient plus capables de vaincre sans eux. Or le royaume de France serait invincible, si les institutions militaires de Charles VII avaient été développées ou simplement maintenues ${ }^{\text {ccclxxxiii }}$.

Machiavel ne s'attarde pas à décrire l'éducation militaire d'un général républicain. Mais le prince, organisateur et chef d'armée, devra savoir l'art de la guerre et s'y exercer. Telle sera son occupation la plus constante. Machiavel lui impose l'éducation physique, morale et technique d'un officier de métier : " Le prince, écrit-il, ne doit jamais éloigner sa pensée de la préparation à la guerre ; en temps de paix, il doit s'y préparer plus encore qu'en temps de guerre. $"{ }^{\text {cclxxxiv }}$. La pratique et l'étude sont également indispensables à un homme que l'honneur et le souci de la réputation obligent à commander en personne. Par la pratique, Machiavel entend, outre l'art de conduire les troupes en manœuvre, l'entraînement aux exercices physiques, et d'abord la chasse ; l'acquisition, sur le terrain, des connaissances de géographie nécessaires au commandement des armées : "Il faut, dit Machiavel, apprendre la nature des sites, la disposition des chaînes de montagnes, des vallées, des plaines, des cours d'eau, des zones marécageuses : ce qui permet au prince de bien connaître son propre pays, 
et par suite, de mieux en concevoir la défense ; en même temps, de comprendre par analogie l'aspect et le caractère physique des autres pays où il peut avoir à porter la guerre. Car les sommets, les vallées, les plaines, les fleuves, les marais de Toscane présentent certaines ressemblances avec ce qu'on peut trouver dans les autres régions d'Italie ; on passe aisément de la connaissance de l'une à la connaissance des autres. " ${ }^{\text {ccllxxxv }}$. L'homme de guerre à qui manque cet apprentissage du terrain sait mal son métier. Machiavel exige p261 en même temps l'étude méthodique de l'histoire militaire. Il cite l'exemple de Scipion, affirme l'utilité pratique de la Cyropédie. Il semble assez mal entendre la guerre moderne; il en parle comme si l'artillerie n'existait pas ${ }^{\text {ccclxxxvi }}$.

$* * *$

Machiavel affirme qu'en raison de la violence constante des rapports que la concurrence vitale établit entre les États, leurs chefs doivent avant tout être des chefs d'armée. Dans le monde tel qu'il est, rien n'augmente le prestige d'un État ou d'un gouvernement plus que des guerres heureuses et des conquêtes. C'est par là que Ferdinand d'Aragon est devenu le premier roi de la chrétienté ccclxxxvii.

Une question pourtant n'est pas abordée, qui aurait dû retenir l'attention d'un politique réaliste. Les avantages matériels, que le chancelier florentin veut uniquement évaluer, peuvent-ils jamais compenser les destructions de biens et les pertes de vies humaines ? Érasme le nie : un prince appliqué à l'administration, à la mise en valeur de son État, réalise plus de bénéfices qu'un conquérant. Il cite les exemples récents et inoubliables de Charles le Téméraire, duc de Bourgogne, de Charles VIII, de Louis XII. La conquête de Naples et de Milan n'a jamais renforcé le pouvoir des rois de France, et n'a eu d'autre effet que de compromettre, par les dépenses dont elle accablait l'État, la prospérité du royaume. Érasme constate que la politique guerrière menée par les princes depuis la néfaste campagne de Charles VIII les ruine et ruine leurs sujets : "Les affaires des rois vont mal, écrit-il dans un Colloque de 1526. François I ${ }^{\mathrm{er}}$ est, contre son gré, l'hôte de Charles-Quint; l'empereur poursuit à grands frais son rêve de monarchie universelle. Tous les princes se ruinent à suivre et à servir par les armes l'un ou l'autre. Toutes les cours éprouvent une pareille fringale de pécune. \" ${ }^{\text {ccclxxxviii }}$. Même quand les peuples n’ont pas 
à subir le passage ${ }_{\text {p262 }}$ des armées amies ou ennemies, ils se privent durement pour payer les frais du jeu cruel mené par les rois. Érasme rappelle, en quelques mots, l'augmentation des tailles, des douanes, des péages, les prélèvements de la fiscalité sur les produits les plus indispensables, les pilleries des gens de finance, le trouble de la circulation monétaire. Il juge donc et déclare à maintes reprises que toute guerre, même heureuse, est un désastre ; l'accroissement de prestige ou de territoire que le succès le plus éclatant peut apporter est toujours payé si cher que la perte excède nécessairement le bénéfice ${ }^{\text {ccclxxxix }}$.

Machiavel ne se pose guère ces questions. Diplomate, politique, théoricien un peu retardataire des méthodes stratégiques, son information économique est moins riche, moins variée, moins curieuse du réel que l'expérience d'Érasme. Sans doute, il sait que certaines entreprises, mal conçues et mal dirigées, ne rapportent rien. Sans doute considère-t-il comme absurde, mal conduite et ruineuse pour la France, la politique royale de conquête italienne. Il ne juge pas beaucoup plus favorablement les efforts de Charles-Quint pour imposer aux princes chrétiens d'Occident l'autorité restaurée d'une monarchie universelle. Mais en revanche il semble admettre que certaines entreprises militaires, bien étudiées et bien menées, ont valu des avantages positifs et réels à certains princes et à certains États ${ }^{\text {ccxxc }}$. Ferdinand le Catholique n'aurait pas imposé le respect de la puissance espagnole à l'Europe si des guerres heureuses n'avaient mis à sa disposition les

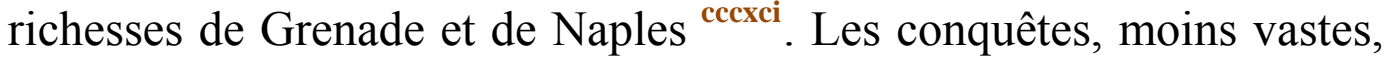
de César Borgia lui auraient certainement assuré les ressources nécessaires pour soutenir l'existence du nouvel État qu'il fondait. Mais surtout Machiavel se souvient des progrès de la grandeur romaine. La conquête de l'Italie, de la Méditerranée, de l'Orient, a mis à la disposition de Rome les trésors du monde. Il sait comment le Sénat préparait et conduisait des campagnes brutales, rapides, infaillibles, et, sur les p263 terres de l'ennemi aussitôt confisquées, installait des colonies pour consolider la conquête. Il sait, comme Montesquieu, que Rome excellait à ruiner les vaincus par la paix après les avoir ruinés par la guerre, en les condamnant à payer des tributs qui faisaient passer aux mains du Sénat la plus grande partie de leurs ressources ${ }^{\text {cccxcii }}$. Grâce à ces méthodes, la guerre enrichit Rome, alors qu'elle appauvrit les États malhabiles. La question des avantages à tirer de la guerre semble ainsi pour Machiavel se confondre avec le problème de l'organisation 
et de l'exploitation des pays conquis ${ }^{\text {ccxciii }}$. Et le débat aboutit à marquer le contraste entre la pratique savante de Rome et les maladresses des rois français en Italie ${ }^{\text {cccxciv }}$.

Il faut de nouveau marquer les limites où s'enferme le génie de Machiavel. Théoricien et praticien de la politique, il n'a étudié qu'en homme politique le fait de la conquête et de l'organisation de la conquête. Il n'a étudié qu'en homme politique la conquête romaine ou les conquêtes françaises en Italie. Il ne considère qu'en homme politique les récentes conquêtes espagnoles. Il n'a pas étudié les conséquences que, pour l'économie romaine ou la société romaine, produisit la possession d'un empire. Sans doute, il n'est pas sans en reconnaître les effets pernicieux pour l'avenir des institutions et des libertés républicaines. Avant Montesquieu, il comprend et il affirme que la république a péri par la prolongation des commandements, fruit de la conquête ; par le fait que les armées, trop longtemps p264 éloignées de Rome et de l'Italie, changeaient de caractère, et, de citoyennes, devenaient prétoriennes, exclusivement dévouées aux ambitions inciviques des généraux ${ }^{{ }^{c c c x c v}}$. Mais il ne parle qu'en politique. Il n'a pas noté l'enrichissement énorme d'une aristocratie de plus en plus étroite, la disparition de la classe moyenne et des petits propriétaires, le développement et la multiplication d'une populace agitée, impuissante en face de ses maîtres et prête à suivre les factieux; la corruption sans cesse aggravée des mœurs, le mépris grandissant des lois. Même la conquête espagnole, dont, politique avant tout, il n'a vu que les résultats politiques, le prestige et la grandeur de la monarchie castillane et aragonaise, allait rapidement provoquer d'autres effets, qui déjà, de son vivant, se laissaient apercevoir: la ruine presque immédiate de l'Italie espagnole, exploitée de façon désastreuse par ses nouveaux seigneurs ; la décadence de l'économie et de la société espagnole dès la seconde moitié du règne de Charles-Quint. De la sorte, même en admettant avec Machiavel que la question des avantages pratiques de la guerre se confonde avec le problème de la conquête, il ne semble pas en avoir analysé, avec l'ampleur, la précision et la curiosité suffisantes, les éléments.

Érasme, instruit par le spectacle du désordre européen depuis un demi-siècle, et naturellement enclin à une vue pessimiste des choses, conduit, d'ailleurs, par son évangélisme sans dogme à réprouver l'usage de la violence et à nier les triomphes apparents de la force, a 
conclu, trop vite peut-être, que la guerre, dans tous les cas, est toujours une mauvaise affaire, désastreuse pour le vainqueur presque autant que pour le vaincu. Machiavel, trop évidemment émerveillé des triomphes de la République romaine; trop facilement ébloui, ce qui était plus grave, par ${ }_{\mathrm{p} 265}$ les triomphes de Ferdinand en Espagne et en Italie, et par les triomphes éphémères de César Borgia, a trop aisément admis la thèse opposée ; trop aisément admis et enseigné que la guerre, pourvu que la conquête soit habilement organisée selon le principe romain, est, pour qui sait vaincre et user de la victoire, une affaire avantageuse, où les bénéfices balancent heureusement les pertes et les dépenses. Car s'il ne l'avait pas pensé, il n'aurait pas écrit en termes formels que rien ne fait estimer un prince autant que les grandes entreprises militaires et les conquêtes ${ }^{\text {ccxcvi }}$. Affirmation qui repose sur une étude trop exclusivement politique de la guerre et de la conquête, et, d'autre part sur une philosophie brutalement positive de l'histoire humaine.

Reste à déterminer dans quel esprit, par quels moyens, il faut conduire la guerre.

«Mon intention étant d'écrire des choses utiles à qui entend ces questions, dit-il, j'ai jugé préférable de rechercher exactement le vrai et le réel plutôt que de suivre des idées imaginaires. Beaucoup d'écrivains ont imaginé des républiques et des monarchies telles qu'on n'en a jamais vu ni connu dans la réalité. Or il y a trop de distance entre la façon dont on vit et celle dont on devrait vivre ; et par suite celui qui abandonne l'usage commun pour faire ce qu'on devrait faire apprend plutôt l'art de se perdre que l'art de se conserver. Car un homme qui voudrait, en toute chose, se conduire selon les règles de la morale, court nécessairement à sa ruine parmi tant d'hommes qui ne sont pas vertueux. Il est donc nécessaire qu'un prince, soucieux de se maintenir, apprenne à négliger parfois la morale, à s'y conformer ou ne pas s'y conformer selon l'occurrence. Laissons de côté ce qui concerne un prince imaginaire, et ne parlons que de vérité. » ${ }^{\text {cccxcvii }}$. Les axiomes où Machiavel définit la conduite qui s'impose aux princes, valent également pour les républiques : 266 l'exemple de la Rome consulaire et sénatoriale suffit à le démontrer. 
C'est surtout dans le troisième livre des Discours sur la première Décade qu'il développe sa doctrine. Certains chapitres, essentiellement techniques, pourraient trouver place dans le traité De l'Art de la Guerre. Mais d'autres définissent sommairement dans quel esprit il faut mener une campagne. Il suffit d'en citer les titres : "Comment l'usage de la fraude dans la conduite de la guerre est chose glorieuse ; - Que la patrie doit être défendue par des moyens infâmes ou glorieux, et que dans l'un et l'autre cas elle est bien défendue ${ }^{\text {cccxcviii }}$. » Il suffit de citer quelques textes : "Bien qu'il soit détestable, en toute entreprise, d'user de la fraude, toutefois, à la guerre, la fraude est louable et glorieuse, et l'on accorde des louanges égales à qui l'emporte sur l'ennemi par la fraude et à qui l'emporte par la force... Quand il s'agit du salut public, ne doit plus entrer en ligne de compte aucune considération de justice ou d'injustice, de pitié ou de cruauté, d'honneur ou d'ignominie. Au contraire, il faut abandonner tout scrupule, et suivre sans hésiter le parti qui sauve l'existence et assure la liberté de l'État ${ }^{\text {ccxcix }} »$. Aux exemples romains, tirés de Tite-Live, il ajoute quelques exemples p267 modernes: «Les Français, dit-il, ont adopté ce principe, en théorie et en pratique, pour défendre l'autorité de leurs rois et la puissance de leur royaume. Rien ne les irrite plus que d'entendre dire : " Tel parti est honteux à prendre par le roi. » Car ils assurent que leur roi ne peut se déshonorer, quelque décision qu'il prenne, en bonne ou en mauvaise fortune. Qu'il perde ou qu'il gagne, il est, de l'avis de tous, seul juge de sa conduite. $\gg{ }^{\text {cd }}$.

Ainsi Machiavel permet au chef d'armée tout ce qui peut assurer la victoire. Il doit rechercher la complète destruction des forces ennemies, employer, pour y parvenir, tous les moyens, les plus expéditifs, les plus cruels, et ne s'imposer aucun scrupule de loyauté et de bonne foi. Machiavel s'accorde mal avec Érasme, qui, en 1516, dans l'Institutio, conseille au prince de mener la guerre avec modération, d'épargner, autant que possible, les vies humaines, et d'y mettre fin dès que s'offre une possibilité de négociation ${ }^{\text {cdi }}$. Pour Machiavel, un État en guerre se doit à lui-même, à ses intérêts, aux intérêts collectifs qu'il défend, de renoncer, une fois en guerre, à tout sentiment d'humanité et de christianisme ; il doit demander à la force tout ce que la force peut donner. 


\section{III}

A la question de la guerre se rattache naturellement la question des traités. La guerre est, en dernière analyse, le seul moyen qui, dans la concurrence où les États sont nécessairement engagés, p268 permet l'établissement de cet équilibre naturel qui résulte des rapports de leurs forces. Cet équilibre s'inscrit dans les traités. Le problème se pose de savoir quelle valeur, quelle autorité on peut leur reconnaître ; quelles limites s'imposent à leur durée. En d'autres termes, dans quelle mesure les États, les magistrats qui dirigent la politique extérieure des républiques, les princes ou les dictateurs qui gouvernent les monarchies, sont tenus d'observer les traités et d'honorer leur signature. Sur cette question Machiavel est revenu deux fois; il l'a discutée au chapitre XVIII du Prince; quelques années plus tard, il démontrait, au livre III des Discours sur la première Décade, chapitre XLII, que les engagements pris par contrainte ne se doivent pas observer ${ }^{\text {cdii }}$.

Le chapitre XVIII du Prince est sans doute, dans son œuvre, celui qui, sincèrement ou non, lui a été le plus souvent reproché ; notamment par Frédéric II, dans cet Examen du Prince de Machiavel, qu'il achevait peu avant de succéder au roi sergent, et de mettre en pratique, sans plus de scrupule, la doctrine du secrétaire florentin.

«Qu'un prince soit louable de maintenir la foi jurée, et de vivre en pleine loyauté, sans user du mensonge, chacun l'entend. » Mais, réaliste sans illusion, Machiavel a constaté que de telles pratiques ont cours uniquement dans les cités imaginées par les philosophes; dans la réalité, les princes et les États se comportent autrement; à suivre les préceptes de la loyauté, ils risqueraient d'être accablés par les moins scrupuleux : «L'expérience de notre temps nous permet de constater que ceux-là parmi les princes ont fait de grandes choses, qui n'ont pas tenu grand compte de la foi jurée, et qui ont su, par la ruse, circonvenir à leur gré l'esprit des hommes. Ils ont finalement triomphé de ceux qui fondaient leur conduite sur la loyauté. » ${ }^{\text {cdiii }}$.p269 
De ce fait brutal, Machiavel donne une théorie élémentaire : «Il y a deux manières de combattre; l'une se conforme au droit, l'autre ne connaît que la force. La première est propre à l'homme, la seconde aux bêtes. Mais comme la première souvent ne suffit pas, il faut aussi recourir à la seconde. C'est pourquoi un chef d'État doit savoir à la fois se conduire aussi bien en bête qu'en homme ${ }^{\text {cdiv }}$. " Ce qui se fait uniquement selon le droit et n'est soutenu que par le droit ne peut durer. Mais la force est malhabile sans la ruse ; la ruse sans la force est impuissante. Il faut donc unir l'une à l'autre, imiter à la fois le lion et le renard. Le lion ne sait pas se tirer d'un piège : le renard ne sait pas se défendre contre les loups. Par suite le prince ne saura pas seulement user de la force, mais de la ruse et du mensonge.

Un chef d'État exercé à la politique, ne doit donc pas observer la foi jurée, lorsque le respect du serment risque de tourner à son désavantage, et que les motifs de son engagement ne subsistent plus ${ }^{\mathrm{cdv}}$. A coup sûr, les promesses faites par contrainte ne se doivent pas tenir. Il n'y a nulle honte à ne pas observer un engagement pris sous la menace de la force. Les traités imposés par la force seront toujours rompus dès que la force manquera ; et qui rompra de tels accords n'encourra nul déshonneur ${ }^{\text {cdvi }} \cdot$ p270

Machiavel n'ignore pas que sa doctrine contredit la morale officielle ${ }^{\text {cdvii }}$. Mais le monde est tel que tout autre conduite serait périlleuse. Les hommes sont menteurs et trompeurs, et qui ne sait tromper et mentir court le risque d'être dévoré. Puisqu'ils ne tiendraient pas leurs engagements envers vous, rien ne vous oblige à tenir les vôtres envers eux. Il suffit donc pour le prince de trouver un prétexte honorable, qui jamais ne manquera. Les hommes, de tout temps, ont agi de la sorte ; les histoires de tous les peuples en conservent le témoignage ; les générations récentes imitent les anciennes. Une infinité d'exemples modernes permet de constater l'éternelle déloyauté des princes : qui a mieux su faire le renard a toujours le mieux réussi. Sans doute faut-il être grand simulateur et dissimulateur; mais qui saura mentir abusera toujours les hommes, leur irréflexion, leur simplicité ${ }^{\text {cdviii }}$.

Machiavel invoque, à l'appui de son dire, certains cas illustres et récents. Le pape Alexandre VI ne fit jamais autre chose que tromper ses contemporains, ne pensa jamais à autre chose, et trouva toujours l'occasion d'y réussir. On ne vit jamais assurer en termes plus in- 
contestables, promettre avec des serments plus solennels, et moins fidèlement tenir. Néanmoins ses tromperies lui réussirent à souhait, parce qu'il connaissait bien cette partie du jeu humain. Certain prince contemporain qu'il ne convient pas de nommer - Machiavel pense évidemment à Ferdinand ${ }_{\mathrm{p} 271}$ le Catholique - ne cesse de prêcher la paix et la bonne foi ; il est pourtant l'ennemi résolu de l'une et de l'autre; et s'il les avait respectées, il aurait plus d'une fois risqué de perdre son prestige ou ses États ${ }^{\text {cdix }}$.

Tout a été dit sur ce fameux chapitre XVIII, et il serait vain d'entrer dans le détail des protestations souvent peu sincères et des réfutations fréquemment banales que, depuis le $\mathrm{XVI}^{\mathrm{e}}$ siècle, il a provoquées. Trois ans plus tard, Érasme, qui toujours ignora le nom de Machiavel, consacrait le huitième chapitre de l'Institutio à la question des traités et des alliances. Il en exige naturellement le respect: "Les princes doivent se montrer si fidèles à tenir leurs engagements, qu'une simple promesse doit rester, à leurs yeux, plus sacrée que le serment le plus solennel d'un particulier. » Mais il ne gardait pas beaucoup d'illusions, et savait trop bien la coutume et l'usage : « Pourtant, ajoute-t-il, nous voyons chaque jour violer des engagements. Et mieux vaut ne pas dénoncer publiquement les responsables. $\gg{ }^{\mathrm{cdx}}$. Les princes et les républiques, en Italie et dans les autres pays chrétiens, n'observaient un traité que dans la mesure de leur convenance. Le 14 janvier 1526, François I ${ }^{\mathrm{er}}$, prisonnier à Madrid, abandonnait à CharlesQuint la Bourgogne. Rentré dans le royaume, il convoquait, dès le printemps, à Cognac, les députés de la province, qui affirmaient leur volonté de rester Français ; une nouvelle ligue conclue avec Clément VII, Venise, et quelques princes p $272_{2}$ italiens, il désavouait aussitôt sa promesse. Machiavel, d'avance, l'avait justifié. La chancellerie impériale, le parti impérial, protestèrent avec une indignation feinte contre la manière dont le roi chevalier observait la foi jurée ${ }^{\text {cdxi }}$. Aucun homme d'État n'eût refusé d'admettre que des engagements pris sous la contrainte de la force, et nuisibles à l'intérêt de l'État, dussent être maintenus autrement que par la force. Et une tradition française, connue de Machiavel, niait que le roi très-chrétien pût jamais se déshonorer. 
Ainsi Machiavel ne fait guère que décrire une pratique habituelle que Commynes, déjà, ne dissimulait guère. Mais jamais aucun théoricien de la politique n'avait encore osé fonder sur cette pratique un système de règles et les proposer aux hommes de gouvernement. Ils sentaient confusément que c'eût été avouer la faillite de la morale profane ou religieuse dans le domaine de la politique, l'inaptitude de l'éthique rationnelle ou de l'Évangile à introduire un peu de justice et d'humanité dans les rapports des peuples. C'eût été abandonner, de façon publique, ces rapports aux hasards de la force. Arrivés là, les plus cyniques reculaient. Machiavel a franchi ce pas; non qu'il fût sensiblement plus cynique que tel autre ; mais sa philosophie désespérée, sa vue pessimiste du passé, du présent, de l'avenir même de l'humanité, ne lui permettaient pas de croire à la puissance de l'esprit que la force ne seconde pas. Dans l'histoire universelle, il refusait de reconnaître autre chose qu'un jeu de forces déchaînées ; - forces contre lesquelles tous les moyens de lutte sont bons et louables, dès qu'il s'agit de défendre, de protéger et de sauver l'État, seul abri que les hommes aient jamais créé pour leurs biens matériels et spirituels. 


\section{Chapitre IV}

\section{Le gouvernement de l'opinion publique}

Il ne suffit pas de définir les différents types de gouvernement, les rapports des États, et de chercher à résoudre le problème de la paix et de la guerre, des traités, de leur valeur et de leur observation. Il faut encore considérer les gouvernés eux-mêmes, et comment ils se prêtent à l'action du gouvernement; d'autre part, dans quelle mesure le gouvernement doit tenir compte de leur opinion, comment il peut la maîtriser, la capter à son profit. Ce problème, Machiavel, habitué à vivre dans une cité libre, ne pouvait l'esquiver. Il y consacre plusieurs chapitres du Prince; il y revient, à plusieurs reprises, dans les Discours sur la première Décade de Tite-Live.

Table des matières

\section{I}

La question que se pose Machiavel se réduit à des termes très simples : comment les hommes qui mènent les affaires publiques obtiendront-ils la faveur de l'opinion ? En quel cas pourront-ils la négliger ? Les politiques florentins ou italiens $\mathrm{du} X V \mathrm{I}^{\mathrm{e}}$ siècle tenaient grand compte du sentiment populaire et connaissaient l'art de le ménager. Machiavel, qui, au cours de sa vie active, eut l'occasion de pratiquer ou de voir pratiquer cette technique, soit à Florence, soit à l'étranger, la résume en un langage emprunté à l'éthique humaniste. Il a pu constater l'avantage 274 d'agir moins sur la raison que sur l'imagination des hommes. Il les sait heureux de trouver, chez ceux qui les gouvernent, certaines vertus, certaines manières de faire, qui, pour parler son 
langage, attirent à un prince la louange ou le mépris ${ }^{\text {cdxii }}$. Il passe en revue sommairement les vertus et les défauts qui renforcent le crédit ou qui affaiblissent l'autorité d'un chef d'État. Le problème est de savoir comment les gouvernants doivent tenir compte des préférences et des répugnances tout instinctives des peuples, dans quelle mesure y satisfaire ou les dédaigner.

Érasme, dans l'Institutio principis christiani, allait, trois ans après l'achèvement du Prince, répondre en moraliste et en chrétien. Un sûr instinct de justice pousse le peuple à exiger du prince toutes les vertus, et l'on doit souhaiter qu'il les possède. Érasme trace donc une image idéale, et l'offre à la méditation de celui qui, en 1519, deviendra l'empereur Charles-Quint : «Un être céleste, dit-il, plus semblable à la divinité qu'à l'homme; accompli en toute sorte de vertus; né pour le bien de tous; envoyé par le ciel afin de soutenir les hommes dans leur détresse ; qui veille à tout et pourvoit à tout; qui par-dessus tout respecte l'intérêt public et y trouve sa joie; dont le cœur est pour tous plus que paternel; qui préfère la vie de chacun à la sienne ; qui nuit et jour ne dirige sa conduite et son effort qu'en vue du plus grand bien de tous; qui est prêt à récompenser toute bonne action, prêt à l'indulgence envers les coupables, pourvu qu'ils travaillent à s'amender; qui, sans nul profit pour lui-même, désire se rendre utile à ses concitoyens, au point de risquer sans hésiter, s'il le faut, sa vie pour assurer leur salut ; qui, dans tout ce qui sert au public, reconnaît son propre avantage ; qui veille sans cesse, afin de permettre le sommeil d'autrui ; qui ne s'accorde aucun repos, afin que la patrie vive en repos ; tourmenté de soucis toujours renaissants, afin d'assurer à ses concitoyens la tranquillité ; dont la vertu, en un mot, est la condition première du bonheur public. " ${ }^{\text {cdxiii }}$. p275

D'avance Machiavel, réaliste désabusé, avait répondu à Érasme. Il se sent en désaccord avec les philosophes de l'antiquité et du Moyen Age, avec Platon, Aristote, Plutarque, avec saint Thomas. Il se sait en désaccord avec Pétrarque ou les humanistes du XV siècle. Les uns et les autres, et Érasme après eux, exigent du prince une perfection inaccessible. Ils lui offrent pour exemple un type idéal de modestie, de justice, de sincérité, de générosité. Machiavel connaît trop la politique pour savoir qu'on n'a jamais vu aucun prince orné de tant de vertus, et qu'à les mettre en pratique, le chef d'État qui, dans le monde réel, doit penser d'abord à sa défense, risquerait un grave danger. Trop 
d'écrivains ont disserté sur des États imaginaires; et la distance est longue entre la façon dont on vit et celle dont on devrait vivre. Si un prince entend d'abord se maintenir, il doit apprendre à négliger parfois la loi morale, à lui obéir ou désobéir selon la nécessité ${ }^{\text {cdxiv }}$.

Ce qui importe donc à une politique réaliste, ce n'est pas la sainteté du prince, mais la solidité du gouvernement. Un excès de vertu pourrait quelquefois être dangereux; le crime peut quelquefois sauver l'État. Un César Borgia hésitant devant l'assassinat et la trahison n'aurait pas créé le duché de Romagne. Le seul problème qui mérite quelque étude est celui du maniement de l'opinion. p276

$$
* * *
$$

Qui gouverne les hommes devra, dans l'intérêt de l'État, respecter certains de leurs préjugés, ou les mépriser s'il le faut. Tels défauts ou tels vices diminuent, auprès des sujets, le prestige et l'autorité du prince ; tels autres qui leur restent indifférents, ne l'exposent à nul péril. Sans doute vaudrait-il mieux que le prince pût se garder à la fois des uns et des autres. Puisque la faiblesse humaine ne le permet guère, il évitera d'abord les plus dangereux; il se gardera des autres, selon ses forces, ou péchera sans inquiétude ${ }^{\mathrm{cdxv}}$. Mais le salut de l'État peut commander le mépris de l'opinion. Il se peut qu'en certains cas le parti le plus unanimement condamnable ouvre l'unique voie de salut public. Alors conviendra-t-il de passer outre aux opinions humaines : «On doit comprendre, dit-il, qu'un prince, et surtout un prince nouveau, ne peut observer toutes les vertus d'un particulier. Il faut qu'il sache, pour la défense de l'État, agir contrairement à la bonne foi, à la charité, à l'humanité, à la religion. » Il doit savoir, selon les circonstances, «ne pas s'écarter du bien s'il le peut, et, si la nécessité le commande, entrer dans le mal avec résolution ${ }^{\text {cdxvi }} \gg$.

Mais les sujets, qui entendent peu la raison d'État, exigent obstinément de leurs chefs certaines vertus. L'hypocrisie devient ainsi le plus indispensable talent d'un politique : car il suffira ${ }_{\text {p277 }}$ que le prince paraisse avoir les vertus qu'il n'a pas. Le prince se gardera soigneusement de ne prononcer aucune parole qui ne s'accorde avec le plus haut idéal de perfection. " Il faut qu'à le voir et à l'entendre, il paraisse toute pitié, toute bonne foi, toute intégrité, et, particulière- 
ment, toute religion : car rien n'est plus nécessaire que d'étaler publiquement cette dernière vertu. $\gg{ }^{\text {cdxvii }}$.

Les hommes s'y tromperont toujours : «Ils jugent en général avec les yeux plutôt qu'avec les mains ; or chacun peut voir, mais il est réservé à peu de toucher. Chacun vous voit tel que vous paraissez; peu se rendent un compte exact de ce que vous êtes; et cette minorité n'ose contredire l'opinion du plus grand nombre, soutenue par la majesté de l'État. » ${ }^{\text {cdxviii }}$. Et comme, en ces matières, aucun appel ne peut être porté devant aucun tribunal, on ne peut considérer que la fin; elle seule, en dernier ressort, permet de juger les moyens : les peuples donneront toujours raison au plus fort. Qu'un prince donc veille avant tout à conserver son État. S'il réussit, les moyens seront toujours estimés honorables, et loués d'un chacun. La foule ne juge que d'après les apparences et les résultats; le monde entier n'est qu'une foule et pense comme une foule. Les isolés, capables de penser et de comprendre, se tairont, ou on les fera taire ${ }^{\text {cdxix }} \cdot$ p278

Ainsi, dans ce fameux chapitre XVIII, où déjà se développe la théorie de la caducité des traités, et du droit toujours réservé aux États de ne pas remplir les engagements les plus solennels, le secrétaire florentin expose, sans hésitation ni réticence, la théorie de l'hypocrisie politique. Conséquence de la nécessité où se trouve l'État de ménager l'opinion; conséquence de l'absurdité des hommes, dont il faut respecter apparemment les préjugés, si l'on veut conserver auprès d'eux le crédit nécessaire. C'est pourquoi, toutes les fois que l'intérêt de l'État, la conservation de l'État, la raison d'État l'exigent, le prince doit mentir, simuler et dissimuler. Et Machiavel assure à ces procédés de gouvernement un succès infaillible.

Table des matières

\section{II}

Il existe pourtant un certain nombre d'affaires où cette hypocrisie systématique n'est pas de mise, parce qu'elle ne servirait de rien. Le prince n'aurait nul intérêt à suivre ou même à feindre de suivre les préjugés des hommes, parce qu'en ces matières, les hommes s'abusent 
trop gravement et toujours. En pareil cas, l'opinion ne saurait que l'égarer. En pareil cas il décide seul, et ne considère que la nécessité publique, dont il est seul juge ; la raison d'État, dont l'opinion ignore les exigences. Il commande, et les sujets obéissent. Ici la persuasion, le ménagement de l'opinion, la dissimulation même et le mensonge sont hors de propos. Seules peuvent et doivent intervenir l'autorité, et, en dernier ressort, la force. Ces domaines réservés sont la gestion financière et la défense de l'État.

Machiavel pose la première question en termes qui, empruntés au vocabulaire traditionnel des historiens et des moralistes antiques, semblent rapetisser le débat, et le réduire à la discussion classique d'un lieu commun. Il compose sur « la libéralité et la parcimonie », un chapitre où le ton et la marche de la discussion rappellent un peu trop les moralistes antiques ${ }_{\text {p279 }}$ ou les humanistes italiens ${ }^{\text {cdxx }}$. Il constate que les peuples aiment les princes enclins à faire largesse. Avant lui, les humanistes avaient unanimement exalté la libéralité de leurs mécènes; peuples et lettrés riaient des souverains trop ménagers. Machiavel répond que la libéralité est une vertu coûteuse : on ne peut la pratiquer à demi. Le prince dépensera de la sorte tout son revenu ; il lui faudra donner à son gouvernement un caractère fiscal, exiger strictement des impôts alourdis. Il s'attirera la reconnaissance d'un petit nombre de privilégiés et la haine du peuple. L'État se trouvera, dès la première alerte, en danger. Si le prince, par prudence, tente de revenir à une politique d'économie, il perd tout le prestige de sa libéralité première, et le contraste entre ses premières largesses et sa nouvelle parcimonie le fait juger plus avare qu'un autre ${ }^{\text {cdxxi }}$.

On doit traduire cette démonstration classique en langage moderne. Il s'agit de la gestion des finances publiques : Machiavel la veut économe, et au besoin avare. Il appartient à cette bourgeoisie florentine, qui, par une sévère administration de sa fortune territoriale, de ses entreprises industrielles, commerciales et financières, avait accumulé, dans son intérêt et dans l'intérêt de la cité, un capital qu'elle ne gaspillait pas volontiers en dépenses privées ou publiques. Il exige de qui gouverne un État ces vertus bourgeoises. Il repousse toute politique de largesse budgétaire, toute dépense inconsidérée en faveur de tels individus, de tels groupes, de telles classes. Il montre qu'une fois engagé dans une politique de facilité financière et de profusion, l'État est perdu. Toutes les ressources dont il dispose s'y engloutissent ; le gouver- 
nement obligé sans cesse d'augmenter les impôts hasarde sa popularité, se rend vite odieux. Il n'est même plus maître d'arrêter sans inconvénients les dépenses engagées.

A l'appui de sa doctrine, Machiavel cite, selon son usage, des p280 exemples antiques et modernes. César, pour conquérir le pouvoir, donna généreusement. Mais s'il avait vécu plus longtemps sans limiter ses profusions, il aurait ruiné l'État, compromis son œuvre et son autorité $^{\text {cdxxii }}$. « De notre temps, continue Machiavel, les seuls princes que nous avons vus faire de grandes choses, sont ceux dont l'opinion publique a dénoncé la gueuserie. » Jules II, candidat au pontificat, voulut s'assurer une réputation de largesse. Une fois élu, peu lui importa de la perdre; il préféra se réserver les ressources nécessaires à ses guerres et à sa politique. En France, Louis XII a pu faire de nombreuses campagnes sans imposer à ses peuples aucune contribution extraordinaire : son économie tenace y a pourvu. Si l'Espagnol Ferdinand s'était montré prodigue, il n'aurait pu engager tant d'entreprises et $y$ réussir ${ }^{\text {cdxxiii. }}$.

Ainsi le gouvernement, responsable du patrimoine commun et des finances publiques, tiendra tête à l'opinion. La prodigalité, qui ruine les peuples, est une vertu qu'ils ont tort d'aimer. Le prince ne lui demandera pas une popularité décevante et ruineuse. Machiavel n'autorise les profusions gouvernementales qu'en un cas unique. Les dépouilles des ennemis vaincus, terres confisquées, rançons ou indemnités de guerre, offrent à l'État l'occasion de largesses faciles. Alors il n'y a pas lieu de lésiner; à dépenser largement le bien d'autrui, un prince, loin de diminuer son prestige, le consolide ${ }^{\text {cdxxiv }}$. Sauf cette exception, Machiavel condamne toute politique d'indulgence financière, et blâme ${ }_{\mathrm{p} 281}$ les gouvernements qui cèdent sur ce point devant le public. Au problème de l'opinion et de la réclame gouvernementale, plutôt qu'à la question financière, Machiavel rattache sommairement l'administration des beaux-arts et de l'économie. Sur le premier point, il pense à la manière de Cosme plutôt que de Laurent, trop magnifique : "Le prince doit montrer qu'il aime les talents, attirer auprès de lui les hommes de valeur, honorer ceux qui excellent dans leur art. ${ }^{c d x x v}$. En matière d'économie, il ébauche, en quelques lignes, un programme libéral et populaire : le gouvernement laissera les citoyens vaquer à leur travail, commerce, agriculture, entreprises diverses ; pas de ces enquêtes menaçantes sur 
la fortune privée, qui découragent la mise en valeur des grands domaines; pas de ces impôts accablants qui découragent tout nouveau projet de trafic. Au contraire, il faut réserver des prix à tous ceux dont l'effort concourt à l'enrichissement de l'État ${ }^{\text {cdxxvi }}$. Mais ces détails l'intéressent si peu que, tout aussitôt, il passe à la nécessité d'offrir aux peuples, fêtes, spectacles et divertissements; le prince y trouvera l'occasion de se montrer, de cultiver sa réputation d'humanité généreuse, sans rien perdre de cette dignité qui doit toujours demeurer intacte $^{\text {cdxxvii }} \cdot$ p282

La réclame est hors de saison lorsqu'il s'agit de défendre l'ordre et le régime politique. Machiavel pose la question et mène le débat en un langage traditionnel, que l'on peut sans peine moderniser. Plus encore que la libéralité, les peuples aiment, chez le prince, la clémence et la

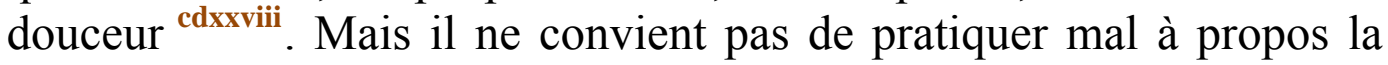
vertu de pitié. On eut tort de blâmer César Borgia pour certaines mesures cruelles qui avaient établi, en Romagne, l'unité de gouvernement, la paix et la confiance publique. A bien considérer les choses, le peuple florentin se montra moins pitoyable, quand, devenu maître de Pistoia, il hésita devant quelques rigueurs nécessaires, et laissa ruiner la ville par les factions. Un gouvernement doit donc mépriser le reproche de cruauté, lorsqu'il s'agit de maintenir l'État. Machiavel allègue Virgile pour affirmer qu'au fondateur d'un État s'impose plus qu'à tout autre la nécessité de se montrer dur ; l'histoire antique et moderne en offrirait de nombreux exemples. Plutôt que de s'y attarder, il se borne à quelques maximes : éviter la précipitation, l'inquiétude irraisonnée, l'affolement; ne pas prendre peur trop vite; se garder de la confiance excessive, qui conduit à des imprudences, et de la méfiance excessive qui inspire une sévérité sans mesure. Mais lorsque l'ordre ou le régime se trouvent menacés, la clémence est une erreur et une faute ${ }^{\text {cdxxix }} \cdot$ p283

Machiavel, à la manière des historiens antiques et des moralistes, se demande s'il vaut mieux qu'un prince soit aimé ou redouté. Il trancha cette question classique selon sa méthode habituelle. Il faudrait inspirer à la fois l'amitié et la crainte. Mais puisque on n'y saurait parvenir, mieux vaut la crainte que l'amitié. "Les hommes sont en général ingrats, changeants, menteurs et dissimulés, prompts à fuir le 
danger, cupides. Si vous leur faites du bien, ils sont tout à vous, ils vous offrent leur sang, leur fortune, leur vie et celle de leurs fils; à condition que vous n'en ayez nul besoin pour le moment. Dès que le danger s'approche, ils se révoltent. Un prince qui a fondé toute sa politique sur leurs bonnes paroles, et qui se trouve sans autre garantie et sans autre recours, est perdu. » Les amitiés qu'un prince acquiert par des bienfaits, mais que son autorité personnelle ne contraint pas à la fidélité, lui sont de peu d'usage. La bassesse des hommes est telle qu'on court moins de risque à se faire craindre qu'à se faire aimer. L'intérêt détruit promptement la reconnaissance; au contraire, la crainte est un sentiment durable; l'appréhension du châtiment ne s'affaiblit jamais ${ }^{\text {cdxxx }}$.

Ainsi un prince ou un gouvernement résolus à se défendre mépriseront la popularité facile des monarques débonnaires. Mais il faut éviter avec soin la réputation de se complaire aux châtiments et aux supplices. L'hypocrisie du prince le servira. Il faudra qu'à le voir et à l'entendre, il paraisse tout humanité ; qu'il joue devant le peuple la comédie de l'humanité. Mais on trompe aisément les hommes, et l'art d'obtenir obéissance et respect sans encourir la haine est peu compliqué. Il suffira de ne pas inquiéter les sujets dans la possession de leurs biens, car nulle offense ne se pardonne moins aisément ; il suffira que p284 le prince respecte leurs femmes; conseil qui n'était pas inutile après les excès de ces tyrans antiques ou italiens en qui Machiavel n'a jamais reconnu des politiques. Si la mort d'un suspect importe à l'État, et si l'on peut, devant l'opinion, justifier légalement la sentence, on ne doit jamais hésiter. Mais il faut ménager la richesse plus que le sang: car les hommes oublient plus vite la mort de leur père que la perte de leur patrimoine ${ }^{\text {cdxxxi }}$. Dures et froides maximes, où Montesquieu a pu croire que le génie de Machiavel s'égarait ${ }^{\text {cdxxxii }}$.

$$
* * *
$$

Une réputation de rigueur est indispensable à qui veut conduire une armée. Le chef de l'État, en campagne, ne redoutera même plus de passer pour cruel : on ne conserve pas autrement l'autorité. Hannibal, qui menait la guerre en pays étranger, avec une armée composée de troupes fort diverses d'origine et de langue, ne les tint en respect qu'au moyen d'une dureté véritablement inhumaine, qui imposait la crainte et l'obéissance : tous ses talents n'y auraient pas suffi. Les his- 
toriens qui admirent ses campagnes ont tort de le juger cruel. Inversement Scipion l'Africain, malgré tout son génie, vit en Espagne ses soldats se révolter, par suite de la douceur excessive de son commandement. p285 Il avait laissé fléchir une discipline sur laquelle un prince, chef d'armée, un gouvernement responsable de la conduite d'une guerre, ne doivent rien concéder à l'opinion ${ }^{\text {cdxxxiii }}$.

$\underline{\text { Table des matières }}$

\section{III}

Ainsi, pour tout ce qui regarde la conservation de l'État, le gouvernement ne décide et n'agit que par lui-même et selon ses intérêts. De telles questions se règlent d'autorité. La seule force décide, ordonne, et agit. Reste à définir les domaines où le prince doit tenir compte de l'opinion, sans lui céder jamais sur le fond des choses, et ne lui donner que des satisfactions apparentes et illusoires.

$* * *$

La religion est le principal. Machiavel, dans le Prince, n'insiste pas ${ }^{\text {cdxxxiv }}$. Un écrit qu'il ne destinait pas à rester secret ne pouvait livrer toute sa pensée. Un chapitre des Discours la développe librement. Comme le pacte constitutionnel d'un État civil, l'autorité de fait créée par un despote ne peut trouver d'appui véritablement stable que dans la religion. La psychologie des peuples offre son concours à la politique. Si la crainte religieuse vient à s'affaiblir, le gouvernement y supplée mal par la crainte des tribunaux; les effets en sont limités et variables ; les effets du sentiment religieux sont permanents ${ }^{\text {cdxxxv }}$. Princes ou républiques doivent avant tout veiller à la conservation des croyances et du culte, maintenir une religion d'État, et des prêtres dont ${ }_{\text {p286 }}$ la parole et l'action restent subordonnées aux fins de l'État. Un politique ne se croira pas obligé de suivre en toute chose leur avis : il aurait trop à faire. Mais il évitera de les contredire publiquement, leur accordera toutes les marques du respect, punira toute offense publique au dogme ou aux ministres de l'Église, et pratiquera ostensiblement la religion, même s'il n'y croit pas ${ }^{\text {cdxxxvi }}$. 
Ainsi se définit, en face de l'opinion, la politique religieuse du gouvernement. Il respecte l'attachement du peuple aux formes du culte et aux traditions sacrées. Il fait montre de la piété qui plaît aux simples et réjouit l'Église. Mais en même temps qu'il se conforme aux exigences de l'opinion, il la dirige. En échange des égards et des privilèges accordés par l'État, il exige que le clergé, par la parole et par l'action, soutienne ses mesures administratives et ses lois, ses entreprises extérieures, et lui assure la fidélité des populations et leur obéissance. De toutes les vertus qu'un prince doit paraître posséder, le respect de la religion est la plus nécessaire ${ }^{\text {cdxxxvii }}$.

$$
* * *
$$

La politique étrangère ne regarde pas le sujet : elle forme le secret essentiel des gouvernements. Érasme critique le droit de paix et de guerre, que la coutume réserve au prince; il aboutit à formuler l'obligation de prendre, sur toute déclaration de guerre, l'avis du pays et d'en obtenir le consentement ${ }^{\text {cdxxxviii }}$. Machiavel ne se pose pas un instant cette question. Dans une monarchie, le prince seul est juge de l'opportunité de la guerre. Dans une république, la guerre est encore affaire du gouvernement, et quelques-uns seuls en décident : le Sénat romain ; la Seigneurie et les Dix de la Liberté et de la Paix.

Mais si le peuple n'a pas à donner d'avis, encore veut-il croire que le gouvernement a pour lui le bon droit, et que ses revendications s'accordent avec la lettre et l'esprit des traités. Il veut ${ }_{\text {p } 287}$ croire que ses gouvernants ont tenu leur parole, et que la responsabilité des événements appartient tout entière à l'ennemi. Sur l'observation des traités, Machiavel a défini sa doctrine ; nul gouvernement n'y est tenu, quand il a signé sous la pression de la force; quand les conditions de la politique générale ou particulière qui l'ont conduit à signer ne subsistent plus, ou se sont modifiées à son désavantage. Du moins faut-il considérer l'opinion, à l'étranger et dans le pays; à l'étranger, car le gouvernement doit y ménager son crédit ; à l'intérieur, car la simplicité des peuples est telle qu'ils pourraient douter du succès d'une entreprise où ils verraient la justice du côté de l'adversaire. La plus grande maladresse en pareil cas est de braver trop insolemment la morale commune. Sans doute Machiavel pense-t-il que François $\mathrm{I}^{\mathrm{er}}$ n'aurait pas dû rompre, sans explication ni délai, le traité de Madrid. Erreur de faible conséquence dans le royaume, puisque devant l'opinion natio- 
nale le roi ne perdait jamais l'honneur; mais grave devant l'Europe, où l'autorité morale du gouvernement français allait se trouver pour longtemps compromise. Il faut donc qu'un gouvernement sache mentir, dissimuler, présenter sous des semblants honorables tous les manquements à la lettre et à l'esprit des traités. La simplicité des hommes rend cette tâche facile à la diplomatie. L'essentiel est de rejeter sur l'adversaire toute la responsabilité des événements ${ }^{\text {cdxxxix }}$.

Par là se trouve de nouveau posée la question des moyens divers qui permettent de travailler l'opinion à l'intérieur et à l'extérieur. Machiavel ne les définit pas. Mais on peut sans peine compléter sa pensée, qui conduit à un problème pratique de propagande officielle et officieuse. Problème de l'utilisation du clergé, de ces prédicateurs séculiers et réguliers qu'Érasme déplorait de voir, en tout pays, garantir aux armées rivales l'assistance divine; problème de l'utilisation de la presse, et de ces publicistes plus ou moins officieux dont la politique $\mathrm{du} \mathrm{XVI}^{\mathrm{e}}$ siècle appelait le concours. Les agents de propagande, clercs et laïques, auront pour tâche, lorsqu'un État s'engage dans quelque p288 grande aventure, de démontrer à l'étranger et aux nationaux que trois des vertus auxquelles tiennent les hommes, la bonne foi, le respect du droit, l'horreur du sang versé, apparaissent évidemment de son côté ${ }^{\text {cdxl }}$.

Ainsi se développe ce que l'on peut appeler, dans la doctrine de Machiavel, le gouvernement de l'opinion publique. Ce gouvernement recourt essentiellement à deux moyens : la force et la dissimulation. L'emploi de l'un ou de l'autre doit se régler selon la nature des questions à résoudre, selon les intérêts en jeu, selon l'utilité pratique de l'État; et c'est la raison d'État qui décide en arbitre suprême l'emploi de l'une ou de l'autre ${ }^{\text {cdxli }}$. Doctrine singulièrement pessimiste et brutale, qui repose à la fois sur le mépris des hommes, de leur facilité à se tromper et à se laisser tromper; et sur l'exaltation de la seule grandeur humaine que Machiavel reconnaisse, et qui est l'État. 


\section{Chapitre V}

\section{L'Esprit de Machiavel}

Ainsi, Machiavel, pendant quatorze années de voyages diplomatiques et d'action gouvernementale, quinze autres de regrets, de rancunes, d'ennui et de méditations solitaires, s'était efforcé de définir une pensée qui restait comme à dessein énigmatique et fuyante. La dure netteté de formules concises et dédaigneuses contraste dans son œuvre avec l'incertitude apparente d'une double doctrine dont les thèses ne cherchent pas à réduire leurs antinomies. La théorie monarchique de Machiavel se développe selon les règles d'une méthode qui, exigeante en fait d'évidence, choisit et critique, ordonne et dispose des notions empruntées à l'expérience contemporaine et à l'histoire. Cette démonstration écarte les modèles classiques, néglige également philosophes et théologiens, appliqués à concilier, avec l'éthique rationnelle ou l'Évangile, l'art de gouverner les hommes. La théorie républicaine se développe en une glose géniale, mais incomplète, à l'œuvre mutilée d'un historien républicain. Également indifférente à ce qui ne s'identifie pas avec le bien public et la conservation de l'État, également nourrie de substance historique et d'expérience vécue, également fondée sur une confrontation incessante du présent au passé, aussi ferme dans ses axiomes, sa critique et ses conclusions, bien que la lassitude, la contrainte d'autres tâches entreprises, et la mort tôt survenue, aient empêché l'auteur d'en résumer, comme dans le livre du Prince, l'égale évidence en un aussi bref enchaînement de théorèmes. p290 
La première avait servi à justifier, devant l'inquiétude de Machiavel, un idéal d'action entrevu pendant quelques années, du triste automne de 1513 à la fin prématurée de Laurent. Action également incertaine ; mesquine par les hommes qui s'y entendirent inviter et s'en désintéressèrent, grandiose par le projet de restauration nationale qui lui donnait sa raison d'être et un horizon à la mesure de l'Italie. Bientôt il ne resta, du Prince, que le dur bréviaire d'un absolutisme assez inflexible dans ses principes et sa conduite pour s'imposer, assez bienfaisant dans ses effets pour durer; mais dont la technique, dévoilée sans réticence, pouvait offrir, à quelque tyran ingénieux et dissimulé, les chances d'un succès facile et détestable : le cardinal de Richelieu affirme que certaines maximes, bonnes pour les grands esprits, ouvriraient à ceux qui sont médiocres une voie à la tyrannie ${ }^{\text {cdxlii. }}$. En fait, on peut admettre que le Prince, à qui veut en saisir le sens profond, résume la théorie d'un despotisme éclairé, qui, n'accordant que peu de confiance au cœur des hommes, moins encore à leur esprit, persiste à les conduire malgré eux et de force vers un ordre conçu par la raison.

Attristé par la disparition des deux jeunes Médicis auxquels il avait en vain offert l'occasion d'une œuvre héroïque, Machiavel, après 1519 , ne voulait plus penser qu'à la réforme républicaine de Florence. Son projet, accordé aux nécessités d'un petit État italien, se bornait à la reconstruction d'une république désormais capable de stabilité. Peu importe que, pour concilier vertu républicaine et honneur monarchique, il lui plût d'admettre, hypothèse hasardeuse, le concours d'un prince citoyen, séduit par la grandeur de son renoncement. La doctrine politique du secrétaire florentin fut désormais républicaine. Mais il manquait à la cité de Machiavel ce qui avait manqué à la cité antique, à la commune médiévale ; parmi ces libertés nécessaires que Thiers un jour énuméra, l'on n'y eût retrouvé que la sécurité. Machiavel républicain n'a jamais pris le soin de définir en détail les droits des citoyens. La république de Machiavel, comme la monarchie, est un État qui d'abord travaille à sa conservation, et lutte pour sa grandeur. Monarchique ou républicaine, la politique de Machiavel ne s'est jamais proposé pour fin d'assurer aux individus p291 le plein développement de leur personne humaine au moyen, de droits sans cesse élargis; mais d'assurer le salut et la puissance de l'État, grâce à l'effort dirigé des individus, grâce au dévouement exigé des individus. La seule différence est qu'ils collaborent à l'œuvre commune en vertu non d'un 
devoir d'obéissance personnelle au souverain, mais d'un contrat théoriquement conclu entre égaux.

Une fois réduite à ses thèses essentielles, la doctrine monarchique de Machiavel peut sembler brève et décevante, étroit et borné l'horizon de son prince : petit seigneur, chef d'un petit État, comme le tyran de l'antiquité grecque, ou le tyran italien des XIV et $\mathrm{XV}^{\mathrm{e}}$ siècles ; comme César Borgia. Il est trop aisé de constater que l'auteur volontairement néglige quelques exemples éclatants offerts à son étude par l'histoire ancienne, et qui lui auraient permis d'étudier l'action princière étendue aux plus lointaines limites du monde civilisé. Dans les grandes monarchies qui déjà se disputaient, en Europe, sur les champs de bataille italiens, le prestige, la richesse et la puissance, l'œuvre récente d'un Louis XI, l'œuvre contemporaine d'un Ferdinand le Catholique auraient mérité de retenir un théoricien de la monarchie. " Nerva César, écrit Tacite, a uni deux choses jadis incompatibles, le pouvoir du prince et les institutions libres; Trajan de jour en jour rend l'autorité plus douce. $\gg{ }^{\text {cdxliii }}$ Mais le chancelier florentin aborde à peine le débat d'une conciliation possible entre formes princières et républicaines dans une monarchie tempérée. Il sait les bienfaits apportés au monde antique par la modération de quelques empereurs qu'un long établissement inclinait au libéralisme ; mais il n'a guère voulu considérer que l'installation parfois tragique, le plus fréquemment violente et contrastée, d'un prince nouveau, et le maintien d'une autorité souvent conquise de haute lutte. Il a dû, par là, prendre en considération la force plutôt que la légalité.

Pareillement incomplète et sommaire peut apparaître la doctrine républicaine des Discours sur la première Décade. Elle résume en quelques traits décisifs la conduite de la cité antique, de la république athénienne, de la république romaine au temps p292 lointain dont TiteLive, dans ces dix premiers livres, se fit l'historien; Rome alors n'était pas encore la capitale d'un empire. Cette doctrine peut convenir à Florence, enfermée au cœur de ses domaines toscans; moins à Venise colonisatrice et maîtresse du commerce oriental. Il faudrait quelque effort d'interprétation et d'accommodement pour l'adapter aux besoins et aux devoirs d'une grande république moderne. 
Ainsi la double théorie de Machiavel conserve un dessin primitif, archaïque, en harmonie avec les aspects d'un monde évanoui. Et pourtant, dans les limites que volontairement elle accepte, dans le cadre d'une étude volontairement restreinte à quelques types élémentaires, malgré le caractère souvent élémentaire des maximes où elle aboutit, la doctrine conserve une solidité classique. Machiavel, comme Montesquieu, pose des principes, et voit les cas particuliers s'y plier comme d'eux-mêmes. La réduction, conforme à la tradition humaniste, des problèmes de toute politique aux termes dans lesquels les concevait l'antiquité gréco-romaine, a pour but et pour effet d'en dégager les éléments essentiels et permanents; elle permet de construire un système inébranlable d'axiomes qui valent pour la première entreprise de tout grand effort en politique. Le Prince résume en règles sommaires et pratiques la création, la défense et le progrès d'une monarchie autoritaire, qui reste une forme encore vide: mais l'évolution de la société qu'elle contraint à la discipline de l'État accordera peu à peu l'esprit des lois et les nécessités d'une histoire en perpétuel mouvement. Ainsi l'empire de Nerva, de Trajan, des Antonins, en vertu d'une évolution conditionnée par les changements du monde romain, naît de la dictature de César et de l'empire d'Auguste, sans que s'y effacent les traits de la fondation primitive. Les Discours sur la première Décade codifient l'art d'instituer et de conserver une république où l'autorité nécessaire de l'exécutif se concilie avec la tutelle d'intérêts aristocratiques et populaires; où la constitution, qui assure le maintien de quelques droits essentiels, néglige d'importantes libertés; où le législateur ne semble pas se mettre vraiment en peine d'économie ni de problèmes sociaux. Mais quand il sera nécessaire d'adapter, aux besoins, aux désirs, aux idées d'une ${ }_{\mathrm{p} 293}$ cité politiquement vivante ${ }^{\text {cdxliv }}$ le texte de la constitution première, l'esprit même de ces lois organiques déterminera le sens de leur révision. La grandeur de Machiavel est de n'avoir voulu traiter que de principes, de commencements, et parfois de recommencements. Dans le détail de l'application, Aristote, de génie plus vraiment réaliste, avait pénétré plus avant. Instruit par Machiavel et par deux siècles d'une nouvelle histoire, Montesquieu, dont le projet plus large s'accorde au fond avec le sobre dessein de Machiavel, trouvera plus à dire sur la pratique et les principes mêmes. Le secrétaire florentin n'avait entendu travailler 
que pour les fondateurs et réformateurs. A eux s'adressait, et continue de s'adresser, une œuvre classique.

Table des matières

\section{II}

Machiavel nous a donc légué un esprit plutôt qu'un corps de doctrine. II faut essayer de saisir cet esprit, à l'aide surtout de ses deux grands livres. Le détail de son activité politique et diplomatique, le détail pittoresque et parfois tragique de sa vie et de sa carrière, appartiennent à l'histoire de Florence et de l'Italie; ses comédies, ses nouvelles, ses vers, appartiennent à l'histoire des lettres italiennes ; l'héritage de sa philosophie politique appartient à l'histoire générale de la pensée.

L'humanisme florentin avait restitué au monde moderne l'antiquité grecque ; il y reconduisait la politique et la philosophie comme à une première origine. Machiavel n'est pas Grec. L'auteur du Prince ou des Discours sur Tite-Live peut se souvenir des tyrannies ou des cités libres qui naquirent et grandirent sur le sol de l'Héllade ou de l'Asie Mineure, de l'Italie méridionale ou de la Sicile. Mais ce n'est pas la Grèce victorieuse à Salamine ou à Platées qui lui enseigna la grandeur civique et nationale; ce n'est pas l'hellénisme des successeurs d'Alexandre qui lui a révélé la tâche universelle d'une civilisation supérieure. Dans le passé ${ }_{\text {p294 }}$ grec, Machiavel a considéré surtout quelques réussites éclatantes de politique républicaine ou princière. Le culte que, comme Montesquieu, il réserve aux législateurs de génie, et qui conduira Montesquieu à ne pas rejeter sommairement la république de Platon ${ }^{\text {cdxlv }}$, se refuse pourtant à ce prophète désarmé. La politique d'Aristote, subordonnée à une éthique soucieuse de l'achèvement du type humain, n'a guère offert à son désir de réalisations certaines que des analyses de formes constitutionnelles et des calculs d'agencement. Le secrétaire florentin n'est pas assez humaniste pour bien entendre Aristote. 
Montesquieu assure qu'on ne peut jamais quitter les Romains ${ }^{\text {cdxlvi }}$; Machiavel en offrirait la preuve; il reste prisonnier de leur histoire. Il admire passionnément l'œuvre de cette république dont Polybe décrivit les magistratures et les comices, dont Cicéron, théoricien de droit public, analyse la constitution. Il aime la sagesse de ce régime qu'il juge libre, modéré, perfectible ; il suit avec joie les succès d'une cité souveraine du monde par la force de ses lois républicaines. Tite-Live pensait redevenir le contemporain des consuls et des préteurs qui avaient fondé le gouvernement sénatorial et assuré sa défense ; Machiavel, dans les veillées de San Casciano, les a passionnément interrogés. Mais Rome est restée pour lui la République maîtresse d'un empire conquis; sujette d'un empereur, elle n'a plus compté à ses yeux. L'histoire romaine ne l'a instruit que jusqu'à Pharsale; il n'a demandé aux Césars nul conseil, nulle leçon. Il a rétréci à outrance l'immense histoire de Rome. Le monde, après la guerre civile, lui a paru vide, pauvre de grands hommes, riche en exemples néfastes, en traditions malfaisantes. Nul admirateur de Rome n'a plus résolument nié tout ce qui dans l'œuvre historique de la Ville Éternelle, a le plus puissamment contribué à la formation des peuples modernes ; le travail, prolongé quatre siècles, de l'administration impériale ; l'enseignement quatre fois séculaire des jurisconsultes. C'est dans cette mesure, avec ce dur parti pris, que Machiavel est Romain. Sa passion romaine s'exalte dans un effort désespéré pour ressusciter un régime et une tradition depuis Sylla frappés de mort.

Il apparaît ainsi comme le précurseur authentique de nos Jacobins. Il s'est inspiré à la lecture des mêmes livres, au culte des p295 mêmes grands hommes, à la méditation de mêmes scènes de l'histoire. Il a puisé dans Tite-Live, Cicéron, Tacite ou Plutarque, les mêmes admirations, les mêmes mépris, les mêmes haines. Il diffère d'eux pourtant parce que l'enthousiasme civique, puisé aux sources romaines, ne leur suffit pas. Ils entendaient encore modeler à nouveau le monde selon quelques vues de l'esprit, quelques affirmations passionnées du sentiment. Machiavel, presque aussi prompt qu'eux à déceler et à désirer, dans l'histoire universelle, l'intervention bienfaisante du législateur de génie, se sent plus qu'eux retenu par certaines leçons de prudence et de mesure qu'il doit au positivisme romain, à l'étroite conception romaine de l'État. 
Ainsi Machiavel cherche librement, dans la double tradition antique, les certitudes qui pouvaient rendre à un partisan vaincu le goût de vivre. Avec une égale indépendance, il accueille ou rejette les traditions ou les formes d'esprit qui s'imposaient aux hommes de son temps. Il les soumet à une critique pour laquelle le dévouement civique atteint seul au plus haut sommet de la vertu humaine.

Il ne comprend pas, il n'aime pas le christianisme. Bien avant Frédéric Nietzsche, il affirme que Rome catholique, par son exaltation de l'humilité, a détruit dans le monde moderne l'énergie agissante. Il repousse comme une chimère conçue par des esprits barbares, mal informés des réalités et des grandeurs terrestres, cet universalisme catholique où Dante, malgré son amour de Florence et de l'Italie, accordait les peuples réconciliés. Il ne s'intéresse qu'à la nation; non pas à la chrétienté ; non pas à l'humanité. Son idéal d'homme d'État ne peut admettre qu'une religion d'État, capable d'enseigner une morale d'action civique, d'adhésion active à une politique nationale. Il assure que le christianisme, à l'origine, présentait ce caractère, et que les modernes l'ont mal compris et détourné de sa voie. Soucieux avant tout d'assurer le service de l'État et de la nation, Machiavel condamne le catholicisme médiéval, parce qu'il reste indifférent à la nation et qu'il enseigne à l'individu des vertus dont la nation ne saurait se prévaloir. Peu importent les progrès et la perfection de la vie intérieure, si l'individu seul y doit gagner le salut : les vieux Florentins préféraient le bien de leur ville à leur part de ${ }_{\mathrm{p} 296}$ Paradis ; l'intérêt même spirituel de l'individu ne compte pas en face des intérêts de la cité ou de la nation. Aussi Machiavel se détourne avec indifférence, avec colère, avec rancune, des saints et des ascètes qui offrent aux modernes la séduction d'un idéal vainement humilié. Il semble rêver d'une réforme qui, au christianisme des prêtres et des moines, substituera le christianisme héroïque des soldats et des citoyens.

L'humanisme lui affirmait aussi hautement, au nom d'autres doctrines, le prix infini des âmes individuelles. Chez les premiers disciples de Pétrarque, comme dans les écoles modernes et plus savantes, qui pourtant ne pouvaient oublier qu'elles lui devaient leur première initiation, le spiritualisme grec et l'idéal hellénique de grandeur humaine par la noblesse de la pensée, s'accordaient avec le patriotisme 
un peu bref de Rome et son idéal de grandeur humaine par la vertu civique; un christianisme rasséréné s'accordait avec un hellénisme conscient du tragique de la vie mortelle. Le secrétaire florentin n'a pas accueilli ces leçons. Non pas seulement parce que son savoir, ses lectures, ses goûts, ses ardeurs, n'étaient pas d'un Marsile Ficin ou d'un Politien. Mais l'humanisme contenait une éthique spiritualiste et volontiers chrétienne; elle se fondait sur le dogme, accepté sans trop de réserves, ou sur une sorte de platonisme sans doctrine, prompt à s'entendre avec l'Évangile. Pas plus que la religion ou la métaphysique des humanistes, leur éthique ne pouvait séduire Machiavel. Ses principes étaient autres, son éthique s'orientait selon d'autres vues.

Table des matières

\section{III}

L'éthique de Machiavel constitue, dans les premières décades du $\mathrm{XVI}^{\mathrm{e}}$ siècle, une nouveauté. L'éthique des chrétiens a pour centre l'âme humaine et son salut ; l'éthique humaniste, l'âme humaine et sa grandeur. L'une et l'autre ont pour objet l'individu et pour fin sa destinée, qu'il s'agisse de le soustraire à la commune bassesse, ou de le relever d'une chute et de guérir ses plaies. L'éthique de Machiavel ne prend pas souci de l'individu et de sa destinée : elle ne lui demande que de servir. Elle est p297 essentiellement une éthique du service dû par l'homme à une œuvre qui dépasse son horizon.

Ce service se résume essentiellement dans l'obéissance du citoyen et du soldat aux ordres de l'État. La nécessité d'obéir lui impose des devoirs et ne lui reconnaît pas de droits : l'État peut toujours reprendre les franchises concédées. Ainsi les grands chefs d'ordres avaient plié leurs religieux à une discipline passionnément acceptée. Parmi ses contemporains, Machiavel est moins proche d'Érasme que d'Ignace de Loyola. Sans doute réclame-t-il un minimum de sécurité, de liberté républicaine. Mais sa république romaine et jacobine exige de l'individu, s'il le faut, le renoncement et l'abdication ; l'État, républicain ou princier, exerce sa contrainte par delà le bien et le mal, et jusqu'au crime, sur l'individu. Dès qu'il s'agit de servir l'État, le centre du débat moral se déplace; l'impératif de la loi morale perd son ca- 
ractère absolu pour qui est commandé, et se réduit au devoir d'obéir ; le problème éthique se pose uniquement pour qui commande au nom de l'État. Il n'est d'éthique que du gouvernement.

$$
\text { *** }
$$

Pour en établir les préceptes, il faudrait définir au préalable l'État et son rôle humain. Le secrétaire florentin n'est pas entré dans ces contestations ; il prend l'État comme un fait; il offre à l'État son service et le service des hommes. Il semble reconnaître tacitement en lui le garant et le tuteur des biens que crée la vie de société, et qu'il ne se donne pas la peine d'énumérer. Il lui faudrait poser le problème entier de la civilisation humaine, s'acheminer patiemment sur les traces de Platon et d'Aristote ou de saint Thomas. Il n'avait pas le goût de rouvrir d'aussi longues disputes. Selon l'idée que les écoles ont pu se faire de la civilisation, de ses acquisitions essentielles, de son évolution possible, de ses fins idéales, varient leurs conceptions de l'État, de son rôle, de ses exigences licites, et par là, du devoir des gouvernants. Machiavel, sommairement, accepte l'idéal que lui offrent, dans l'histoire, l'exemple de la première société romaine et du gouvernement qu'elle a créé, la république sénatoriale et consulaire ; combinaison modérée d'aristocratie et de démocratie, de hardiesse novatrice et de traditionalisme conservateur. Mais il n'en a guère analysé que le mécanisme constitutionnel et politique ; il n'a pas cherché à comprendre, en historien de l'économie ${ }_{\mathrm{p} 298}$ et de la société, le type de civilisation qui a créé, pour ses besoins et sa défense, la république romaine. Sommairement, il a défini l'éthique gouvernementale d'après celle d'un État dont il n'a pas défini la nature profonde.

Cette éthique n'impose, à qui ordonne au nom de l'État, que le seul devoir de le conserver. Elle permet, en vue de cette fin, l'usage de tous les moyens, sans nul égard aux lois qui règlent les rapports humains. Comme cette conservation exige force et puissance, l'éthique gouvernementale prescrit le maintien, la préservation, au besoin une sage réforme des lois constitutionnelles; le maintien de l'équilibre social et de la paix sociale ; le maintien et l'accroissement de la force militaire, de la richesse privée et publique. Machiavel, dédaigneux de l'économie, n'a pas pris la peine de montrer d'avance, aux mercantilistes du XVII ${ }^{\mathrm{e}}$ siècle, comment le commerce et l'industrie créent les ressources financières de l'État; il a traité longuement des questions 
militaires, dans l'Art de la Guerre, les Discours et le Prince; il ne s'est guère attardé aux problèmes sociaux. Plus volontiers il applique son génie d'historien politique a l'étude des conditions qui, dans un État princier et de préférence républicain, assurent l'équilibre politique et la force politique. Ainsi l'éthique gouvernementale se réduit à une technique du gouvernement le plus efficace.

Une pareille technique admet la double primauté de l'art militaire et de l'art politique. L'individu est avant tout soldat et citoyen : l'État est d'abord militaire et politique. Pas de bonnes lois où manque la bonne organisation de l'armée ; pas de bonne organisation de l'armée où il n'y a pas de bonnes lois. Les autres formes de l'activité humaine doivent rester subordonnées à la politique et à la défense de l'État par les armes.

II appartient donc à la politique de régler et de discipliner selon ses fins la vie spirituelle des individus et l'action des Églises; ce qui conduit nécessairement à instituer, entre elles et l'État, une collaboration où elles risquent le sacrifice d'essentielles libertés. Il appartient à la politique d'admettre ou de rejeter, en dernier ressort, l'opportunité de toute modification au régime social sur lequel reposent l'ordre traditionnel de la cité, l'équilibre et la stabilité de l'État. Malgré le libéralisme sommaire que Machiavel semble admettre en économie, la logique $_{\mathrm{p} 299}$ de la doctrine devrait conduire à l'idée d'une organisation du travail exactement contrôlée et dirigée ; à la dictature industrielle et commerciale d'un Colbert ou d'un Frédéric II.

Les devoirs de l'État et du gouvernement envers l'individu s'ordonnent selon la même éthique de défense et de force. Machiavel les réduit à peu de chose. Il ne demande, pour l'individu, que le minimum de liberté et de sécurité sans lequel l'homme, moralement et physiquement diminué, perd, avec le goût du travail et die l'action, l'aptitude au service.

Ce républicain n'a pas pris soin de définir, avec une précision exigeante, les droits naturels du citoyen ; il s'accommode aisément d'un despotisme éclairé. L'esprit socialiste lui demeure étranger. Platon avait écrit, dans les Lois, que l'État parfait est celui où se réalise la communauté des biens, et qu'ensuite les États les mieux disposés sont 
ceux qui s'en rapprochent le plus ${ }^{\text {cdxlvii }}$. Thomas More, contemporain de Machiavel, l'avait redit en un langage où l'émotion évangélique se tempérait d'ironie érasmienne ${ }^{\text {cdxlviii }}$. Le secrétaire florentin, qui n'a pas développé les conséquences économiques de sa doctrine, qui accepte l'héritage de l'histoire, et, rendu prudent par l'étude du passé romain, redoute les conséquences troubles de lois agraires, n'attribue pas volontiers à l'autorité publique le rôle d'une Providence; il n'inscrirait pas à son programme la nécessité d'améliorer les conditions matérielles et morales des prolétaires. Il ne paraît pas souhaiter, en général, et sauf l'exception de circonstances tragiques, l'intervention du magistrat ou du prince pour discipliner, selon quelques principes de justice et d'humanité, les rapports, déjà difficiles et tumultueux à Florence, du capital et du travail.

Table des matières

\section{IV}

Ainsi Machiavel définit lès règles d'action et de conduite qu'il impose aux chefs princiers et républicains des États. Sous une plus dure et plus nette lumière apparaissent les erreurs dont il entend les garder. p300

Il condamne tout gouvernement dont l'action ne sert que des avantages particuliers : monarchie où le prince ne poursuit que des satisfactions de commodité personnelle ou d'orgueil familial ; république dominée, comme à Florence, par un petit nombre de familles, entêtées à confondre le bien de l'État avec la prospérité de leur négoce, de leur industrie, de leur banque. Sans doute, il souhaite, il juge bienfaisante, dans une cité libre, l'action de grands partis, organisés comme à Rome pour la défense de quelques principes et de certains intérêts collectifs. Mais le gouvernement ne fait œuvre gouvernementale que s'il se tient au-dessus des partis, des principes de parti, des intérêts de caste ${ }^{\text {cdxlix }}$. Thomas More avait écrit que l'art de gouverner les hommes semblait se réduire à une entente secrète de riches qui, sous prétexte de bien public, réglaient entre eux des affaires privées ${ }^{\text {cdl }}$. Un autre grand Anglais, William Pitt, au XVIII ${ }^{\mathrm{e}}$ siècle, essaya d'interrompre cette pratique des gouvernements de partis et de classes dont l'ami d'Érasme 
avait semblé d'avance dénoncer les tares ; il devait, sans trop y réussir, tenter la création d'un gouvernement étranger et supérieur aux ententes politiciennes et aux avantages de classe, capable seul de représenter la pérennité de la nation, de son esprit, de ses intérêts véritables et constants. Machiavel a cru peut-être, sur la foi de Tite-Live, que la république romaine, apparemment fondée sur l'accord du patriarcat et de l'élément démocratique, satisfaisait un tel idéal. Il n'a jamais pris grand'peine à décrire la mise en pratique, chez les modernes, du principe qui restituait au gouvernement, en face des partis et des classes, sa raison d'être et sa liberté.

Une telle politique appelle à son aide le calcul ; elle semble exclure d'abord le sentiment. Elle semble écarter l'enthousiasme, le mirage romantique. Dans la conduite intérieure de l'État, comme dans ses rapports avec l'étranger, elle doit, semble-t-il, se méfier de toute démarche que la raison, appliquée à la mesure de l'utile et du possible, n'a pas approuvée. A l'art de la politique, Machiavel impose la sobriété d'un strict réalisme. Et ${ }_{\mathrm{p} 301}$ pourtant, ce classique peut paraître, à certains moments, un romantique. Cet élève de la hardiesse prudente de Rome n'a jamais voulu nier le rôle que jouent, dans l'histoire universelle, l'inspiration, le génie, l'action, discernée par Platon et par Goethe, de quelque démon inconnu. Il admire les prophètes armés, législateurs ou fondateurs de cités ou d'empires, qui imposent aux hommes leur vouloir et leur passion. Mais, pour que la passion, aidée par la force, ait la vertu de renouveler un monde, il faut qu'elle soit nourrie de certitude dialectique autant que de sentiment. Si Machiavel n'écarte pas du domaine de la pratique la poésie et l'intuition, cette poésie est vérité, cette intuition est faite de théorie et de calcul. Peu importe que, parfois, à Florence et à Rome, son intuition de poète l'ait égaré à suivre des fantômes; que son calcul se soit montré parfois peu strict et sa théorie illusoire ; que, trop passionné pour être équitable, il ait dénié toute justice aux princes italiens et aux condottieri. Son œuvre d'écrivain compte plus que son action ; plus que sa politique et ses jugements politiques, l'idée qu'il eut de la politique. Cette idée est d'un réaliste qui sait, en réaliste, le prix et l'action de la poésie.

Il écarte du moins toute opinion préconçue qui, au nom de quelque thèse doctrinale, entend d'abord guider ou lier la conduite de l'homme 
d'État. Proche du peuple par la médiocrité d'une existence toujours étroite, par une méfiance de classe envers la noblesse foncière ou d'argent, par certains de ses divertissements et une vive impatience de la gêne et des conventions, assez volontiers plébéien de langage, il n'admet pas sans réserve cette tradition démocratique dont il a recueilli l'héritage florentin, et qui, d'ailleurs, depuis longtemps n'avait servi qu'à masquer le pouvoir d'une oligarchie marchande, industrielle et financière. S'il lui arrive d'affirmer que la voix populaire est la voix de Dieu, il sait aussi que la plèbe est à la fois hardie et débile, que le peuple se comporte comme s'il désirait sa propre ruine ${ }^{\text {cdli }}$; Savonarole a, p302 mieux que Machiavel, aimé les gens de labeur. En revanche, malgré son culte pour le passé consulaire et sénatorial de Rome, et ses illusions sur le dur régime dont la force venait du privilège patricien, il n'a jamais affirmé la mission historique des aristocraties. Les leçons de Polybe et de Cicéron l'invitaient à se méfier de toute école exclusive, à rechercher, entre les divers principes de gouvernement, une conciliation habilement opportune. Mais sa volonté de n'accepter, comme Descartes, aucune notion qui ne parût établie et prouvée avec évidence, son goût de l'expérience et de la démonstration scientifique, relevaient au-dessus de ces combinaisons et de cet éclectisme, jusqu'à l'idée d'une politique strictement et résolument positive.

Ce positivisme n'est pas banale prudence. Il n'exclut rien de ce que la raison, éclairée par l'expérience, juge réalisable. Et par là rentre dans le système ce qu'une certaine hésitation conservatrice en avait d'abord écarté. Aucun programme d'action n'est exclu, que la raison, instruite par l'étude exacte des faits, peut tenir, en de certaines circonstances pour possible et bienfaisant. Machiavel n'est pas révolutionnaire ; et pourtant il ne rejetterait sans examen aucun plan de reconstruction politique, économique ou sociale qui parût s'accorder avec les données, exactement définies, non pas seulement de l'histoire et de la tradition, mais des contingences les plus immédiates. Machiavel n'est pas socialiste ; et cependant il admet que le dictateur, en certains cas, doive détruire tout l'héritage du passé, disperser l'ancienne richesse, créer, pour les anciens pauvres, une opulence nouvelle. Il préfère l'intervention réformatrice et ses lenteurs mesurées; mais à ce prophète armé qu'il attend et qui viendra, il concède volontiers 
l'usage illimité de la force pour improviser à coup sûr la création d'un monde rajeuni. Rien de rationnel, rien d'expérimental, rien de possible et d'agissant n'est exclu.

Le même positivisme, aussi exigeant en matière de certitude, aussi capable, pour guider l'action, de prudence et de hardiesse, impose la même discipline aux relations extérieures des États. Il p303 écarte l'universalisme chrétien parce que les conditions générales de l'espèce humaine, et, particulièrement, l'histoire violente de l'Europe déchirée, en offrent comme une tragique réduction à l'absurde. Il accepte le fait de la concurrence qui seule établit, entre les peuples, la hiérarchie des forces et des talents, et les classe selon le jugement de l'histoire. Telles étant les données du réel, une politique exactement positive peut seule choisir, selon la raison et l'opportunité, entre un patient équilibre et le brusque élan, toujours licite, du plus fort vers la conquête de la puissance.

Ce positivisme est et n'est pas mépris des hommes. Machiavel s'accorde et ne s'accorde pas avec Hobbes. Il peut affirmer que les hommes sont fourbes et menteurs et ne méritent que d'être conduits par des mensonges. Il écrit alors que l'art de les gouverner se réduit à l'art de tenir en respect leur naturelle malfaisante ${ }^{\text {cdlii. }}$. Il peut affirmer qu'ils sont en général médiocrement bons et médiocrement méchants ; à qui les gouverne de choisir pour eux entre le bien et le mal. «Les hommes, dit Montesquieu, fripons en général, sont en gros de très honnêtes gens ; ils aiment la morale cdliii....» Et Machiavel a encore tenu compte de cet élément de vertu, par où se relève, aux yeux du politique positif, une nature dégradée. Mais le politique positif n'en conclut pas uniquement à la suprême convenance d'une ingénieuse hypocrisie d'État. Machiavel est assez grand pour comprendre certaines grandeurs. II sait que certaines vertus, nées de la douleur, éprouvées par la douleur, interviennent, forces actives, dans l'histoire humaine. Il sait, il veut les attirer dans son jeu; mais il est pris lui-même à son propre jeu ; et la plus belle page qu'il ait écrite, est, conclusion pratique d'un livre de froid calcul et d'expérience désabusée, l'ardent appel à un peuple instruit par le malheur. 
Cette politique positive et réaliste, qui utilise pour ses fins les moyens les plus bas et les plus nobles, parce que noblesse et bassesse sont également choses humaines et réelles, demeure avant tout une œuvre de l'intelligence. Elle ne veut pas, ou ne p304 voudrait pas s'égarer à la poursuite de fantômes créés par les sens et l'imagination. Elle affirme la primauté de la raison, seule apte à guider le libre vouloir ; elle reconnaît à la seule raison le droit de résoudre les problèmes que pose la vie des hommes en société, de décider, de commander et d'illuminer l'action. Sans doute, Machiavel sait que, sans la force, la raison reste impuissante parmi les forces déchaînées ; mais il ne désespère pas de lui procurer des armes, et les revanches qui lui sont dues, et la maîtrise qui lui appartient. Peu sensible à l'effet des causes économiques, il dirait que le drame de l'histoire trouve son explication dernière dans les esprits et dans les cœurs ${ }^{\text {cdliv }}$. Il se méfie des cœurs, faibles, capables d'illusion, de mensonge et de traîtrise. C'est à la raison qu'il veut rendre la conduite des affaires humaines. A elle d'utiliser, en vue d'une œuvre que seule elle peut concevoir et mesurer, toutes les puissances de l'homme, et d'imposer sa discipline aux forces précieuses et folles qui naissent des cœurs. Exactement instruite des lois qui contraignent l'histoire à la fatalité de retours éternels, elle connaît les limites nécessaires de sa propre action. Elle sait que la nature humaine et la destinée humaine répondent mal à l'immense espérance des hommes. Elle accepte l'ordre universel, et ne croit pas vain d'y jouer sa partie. 


\section{Addenda}

P. 19. Sur la politique de Pétrarque, voir Paul Piur, Petrarcas Bach ohne Namen unddie päpstliche Kurie: ein Beitrag zur Geistesgeschichte der Frührenaissance ; Halle, 1925, in- $8^{\circ}$; particulièrement chap. I et II, p. 6-98.

P. 105. Le traité Dell'arte della guerra a donné lieu à une étude importante de Martin Hobohm, Machiavellis Renaissance der Kriegskunst; I, Machiavellis florentinisches Staatsheer; II, Machiavellis Kriegskunst ; Berlin, 1913, 2 vol. in- $8^{\circ}$; compte rendu assez sévère de E. Fueter, Historische Zeitschrift, 113 (1914); p. 578-583. 


\section{Index 1}

1 Les chiffres renvoient aux pages. 
ACCOLTI (Benedetto), 25, 45.

ADRIANI (Marcello Virgilio), 46.

ADRiATiQue (Mer), 15, 56, 210, 221, 223.

ALEXANDRE LE GRAND, roi de Macédoine, 293.

ALEXANDRE VI, pape, 11, 45, 47, 49, $55,56,58-59,67-68,80,93,98$, $150,209,210,212-213,220-221$, 223-224, 229, 237, 239, 270.

AlighiERI (Dante) ; - Divine Comédie, 12, 15, 24, 39, 41, 76, 84, 90, 163.

- De Monarchia, 15, 23, 41, 76, 78, 163, 254.

- Idéal religieux et politique, 1217, 22-23, 25-26, 40-41, 43, 52, 61, $72-73,75,76-78,84,87,90,123$, 144, 146, 150-151, 163, 241, 295, 303.

- Doctrine de la paix universelle, 247-251, 254.

AlLEMAGNE, 17, 25, 62, 66-67, 73, $124,162,212,246$.

ALPES, 59, 61, 77.

ALSACE, 233.

AMBoISE (Georges d'), ministre de Louis XII, 65, 66, 149, 230.

AMÉRIQUE, 187, 235.

ANGE (Château Saint-), à Rome, 59.

ANGLETERRE, 9, 17, 25, 48, 67, 142, $149,176,187,234,259,300$.

Antilles, 235.

ANTONINS (les), empereurs, 235, 292.

ANVERS, 136, 142, 252.

APENNIN, 49, 108, 221.

APPIANI (les), seigneurs de Piombino, 238.

ARABEs, 37, 134.

ARAGON, 47, 51, 63, 261.
ARAGONAIS (famille des) de Naples, $56,81,87$.

Archipel, 234.

ARISTOTE ; - sa philosophie, 37, 250.

- Sa politique, 10, 12-13, 38, 121, 123-124, 250-251，275, 293-294, 297.

ARNO (fleuve), 29.

Asie Mineure, 293.

ASSYRIEN (empire), 233.

ATHÈNES, 95, 127, 131, 166, 196.

AtLANTiQue (Océan), 136.

Augsbourg, 17, 62, 136.

Auguste (Gaius Julius Caesar Octavianus), empereur, 148, 227, 234235, 292.

Augustin (Saint), 226.

AUTRICHE, 63, $184 . \quad-$ Maison d'Autriche, voir Habsbourg.

Avignon, 14, 16, 67.

BAGLIONI (Gianpaolo), seigneur de Pérouse, 212, 238.

BÂLE, 44, 141, 251.

BALTiQue (Mer), 62.

BAVIĖRE (Louis de), empereur, voir Louis.

BERNARD (Saint), 13.

BIONDO (Flavio), 158.

BisCEglie (Alfonso Borgia, duc de), 56.

BISMARCK (Otto, prince de), 124.

BOCCACE (Jean), en italien Giovanni Boccaccio, 24, 26, 41, 44.

BOĖCE (Anitius Severinus Boetius), 161.

BOËTIE (Étienne de la), 11.

BolOGNE, 47-48, 56, 112, 221, 223, 229. 
BONAPARTE (Napoléon), voir Napoléon $\mathrm{I}^{\mathrm{er}}$.

BonaVENTURE (Saint), 13.

Bonne-Espérance (Cap de), 54.

BORGIA (famille des), 47, 58; voir Alexandre VI et Borgia (César).

Borgia (César), 11, 15, 47, 49, 55-60, $68,74,81,87,93,95,97-98,105$, $142,149-150,161,209-210,213$, $216,220-225,228-230,236-241$, $255,257-259,262,264-265,275$, 282, 291.

Boscoli (Pietro Paolo), 68-69, 116.

Bossuet (Jacques-Bénigne), 176.

BOURBONS (famille des), 203.

Bourgogne, 63, 228, 233, 261, 271.

Bozen, ville du Tyrol, 61 .

BRACCIOLINI (Poggio), 21-23, 25, 38, 45, 137, 157, 159-160.

BRÊME, 62.

Brescia, 48.

BRÉSIL, 234.

Bretagne, 228.

BRIENNE (Gautier de), duc d'Athènes, 166.

BRUGES, 136.

BRUNI (Lionardo), 21-23, 33, 38, 45, 121, 137, 157-160.

BRUTUs l'Ancien (Marcus), 197.

BRUTUS (Marcus), 14, 23.

BuONDELMONTI (Zanobi), 108.

BuONARRoti (Michel-Ange), 41, 43, 47, 72, 95-96, 112, 241.

CALVIN (Jean), 42.

CAMiLle (Marcus Furius Camillus), 201.

Campanie, 210.

CANNES (bataille de), 145.
CANOSSA, 162.

CAP (le), voir Bonne-Espérance (Cap de).

CAPPONI, (famille florentine).

- Agostino, 68-69.

- Gino, 158.

- Niccolò, 112.

CAREgGi, près de Florence, 120.

CARPI, ville de l'Italie du Nord, 105.

CARthage, 52-53, 75, 145, 226, 259.

CASCIANO (San), bourg de Toscane, 29, 50, 72-74, 108, 294.

CAssius (Caius), 14.

CAssius (Dion), 236.

Castille, 63.

CASTRACANI (Castruccio), 105.

CATEAU-CAMBRÉSIS (traité de), 46.

CATHOLICISME, 44, 251, 295.

CATHOLIQUES (rois), voir Ferdinand d'Aragon et Isabelle de Castille.

CATILINA (Lucius Sergius), 14, 119, 236.

CAVAlCANTI (Giovanni), historien, 158.

CÉSAR (Jules), Caius Julius Caesar, 14, 23, 36, 47, 127, 146, 148-150, 189, 193, 196, 201, 203, 216, 234, 236237, 280, 292.

- César, voir Empire.

Cesena, 59, 222, 239.

Ceylan, 234.

Charlemagne, 79.

Charles IV, empereur, 17, 61, 75, 151.

ChARLES-Quint, empereur, 17, 32, 62, 77-78, 100, 109, 111-112, 115, 127, 148, 162, 237, 253, 261-262, 264, 271-272, 274.

Charles V, roi de France, 17.

Charles VII, roi de France, 259-260. 
Charles VIII , roi de France, 42, 4648, 51, 209, 234, 253, 258-259, 261.

Charles X, roi de France, 208.

Charles le TÉMÉraire, duc de Bourgogne, 17, 233, 261.

ChristianisMe, 12, 231，246，261, 296.

Cicéron (Marcus Tullius), 20, 23-24, $38,40,86,119-120,145,155-158$, 193, 226, 236, 251, 294-295, 302.

CInCINNATUS (Lucius Quinctius), 93, 201.

Ciompi (les), nom des ouvriers cardeurs de laine à Florence, 136, 166.

Città di Castello, 238.

Civitavecchia, 112.

ClÉment V, pape, 16.

ClÉMENT VI, pape, 17.

CLÉMENT VII, pape, 11, 100, 108-112, 115-116, 162, 166, 172.

Cognac, 111, 112, 271.

COLA DI RiENZO, 38, 75, 90, 150-151, 241.

Colbert (Jean-Baptiste), 299.

Cologne, 210, 252.

Colonna (famille), 212, 221.

COMMYNES (Philippe de), 272.

Compagni (Dino), 137, 153.

Conciles, 16, 20, 44, 48, 212.

Constance (Concile de), 44.

CONSTANTIN (Flavius Valerius Aurelius Constantinus), empereur, 78, 246.

CONSTITUANTE (Assemblée Nationale), 186, 189.

Contre-Réforme, 183.

COPERNIC (Nicolas), 25.

Cordoue (Gonzalve de), 59.

Cromwell (Olivier), 203.
Cyrus, roi des Perses, 90, 95, 220.

DALMATIE, 54, 234.

DANTE, voir Alighieri.

DAVID, 231.

DESCARTES (René), 19, 302.

Dictature (la) dans l'œuvre de Machiavel, 90-93, 101, 150.

Diodore de Sicile, 105.

DiOMÈDE dans la Divine Comédie, 15.

DOMINIQUE (Saint), 199.

DORIA (Andrea), 112.

ÉGLISE. - Autorité spirituelle de l'Église, 13, 55, 62, 67, 100-101, 124, 286, 287. - Pouvoir temporel, 55, 60, 67-68, 101, 243.

— Églises nationales, 16, 17, 65.

- Idée de la réforme de l'Église, 42, 44-45, 84, 199.

ÉGYPTE, 95, 185.

ÉMILIE, région de l'Italie du Nord, 56, 237.

EMPIRE : Empire romain, 14, 55, 119, 127-128, 149, 160-161, 163, 189, 234, 255, 291, 294.

- Saint-Empire romain germanique, 13-14, 16-17, 36, 39, 61, 76$78,80,89,127,147-148,165,210-$ 212, 246, 248, 254.

- Empire français, 143.

ENGELS (Frédéric), 246.

ÉRASME (Desiderius Erasmus), 10, 12, $67,141-142,214,252-254,261-$ 262, 264, 267, 271, 274-275, 286287, 297, 300 .

Espagne. - Conquête de l'Espagne par Rome, 146.

- Monarchie espagnole, 54, 63, 76, 79, 148-149, 233, 262, 264, 280.

- Espagnols en Italie, 48-49, 54, 
$59,62-63,67,73,76,80,89,119$, $148,223-224,229-230,235,237-$ 239, 255.

- Empire colonial, 234-235.

EsTE (famille d'), 24, 56, 81.

EUROPE, 31, 61, 66, 128-131, 136, 145, $147,153,210,213,227,230,251$, 253-254, 262, 291, 303.

ÉVANGILE, 17, 120, 254, 289, 296.

— Évangile éternel, 42.

ÉVÊCHÉS (Les trois), 233.

FABIUS MAXIMUS (Quintus), 201.

FAENZA, 56, 59, 229, 238.

FERDinAND LE CATHOLIQUe, roi d'Aragon, 10, 47-49, 56, 59, 63, 255, 259, 261-262, 271, 280, 291.

FERMO, 226, 240.

FERRARE, 24, 56, 81.

FICIN (Marsile), 33, 37-38, 44, 251, 296.

FLORE (Joachim de), 14, 42.

FLORENCE. - Histoire politique, 12, 18, 21-23, 29-30, 33-36, 39-40, 42, 45-46, 48-49, 52-53, 66, 68-71, 73, 74, 89-93, 97, 100-103, 108-109, $111-112,115,117-119,139,142$, $144,147,150,159,165-171,178$, 180, 196, 202, 216-217, 239, 273, 290, 292-293, 299, 301.

- Histoire de l'économie et de la société, 18, 29, 32, 40, 135-136, 144, 146, 148, 157, 166, 190-191, 279, 299-300.

- Politique religieuse, 45, 135, 183, 295-296.

- Politique extérieure, 49-50, 52, $56,58,60,63,70,76,111,112$, 229, 240, 244, 255-259, 286.

- Humanisme, 24, 36, 39, 44, 119120, 251, 293, 300.

- Art, 23, 94, 241.
- Voir Alighieri (Dante), Borgia (César), Machiavel, Médicis.

Floride, 235.

FogLIANI (Giovanni), 226.

FoIX (Gaston de), 48.

FORLÌ. 56. 59, 229, 239, 259.

FRANCE. - Monarchie française, 9, 16, 17, 54, 62-64, 75, 79, 84, 106, $148-149,162,163,176-177,184-$ 185, 200, 228, 233, 243, 259-261, 267, 271-272, 230.

- Politique française en Italie, 54, 56, 60, 62, 66-68, 73, 79, 89, 95, $106,119,259-263$.

- Vie intellectuelle, 25.

- Révolution et restaurations monarchiques, 187, 203.

- Colonies, 234.

Francfort-sur-le-Mein, 17.

Franche-Comté, 233.

FRANCISCAIN (ordre), 13, 84, 105, 189.

FrANÇOIS D'AsSISE (Saint), 13, 84, 199.

FrANÇOIS I $^{\text {er }}$, roi de France, 11, 17, $100,109,111,234,253,261,271$, $272,287$.

Franconie, 62.

Frédéric Barberousse, empereur, 52.

FRÉDÉRIC III, empereur, 17, 36, 40, 77.

FRÉDÉRIC, roi de Naples, 47, 51.

FRÉDÉRIC II, roi de Prusse, 268, 299.

FUGGER (les), banquiers à Augsbourg, 62, 136.

Fustel de Coulanges, 188, 205.

GALILÉE (Galileo Galilei), 25.

Gallicanisme, 184-185.

GANDIA (Jean Borgia, duc de), 56.

GARIGLIANO, fleuve de l'Ialie du Sud, 95. 
GASCOGNE, 228.

- Gascons, 63.

GÊNES, 18, 47, 68, 191.

Genève, 42.

GeNTILLET (Étienne), 11.

GERSON (Jean), 18.

GiBELINS, 36, 41, 52, 163, 166, 248.

GIOBERTI (Vincenzo), 99.

GoETHE (Wolfgang), 123, 301.

GonZAGuE (famille des), 24, 81.

GRACQUES (Tiberius et Caius Gracchus, les), 36, 146, 188, 193.

GRÈCE，38，73，120，121，124，128$130,153,156-157,234,291,293-$ 294, 296.

GRÉGOIRE VII, pape, 162.

GRÉGOIRE XI, pape, 16.

GRENADE, 262.

Guarino de Vérone, 24.

GuELFES, 40, 60, 66, 77-78, 149 163, 165.

GUICHARDIN (François), en italien Francesco Guicciardini.

- Son œuvre, 9-12, 52, 63, 101, 170, 216.

- Rôle politique et jugements divers, $10,62-63,110,111,162,167,32$, 48, 170, 216.

- Critique de Machiavel, 92-93, 114-116, 150.

Guidobaldo De Montefeltro, duc d'Urbino, 58, 238, 240.

HABSBOURG (famille de), 17, 230, 233, 254.

Hambourg, 62.

HANNIBAL, 75, 188, 284.

HANSE (la), 17, 62.

HEGEL (Georg-Wilhelm-Friedrich), 247, 265.
HeLlade, voir Grèce.

HENRI VII, empereur, 36, 52, 61, 75, 90, 151, 163.

HENRI II, roi de France, 11.

HENRI IV, roi de France, 162.

HERDER (Johann-Gottfried), 132.

HoBBEs (Thomas), 303.

HOHENZOLLERN (famille de), 184.

HollaNDE, 100, 176, 234.

HUMANISME, 18-19, 21, 38, 119, 128-

129, 157, 251, 275, 293, 296.

Hus (Jean), 246.

IMOLA, 56, 259.

INNOCENT VIII, pape, 40, 212.

INDES, 54, 136, 234-235.

Innsbruck, 61 .

Inquisition, 183.

Isabelle de Castille, 233.

ISLAM, 246.

ISRAËL, voir Juifs.

ITALIE. - Italie antique, 124, 146, 262-263, 293.

- Régions et gouvernements, 24, 32, 50-56, 59-60, 66, 74, 81, 89, 93, $97,100-101,111,143,149,212$, 216, 234, 239, 260, 271.

- Histoire politique, 14, 16-17, 20, $31,34,47,49,60,97,101,109$, $111,128-129,133,135,143,149$, $153,157,160-164,167,206,212-$ 213, 216, 232, 251.

- Guerres d'Italie, 41, 46, 53, 6364, 66-67, 82, 171, 221, 230, 234, 253, 258, 263-264, 291.

- L'Italie et les étrangers, 54, 5960, 66, 90, 96, 99, 227, 240, 242.

- Misère et divisions de l'Italie, 73-74, 79-80, 82, 90, 97, 251, 258.

- Particularisme italien, 114-115, 147. 
- Sentiment national, 14-15, 7577, 87, 98, 100-101, 114, 118, 146148, 295.

— Vie religieuse, 79, 183, 273.

- Vie intellectuelle et artistique, 14, 15, 24, 25, 41, 279.

- Idée de la réforme politique et morale de l'Italie, 93, 140, 150-151, 212, 217, 290.

JACOBINS, parti politique français, 294295, 297.

JEAN (Saint), évangéliste, 86.

JEAN XXII, pape, 17.

Jésus-Christ, 14, 254.

JOSEPH II, empereur, 184-185.

JUIFs, 43, 95, 113, 203, 246.

Kabbalistes, 37.

LANDINO (Cristoforo), 40, 46.

Leipzig, 252.

LÉON X, pape, 40, 67-69, 80, 93, 95, 98-101, 103-104, 107-108, 115, $117,211,213-214$.

LETO (Pomponio), 38.

LEVANT, 54, 136.

Liberté politique, 184-189.

LiguE (Sainte), 49-50, 68, 211.

LOCHES, 47.

LOCKE (John), 176.

LOMBARDIE, 60, 79, 82, 91, 95, 119 , $162,229$.

LONDRES, 142.

Lorraine, 233.

LOUIS DE BAVIÈRE, empereur, 16, 90.

LouIS XI, roi de France, 17, 291.

LouIS XII, roi de France, 47-49, 51,

56, 60-61, 66, 142, 221-223, 229, 237-238, 240, 255, 259, 261, 280.
LOUVAIN, 141, 252.

LOYOLA (Ignace de), 297.

Lübeck, 62.

LUCQUES, 105, 223.

Ludovic Le More, duc de Milan, 47, 51.

LUNIGIANA, région toscane, 29, 93.

LUTHER (Martin), 44, 62, 86, 212, 214, 246.

LYCURGUE, 43, 126, 132, 150.

MACÉdOINE, 231, 234, 293.

MaChiAVEL (Nicolas), en italien Niccolò Machiavelli. - Famille, jeunesse, formation, 29-66.

- Decennali, 70.

- Il Principe, 10, 15, 24, 50-52, 66, 93, 96, 98, 100, 103, 105, 111, $116-117,140-142,151-152,159-$ $161,164,166,175,183,202,216$, 218, 230, 232-233, 235-236, 240, 251, 254, 258-261, 265, 268-290, 292-293, 298.

- Discorsi sopra la prima Deca di Tito Livio, 9, 15, 52, 60, 64, 79-80, 82, 91, 93, 98-103, 108, 232-233, 251, 254, 266-268, 273, 285-286, 289-293, 298.

- Discorso sopra il riformar lo stato di Firenze, 64, 83,103, 110 , 116-117, 139.

- Vita di Castruccio Castracani da Lucca, 105, 108, 116, 152.

- Dell' arte della guerra, 52, 105107, 135, 152, 166-171.

- Ritratto delle cose della Magna, 61-63, 70.

- Ritratto di cose di Francia, 6266, 70, 84.

- La Mandragola, 41, 109.

- Machiavel et Aristote, 38, 121124.

— Et Polybe, 125-126. 
- Et Tite-Live, voir Tite-Live.

- Et Dante, 12, 15, 72, 78, 241242, 247, 251.

- Et Montesquieu, 138-141, 143, 178.

- Vie et action politique, 43-46, 49-51, 54, 67-69, 93-116.

- Rapports avec les Médicis, 36, 93-98, 102-105, 107-112, 116.

- Jugement sur César Borgia, 5560, 74-81, 220-226, 237-241.

- Jugement sur Jules II, 59-61, 67, 74.

- Sur l'Empire, 36, 61-63, 70, 7778.

- Sur la France, 63-66, 70, 84.

- Sur Venise, 55, 106, 255-257.

- Machiavel et la restauration nationale de l'Italie, 9, 72, 74-76, 8184, 87, 89-102, 106, 111, 113, 290.

- Et la réforme de la constitution florentine, 102-103, 199, 290.

- Et le Saint-Siège, 78-80, 210214.

- Et le christianisme, 44, 85-87, 122, 210-214, 285.

- Et les rapports de l'Église et de l'État, 173-185, 295-296, 298.

- Éthique de Machiavel, 72, 122, 132-134, 216-227, 296-299.

- Machiavel et les prophètes, 4243, 76-77, 189, 246, 250, 301.

- Machiavel fondateur de la science politique et de la politique positive, 118-151, 302-304.

- Théorie du gouvernement légal, 176-202.

- Programme républicain, 143147, 194-196, 290-292, 294-295.

- Monarchie bien réglée et restauration monarchique, 202-210.

- Dictature, 199-202.

- Théorie du pouvoir princier fondé sur la force, 215-227.

— Théorie de la conquête, 227-232.
— Le mythe de César Borgia, 233242.

- Théorie de la paix, de la guerre et des traités, 243-272, 297-304.

— L'économie, 190-192, 281, 299.

- Le gouvernement de l'opinion publique, 273-288, 303-304.

- Machiavel historien, 151-171.

- L'esprit de Machiavel, 289-304.

MACHIAVELli (famille). - Bernardo, 29.

- Girolamo, 29.

MADRID (captivité de François $\mathrm{I}^{\mathrm{er}}$ et traité de), 109, 111, 253, 271, 287.

Mahométans, 185.

MAIN, 210.

MAINE, 47.

MANFREDI (Astorre), 56.

Mantoue, 24, 75, 81, 229.

MARC (Saint), 255.

MARC-AurÈLE (Marcus Aurelius Antoninus), empereur, 183, 189.

MARCHES, 55, 56, 111, 222, 223, 226.

MARIGNAN (bataille de), 100, 107.

MARIUS (Caius), 146, 193.

MARSUPPINI (Carlo), 45.

MARX (Karl), 246.

MATTEO (fra), 113.

MAZZINI (Giuseppe), 133.

Maximilien $\mathrm{I}^{\mathrm{er}}$, empereur, 17, 36, 40, 61, 77, 142, 211, 255.

MAYENCE, 210, 252.

Mèdes, 95

MÉDICIS (famille des), 18, 23, 29-32, 50, 52-53, 68, 72, 76, 93-94, 97, 100-103, 107, 109, 112-114, 116$117,119,136,144,151,165-171$, 192, 196-197, 206, 209, 214, 216, 236-237, 257. 
MÉdicis (Cosme de), 32-33, 35, 42, $56,101-102,110,165-168,170$, 197-198, 206, 209, 236, 281.

MÉDICIS (Laurent de), le Magnifique, 31-35, 37-40, 42, 56, 67-68, 93, 95, 101-102, 110, 119, 147, 166-171, 206, 209, 237, 244, 281, 290.

MÉDICIS (Julien de), frère de Laurent le Magnifique, 34, 102, 119, 169.

MÉDICIS (Pierre de), fils de Laurent le Magnifique, 42,95, 102, 209.

MÉDICIS (cardinal Jean de), fils de Laurent le Magnifique, voir Léon X.

MÉDICIS (Julien de), duc de Nemours, fils de Laurent le Magnifique, 93101, 113, 151, 217, 241, 242, 290.

MÉDICIS (Laurent de), duc d'Urbino, fils de Pierre de Médicis, 95-102, $108,113,115-116,151,217,241-$ 242, 290.

MÉDICIS (cardinal Jules de), fils de Julien, frère de Laurent le Magnifique, 100, 102-104, 107-108; voir Clément VII.

MÉDICIS (Hippolyte de), fils de Laurent, duc d'Urbino, 108, 112, 115.

MÉDICIS (Alexandre de), fils de Laurent, duc d'Urbino, 108, 112, 115.

Medina del Campo, 59.

MÉditerRANÉE (Mer), 210-233.

MEXIQUe, 234-235.

MiCHEL-ANGE, voir Buonarroti.

Michele di Lando, 166.

MiLAN, 17, 20, 32, 47-48, 50-53, 60$61,78,81,83,89,119,130,147$, 169, 190, 221, 228-229, 258, 261.

MinerbetTi (Piero), 158.

Mirandole (La), ville de l'Italie du Nord, 47.
MirAndole (Pic de la), 37-38, 40, 44, 251.

Modène, 93.

MoÏSE, 43, 90, 95, 132, 150, 179, 220.

Montaigne (Michel de), 11-12.

Montefeltro (Guidobaldo de), 238.

MonTESQuieu (Charles de Secondat, baron de), 24, 35, 43, 52, 64-65, 7071, 83-84, 101, 126, 129, 138-141, $143,145,151,176,178,186,190-$ 192, 200, 263, 281, 284, 292-294, 303.

More (Thomas), 10, 12, 141-142, 189, 204, 252-253, 299-300.

Moyen Age, 10, 18, 32, 77, 107, 134, 136, 141, 160, 176, 248, 275.

NABIS, roi de Sparte, 205-206, 209.

NAPLES, 41, 47-49, 51, 53, 56, 59, 81$82,87,91,95,119,147,190,223$, 228-229, 238, 261-262.

NAPOLÉON I ${ }^{\mathrm{er}}, 107,185,203,208,234$.

NARDI (Jacopo), 68, 170.

NAVARRE, 59, 240.

NELLi (Bartolommea de'), 29.

Nemours, 93.

NEO-GUELFE (parti), 99.

NEPI, ville de l'Etrurie méridionale, 238.

NÉRON (Nero Claudius Germanicus), empereur, 23.

Nerva (Marcus Cocceius), empereur, 189, 291, 292.

NiETZSCHE (Friedrich), 295.

Nord (Mer du), 62.

Normandie, 228.

NOVARE, 107.

NuMA, roi de Rome, 43, 132, 179.

NuREMBERG, 17, 62. 
OCCIDENT, 230, 248.

Oliverotto, seigneur de Fermo, 226, 240.

OMBRIE, 47, 56, 111, 116, 223.

ORCO (Remirro de), 222.

ORDELAFFI (les), seigneurs de Forlì, 239.

ORICELLARI (Orti), jardins à Florence, 108, 112, 122.

ORIENT, 136, 146, 230.

ORSINI, famille romaine, 212, 221, 259.

OSTIE, 59.

Ostrogoths, 161.

Oxford, 25.

PARIS, 25, 252.

PARME, 93.

PASCAL (Blaise), 247.

PASSERINI (Cardinal Silvio), 108, 112.

Paul II, pape, 119.

PAVIE (bataille de), 109, 253.

PAYs-BAs, 10, 17, 136, 162, 176.

PAZZI (conjuration des), 30, 102, 119, 169.

PÉROU, 234.

Pérouse, 108, 212, 222-223, 238.

Perses, 95.

Pesaro, 56, 239.

PÉTRARque (Francesco Petrarca), 1820, 23-26, 41, 43, 61, 72-73, 75, 90, $96,119,128,150-151,153,241$, 295, 296.

Pharsale (bataille de), 36.

PhilipPe, roi de Macédoine, 231.

PhilipPe le Bel, roi de France, 17.

PhILIPPE II, roi d'Espagne, 10, 176.

Picardie, 233.

PIE III, pape, 58, 221, 224.
PIE VII, 185.

PIE IX, 99.

Piombino, 223, 229, 233.

PISE, 40, 46, 49, 51, 56, 105, 209, 223, $229,258-259$.

- Concile gallican de Pise, 48, 50, 61.

PistoiA, 105, 282.

PITT (William), lord Chatham, 300.

Plaisance, 93.

PlatéEs (bataille de), 293.

Platon, 10, 12, 119, 226, 275.

- République de Platon, 43, 120, 251, 294, 297, 299, 301.

Platonisme, 37, 296.

Plutarque, 92, 149, 236, 275, 295.

PolignaC (Jules de), 208.

Politien (Ange), 37-39, 46, 119, 296.

Pologne, 233.

Polybe, 36, 38, 125-126, 137, 145, 156-158, 182, 245, 294, 302.

POMPÉE (Cneus Pompeius Magnus), 193.

PONTANO (Giovanni), 119.

PORCARI (Stefano), 38.

Portugais, 234-235.

Pouille, 210.

Provinces Unies, 176.

PRUSSE, 184.

PULCI (Luigi), 37.

RAVENNE, 48, 54, 107.

RÉFORME PROTESTANTE，44，62，67, 100, 162, 212, 246.

Reggio d'Émilie, 93.

Renaissance italienne, 9, 14-15, 143.

RHIN, 210.

RICHELIEU (Armand-Jean, cardinal de), 290. 
RIMINI, 56, 59, 81, 221, 229, 238.

Roland, 37.

ROMAGNE, 47, 49, 55-59, 82, 84, 110, $150,210,213,216,220-224,229$, 237-240, 275, 282.

ROME : ville et campagne, 56, 59, 67, $72-73,82,111$.

- Rome sous les rois, 178-179.

- Sous la République, 19-21, 23, $25,35-36,38,52,71,73,75,90$, $102,105,119-120,124,128-130$, $133,141,145-146,148,150,153$, $157,165,182-183,187-189$, 192196, 198, 200, 202, 228, 234, 241, 255, 262-264, 266-267, 286, 291292, 295-300, 302.

- Sous les empereurs, 23, 25, 36, $63,119-120,124,131,137,149$, 153, 158, 189, 234-236, 246, 255, 294.

- Sous les papes, 16, 40, 49, 79$80,89,93,100,111-112,119,162$, 184-185, 214, 224, 238-240, 253, 295,301 .

Romulus, 92, 132, 150, 220.

ROUEN, 66.

Rouge (Mer), 54.

Roussillon, 233.

Rovere (Francesco Maria della), duc d'Urbino, 93, 95.

ROVERE (cardinal Giuliano della), 224, 238, voir Jules II.

RuCELlai (Cosimo), 108.

SALAmine (bataille de), 293.

SAlluste (Caius Sallustius Crispus), 166.

Salutati (Coluccio), 33, 38, 45.

SAVONAROLE (Jérôme), 42-45, 52, $118,119,178-180,220,246,301$, 302.

SCALA (Bartolommeo), 45.
SCHINER (Cardinal Matthieu), 16, 20, 44, 67.

SCIPION (Publius Cornelius) l'Africain, 23, 36, 75, 261, 284.

Scolastique, 226.

SÉNÈQUE (Lucius Annaeus Seneca), $119,120$.

SFORZA (famille), 18, 32, 57, 81, 87.

SFORZA (Francesco), duc de Milan, 56, 258.

SFORZA (Galeazzo-Maria), 119, 169.

SFORZA (Giovanni), seigneur de Pesaro, 239.

SiCILE, 59, 293.

SIÈGE (Saint), 13, 14, 16-17, 20, 33, 39-40, 47, 54-55, 59-60, 62, 66-68, 72, 77-80, 83-84, 87-89, 97-101, $112-114,136,147,161-163,165$, 210, 213-214, 223, 229-230, 239, 243, 246, 248, 253-255.

SiENNE, 23, 50, 56, 223, 229.

SimONETTA (Giovanni), 158.

SinigAGLIA, 57, 222, 226, 238.

SIXTE IV, pape, 212.

SODERINI (Piero), 49-50, 54, 68-69, 93, 108, 144, 196, 255.

SolON, 93, 127, 132.

Sordello de mantoue, 75.

Souabe, 62 .

SPARTE, 52, 126, 205-206.

STEFANI (Marchionne di Coppo), 158.

Stettin, 62.

STOÏCISME, 86, 120.

Stralsund, 62.

Strasbourg, 252.

STUARTS (famille des), 203.

SuÉTONE (Caius Suetonius Tranquillus), 236.

SUISSES (Cantons), 47-49, 61, 67, 79, 106, 147, 259-260. 
Sylla (Lucius Cornelius), 146, 193, 196, 201, 294.

SYLVESTRE I ${ }^{\mathrm{er}}$, pape, 78.

SYMMAQUE (Quintus Aurelius Symmachus), 161.

SYRACUSE, 105, 226, 240.

Taborites, 189.

TACITE (Caius Cornelius Tacitus), 62, 63, 77, 232, 291, 295.

TAINE (Hippolyte), 73, 156.

THÉODORIC, roi des Ostrogoths, 161.

THÉSÉE, 90, 95, 150, 220.

THIERs (Adolphe), 290.

ThOMAs (Saint) d'Aquin, 12-13, 275 297.

THUCYDIDE, 71, 156, 158-159.

TIBÈRE (Tiberius Claudius Nero), empereur, 23.

TIBUlle (Aulus Albius Tibullus), 72.

Tite-Live (Titus Livius), 19, 21, 24.

- Machiavel et Tite-Live, 36, 38, 70, 77, 93, 129, 137, 145, 153-159, 165, 204, 216, 236, 241, 251, 255, 267, 292, 294-295.

Toscane, 29, 56, 68, 82, 91, 95, 98, $105,108,111,115,146-147,150$, 153, 166, 221, 223, 229, 239, 260, 292, 300 .

- Langue toscane, 37-38, 41.

Touraine, 47.

TRAJAN (Marcus Ulpius Trajanus), empereur, 181, 291-292,

TRENTE, 61.

TRÈVES, 210.

TUDORS, 142.

TuRCS, 230, 234.

TYROL, 61 .

Tyrrhénienne (Mer), 14.
Ulysse, 15.

Universités, 250.

URBINO (duché d'), 58, 93, 95-96, 98, $100,102,108,116,217,221-222$, $238,240$.

Utrecht, 108.

VALENCE (ville d'Epagne), 55.

VALOIS (famille des), 228, 230, 233.

VAL D'ElsA, en Toscane, 29.

VAL Di Pesa, en Toscane, 29.

VALLA (Laurent), 39, 78.

VELLUTI (Donato), 137, 153.

VENISE, 18, 47-48, 51, 54, 59, 60, 67, 73, 79, 89, 106, 136, 147, 164, 196, 199, 212, 221, 224, 229, 234-235, 238, 240, 244, 252, 255-257, 259, 272, 292.

Vérone, 54.

VETTORI, (Francesco), 72, 93, 95.

VICO (Giovambattista), 132.

VILLANI (Giovanni et Matteo), 137, $153,158$.

VINCI (Léonard de), Lionardo da Vinci, 25-26, 39, 123, 129-130, 134, 158.

VIRGILE (Publius Vergilius Maro), 38, 282.

VIRGILIO (Giovanni del), 250.

VISCONTI (famille), 18, 20, 24, 33, 52, 56-57, 81, 105.

Vitelli (seigneurs de Città di Castel1o), 238, 259.

Volterra, 105.

Westphalie, 210.

XÉNOPHON, 105, 152, 261. 
Table des matières

\section{Notes de fin}

Essais, II, 10.

ii Paradiso, XVI, 46-66, 112-154.

iii De Monarchia, I, 3.

iv Telle semble être la signification symbolique de l'Aigle impériale que dessinent, dans le ciel de Jupiter, les âmes lumineuses de tous ceux qui sur terre ont travaillé à la création du droit ; âmes de l'antiquité juive et de l'antiquité héroïque, de la Rome impériale et du monde féodal (Paradiso, XVIII, 70-136, XIX, 1-24, XX, 16-72).

v Inferno, I, 101-111; Purgatorio, XXXIII, 37-45 ; Paradiso, XXVII, 61-63, 142-428.

vi Paradiso, XII, 139-141.

vii Discorsi sopra la prima Deca di Tito Livio, I, 10 ; Tutte le opere storiche e letterarie di Niccolò Machiavelli, éd. Guido Mazzoni et Mario Casella ; Florence, 1929 , in- $8^{\circ}$; p. 74-75.

viii Discorsi, I, 12 ; p. 79. Sur les réserves qui s'imposent relativement à la confiance que Machiavel (Il Principe, 11 et 26, p. 24 et 50) semble accorder à Léon X, voir p. 98-100.

ix V.p. 220-225.

x V. l'ouvrage de Fr. Ecole, Dante e Machiavelli ; Quaderni di Polilica, 2 ; Rome, 1922 , in- $8^{\circ}$.

xi Dell'arte della guerra, VII ; p. 367 : Questa provincia pare nata per risuscitare le cose morte, come si è visto della poesia, della pittura e della scultura.

xii Hans Baron; Das Erwachen des historischen Denkens im Humanismus des Quattrocento'; Historische Zeitschrift, 1933 ; 147, p. 5-20. Sur Pétrarque et à ce propos, p. 5-7.

xiii Fr. von Bezold; Republik und Monarchie in der italienischen Literatur des $X V^{t e n}$ Jahrhunderts ; Historische Zeitschrift, 1898 ; Neue Folge, 45, p. 433468 ; v. p. 448-449.

xiv Fr. von Bezold, ibid., p. 135, n. 1 ; Invective de Coluccio Salutati contre Antonio Loschi : Quid enim est Florentinum esse, nisi tam natura quam lege civem esse romanum ? - Manifeste de la Seigneurie en guerre contre Milan (1424) : Suorum antiquorum patrum Romanorum more, quorum sunt filii, se- 
men, sanguis et ossa. - L. Bruni ; Laudatio florentinae urbis : Quamobrem ad vos quoque, viri Florentini, dominium orbis terrarum jure quodam haereditario ceu paternarum rerum possessio pertinet.

La valeur réelle des Historiarum florentini populi libri XII a été trop diminuée par Burckhardt, par Voigt, et même par Pasquale Villari (Niccolò Machiavelli e i suoi tempi ; Florence, 1877, 3 vol. in- $8^{\circ}$ : $4^{\mathrm{e}}$ édition, Milan, 1927 ; 2 vol. in- $8^{\circ}$, sans les appendices documentaires ; III, p. 199-202). G. Salvemini (Magnati e popolani in Firenze dal 1280 al 1925 ; Publ. del R. Istituto di Studi Superiori, Florence, 1899, in-4º, p. 243), a, le premier, réhabilité 1'historien. Cette réhabilitation a été poursuivie par Emilio Santini (Lionardo Bruni e $i$ suoi Historiarum florentini populi libri XII ; contributo allo studio della storiografia umanistica fiorentina ; Pise ; Annali della R. Scuola Normale Superiore di Pisa ; filosofia e filologia, XXII ; 1910, in- $8^{\circ}$ ), et dans la préface de l'édition des Historiarum... libri XII (Rerum italicarum scriptores, XIX, 2 ; Città di Castello, 1926, in-4º). - Cf. Benedetto Croce, Intorno alla storia della storiografia ; Critica, 1913, XI, p. 161-259 ; IV, La storiografia del Rinascimento, p. 198-209.

xvi Fr. von Bezold, p. 436-438; p. 436, n. 3 : Paritas juris; paritas reipublicae adeundae ; nec est ullus locus in terris in quo jus magis aequum sit omnibus.

xvii Fr. von Bezold, p. 448-449.

${ }^{\text {xviii }}$ Fr. von Bezold, p. 437-438 ; Vittorio Rossi, Il Quattrocento ; Storia letteraria d'Italia ; Milan, $2^{\mathrm{e}}$ éd., 1933, in- $8^{\circ}$; p. 156.

xix Le traité de Léon Battista Alberti, intitulé Momus sive de Principe, ne sort pas de cette école, et ne doit rien non plus aux Florentins. L'auteur, qui fut un savant universel, un humaniste, un grand artiste et un architecte de génie, l'a écrit à Rome vers 1446-1448, pour fixer sa propre pensée sur le problème général du gouvernement. Il trace le type idéal d'un prince vertueux, modéré, éclairé, qui, sauf l'énergie, n'a rien de commun avec le Prince de Machiavel. La question des devoirs de tout gouvernement l'intéresse plus que la personne du prince. Voir le livre important de P.-H. Michel, La pensée de Léon Battista Alberti (1404-1472) ; Paris, 193, in- $8^{\circ}$, p. 291-295.

xx P. Duhem, Léonard de Vinci, ceux qu'il a lus et ceux qui l'ont lu; Paris, 1906-1913, 3 vol. in- $8^{\circ}$.

xxi V. Rossi, Il Quattrocento, p. 43. - Cf. Machiavel, Discorsi sopra la prima Deca di Tito Livio, II, Introd., p. 135 : Laudano sempre gli uomini, ma non sempre rngionevolmente, gli antichi tempi, e gli presenti accusano.

xxii Dédicace du Prince à Laurent, duc d'Urbino; Il Principe, p. 3 : Una lunga esperienza delle cose moderne e una continua lezione delle antique.

xxiii Il ne peut être question de donner ici une bibliographie complète de la question. A la base de toute élude sur Machiavel, restent les ouvrages de P. Villari, Niccolò Machiavelli, cité p. 20, n. 15, et d'Oreste Tommasini, La vita e gli 
scritti di Niccolò Machiavelli nella loro relazione col machiavellismo; Rome 1883-1911, 2 vol. in- $8^{\circ}$. On peut citer parmi les travaux les plus récents: Orestes Ferrara, Machiavel ; trad. fr. par Francis de Miomandre, Paris, 1928, in- $8^{\circ}$; The private correspondence of Niccolò Machiavelli, Baltimore, 1929, in- $8^{\circ}$; Felice Alderisio, Machiavelli ; l'arte dello Stato nell'azione e negli scritti ; Turin, 1930, in- $8^{\circ}$; Giuseppe Prezzolini, Vita di Niccolò Machiavelli fiorentino; Florence, 1934, in- $8^{\circ}$. — Études sut l'œuvre et la doctrine : Francesco Ercole, La politica del Machiavelli ; Rome, 1926, in- $8^{\circ}$; et surtout Federico Chabod, Del Principe di Niccolò Machiavelli ; Nuova Rivista Storica, 1925 , p. 35-71, 189-216, 437-473 ; publié en un volume sous le même titre, Milan-Rome, 1926, in- $8^{\circ}$. Du même, introd. à son édition du Prince (Il Principe de Niccolò Machiavelli, Turin, 1926, in- $\left.8^{\circ}\right)$. Voir également $l^{\prime}$ introduction de L. Russo à son édition du Prince (Florence, 1930, in- $8^{\circ}$ ). Alfredo Oriani (La lotta politica in Italia, $2^{\mathrm{e}}$ éd., Milan, 1895 , in- $8^{\circ}$; p. 117-122) traite assez durement Machiavel; G. Toffanin (Machiavelli e il tacitismo ; la politica storica della Contro-Riforma ; Padoue, 1921, in- $8^{\circ}$ ) le rattache assez artificiellement à une politique qui se fonde elle-même sur une interprétation artificielle de l'humanisme. - La Rivista d'Italia a publié, en 1927, pour le quatrième centenaire de Machiavel, une série d'articles : Ch. Benoist, Le machiavélisme perpétuel ; t. II, p. 217-223 ; Filippo Meda, Il machiavellismo, p. 224-236 ; Guido Mazzoni, Il Machiavelli drammaturgo, p. 237-250 ; Michele Scherillo, Le prime esperienze politiche del Machiavelli, p. 207-278 ; Vittoria Cian, Machiavelli e Petrarca, p. 279-288 ; A. Galletti, Niccolò Machiavelli umanista, p. 289-309 ; Francesco Ercole, Il « Principe », p. 310-323 ; Antonio Panella, Niccolò Machiavelli storico, p. 324-340 ; Plinio Carli, Niccolò Machiavelli scrittore, p. 341-358; Romolo Caggese, Ciò che è vivo nel pensiero politico di Machiavelli, p. 359-370. — En Allemagne, littérature abondante ; à retenir avant tout Friedrich Meinecke, Die Idee der Staatsräson in der neueren Geschichte; $3^{\mathrm{e}}$ éd., Munich et Berlin, 1939, in- $8^{\circ}$, p. 31-60. — En français, Charles Benoist, Le machiavélisme ; I, Avant Machiavel ; Paris, 1907, in- $8^{\circ}$; II, Machiavel ; 1934 ; III, Après Machiavel ; 1936 ; Pierre Mesnard, L'essor de la pensée politique au $X V I^{e}$ siècle, Paris 1936, in-8 ${ }^{\circ}$; p. 17-85. — Éditions : Opere di Niccolò Machiavelli, cittadino e segretario fiorentino ; Gênes, 1798, 10 vol. in-12 ; Opere di Niccolò Machiavelli ; éd. Italia, Milan, 1819, 11 vol. in-12 ; Opere complete di Niccolò Machiavelli, Florence, 1843, in-4 Opere complete di Niccolò Machiavelli, éd. par L. Passerini, P. Fanfani, G. Milanesi ; Florence, 1873-1876, 6 vol. in- $8^{\circ}$; incomplète ; la meilleure pour les légations et commissions diverses (t. 3-6) ; Tutte le opere storiche e letterarie di Niccolò Machiavelli, éd. Guido Mazzoni e Mario Casella, Florence, 1929, in- $8^{\circ}$. - Il Principe, éd. G. Lisio, Florence, 1928, in- $8^{\circ}$; éd. G. Moro, Florence, 1927, in- $8^{\circ}$; éd. M. Casella, Milan 1929, in- $8^{\circ}$; éd. L. Russo, Florence, 1930, in- $8^{\circ}$. - Il Principe e i Discorsi sopra la prima Deca di Tito Livio, éd. A. Oxilia, San Casciano, 1927 ; in- $8^{\circ}$. — Dell'arte della guerra, éd. 
E. Barbarich, Florence, 1929, in-8 ${ }^{\circ}$ - Istorie florentine, éd. Plinio Carli, Florence, 1927, 2 vol. in- $8^{\circ}$. — Lettere, éd. G. Lesca, Florence, 1929, in- $8^{\circ}$. La plus récente traduction française du Prince a paru dans la Collection des «Textes et traductions pour servir à l'histoire de la pensée moderne » : Machiavel, Le Prince, trad. de Colonna d'Istria; introduction de Paul Hazard; Paris, 1929, in- $8^{\circ}$. — On a utilisé, dans le présent travail, l'excellente édition Tutte le opere, de G. Mazzoni et M. Casella. Elle ne donne malheureusement qu'un choix de lettres, et il y manque, pour l'étude de la pensée politique et historique de Machiavel, une pièce importante, le Discorso sopra il riformar lo stato di Firenze.

${ }^{x x i v}$ Fr. Guicciardini : Storie florentine dal 1378 al 1509 ; éd. Roberto Palmarocchi : Scrittori d'Italia, Bari, 1931, in- $8^{\circ}$; cap. 9, p. 80 : Non era spezie di una città libera e di un cittadino privato ; ma di uno tiranno e di una città che servissi.

xxv Romolo Caggese ; Firenze della decadenza di Roma al Risorgimento d'Italia ; Florence, 1912-1921, 3 vol. in- $8^{\circ}$; II, Dal priorato di Dante alla caduta della Repubblica (1913) ; cap. 4, Le origini della Signoria ; cap. 5, La Repubblica medicea ; p. 289-379, 381-518. - V. Ricchioni, La costituzione polilica di Firenze ai tempi di Lorenzo il Magnifico (Sienne, 1913, in-16), cite, p. 7, 12 et 16 , à propos du gouvernement de Laurent, une relation anonyme et contemporaine, extraite des Archives d'État de Florence (Mediceo avanti il Principato, filza $99, \mathrm{f}^{\circ} 91 \mathrm{r}^{\circ}$ ) : La base e fondamento di questo reggimento ha a consistere in tre cose : la prima nelli amici, perchè il comune interesse gli farà volere il medesimo... La seconda nelli artefici, li quali essendo buona parte della città e dandogli la parte delli onori e dell'utile, saranno una buona difesa dello stato, massime essendo accarezzati e stimati... La terza nella plebe, la quale se sarà difesa dalle ingiurie e provvista delle cose necessarie, sempre ce ne varrete a vostro modo, tenendola contenta con qualche liberalità e festeggiamenti pubblici. - Sur le mouvement politique et social qui porta Florence de la république au principat, Antonio Anzilotti, La crisi costituzionale della Repubblica fiorentina ; Florence, 1912, in- $8^{\circ}$; La costituzione interna dello Stato fiorentino sotto il duca Cosimo $\mathrm{I}^{\circ}$ de' Medici ; Florence, 1910, in-16 ; Francesco Ercole, Dal comune al principato; Florence, 1929, in- $8^{\circ}$. — Sur Machiavel spectateur et historien de cette évolution, F. Chabod, Del Principe di Niccolò Machiavelli, cité p. 30, n. 1.

${ }^{\text {xxvi }}$ Fr. Guicciardini, Storie florentine, cap. 9, p. 75 ; Si ingegnò che a' tempi sua fussino tutte le arti e le virtù più eccellenti in Firenze che in altra città d'Italia. - Machiavel, Istorie florentine, VIII, 36 ; Tutte le opere, p. 620 ; Amava meravigliosamente qualunque era in una arte eccellente... Della architettura, della musica e della poesia meravigliosamente si dilettava...

xxvii Fr. Guicciardini ; Dialogo e discorsi del Reggimento di Firenze, éd. Roberto Palmarocchi, Bari, Scrittori d'Italia, 1932, in- $8^{\circ}$; lib. II, p. 95 : Che vitupe- 
rio era alla patria nostra, che sempre si è chiamata libera..., che si intendessi che era ridotta in arbitrio di uno privato cittadino ? - Storie florentine, 9, $\mathrm{p}$. 74 : Si può dire che la città non fussi a suo tempo libera, benchè abondantissima di tutte quelle glorie e felicità che possono essere in una città, libera in nome, in fatto e in verità tiranneggiata da uno suo cittadino. - P. 80 :... Ed in somma bisogna conchiudere che sotto lui la città non fussi in libertà, nondimeno che sarebbe stato impossibile avessi avuto un tiranno migliore e più piacevole ; dal quale uscirono per inclinazione e bontà naturale infiniti beni, per necessità della tirannide alcuni mali, ma moderati e limitati quando la necessità sforzava.

xxviii Esprit des Lois, VIII, 3.

${ }^{\text {xxix }}$ Dell'arte della guerra, I; p. 272 : Roma... mentre ch'ella tu bene ordinata (elle fu fino a' Gracchi)... - Discorsi sopra la prima Deca di Tito Livio, III, 8, p. 213 : ...Ne' tempi di Mario e di Silla, dove già la materia era corrotta.

${ }^{x x x}$ Discorsi..., I, 10 ; p. 74-75 : Ne sia alcuno che s'inganni, per la gloria di Cesare... E conoscerà allora quanti oblighi Roma, l'Italia, e il monde, abbia con Cesare. - Ibid., p. 74 : ... vivere... più tosto Scipioni che Cesari.

${ }^{x x x i}$ V. Rossi, Il Quattrocento, p. 106-157. - V. p. 61-62.

xxxii Lorenzo de' Medici il Magnifico, Opere, a cura di Attilio Simioni ; Scrittori d'Italie, Bari, 1913-1914, 2 vol. in-8 ; II, p. 33-70.

xxxiii V.p. 121-124.

xxxiv Peuples et civilisations, Histoire générale publiée sous la direction de Louis Halphen et Philippe Sagnac; VIII, La fin du moyen âge, par H. Pirenne, A. Renaudet, É. Perroy. M. Handelsman, L. Halphen ; Paris, 1931; I, p. 517-522 ; II, p. 160 ; IX, Les débuts de l'âge moderne, La Renaissance et la Réforme, par H. Hauser et A. Renaudet ; 2 éd., Paris, 1938 ; p. 101-104.

xxxv A. Renaudet, Laurent le Magnifique; Hommes d'État, Paris, 1937, 3 vol. in- $8^{\circ}$; II, p. 403-507 ; p. 473-476 ; - P. Villari, Machiavelli e i suoi tempi, I, p. 197.

xxxvi Francesco De Sanctis, Storia della Letteratura italiana, nuova edizione, a cura di Benedetto Croce ; Scrittori d'Italia, Bari, 1912, 2 vol. in- $8^{\circ}$; II, p. 6568 .

xxxvii Discorso o dialogo intorno alla nostra lingua ; p. 772-773 : Il quale in ogni parte mostrò d'essere, per ingegno, per dottrina e per giudizio, uomo eccellente, eccetto che dove egli ebbe a ragionare della patria sua; la quale fuori d'ogni umanità e filosofico istituto perseguitò con ogni specie d'ingiuria.

xxxviii Montesquieu ; Cahiers (1716-1755) : textes recueillis et présentés par Bernard Grasset ; Paris, 1941, in- $8^{\circ}$; p. 114.

xxxix Il Principe, 6, p. 13 : Tutti e' profeti disarmati vinsono, e li disarmati ruinorono. 
Lettere familiari, I, p. 877 : E così, secondo el mio iudizio, viene secondando e' tempi, e le sua bugie colorendo.

xli p. 162 et n. 14 .

xlii Discorsi, II, 2, p. 141; v. p. 84-87. De même, I, Introd., p. 56 : La debolezza nella quale la présente religione ha condotto el mondo...

xliii P. Villari, Niccolò Machiavelli, I, p. 312-315. - Sur les fonctions exercées par Machiavel, D. Marzi, La Cancelleria della Repubblica fiorentina; Rocca San Casciano, 1910, p. 286-307.

xliv Fr. Giucciardini, Storia d'Italia, éd. Costantino Panigada; Scrittori d'Italia, Bari, 1939, 5 vol. in- $8^{\circ}$; lib. X, cap. 6 ; III, p. 129-130: Altri, considerando forse più intrinsecamente la sostanza delle cose, nè si lasciando abbagliare gli occhi dallo splendore del nome, temevano che le guerre che si cominciavano con intenzione di liberare Italia da' barbari nocerebbono molto più agli spirili vitali di questo corpo che non aveano nociuto le cominciate con manifesta professione e certissima intenzione di soggiogarla ; ed essere cosa più temeraria che prudente lo sperare che le armi italiane, prive di virtù, di riputazione, di capitani di autorilà, nè conformi le volontà de' principi suoi, fussino sufficienti a cacciare di Italia il vincitore, al quale, quando mancassino tutti gl'altri modi, non mancherebbe mai la facultà di riunirsi con $\mathrm{i}$ vinti, a rovina comune di tutti gl'Italiani ; ed essere molto più da temere che questi nuovi movimenti dessero occasione di depredare Italia a nuove nazioni, che da sperare che, per l'unione del pontefice e de' Viniziani, s'avessino a domare i Franzesi e gli Spagnuoli.

xlv Villari, Machiavelli, I, p. 383-384.

xlvi A. Renaudet ; Le concile gallican de Pise-Milan; documents florentins (15101512) ; Bibliothèque de l'Institut français de Florence (Université de Grenoble); $\mathrm{I}^{\text {re }}$ série, tome VII ; Paris 1922, in-8 ; p. 187-659.

xlvii V. p. 24, n. 20.

xlviii Il Principe, 24 ; Cur Italiae principes regnum amiserunt ; p. 47.

xlix Il Principe, 12 ; Quot sunt genera militiae et de mercenariis militibus ; p. 2427. - P. 20 : Ma come venne el forestiero, le mostrorono quello che erano; onde che a Carlo re di Francia fu licito pigliare la Italia col gesso. - P. 2627 : E il fine della loro virtù è stato, che Italia è stata corsa da Carlo, predata da Luigi, sforzato da Ferrando e vituperata da' Svizzeri... Tanto che gli hanno condotta Italia stiava e vituperata.

I Ibid. p. 25 ; E chi diceva come e' n'erano cagioni e'peccati nostri, diceva il vero ; ma non erano già quelli che credeva, ma questi che io ho narrati : e perché elli erano peccati de' principi, ne hanno patito la pena ancora loro.

li Del Reggimento di Firenze, lib. I, p. 35 : ... Cavare le armi di mano a' cittadini, e spegnere tutta la virilità che aveano. 
Il Principe, 12, p. 25 : E con più difficultà viene alla obedienza di uno suo cittadino una republica armata di armi proprie, che una armata di armi esterne. Stettono Roma e Sparta molti secoli armate e libere. E' Svizzeri sono armatissimi e liberissimi. Delle armi mercenarie antiche in exemplis sono e' Cartaginesi...

Discorsi, III, 31, p. 243-244 ; Nella fortuna, parendo loro aversela guadagnata con quella virtù che non avevano... La viltà dello animo loro, causata dalla qualità de'loro ordini non buoni nelle cose della guerra, gli fece ad un tratto perdere lo stato e l'animo. E sempre interverrà cosi a qualunque si governa comme loro. - Cf. Dell'arte della guerra, I, p. 277 : E se i Viniziani fussero stati savi in questo come in tutti gli altri loro ordini, eglino arebbono fatto una nuova monarchia nel mondo.

liv Discorsi, I, N. 17, p. 86 : Pertanto dico, che nessuno accidente benchè grave e violento, potrebbe ridurre mai Milano o Napoli liberi, per essere quelle membra tutte corrotte.

Iv Operette letterarie in versi, p. 872 :

Le notte che morì Pier Soderini, L'anima andò de l'inferno a la bocca ; Gridò Pluton : «Ch'inferno ? anima sciocca, Va su nel limbo fra gli altri bambini ».

lvi

lvii

Les lettres de Machiavel aux Dix et à la Seigneurie, au cours de ces diverses légations, se trouvent dans la grande édition des Euvres (Le Opere di Niccolò Machiavelli, éd. par L. Passerini, P. Fanfani, G. Milanesi ; Florence, 18731877 ; 6 vol. in- $\left.8^{\circ}\right)$, t. 3-6.

lviii F. Chabod, Del Principe, Nuova Rivista Storica, 1925, p. 201-203.

lix Lettre datée d'Urbino, 26 juin 1502, « ante lucem », adressée aux Dix par les deux orateurs, Francesco Soderini, évêque de Volterra, et Machiavel ; rédigée par Machiavel (Opere complete, éd. Passerini-Fanfani-Milanesi, IV, p. 14-15 : Questo signore è raolto splendido et magnifleo, e nelle armi è tanto animoso, che non è si gran cosa che non li paia piccola, e per gloria e per acquistare stato mai si riposa, nè conosce fatica o periculo. Giugne prima in un luogo che se ne possa intendere la partita donde si lieva ; fassi ben volere a' suoi soldati ; ha cappati e' migliori uomini d'Italia ; le quali cose lo fanno vittorioso e formidabile, adgiunto con una perpetua fortuna.

lx P. Villari, I, p. 420-430. — Descrizione del modo tenuto dal duca Valentino nello ammazzare Vitellozzo Vitelli, Oliverotto da Fermo, il signor Pagolo e il Duca di Gravina Orsini, p. 743-747.

Ixi Il Principe, 7, p. 17 : E lui mi disse, ne' di che fu creato Iulio II, eue aveva pensato a ciò che potessi nascere, morendo el padre, e a tutto aveva trovato 
remedio, eccetto che non pensò mai, in su la sua morte, di stare ancora lui per morire.

lxii P. Villari, I. p. 468-469.

Ixiii V.p. 48, n. 22

Ixiv Discorsi, I, 27, p. 95 : Quel furore con il quale governava tutte le cose ; III, 9, p. 215 : Papa Iulio II procedette in tutto il tempo del suo pontificato con impeto e con furia; e perchè gli tempi l'accompagnarono bene, gli riuscirono le sue imprese tutte. Ma se fossero venuti altri tempi che avessono ricerco altro consiglio, di necessità rovinava; perchè non arebbe mutato nè modo nè ordine nel maneggiarsi.

Ixv Il Principe, 11, De principatibus eccleciasticis, p. 23-24 ; v. p. 210-212.

lxvi Discorsi, I, 12, p. 79 ; v. p. 78-79.

lxvii Ibid. : Ne' tempi nostri, ella tolse la potenza a' Viniziani con l'aiuto di Francia ; di poi ne cacciò i Franciosi con l'aiuto de' Svizzeri.

Ixviii A. Renaudet : Le concile gallican de Pise-Milan, p. 5 ; Machiavel aux Dix ; Blois, 18 août 1510 : Che Iddio lasci seguire quello che sia el meglio, e cavi di corpo al Papa quello spirito diabolico che costoro dicono gli è entrato addosso : acciochè non facci calpestare voi e sotterrare se : che in vero, se Vostre Signorie fussino poste altrove, sarebbe da desiderarsi, acciocchè ancora ad codesti preti toccassi di questo mondo qualche boccone amaro.

lxix P. Villari, Niccolò Machiavelli, II, p. 67-70.

Ixx O. Tommasini, La vita e gli scritti di Niccolò Machiavelli ; I, p. 388-390.

lxxi Rittratto delle cose della Magna, p. 740-743.

Ixxii Un mot seulement sur la richesse des villes et leur bonne administration; p. 742 : Ma vegnamo alle comunità franche ed imperiali, che sono il nervo di quella provincia, dove è danari e l'ordine.

lxxiii P. 742 : La potenzia della Magna si tiene certo più assai nelle comunità che nelli principi.

Ixxiv P. 741 : Tanto che, considerato tutte queste disunioni in comune, e aggiuntovi poi quelle che sono tra l'un principe e l'altro e l'una comunità e l'altra, fanno difficile questa unione dello Imperio.

${ }^{\text {Ixxv }}$ P. 740 : Della potenzia della Magna alcuno non debbe dubitare, perchè abunda di uomini, di ricchezze e d'arme... E così si godono questa loro rozza vita e libertà.

lxxvi Discorsi, I. 12 : Alcuna provincia non fu mai unita o felice, se la non viene tutta alla ubbidienza d'una republica o d'uno principe, corne è avvenuto alla Francia ed alla Spagna.

Ixxvii P. Villari, Niccolò Machiavelli, I. p. 353-361, 471-473 ; II, p. 126-132, $147-$ 169. 
Ixxviii Ritratto di cose di Francia, p. 731-739 ; ajouter De natura Gallorum, p. 730731.

lxxix P. 732 : E di qui nasce che le gente d'arme francese sono oggi le migliore che sieno, perchè si truovono tutti nobili e figlioli di signori.

${ }^{\text {lxxx }}$ P. 732 : E di poi sono per le terre tutti ignobili e gente di mestiero; e stanno tanto sottoposti a' nobili e tanto sono in ogni azione depressi, che sono vili. E però si vede che il re nelle guerre non si serve di loro, perchè fanno cattiva prova, benchè vi sieno li Guasconi, di chi ' 1 re si serve, che sono un poco meglio che gli altri ; e nasce perchè sono vicini a' confini di Spagna, che vengono a tenere un poco dello spagnuolo. Ma hanno fatto, per quello che s'è visto da molti anni in qua, più prova di ladri che di valenti uomini... E perè il re di Francia si serve sempre o di Svizzeri o di lanzchenecche. - Machiavel blâme Louis XI de ne pas avoir conservé les Ordonnances militaires de Charles VII, qui auraient pu rendre le royaume invincible (Il Principe, 13, p. 28) : Carlo VII... ordinò nel suo regno l'ordinanza delle gente d'arme e delle fanterie. Dipoi il re Luigi, suo figliuolo, spense quella de' fanti e cominciò a soldare Svizzeri ; il quale errore, seguitato dagli altri, è, corne si vede ora in fatto, cagione dei pericoli di quel regno. El regno di Francia sarebbe insuperabile, se l'ordine de Carlo era accresciuto o pre-servato. - Cf. Dell'arte della guerra, I, p. 278.

lxxxi P. 733 ; de même, Discorsi, III, 36, p. 200-201.

lxxxii P. 731-732.

Ixxxiii Esprit des Lois, II, 4. - É. Carcassonne, Montesquieu et le problème de la Constitution française ; Paris, 1926, in- $8^{\circ}$; p. 221-260 ; 261-296.

Ixxxiv Voir la note précédente. - Discorsi, I, 58, p. 130; III, 1, p. 195 ; Discorso sopra il riformar lo stato di Firenze, falto ad istanza di papa Leone X (Opere complete di Niccolò Machiavelli, Florence. 1843, in-4º); p. 452 : Perchè un principe solo, spogliato di nobiltà, non può sostenere el pondo del principato ; però è necessario che infra lui e l'universale sia un mezzo che l'aiuti a sostenerlo. Vedesi questo in tutti gli stati di principe, e massime nel regno di Francia, dove i gentiluomini signoreggiano i popoli, i principi i gentiluomini, e il re i principi.

Ixxxv P. 735 : Sono e popoli di Francia umili e ubbidientissimi, e hanno in grande venerazione el loro re.

Ixxxvi P. 733-739. - En 1513, Machiavel indique toutefois dans le Prince (4, p. 10-11) la possibilité, pour un prince étranger, d'envahir le royaume de France, en profitant de la défection de quelque grand féodal. Mais une telle invasion, par suite de la solidité de la monarchie, serait sans lendemain. Il semble ainsi prévoir la trahison du connétable de Bourbon en 1522.

Ixxxvii Il Principe, 3, p. 8-10; - p. 10 : Dicendomi el cardinale di Roano che gli Italiani non si intendevano della guerra, io gli risposi che e' Francesi non si in- 
tendevano dello stato; perchè, se se n'intendessono, non lascerebbono venire la Chiesa in tanta grandezza.

lxxxviii Jacopo Nardi, Istorie della città di Firenze, éd. A. Gelli, Florence, 1858, 2 vol. in- $8^{\circ}$; II, p. 21 ; cité par P. Villari, Niccolò Machiavelli, II, p. 191.

Ixxxix P. Villari, Niccolò Machiavelli, II, p. 191-202. — Piero Soderini se retira à Rome, où il mourut en 1522.

xc V.p. 72-73.

xсі P. 799-816.

xcii Discorsi, I, Introd. p. 56 : Dal non avere vera cognizione delle storie, per non trarne, leggendole, quel senso ne gustare di loro quel sapore che le hanno in sè.

xciii Discorsi, I, Introd., p. 56 : Corne se il cielo, il sole, li elementi, li uomini, fussino variati di modo, di ordine e di potenza, da quello che gli erono antiquamente. - I, 11, p. 78 : Perchè gli uomini, come nella prefazione nostra si disse, nacquero, vissero e morirono sempre con uno medesimo ordine. - II, Introd., p. 135 ; Giudico il mondo sempre essere stato ad uno medesimo modo.

xciv Thucydide, Guerre du Péloponnèse ; I, 22, 4.

xcv Istorie florentine, III, G, p. 450 : Tanto quelli cittadini stimavono allora più la patria che l'anima.

${ }^{\text {xcvi }}$ Sur Fr. Vettori, v. Louis Passy, Un ami de Machiavel, François Vettori, sa vie et ses ouvres ; Paris, 1914, 2 vol. in- $8^{\circ}$. — La lettre du 10 décembre 1913, p. 884-880.

xcvii 885 : ...Rivestito condecentemente, entro nelle antique corti delli antiqui uomini, dove, da loro ricevuto amorevolmente, mi pasco di quel cibo che solum è mio, e che io nacqui per lui... Tutto mi transferisco in loro.

xcviii V.p. 24, n. 20.

xcix Tout ceci a été admirablement vu et dit par Fr. de Sanctis, Storia della Letteratura italiana, II, 15, 62-76.

c Les Origines de la France contemporaine ; Le Régime moderne, I, p. 7.

ci V.p. 51-53.

cii Purgatorio, VI, 76-151.

ciii Purgatorio, VI, 103-1055 :

Ch'avete tu e'l tuo padre sofferto, per cupidigia di costà distretti, che'l giardin de lo' imperio sia diserto.

civ Fr. de Sanctis, Storia della Letteratura ilaliana, II, p. 68.

cv V.p. 61-62.

cvi Fr. de Sanctis, Storia della Letteratara italiana, II, p. 88.

cvii V. p. 42-43 et n. 16. 
${ }^{\text {cviii }}$ Fr. de Sanctis, Storia della Litteratura italiana, II, p. 66-67.

cix V. p. 61-62. - Fr. Ercole, Dante e Machiavelli, Rome 1922, in- $8^{\circ}$, cite, p. 10, n. 5, une proclamation de Maximilien, lors de la campagne de 1508 : Denotando a tutt li popoli... come lo imperio sia stato istituito da Dio, e che luy vigniva a la coronazione per liberare tutta Italia de man de tirani... e de occupadori della libertà delli popoli.

cx V.p. 62.

cxi Le Opera di Dante; testo critico della Società dantesca italiana ; Florence, 1924, in-8 ${ }^{\circ}$; De Monarchia, III, 10, 14-15 : Sed Ecclesia omnino indisposita erat ad temporalia recipienda per preceptum prohibitivum expressum ut habemus per Mattheum sic : «Nolite possidere aurum neque argentum neque pecuniam in zonis vestris, non peram in via, etc. » Nam etsi per Lucam habemus relaxationem precepti quantum ad quedam, ad possessionem tamen auri et argenti licentiatam Ecclesiam post prohibitionem illam invenire non potui... Patet igitur quod nec Ecclesia recipere per modum possessionis, nec ille conferre per modum alienationis poterat.

cxii V.p. 161-162.

cxiii Discorsi, I, 12, p. 79 : E perchè molti sono d'opinione che il bene essere delle città d'Italia nasca dalla Chiesa romana, voglio, contro a essa, discorrere quelle ragioni che mi occorrono... La prima è, che per gli esempli rei di quella corte, questa provincia ha perduto ogni divozione e ogni religione... Abbiamo, adunque, con la Chiesa e con i preti noi Italiani questo primo oblige di essere diventati senza religione e cattivi : ma ne abbiamo ancora uno maggiore, il quale è la seconda cagione della rovina nostra. Questo è che la Chiesa ha tenuto e tiene questa provincia divisa... Perchè avendovi quella abitato e tenuto imperio temporale, non è stata si potente ne di tanta virtù che l'abbia potuto occupare la tirannide d'Italia e farsene principe ; e non è stata, d'altra parte, si debole, che per paura di non perdere il dominio delle sue cose temporali, la non abbia potuto convocare uno potente che la difenda contro a quello che in Italia fusse diventato troppo potente : come si è veduto anticamente per assai experienze, quando, mediante Carlo Magno, la ne cacciò i Longobardi, ch' erano già quasi re di tutta Italia ; e quando ne' tempi nostri elle tolse la potenza a' Viniziani con l'aiuto di Francia; di poi ne cacciò i Franciosi con l'aiuto de' Svizzeri...

cxiv Il Principe, 24 ; Cur Italiae principes regnum amiscrunt ; p. 47

cxv Discorsi, I, 55 p, p. 127 : Gentiluomini sono chiamati quelli che oziosi vivono delle rendite delle loro possessioni abbondantemente, sanza avere cura alcuna o di coltivazione o di altra necessaria fatica a vivere. Questi tali sono perniziosi in ogni republica ed in ogni provincia ; ma più perniziosi sono quelli che oltre alle predette fortune comandano a castella, ed hanno sudditi che ubbidiscono a loro, Di queste due spezie di uomini ne sono pieni il regno di Napoli, Terra di Roma, le Romagna e la Lombardia. Di qui nasce che in quelle pro- 
vincie non è mai surta alcuna republica nè alcuno vivere politico ; perchè tali generazioni di uomini sono al tutto inimici d'ogni civiltà.

cxvi Discorsi, I, 55, p. 127-128 : Dove è equalità, non si può fare principato; e dovè la non è, non si può fare republica. — Et surtout, Discorso sopra il riformar lo stato di Firenze (Opere complete, Florence, 1843. in-4, p. 452) : Perchè un principe solo, spogliato di nobiltà, non può sostenere il pondo del principato; però è necessario che infra lui e l'universale sia un mezzo che l'aiuti a sostenerlo. Vedesi questo in tutti gli stati di principe, e massime nel regno di Francia, come i gentiluomini signoreggiano i popoli, i principi i gentiluomini, ed il re i principi.

cxvii Esprit des Lois, II, 4 ; v. p. 65, n. 61.

cxviii Discorsi, I, 12, p. 79 : Questa provincia ha perduto ogni divozione e ogni religione : il che si tira dietro infiniti inconvenienti e infiniti disordini ; perchè, così come dove è religione si presuppone ogni bene, così, dove quella manca, si presuppone il contrario. - Cf. p. 179-182.

cxix Discorsi, II, 2, p. 141 : La nostra religione... ci fa stimare meno l'onore del mondo ; onde i gentili, stimandolo assai, ed avendo posto in quello il sommo bene, erano nelle azioni loro più feroci... La religione antica... non beatificava se non uomini pieni di mondana gloria; comme erano capitani di eserciti e principi di republiche. La nostra religione ha glorificato più gli nomini umili e contemplativi, che gli attivi. Ha dipoi posto il sommo bene nella umiltà, abiezione, e nel dispregio delle cose umane ; quell'altra lo poneva nella grandezza dello animo, nella fortezza del corpo, ed in tutte le altre cose atte a tare gli uomini fortissimi. E se la religione nostra richiede cbe tu abbi in te fortezza, vuole che tu sia atto a patire più che a fare una cosa forte. Questo modo di vivere, adunque, pare che abbi renduto il mondo debole, e datolo in preda agli uomini scelerati, i quali securamente lo possono maneggiare, veggendo come l'università degli uomini, per andarne in Paradiso, pensa più a sopportare le sue battiture che a vendicarle. - Discorsi, Prefazione, p. 56 : la debolezza nella quale la présente religione ha condotto el mondo.

cxx Discorsi, II, a. p. 141: Nasce più sanza dubbio dalla viltà degli uomini, che hanno interpetrato la nostra religione secondo l'ozio e non secondo la virtù. Perchè se considerassono come la ci permette la esaltazione e la difesa della patria, vedrabbono come la vuole che noi l'amiamo ed onoriamo. - I, 12, p. 79 : La quale religione, se... si fusse mantenuta secondo che dal datore di essa ne fu ordinato... - III, 30, p. 241 : E chi legge la Bibbia sensatamente...

cxxi Discorsi, II, 2, p. 141: Queste educazioni e si false interpretazioni.

cxxii V. p. 14, n. 5. - Inferno, I, 101-111:

...infln che'l Veltro

verrà, che la farà morir con doglia.

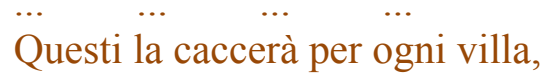


fin che l'avrà rimessa ne lo' nferno, la onde invidia prima dipartilla.

cxxiii

Purgatorio, XXXIII, 37-45 :

Non sarà tutto tempo senza reda

l'aquila...

Cf. Paradiso, XXVII, 61-63, 142-148.

cxxiv Il Principe, 26, Exhortatio ad capessendam Italiam in libertatemque a Barbaris vindicandam; p. 49-51.

cxxv Discorsi, I, 9 ; p. 72-74 : Corne egli è necessario essere solo a volere ordinare una republica di nuovo, o al tutto fuor degli antichi suoi ordini riformarta.

cxxvi Discorsi, I, 34, p. 102-104 : L'autorità dittatoria fece bene e non danno alla republica romana. - Il Principe, 26, p. 50 : Aspetta qual possa essere quello che sani le sue ferite, e ponga fine a' sacchi di Lornbardia, alle taglie del Reame e di Toscana, e la guarisca di quelle sue piaghe già per lungo tempo infistolite.

cxxvii Discorsi, I, 34 ; v. n. 5 ; 35, p. 104-105 : La cagione perchè la creazione in Roma del decemvirato fu nociva alla libertà di quella republica; - 40, p. 110-113: La creazione del decemvirato in Roma, e quello che in essa è da notare.

cxxviii Discorsi, I, 9, p. 73 : Nè mai uno ingegno savio riprenderà alcuno di alcuna azione straordinaria, che per ordinare un regno o costituire una republica, usasse. Conviene bene che, accusandolo il fatto, lo effetto lo scusi.

cxxix Discorsi, I, 17, p. 85-86; Un popolo corrotto, venuto in libertà, si può con difficultà grandissima mantenere libero. Ma non si vede il più forte esemplo che quello di Roma ; la quale, cacciati i Tarquinii, potè subito prendere e mantenere quella libertà ; ma, morto Cesare, morto Caio Caligola, morto Nerone, spenta tulta la stirpe cesarea, non potè mai, non solamente mantenere, ma pure dar principio alla libertà... - P. 86 : Pertanto dico, che nessuno accidente, benchè grave e violento, potrebbe ridurre mai Milano o Napoli liberi, per essere quelle membra tutte corrotte. Il che si vide dopo la morte di Filippo Visconti ; che volendosi ridurre Milano alla libertà, non potette e non seppe mantenerla. - 18, p. 86-88; In che modo nelle città corrotte si potesse mantenere un stato libero, essendovi ; o non essendo, ordinarvelo. - P. 88 : A fare questo, non basta usare termini ordinari ; essendo modi ordinari cattivi ; ma è necessario venire allò straordinario, come è alla violenza e all' armi, e diventare innanzi a ogni cosa principe de quella città, e poterne disporre a suo modo.

cxxx Discorsi, I, 9, p. 73 : Che quell'autorità che ha presa non la lasci ereditaria ad un altro.

cxxxi Fr. Guicciardini, Scritti polilici e Ricordi, éd. R. Palmarocchi ; Scrittori d'Italia, Bari, 1933, in- $8^{\circ}$; Considerazioni intorno ai discorsi del Machiavelli sopra la prima Deca di Tito Livio ; I, 10 ; p. 21 : Però questi pensieri che e' ti- 
ranni deponghino la tirannide, e che e' re ordinino bene e' regni, privando la sua posterità della successione, si dipingono più facilmente in su' libri e nelle immaginazioni degli uomini che non sene eseguiscono in fatto.

cxxxii Ibid., I, 9, p. 18 : Non è dubbio ohe uno solo può porre migliore ordine alle cose che non fanno molti, e che uno in una città disordinata merita laude, se, non potendo riordinarla altrimenti, lo fa con la violenzia o con la fraude e modi estraordinari. Ma è da pregare Dio che le republiche non abbino necessità di essere racconcie per simile via, perchè oltre che gli animi degli uomini sono fallaci, e può uno sotto questo onesto colore occupare la tirannide, ci è anche pericolo che la volontà da principio buona non diventi cattiva...

cxxxiii Cf. p. 91, n. 7.

cxxxiv Lettere familiari, p. 886 : Io mi logoro, e lungo tempo non posso star cosi che io non diventi per povertà conlennendo, appresso al desiderio arei che questi signori Medici mi cominciassino adoperare, se dovessino cominciare a farmi voltolare un sasso...; e per questa cosa, quando la fussi letta, si vedrebbe che quindici anni che io sono stato a studio dell'arte dello stato, non gli ho nè dormiti nè giuocati : e doverrebbe ciascheduno aver caro servirsi d'uno che alle spese d'altri fussi pieno di esperienzia. E della fede mia non si doverrebbe dubitare, perchè, avendo sempre osservato la fede, io non debbo imparare ora a romperla; e chi è stato fedele e buono quarantatre anni, che io ho, non debbe potere mutare natura; e della fede e bontà mia ne è testimonio la povertà mia.

cxxxv Il Principe, 22 ; De his quos a secretis principes habent; p. 45 : Quello che ha lo stato di uno in mano, non debbe pensare mai a se, ma al principe, e non li ricordare mai cosa che non appartenga a lui. E dall' altro canto, el principe, per mantenerlo buono, debbe pensare al ministro, onorandolo, faccendolo ricco, obligandoselo participandogli onori e carichi... - De même, 23, Quomodo adulatores sint fugiendi ; p. 46-47. - Il est probable que Montesquieu s'est souvenu de ces deux chapitres dans quelques lignes des Pensées qu'il écrivait pour lui-même : Cahiers, p. 102 : Le premier talent d'un grand prince est celui de savoir bien choisir les hommes. - Cf. Machiavel, p. 45 : E la prima coniettura che si fa del cervello di uno signore, à vedere gli uomini che lui ha d'intorno. - Sur la flatterie, Cahiers, p. 102-103.

cxxxvi Il Principe, 26, p. 49-51 ; Exhortatio ad capessendam Italiam in libertatemque a Barbaris vindicandam. - P. 51 : Non si debbe adunque lasciare passare questa occasione, acciò che la Italia, dopo tanto tempo, vegga un suo redentore. Ne posso esprimere con quale amore e' fussi ricevuto in tutte quelle provincie che hanno patito per queste illuvioni esterne ; con che sete di vendetta, con che ostinata fede, con che pietà, con che lacrime. Quali porte se gli serrerebbano ? Quali populi gli negherebbano la obedienzia ? Quale invidia se gli opporrebbe? Quale Italiano gli negherebbe l'ossequio? A ognuno puzza questo barbare dominio. Pigli adunque la illustre casa vostra questo assunto con quello animo e con quella speranza che si pigliano le imprese iuste... 
cxxxvii Il Principe, 26, p. 50 : Nè ci si vede, al presente, in quale lei [1'Italia] possa più sperare che nella illustre casa vostra, quale con la sua fortuna e virtù, favorita da Dio e dalla Ghiesa, della quale è ora principe, possa farsi capo di questa redenzione.

cxxxviii V. p. 78 et 79 , n. 26.

cxxxix Fr. Guicciardini, Scritti politici e Ricordi ; Ricordi, Série $1^{\text {a }}, 14$; p. 243 : Tre cose desidero vedere innanzi alla mia morte ; ma dubito, ancora che io vivessi molto, non ne vedere alcuna; uno vivere di republica bene ordinato nella città nostra, Italia liberata da tutti e' barbari, e liberao il mondo dalla tirannide di questi scellerati preti.

cxl Discorso sopra il riformar lo stato di Firenze (Opere complete, Florence, 1843 , in $-4^{\circ}$, p. 452 ) : Tutte le altre cose son vane e di brevissima vita. - P. 451 ; Ogni dieci anni portorno periçolo di perdere lo stato.

cxli Discorso sopra il riformar lo stato di Firenze, p. 455-456 : Credo che il maggior bene che si faccia ed il piu grato a Dio sia quello che si fa alla sua patria. Oltre di questo non è esaltato alcun uomo tanto in alcuna sua azione quanto sono quelli che hanno con leggi e con istituti riformato le republiche e i regni... Non dà adunque il cielo maggiore dono ad un uomo, ne gli può mostrare piu gloriosa via di questa; ed in fra le tante felicità, che ha date Dio alla casa vostra ed alla persona di Vostra Santità, è questa la maggiore, di darle potenza e subietto di farsi immortale, e superare di gran lunga per questa via la potenza e la avita gloria.

cxlii Lettre de Filippo Strozzi à son frère Lorenzo, en date du 17 mars 1519, citée par P. Villari, Niccolò Machiavelli, III, p. 49 : Piacemi assai abbiate condotto el Machiavello in casa e'Medici, che ogni poco di fede acquisti co'padroni è persona per surgere.

cxliii Vita di Castruccio Castracani da Lucca, p. 747-763.

cxliv Dell'arte della guerra, p. 263-370.

cxlv Ibid., I, p. 277 : E se i Viniziani fussero stati savi in questo come in tutti gli altri loro ordini, eglino arebbono fatto una nuova monarchia nel mondo.

cxlvi Ibid., I, p. 278 : Quanto allo errore che fa il re di Francia a non tenere disciplinati i suoi popoli alla guerra..., non è alcuno..., che non giudichi questo difetto essere in quel regno e questa negligenza sola farlo debile.

cxlvii Ibid., VII, p. 366 : Ma torniamo agli Italiani, i quali... rimangono il vituperio del mondo. Ma i popoli non ne hanno colpa, ma si bene i principi loro... Credevano i nostri principi italiani, prima ch'egli assaggiassero i colpi delle oltremontane guerre, che a uno principe bastasse sapere negli scrittoi pensare una acuta risposta, scrivere una bella lettera, nostrare ne'detti e nelle parole arguzia e prontezza, sapere tessere una fraude, ornarsi di gemme e d'oro, dormire e mangiare con maggiore splendore che gli altri, tenere assai lascivie intorno, governarsi co'sudditi avaramente e superbamente, marcirsi nello ozio, 
dare i gradi della milizia per grazia, disprezzare se alcuno avessc dimostro loro alcuna lodevole via, volere che le parole loro fussero responsi di oraculi ; ne si accorgevano i meschini che si preparavano ad essere preda di qualunque gli assaltava. Di qui nacquero poi nel mille quattrocento novantaquattro i grandi spaventi, le subite fughe e le miracolose perdite...

cxlviii Général baron Gourgaud; Sainte-Hélène ; journal inédit de 1815 à 1818 ; publ. par le vicomte de Grouchy et A. Guillois ; Paris, s. d. [1899], a vol. in$8^{\circ}$; I, p. 296.

cxlix Dell'arte della guerra, III, p. 309-310. - Cf. Discorsi, II, 17, p. 163-166; Quanto si debbino stimare dagli eserciti ne' presenti tempi le artiglierie ; e se quella opinione, che se ne ha in universale, è vera.

cl Henri Hauvette, Un exilé florentin à la cour de France au XVI siècle ; Luigi Alamanni (1495-1556) sa vie et son œuvre ; Paris, 1903, in-8 ; p. 12-19.

cli

La Mandragola, p. 694 :

E se questa materia non è degna,

Per esser pur leggieri,

D'uom che voglia parer saggio e grave,

Scusatelo con questo, che s'ingegna

Con questi van pensieri

Fare el suo tristo tempo più suave ;

Perch'altrove non have

Dove voltare el viso ;

Chè gli è stato interciso

Monstrar con altre imprese altra virtue,

Non sendo premio alle fatiche sue.

clii Discorsi, II, 31 ; Quanto sia pericoloso credere agli sbanditi ; p. 190 : Debbesi considerare pertanto quanto sia vana e la fede e le promesse di quelli che si truovano privi della loro patria. Perchè, quanto alla fede, si ha a estimare che, qualunque volta e' possano per altri mezzi che per i tuoi rientrare nella patria loro, che lasceranno te ed accosterannosi a altri, nonostante qualunque promesse ti avessono fatte. E quanto alle vane promesse e speranze, egli è tanta le voglia estrema che è in loro di ritornare in casa, che ei credono naturalmente molte cose che sono false, e molte a arte ne aggiungano.

cliii Istorie florentine, III, 1, p. 444 : Firenze a quel grado è pervenuta, che facilmente da uno savio dator di leggi potrebbe essere in qualunque forma di governo riordinata.

cliv Istorie florentine, p. 375-621; - p. 377 : Al santissimo e beatissimo Padre Signore Nostro Clemente settimo lo umile servo Niccolò Machiavelli... E perchè dalla V. S. Beatitudine mi fu imposto particularmente e comandato che io scrivessi in modo le cose fatte da' Suoi maggiori, che si vedessi che io fussi da ogni adulazione discosto..., dubito assai, nel descrivere la bontà di Giovanni, la sapienzia du Cosimo, la umanità di Piero e la magnificenzia e prudenzia di 
Lorenzo, che non paia alla V. S. che abbia trapassati i comandamenti Suoi... Et se sotto a quelle loro egregie opere era nascosa una ambizione alla utilità comune, come alcuni dicono, contraria, io che non ve la conosco non sono tenuto a scriverla.

clv Il Principe, 18, p. 34-35 ; Quomodo fides a principibus sit servanda : ... Non può, pertanto, uno signore prudente, nè debbe, osservare la fede, quando tale osservanzia li torni contro, e che sono spente le cagioni che la feciono promettere.

clvi Opere complete, éd. Italia, Milan, 1813, n vol. in-12 ; XI, p. 240-241 : E' conoscesi da ogni parte la facilità che sarebbe trarre quei ribaldi da quel paese. Questa occasione, per amor de Dio, non si perda... Liberate diuturna cura Italiam. Extirpate has immanes belluas, quae 'hominis praeter faciem et vocem nihil habent.

clvii Fr. Giucciardini ; Scritti politici e Ricordi ; Considerazioni intorno ai discorsi del Machiavelli sopra la prima Deca di Tito Livio ; I, 12, p. 22-23 (v. p. 78 et 79, n. 26) : Non si può dire tanto male della corte romana che non meriti se ne dica più, perché è una infamia, uno esemplo di tutti i vituperi e obbrobrii del mondo... Ma non so già se il non venire in una monarchia sia stala felicità o infelicità di questa provincia... E se bene la Italia divisa in molti dominii abbia in varii tempi patito molte calamità..., nondimeno in tutti questi tempi ha avuto al riscontro tante città floride che non arebbe avuto sotto una republica, che io reputo che una monarchia gli sarebbe stata più infelice che felice... Però se la Chiesa romana si è opposta alle monarchia, io non concorro facilmente essere stata infelicità di questa provincia, perché l'ha conservata in quello modo di vivere che è piu secondo la antiquissima consuetudine e inclinazione sua. - Machiavel lui-même (Dell'Arte della Guerra, II, p. 301) finit par reconnâ̂tre que la multiplicité des États libres pourrait favoriser le développement d'un plus grand nombre d'hommes de valeur: Conviene pertanto che, dove è assai potestadi, vi surga assai valenti uomini; dove ne è poche, pochi... Sendo adunque vero che, dove sia più imperii, surga più uomini valenti, seguita di necessità che spegnendosi quelli, si spenga di mano in mano la virtù.

clviii V.p. 110, n. 33.

clix Discorsi, I, p. 56 : Entrare per una via, la quale, non essendo ancora da alcuno trita... - Sur la question des sources de Machiavel, v. Allan H. Gilbert, Machiavelli's Prince and its foreunners ; Durham (North Carolina), 1938, in- $8^{\circ}$.

clx P. Villari, Niccolò Machiavelli, II, p. 240-291.

clxi Ibid., p. 242.

clxii $\mathrm{C}$ 'est surtout le livre $\mathrm{V}$ qui semble avoir suggéré le plus d'idées à Machiavel ; par exemple : chap. VIII, 20 ; Principe, 6 ; — IX, 11 ; Pr. 16; — IX, 13 ; Pr. 17 ; — IX, 13 ; Pr. 18 ; — IX, 13 ; Disc. III, 26 ; — IX, 17 ; Disc. II, 26. — Allan H. Gilbert donne un relevé détaillé pour le Prince. 
clxiii

Discorsi, II, Introd., p. i35 : Una città o una provincia... ordinata al vivere politico ; III, 8, p. 213 : Una città che ancora viva politicamente. - II, Introd., p. 136 : Estrema miseria, infamia e vituperio ; dove non è osservanza di religione, non di leggi, non di milizia ; ma sono maculati d'ogni ragione bruttura... E veramente, se la virtù che allora regnava, ed il vizio che ora regna, non fussino più chiari che il sole... acciochè gli animi de' giovani che questi mia scritti leggeranno possino fuggire questi e prepararsi ad imitar quegli... - I, Introd., p. 56 : Che di quella antica virtù non ci è rimasto alcun segno... Quel male che ha fatto a molte provincie e città cristiane uno ambizioso ozio. - I, 47, p. 118 : Dopo il 1494, sendo stati i principi della città cacciati da Firenze, e non vi essendo alcuno governo ordinato, ma più tosto una certa licenza ambiziosa, ed andando le cose publiche di male in peggio...

clxiv Polybe, Histoires, VI, 3-10.

clxv Tout ce développement dans Discorsi, I, 2, p. 60-61.

clxvi Discorsi, I, 2, p. 61 : E questo è il cerchio nel quale girando tulte le republiche si sono governate e si governano; ma rade volte ritornano ne' governi medesimi... Ma bene interviene che, nel travagliare una republica, mancandole sempre consiglio e forze, diventa suddita d'uno stato propinquo, che sia meglio ordinato di lei. - Le même cycle est présenté de façon un peu différente dans les Cahiers, p. 206 : Presque toutes les nations du monde roulent dans ce cercle : d'abord elles sont barbares; elles conquièrent, et elles deviennent des nations policées : cette police les agrandit, et elles deviennent des nations polies; la politesse les affaiblit; elles sont conquises et redeviennent barbares : témoins les Grecs et les Romains.

clxvii Polybe, VI, 10-11. La même doctrine se trouve exposée par Cicéron dans le De legibus, III, et dans le premier livre du De Republica, encore perdu à l'époque de Machiavel. Cf. Léon Homo, Les institutions politiques romaines ; de la cité à l'État; L'Évolution de l'Humanité ; n 18 ; Paris, 1927, in-8 ; p. 136-147.

clxviii Discorsi, I, 2, p. 61-62.

clxix Discorsi, I, 2, p. 62 ; Polybe, VI, 11-18. - Cf. début de 16 : To1

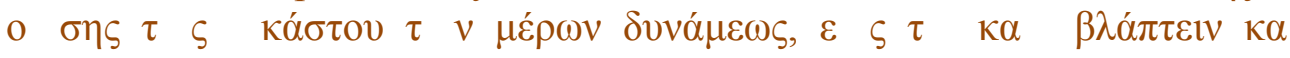

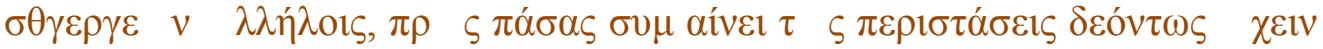

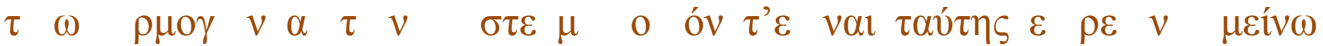
$\pi \mathrm{o} \lambda \iota \varepsilon \dot{\alpha} \alpha \varsigma$ $\sigma u ́ \sigma \tau \alpha \sigma \iota$.

clxx V.p. 78.

clxxi Il connaît l'ouvrage capital de Flavio Biondo, Historiarum ab inclinatione Romanorum Decades, terminé à Rome peu après 1453. Mais c'est surtout dans ses Istorie fiorentine qu'il l'a utilisé ; cf. P. Villari, Machiavelli, III, p. 207, et 221-227 ; Brani del libro I delle Istorie del Machiavelli messi a riscontro con altri delle Storie di Flavio Biondo. 
clxxii Discorsi, I, Introd. p. 56 : Non avere vera cognizione delle storie, per non trrne, leggendole, quel senso, nè gustare di loro quel sapore che le hanno in sè.

clxxiii Esprit des Lois, Préface. - Sur Montesquieu lecteur de Machiavel, v. Ettore Levi Malvano, Montesquieu e Machiavelli ; Bibliothèque de l'Institut français de Florence, $1^{\text {re }}$ série, 2 ; Paris, 1912, in- $8^{\circ}$.

clxxiv G. Séailles ; Léonard de Vinci, l'artiste et le savant; essai de biographie psychologique; Paris, 1892 , in- $8^{\circ}$, p. 203, 343-344 : al frutlo matematico.

clxxv Discorsi, I, Introd. p. 56 : texte cité p. 118, n. 14 : ...gustare di loro quel sapore che le hanno in se. En réalité, la formule lui vient peut-être de Polybe,

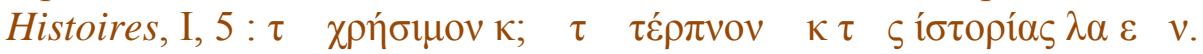

clxxvi Machiavel attribue un grand prix au libre arbitre humain, et à l'énergie individuelle, qui répond à l'invitation de la fortune : Il Principe, 26, p. 50 : Ogni cosa è concorsa nella vostra grandezza : el rimanente dovete far voi. Dio non vuole fare ogni cosa, per non ci torre el libero arbitrio, e parte di quella gloria che tocca a noi. - De toute manière, même en attribuant au destin une puissance irrésistible, les hommes, qui ne peuvent savoir où elle les conduit, ne doivent jamais s'abandonner : Discorsi, II, 29, p. 187 : Affermo bene, di nuovo, questo essere verissimo, secondo che per tutte le istorie si vede, che gli uomini possono secondare la fortuna e non opporsegli; possono tessere gli orditi suoi e non rompergli. Debbono, bene, non si abbandonare mai ; perchè, non sappiendo il fine suo, e andando quella per vie traverse ed incognito, hanno sempre a sperare, e sperando non si abbandonare, in qualunque fortuna ed in qualunque travaglio si truovino.

clxxvii Indications sur l'éthique de Machiavel et les principes de cette éthique dans l'ouvrage de Francesco Ercole, La politica di Machiavelli ; Rome, 1926, in$8^{\circ} ; 1^{\mathrm{a}}$ parte ; L'etica del Maohiavelli.

clxxviii Dell'arte della guerra, VII, p. 367 : Di che non voglio si sbigottiate o diffidiate; perchè questa provincia pare nata per risuscitare le cose morte, come si è visto della poesia, della pittura e della scultura.

clxxix Les libertés publiques déterminent pour Machiavel la force et la prospérité d'un État: Discorsi, II, 2, p. 139-140 : Si vede per esperienza le cittadi non avere mai ampliato nè di dominio nè di ricchezza se non montre sono state in libertà... Subito che nasce una tirannide sopra un vivere libero, il manco male che ne risulti a quelle città è non andare piu innanzi, nè crescere più in potenza o in ricchezze...

clxxx Lettre a Francesco Vettori; Florence, 9 avril 1513; p. 883 : Non sapendo ragionare nè dell'arte della seta e dell'arte della lana, nè de' guadagni, ne delle perdite, e' mi conviene ragionare dello stato. - Sur Machiavel économiste, sommaires indications dans l'étude de Jean Thévenet, Les idées économiques d'un homme d'État dans la Florence des Médicis; Machiavel économiste; 
Villefranche-sur-Rhône, 1922, in- $8^{\circ}$; cf. Gino Arias, Il pensiero economico di Niccolò Machiavelli ; Annali di economia, Milan, mars 1926, p. 1-30.

clxxxi A. Renaudct, Érasme économiste, dans Mélanges offerts à Abel Lefranc, Paris, 1936, in- $8^{\circ}$, p. 130-141 ; p. 134 ; — Érasme, Opera omnia, Leyde, 1703-1706, 10 vol. in-f ; $^{\circ}$ II, Adagia, 337 B : Hodie res adeo recepta est apud Ohristianos, ut... foeneratores propemodum inter Ecclesiae columina habeantur...

clxxxii Esprit des Lois, VI, 5 : J'adopterais bien la maxime de ce grand homme...

clxxxiii Livres XIII-XVIII, XX-XXIII, XIX, XXIV, XXV.

clxxxiv Livres XXVI et XXIX, XXVII, XXX-XXXI.

clxxxv Indications précieuses sur le gouvernement et la politique de Florence, dans Discorsi, I, 47 ; II, 23 ; III, 9 ; III, 30.

clxxxvi E. Levi-Malvano, Montesquieu e Machiavelli, particulièrement cap. 3, Idee generali, et 4, I Romani.

clxxxvii A. Renaudet, Études érasmiennes ; Paris, 1939, in-8 ; p, 76-85.

clxxxviii Discorsi, III, 30, p. 242 : Quell'altro creveda col tempo, con la bontà, con la fortuna sua, col benificare alcuno,... potere superare tanti che per invidia se gli opponevano, sanza alcuno scandalo, violenza e tumulto; e non sapeva che il tempo non si può aspettare, la bontà non basta, la fortuna varia, e la malignità non truova dono che la plachi. - Cf. I, 47, p. 118 : Dopo il 1494, sendo stati i principi della città cacciati da Firenze, e non vi essendo alcuno governo ordinato, ma più tosto una certa licenza ambiziosa....

clxxix Considérations sur les causes de la grandeur des Romains et de leur décadence, ch. 4.

cxc Discorsi, II, 33, p. 192 : Io estimo che sia da considerare, loggendo questa liviano istoria, volendone lare profitto, tutti e' modi del procedere del Popolo e Senato romano.

cxci Sur les traditions du particularisme italien, v. le texte de Guichardin, Considerazioni sui Discorsi del Machiavelli, I, 12, cité p. 114, n. 36.

cxcii V. p. 82, n. 28. - Discorsi, I, 65, p. 127 : Ed a volere in provincie fatte in simil modo introdurre una republica, non sarebbe possibile : ma a volerle riordinare, se alcuno ne fusse arbitro, non arebbe altra via che farvi uno regno.

cxciii Ritratto delle cose della Magna, p. 740-742.

cxciv V.p. 12, n. 7.

cxcv V.p. 65, n. 63.

cxcvi V.p. 66, n. 65 .

cxcvii Sur Machiavel historien. E. Fueter, Histoire de l'historiographie moderne; trad. fr., Paris, 1914, in- $8^{\circ}$; p. 78-83 ; - Antonio Panella, Machiavelli storico ; Rivista d'Italia, 1937, II, p. 324-340 (v. p. 30, n. 1). 
cxcviii V. p. 21-23.

cxcix Tite-Live; Historiarum Praefatio : Ad illa mihi se pro se quisque acriter intendat animum, quae vita, qui mores fuerint ; per quos viros, quibusque artibus domi militiaeque et partum et auctuni imperium sit. Labenle deinde paulatim disciplina, velut desidentes primo mores sequatur animo, deinde ut magis magisque lapsi sint, tum ire coeperint praecipites, donec ad haec tempora, quibus nec vitia nostra nec remedia pati possumus, perventum est. Hoc illud est praecipue in cognitione rerum salubre ac frugiferum, omnis te exempli documenta in inlustri posita monumento intueri ; inde tibi tuaeque reipublicae, quod imitere, capias ; inde, foedum inceplu, foedum exitu, quod vites. Ceterum aut me amor negotii suscepti fallit, aut nulla unquam respublica nec major nec sanctior nec bonis exemplis ditior fuit; nec in quam civitatem tam serae avaritia luxuriaque immigraverint, nec ubi tantus ac tam diu paupertati ac parsimoniae honos fuerit : adeo quanto rerum minus tanto minus cupiditatis erat. Nuper divitiae avaritiam et abundantes voluptates desiderium per luxum atque libidinem pereundi per-dendique omnia invexere...

cc Tite-Live, XLIII, 13 : Ceterum et mihi, vetustas res scribenti, nescio quo pacto antiquus fit animus.

cci De Oratore, II, 15 : Videtisne quantum munus sit oratoris historia ? Haud scio an flumine orationis et varietate maximum : neque tamen eam reperio usquam separatim instructam rhetorum praeceptis; sita sunt enim ante oculos. Nam quis nescit primam esse historiae legem, ne quid falsi dicere audeat, deinde ne quid vere non audeat, ne qua suspicio gratiae sit in scribendo, ne qua simultatis ? Rerum ratio ordinem temporum desiderat, regionum descriptionem; vult etiam, quoniam in rebus magnis memoriaque dignis consilia primum, deinde acta, postea eventus exspectantur, et de consiliis significari quid scriptor probet, et in rebus gestis declarari non solum quid actum aut dictum sit, sed etiam quomodo ; et cum de eventu dicatur, ut causae explicentur omnes, vel casus, vel sapientiae, vel temeritatis, hominumque ipsorum non solum res gestae, sed etiam qui fama ac nomine excellant, de cujusque vita atque natura. Verborum autem ratio et genus orationis fusum atque tractum, et cum lenitate quadam aequabili profluens, sine hac judiciali asperitate, et sine sententiarum forensium aculeis prosequendum est.

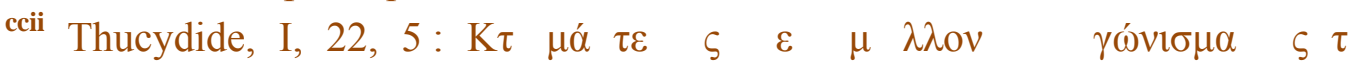
$\pi \alpha \rho \alpha \chi \rho \quad \mu \alpha \quad \kappa o v ́ \varepsilon \imath \sigma \tau \gamma \kappa \varepsilon \quad \tau \alpha \mathrm{l}$.

cciii Albert Grenier, Le Génie romain dans la religion, la pensée et l'art; L'Évolution de l'humanité, $\mathrm{n}^{\circ} 17$; Paris, 1925, in-8 $8^{\circ}$ : p. 395-404

cciv V. p. 21-22.

ccv G. Salvemini, Magnati e popolani a Firenze dal 1280 al 1295 ; p. 243 : ... spesso storpiando i fatti per adattarli ai suoi sistemi. - V. p. 21, n. 15. 


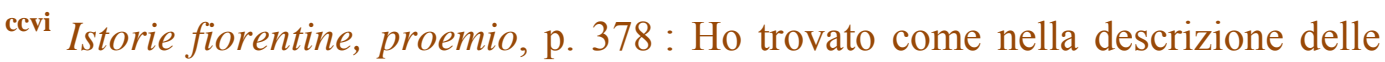
guerre fatte dai Fiorentini con i principi e popoli forestieri sono stati diligentissimi, ma delle civili discordie e delle intrinseche inimieizie, e degli effetti che da quelle sono nati, averne una parte al tutto taciuta e quell'altra in inodo brevemente descritta, che ai leggenti non puote arrecare utile o piacere alcuno. Il che credo facessero, o perchè parvono loro quelle azioni si deboli che le giudicorono indegne di essere mandate alla memoria delle lettere, o perchè temessino di non offendere i disoesi di coloro i quali, per quelle narrazioni, si avessero a calunniare... Se niuna lezione è utile a' cittadini che governano le republiche, è quella che dimostra le cagione degli odi e delle divisioni della città...

ccvii Istorie fiorentine, I, 4-6, p. 383-384 : E se tante virtù non fussero state bruttate, nell'ultimo della sua vita, da alcune crudeltà causate da varii sospetti del regno suo, come la morte di Simmaco e di Boezio, uomini santissimi, dimostrano, sarebbe al tutto la sua memoria degna da ogni parte di qualunque onore ; perchè mediante la virtù e bontà sua, non solamente Roma e Italia, ma tutte le altre parti dello occidentale imperio, libere delle continue battiture che per tanti anni da tante inundazione di barbari, avevano sopportate, si sollevorono, e in buono ordine e assai felice stato si ridussero.

ccviii Ibid. I, 9, p. 388 : Di modo che tutte le guerre che dopo questi tempi furono da' barbari fatte in Italia, furono in maggior parte dai pontefici causate, e tutti e' barbari che quella inondorono, furono il più delle volte da quegli chiamati. Il qual modo di procedere dura ancora in questi nostri tempi ; il che ha tenuto e tiene la Italia disunita e inferma.

ccix Ibid. p. 388 : E vedrassi come i papi, prima con le censure, di poi con quelle e con l'armi insieme, mescolate con le indulgenzie, erono terribili e venerandi ; e come, per avere usato male l'uno e l'altro, l'uno hanno al tutto perduto, e dell'altro stanno a discrezione d'altri.

ccx Fr. Guicciardini, Scritti politici e ricordi ; éd. Roberto Palmarocchi ; Scrittori d'Italia, Bari, 1933, in- $8^{\circ}$ : Ricordi, série $1^{\text {a }}, 125$, p. 265 : Io ho sempre desiderato naturalmente la ruina dello stato ecclesiastico, e la fortuna ha voluto che sono stati dua pontefici tali, che sono stato sforzato desiderare ed affaticarmi per la grandezza loro; se non fussi questo rispetto, amerei più Martino Luther che me medesimo, perchè spererei che la sua setta potessi ruinare o almeno tarpare le ale a questa scelerata tirannide de' preti. - Série $2^{\mathrm{a}}$, 28, p. $290: \ldots$ E se non fussi questo rispesto, arei amato Martino Luther quanto me medesimo, non per liberarmi dalle legge indotte dalla religione cristiana nel modo che è interpretata ed intesa comunemente, ma per vedere ridurre questa caterva di scelerati a' termini debiti, cioè a restare o sanza vizi o sanza autorità.

ccxi Purgatorio, XX, 43-44 :

Io fui radice de la mala pianta che la terra cristiana tutta aduggia... 
ccxii Istorie fiorentine, I, 39, p. 407 : I Viniziani, come ei si volsono alla terra, si trassono di dosso quelle armi che in mare gli avevono fatti gloriosi... I Fiorentini ancora aile medesime nécessità ubbidivano, perchè, avendo per le spesse divisioni spenta la nobilità, e restando quella republica nelle mani di uomini nutricati nella mercanzia, seguitavono gli ordini e la fortuna degli altri. Erano adunque 1'armi di Italia in mano o de' minori principio di uomini sanza stato ;... i quali, stando in sulla guerra, avevano fatto come una lega ed intelligenza insieme e riduttala in arte... E in fine la ridussono in tanta viltà, che ogni médiocre capitano, nel quale fusse alcuna ombra della antica virtù rinata, gli arebbe con ammirazione di tutta Italia, la quale per sua poca prudenza gli onorava, vituperati. Di questi adunque oziosi principi e di queste vilissime armi sarà piena la mia istoria.

ccxiii Machiavel se contente de formules classiques pour expliquer les luttes des partis à Florence, et, tout aussitôt, se reporte à l'exemple romain : Istorie fiorentine, III, 1, p. 443 : Le gravi e naturali nimicizie che sono intra gli uomini popolari e i nobili, causate da il volere questi comandare, e quegli non ubbidire, sono cagione di tutti i mali che nascano nelle città, perchè da questa diversità di umori tutte l'altre cose che perturbano le republiche prendono il nutrimento loro. Questo tenue disunita Roma; questo, se gli è lecito le cose piccole alle grandi agguagliare, ha tenuto divisa Firenze ; arvvenga che nell' una e nell'altra città diversi effetti partorissero. - L'étude des causes de la révolution sociale, tentée en 1378 par les salariés de l'Arte della Lana, demeure très sommaire; III, 12, p. 454 : A ciò si aggiugneva uno odio che il popolo minuto aveva con i cittadini ricchi e principi delle Arti, non parendo loro essere sodisfatti delle loro fatiche secondo ohe giustamente credevano meritare... - 13, p. 455 : Gli uomini plebei adunque, cosi quegli sottoposti all'arte della Lana come alle altre, per le cagioni dette erano pieni di sdegno ; al quale aggiugnendosi la paura per le arsioni e ruberie fatte da loro, convennono di notte più volte insieme, discorrendo i casi seguiti, e mostrando l'uno all'altro ne' pericoli si trovavono. - Suit un discours à la manière de Salluste où Machiavel résume les propos des plus hardis (p. 455-457).

ccxiv Istorie fiorentine, II, 30-37, III, 9-18, 26-33.

ccxv Lettere familiari, 30, p. 904 : E pagherei dieci soldi, non voglio dir più, che voi fosse in lato che io vi potessi mostrare dove io sono, perché avendo a venire a certi particulari, arei bisogno d'intendere da voi se offendo troppo, o con lo esaltare o con lo abbassare le cose ; pure io mi verro consigliando, e ingegne-rommi di fare in modo che, dicendo il vero, nessuno si possa dolere.

ccxvi V.p. 110, n. 33.

ccxvii Istorie fiorentine, VII, 5, p. 565 : Fu Cosimo il più reputato e nomato cittadino, di uomo disarmato, che avesse mai non solamente Firenze, ma alcuna altra città di che si abbi memoria... : - 6, p. 566 : Dicendogli alcuni cittadini, dopo la sua tornata dallo esilio, che si guastava la città e facevasi contro a Dio 
a cacciare di quella tanti uomini da bene, rispose come egli era moglio città guasta che perduta; e come due canne di panno rosato facevono uno uomo da bene ; e che gli stali non si tenevono co' paternostri in mano...

ccxviii Istorie fiorentine, VII, 34, p. 588-590 ; VIII, 5-9, p. 593-597 ; Discorsi, III, 6, p. 199-212 ; p. 200 : Debbono desiderare i buoni principi, e, comunque ei si sieno fatti, tollerargli. E veramente, chi fa altrimenti, il più delle volte rovina se e la sua patria. - P. 208 : quelli che rimangono, diventono più insopportabili e più acerbi.

ccxix Istorie fiorentine, VIII, 36, p. 620-621 : Amava meravigliosamente qualunque era in una arte eccellente ; favoriva i letterati... Della architettura, della musica a della poesia meravigliosamente si dilettava; e molte composizioni poetiche, non solo composte, ma comentate ancora da lui appariscono... Noter pourtant que au livre V, 1, p. 499, Machiavel semble dénoncer le goût des lettres et de la philosophie comme une des formes les plus dangereusement séduisantes de cet amour du loisir qui affaiblit les peuples et les entraîne à la décadence : - Avendo le buone e ordinate armi partorito vittorie, e le vittorie quiete, non si può la fortezza degli armati animi con più onesto ozio che con quello delle lettere corrompere ; nè può l'ozio con il maggiore e più pericoloso inganno che con questo, nelle città bene institute, entrare... Vengono pertanto le provincie per questi mezzi alla rovina.

ccxx Istorie fiorentine, VIII, 36, p. 620-621 : Tanto che, a considerare in quello e la vita voluttuosa e la grave, si vedeva in lui essere due persone diverse, quasi con impossibile congiunzione congiunte.

ccxxi Ibid. p. 630 : Fu, quanto alla mercanzia, infelicissimo... Convenue che la sua patria di gran somma di danari lo suvvenisse. - Fr. Guicciardini, Storie fiorentine, 9, p. 80-81 : ... Andandogli male, fu forzato valersi del publico e forse in qualche cosa del privato, con grandissima infamia e carico suo. - Jacopo Nardi, Istorie della città di Firenze, éd. A. Gelli, Florence, 1858, 2 vol. in- $8^{\circ}$; I, p. 19-20.

ccxii Istorie fiorentine, VIII, 36, p. 620 : Per non tentare più simile fortuna, lasciate da parte le mercatantili industrie, alle possessioni, come più stabili e più ferme ricchezze, si volse.

ccxxiii P. 621 : Subito morto Lorenzo, cominciorono a nascere quegli callivi semi i quali, non dopo molto tempo, non sendo vivo chi gli sapesse spegnere, rovinorono, e ancora rovinono la Italia.

ccxiv E. Carcassonne, Montesquieu et le problème de la Constitution française au XVIII ${ }^{e}$ siècle ; Paris, 1926, in- $8^{\circ}$, p. 1-63, 65-102. Cf. p. 65, n. 61-62 ; 83, n. 30.

ccxxv Discorsi, I, 16, p. 85 : In esemplo ci è il regno di Francia, il quale non vive sicuro per altro che per essersi quelli re obligati a infinite leggi, nelle quali si comprende la sicurtà di tutti i suoi popoli. E chi ordinò quello stato, volle che quelli re, dell' armi e del danaio facessero a loro modo, ma che d'ogni altra cosa non ne potessono altrimenti disporre che le leggi si ordinassero. - I, 58, 
p. 130 : Il quale regno è moderato più dalle leggi che alcuno altro regno di che ne' nostri tempi si abbia notizia.

ccxxvi

Discorsi, III, 1, p. 195 : Il quale regno vive sotto le leggi e sotto gli ordini più che alcuno altro regno. Delle quali leggi ed ordini ne sono mantenitori $\mathrm{i}$ Parlamenti, e massime quel di Parigi ; le quali sono da lui rinnovate qualunque volta ei fa una esecuzione contro ad un principe di quel regno e che ei condanna il Re nelle sue sentenze. Ed infino a qui si è mantenuto per essere stato uno ostinato esecutore contro a quella Nobilità : ma qualunque volta ei ne lasciassi alcuna impunita, e che le venissono a multiplicare, sanza dubbio ne nascerebbe o che le si arebbono a correggere con disordine grande, o che quel regno si risolverebbe.

ccxxvii Esprit des Lois, II, 4.

ccxxviii Discorsi, I, 16, p. 85 : E quando uno principe faccia questo, e che il popolo vegga che, per accidente nessuno, ci non rompa tali leggi, comincerà in breve tempo a vivere sicuro e contento.

ccxxix Discorsi, I, 45, p. 115.

ccxxx Discorsi, I, 11, p. 76 : Il quale, trovando uno popolo ferocissimo, e volendolo ridurre nelle obedienze civili con le arti della pace, si volse alla religione, come cosa al tutto necessaria a volere mantenere una civiltà.

ccxxxi Discorsi, I, n, p. 77-78: E benchè agli uomini rozzi più facilmente si persuada uno ordine o una opinione nuova, non è però per questo impossibile persuaderla ancora agli uomini civili e che presumono non essore rozzi. Al popolo fiorentino non pare ne essere ignorante nè rozzo ; e nondimeno da frate Girolamo Savonarola fu persuaso che parlava con Dio...

${ }^{\text {ccxxxii }}$ Fr. Guicciardini, Scritti politici e Ricordi ; Ricordi, série 1 ${ }^{\text {a }}, 31$; p. 245 : Non combattete mai con la religione nè con le cose che pare che dependono da Dio ; perchè questo obietto ha troppa forza nella mente degli sciocchi.

ccxxxiii Discorsi, I, 11, p. 78 : Non sia pertanto nessuno che si sbigottisca di non potere conseguire quel che è stato conseguito da altri; perchè gli uomini, come nella prefazione nostra si disse, nacquero, vissero e morirono sempre con uno medesimo ordine.

ccxxiv Discorsi, I, 12, p. 78 : Quelli principi o quelle republiche, le quali si vogliono mantenere incorrotte, hanno sopra ogni altra cosa a mantenere incorrotte le cerimonie della loro religione, e tenerle sempre nella loro venerazione ; perchè nessuno maggiore indizio si puote avere della rovina d'una provincia, che vedere dispregiato il culto divino.

ccxxxv Ibid. : Mantenere la loro republica religiosa, e per conseguente, buona e unita. E debbono, tutte le cose che nascano in favore de quella, corne che le giudicassono false, favorirle e accrescerle ; e tanto più lo debbono fare, quanto più prudenti sono, e quanto più conoscitori delle cose naturali. 
ccxxxvi Ibid, p. 79 : Come i Romani si servivono della religione per riordinare la città e seguire le lore imprese e fermare i tumulti.

ccxxxvii Discorsi, I, 14, p. 81 : I Romani interpetravano gli auspizi secondo la nécessità, e con la prudenza mostravano di osservare la religione, quando forzati non la osscrvavano ; e se alcuno temerariamente la dispregiava, punivano.

ccxxxviii Discorsi, I, 27, p. 95 : Quanto sia da stimare poco chi vive e regna come loro.

ccxxxix A propos de la guerre de Florence contre Grégoire XI en 1375, dite « Guerra degli otto Santi », Istorie fiorentine, III, 7, p. 449-450 : Durò la guerra tre anni, nè prima ebbe che con la morte del pontifice termine ; e fu con tanta virtù e tanta soddisfazione dello universale amministrata, che agli Otto fu ogni anno prorogato il magistrato; ed erano chiamati santi, ancora che gli avessino stimate poco le censure, e le chiese de' beni loro spogliate, e sforzato il clero a celebrare gli uffici : tanto quelli cittadini stimavono allora più la patria che l'anima.

ccxl A. Debidour, Histoire des rapports de l'Église et de l'État en France de 1789 à 1870 ; Paris, 1898 , in- $8^{\circ}$; p. 190.

ccxli Discorsi, I, 16, p. 83-85 : Un popolo, uso a vivere sotto un principe, se per qualche accidente diventa libero, con difficultà mantiene la libertà. - 17, p. 85-86 : Un popolo corrotto, venuto in libertà, si può con difflcultà grandissima mantenere libero.

ccxlii Esprit des Lois, XI, 2 ; Diverses significations données au mot de liberté ; 3 ; Ce que c'est la liberté.

ccxliii Discorsi, I, 16, p. 85 : Vivere sicuro e contento... La sicurtà di tutti i suoi popoli.

ccxliv Déclaration des Droits de l'Homme et du Citoyen, article 2 : Le but de toute association politique est la conservation des droits naturels et imprescriptibles de l'homme. Ces droits sont la liberté, la propriété, la sûreté et la résistance à l'oppression.

ccxlv Discorsi, I, 16, p. 83-84 : Potere godere liberamente le cose sue sanza alcuno sospetto, non dubitare dell'onore delle donne, di quel de' figliuoli, non temere di sè.

ccxlvi Montesquieu a d'abord considéré la sûreté du môme point de vue que Machiavel ; Cahiers, p. 97 : Tout homme est libre qui a un juste sujet de croire que la fureur d'un seul ou de plusieurs ne lui ôteront [sic] pas la vie ou la propriété de ses biens : — p. 113 : Le seul avantage qu'un peuple libre ait sur un autre, c'est la sécurité où chacun est que le caprice d'un seul ne lui ôtera point ses biens ou sa vie. Un peuple soumis, qui auroit cette sécurité-là, bien ou mal fondée, seroit aussi heureux qu'un peuple libre... Cette sécurité de son état n'est pas plus grande en Angleterre qu'en France, et elle n'étoit guère plus grande dans quelques anciennes républiques grecques... Au reste, je compte 
pour très peu le bonheur de disputer avec fureur sur les affaires d'État et de ne dire jamais cent mots sans prononcer celui de liberté, ni le privilège de haïr la moitié de ses citoyens. - Mais, dans l'Esprit des Lois, il se rallie pleinement à la doctrine anglaise; XII, 2 : Cette sécurité n'est jamais plus attaquée que dans les accusations publiques ou privées. C'est donc de la bonté des lois criminelles que dépend principalement la liberté du citoyen. - Déclaration des Droits, 7 : Nul homme ne peut être accusé, arrêté ou détenu que dans les cas déterminés par la loi et selon les formes qu'elle a prescrites. Ceux qui sollicitent, expédient, exécutent ou font exécuter des ordres arbitraires doivent être punis.

ccxlvii Déclaration des Droits, art. 10-11.

ccxlviii Discorsi, I, 16, p. 84 : ... Esaminare quali cagioni sono quelle che gli fanno desiderare d'essere liberi ; ... una piccola parte di loro desidera di essere libera per comandare ; ma tutti gli altri, che sono infiniti, desiderano la libertà per vivere sicuri.

ccxlix Discorsi, I, 37, p. 106 : Rovinò al tutto la libertà romana. - I, 4, p. 63-64 : Che la disunione della Plebe e del Senato romano fece libera e potente quella republica; - p. 64 : I desiderii de' popoli liberi rade volte sono perniziosi alla libertà, perchè e' nascono, o da essere oppressi, o da suspizione di avere ad essere oppressi.

ccl Discorsi, I, 7, p. 68-70: Quanto siano in una republica necessarie le accuse a mantenerla in libertade. - Cf. III, 28, p. 239-240 : Che si debbe por mente alle opere de' cittadini, perchè molte volte sotto una opera pia si nasconde uno principio di tirannide.

ccli Discorsi, I, 10, p. 75 : Vedrà il senato con la sua autorità, i magistrati co'suoi onori.

${ }^{\text {cclii }}$ La Cité antique, III, $18,17^{\mathrm{e}}$ édition, Paris, 1900, in- $8^{\circ}$; p. 269 : Avoir des droits politiques, voter, nommer des magistrats, pouvoir être archonte, voilà ce qu'on appelait la liberté.

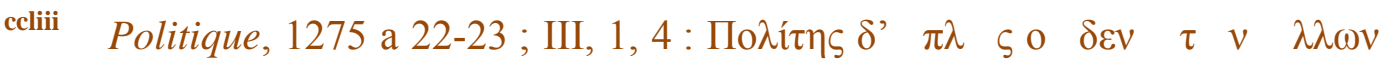

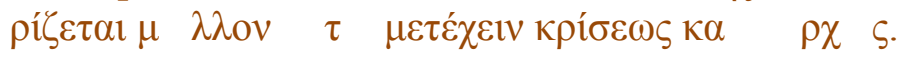

ccliv V. n. 29 : Fustel de Coulanges, La Cité antique, III, 18, p. 269 : Voilà ce qu'on appelait la liberté : mais l'homme n'en était pas moins asservi à l'État. cclv Déclaration des Droits, art. 17.

cclvi Discorsi, I, 10, p. 75 : Godersi i cittadini ricchi le loro ricchezze.

cclvii Discorsi, I, 16, p. 85 ; v. p. 177, n. 2-3.

cclviii V. p. 186, n. 28 et n. 33.

cclix Discorsi, I, 10, p. 75 : E conoscerà allora benissimo quanti obblighi Roma, l'Italia e il mondo abbia con Gesare.

cclx V. p. 82, n. 28. 
cclxi V.p. 135, n. 22.

cclxii Discorsi, I, 55, p. 126-128 : ... Che, dove à equalità, non si può fare principato; e dove la non è, non si può fare republica; - p. 128 : Constituisca, adunque, una republica colui dove è, o è falta, una grande equalità.

cclxiii Esprit des Lois, V, 3 : L'amour de la république, dans une démocratie, est celui de la démocratie; l'amour de la démocratie est celui de l'égalité. L'amour de la démocratie est encore l'amour de la frugalité. Chacun devant y avoir le même bonheur et les mêmes avantages, y doit goûter les mêmes plaisirs, et former les mêmes espérances; chose qu'on ne peut attendre que de la frugalité générale.

cclxiv Discorsi, I, 37, p. 106 : Le republiche bene ordinate hanno a tenere ricco il publico, e gli loro cittadini poveri.

cclxv Discorsi, I, 55, p. 128. - Machiavel démontre que les citoyens appelés à Venise «gentiluomini », ne sont pas à proprement parler des gentilshommes, mais de grands bourgeois : I gentiluomini in quella Republica sono più in nome che in fatto ; perchè loro non hanno grandi entrate di possessioni, sendo le loro ricchezze grandi fondate in sulla mercanzia e cose mobili ; e di più, nessuno di loro tiene castella, o ha alcuna iurisdizione sopra gli uomini.

cclxvi Esprit des Lois, V, 6.

cclxvii Discorsi, I, 37, p. 105-107 : Quali scandoli partorì in Roma la legge agraria ; e come fare una legge in una repubblica, che riguardi assai indietro, e sia contro a una consuetudine antica della città, è scandolosissimo.

cclxviii Ibid., p. 107 : Vedesi per questo ancora, quanto gli uomini stimano più la roba che gli onori...

cclxix Ibid., p. 107 : Il quale fu primo tiranno in Roma : talchè mai poi fu libera quella città.

cclxx Ibid., p. 107 : De’ quali si debbe laudare più la intenzione che la prudenzia. Perchè, a volere levar via uno disordine cresciuto in una republica, e per questo fare una legge che riguardi assai indietro, è partito male considerato.

cclxxi Discorsi, III, 8, p. 213 : Per altri modi si ha a cercare gloria in una città corrotta, che in una che ancora viva politicamente. - V. p. 122, n. 5.

cclxxii Discorsi, I, 58, p. 130 : Una moltitudine... regolata dalle leggi... Ne superbamente dominare nè umilmente servire : come era il popolo romano, il quale, mentre durò la Republica incorrotta, non servi mai umilmente nè mai domino superbamente.

cclxxiii Ibid., p. 131 : Un popolo che comandi e sia bene ordinato.

cclxxiv Ibid., p. 130 : Ma quanto alla prudenzia ed alla stabilità, dico come un popolo è più prudente, più stabile e di migliore giudizio che une principe. E non senza ragione si assomiglia la voce d'un popolo a quella di Dio. — Cf. le titre du chapitre : La moltitudine è più savia e più costante che uno principe. 
cclxxv Discorsi, I, 58, p. 132. Vedesi ancora, nelle sue elezioni ai magistrati, fare, di înga, migliore elezione che uno principe ; nè mai si persuadera a un popolo, che sia bene tirare alla degnità uno uomo infame e di corrotti costumi ; il che facilmente e per mille vie si persuade a un principe. - Cf. Montesquieu, Esprit des Lois, II, 2 : Le peuple est admirable pour choisir ceux à qui il doit confier quelque partie de son autorité.

cclxxvi Ibid. Vedesi, oltra di questo, le città dove i popoli sono principi, fare in brevissimo tempo augumenti eccessivi,... come fece Roma dopo la cacciata de' re, e Atene da poi che la si liberò da Pisistrato...

cclxxvii Ibid. : E se i principi sono superiori a popoli nello ordinare leggi, formare vite civili, ordinare statuti ed ordini nuovi, i popoli sono tanto superiori nel mantenere le cose ordinate...

cclxxviii Ibid. : Le crudeltà della moltitudine sono contro a chi ei temano che occupi il bene commune...

cclxxix Ibid. : ... Un popolo licenzioso e tumultuario... facilmente può essere ridotto nella via buona; a un principe cattivo non è alcuno che possa parlare, ni vi è altro rimedio che il ferro.

cclxxx Discorsi, I, 4, p. 63 : libera e potente.

cclxxxi Discorsi, I, 4, p. 63-64: Che la disunione della plebe e del senato romano fece libera e potente quella republica.

cclxxxii Discorsi, I, 6, p. 67 : Se tu vuoi fare un popolo numeroso ed armato per poter fare un grande imperio, lo fai di qualità che tu non lo puoi poi maneggiare a tuo modo... E' necessario... dare luogo a' tumulti e alle dissenzioni universali, il meglio che si può ; perchè sanza gran numéro di uomini, e bene armati, mai una republica potrà crescere...

cclxxxiii Discorsi, I, 4, p. 64 : E i desiderii di popoli liberi rade volte sono perniziosi alla libertà, perchè e' nascono, o da essere oppressi, o da suspizione di avere ad essere oppressi.

cclxxxiv Discorsi, I, 37, p. 107.

cclxxxv Discorsi, I, 24, p. 92-93 : Le republiche bene ordinate costituiscono premii e pene a' loro cittadini... - 36, p. 105 : Non debbano i cittadini, che hanno avuto i maggiori onori, sdegnarsi de' minori.

cclxxxvi Discorsi, III, 3, p. 197-198 : ... Chi piglia una tirannide, e non ammazza Bruto, e chi fa uno stato libero e non ammazza i figliuoli di Bruto, si mantiene poco tempo... Piero Soderini, il quale si credeva superare con la pazienza e bontà sua quello appetito che era ne' figliuoli si Bruto..., per non sapere somigliare Bruto, e' perde, insieme con la patria sua, lo stato e la riputazione.

cclxxxvii Discorsi, III, 28, p. 239-240. 
cclxxxviii Discorsi, I, 52, p. 122-123 : A reprimere la insolenzia d'uno che surga in una republica potente, non è più sicuro e meno scandoloso modo, che preoccuparli quelle vie per le quali viene a quella potenza.

cclxxxix Discorsi, I, 7, p. 68-70 : Quanto siano in una republica necessarie le accuse a mantenerla in libertade. - Cf. III, 28 ; v. n. 64.

ccxc Discorsi, I, 7, p. 69 : Quando questi modi ordinari non vi siano, si ricorre agli straordinari ; e sanza dubbio questi fanno peggiori effetti che non fanno quelli.

ccxci Discorsi, I, 52, p. 122. - I, 33, p. 101-102: Quando uno inconveniente è cresciuto in uno stato o contro a uno stato, è più salutifero partito temporeggiarlo che urtarlo.

ccxcii Discorsi, III, 1, in fine, p. 196 : E per dimostrare a qualunque, quanto le azioni degli uomini particulari facessono grande Roma e causassino in quella città molti buoni effetti, verrò alla narrazione e discorso di quegli ; intra e' termini de'quali questo terzo libro, ed ultima parte di questa prima Deca, si concluderà.

ccxciii C'est à l'imitation de Venise qu'avait été votée, le 26 août i5oa, la loi en vertu de laquelle le gonfalonier devait exercer dorénavant ses pouvoirs à vie, comme le doge.

ccxciv Discorsi, I, 25, p. 93-94 : Chi vuole riformare uno stato anticato in una città libera, ritenga almeno l'ombra de'modi antichi. - E' necessitato a ritenere l'ombra almanco de'modi antichi, acciò che a'popoli non paia avere mutato ordine, ancorchè in fatto gli ordini nuovi fussero al tutto alieni dal passato.

ccxcv Discorsi, III, 1, p. 193-195 : A volere che una setta o una republica viva lungamente, è necessario ritirarla spesso verso il suo principio. — 22, p. 232 : E se una republica fusse si felice, ch'ella avesse spesso... chi con lo esemplo suo le rinnovasse le leggi, la sarebbe perpetua.

ccxcvi Discorsi, III, 1, p. 195 : E furono sì potenti gli ordini loro nuovi, che ei sono cagione che la disonestà de'prelati e de' capi della religione non la rovinino...

ccxcvii Esprit des Lois, VIII, 12.

ccxcviii Discorsi, I, 34, p. 103 : Quando in una republica manca uno simile modo, è necessario, o, servando gli ordini, rovinare, o, per non ruinare, rompergli... Conchiudendo, dico che quelle republiche, le quali negli urgenti pericoli non hanno rifugio o al dittatore o a simili autoritadi, sempre ne' gravi accidenti rovineranno. - Cf. Montesquieu, Cahiers, p. 212 : Dictateur. - Remède extrême dans les maux extrêmes. C'étoit une Divinité qui descendait du ciel pour le dénouement des choses embrouillées.

ccxcix Discorsi, I, 35, p. 104 : Creato il Dittatore, rimanevano i Tribuni, i Consoli, il Senato, con la loro autorità ; nè il Dittatore la poteva torre loro... In modo che il Senato, i Consoli, i Tribuni, restando con l'autorità loro, venivano a essere come sua guardia, a farlo non uscire della via diretta. E pur questo si deve notare, che, quando si è detto che una autorità, data da' suffragi liberi, non of- 
fese mai alcuna republica, si presuppone che un popolo non si conduca mai a darla, se non con le débite circunstanze e ne' debiti tempi. - Il démontre comment la création du décemvirat, ces garanties nécessaires n'ayant pas été observées, fut nuisible à la liberté romaine.

cc Idem, I, 18, p. 88 : E perchè il riordinare una città al vivere politico presuppone uno uomo buono, e il diventare per violenza principe di una republica presuppone uno uomo cattivo; per questo si troverrà che radissime volte accaggia che uno buono, per vie cattive, ancora che il fine suo fusse buono, voglia diventare principe. - I, 35, p. 104 : Nè giova, in questo caso, che la materia non sia corrotta; perchè una autorità assoluta in breve tempo corrompe la materia.

ccci V. p. 197.

cccii V. p. 176-177; Esprit des Lois, III, 6.

ccciii Il Principe, 9, De principatu civili, p. 20-22.

ccciv Quelques indications sommaires sur les rivalités économiques et sociales d'où provient la décadence des républiques : Discorsi, I, 37, p. 105-106 : Desiderando gli uomini, parte di avère più, parte temendo di non perdere lo acquistato, si viene aile inimicizie ed alla guerra... - Discorsi, I, 18, p. 88 : ... La difficultà, o impossibilità, che è nelle città corrotte, a mantenervi una republica, o a crearvela di nuovo. E quando pure la vi si avesse a creare o a mantenere, sarebbe necessario ridurla più verso lo stato regio che verso la stato popolare...

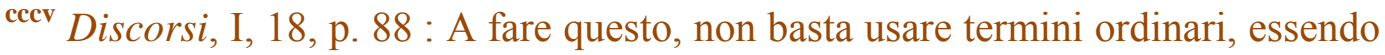
modi ordinari cattivi; ma è necessario venere allo straordinario, corne è alla violenza ed all'arme, e diventare innanzi a ogni cosa principe di quella città, e poterne disporre a suo modo.

cccvi Thomas More, L'Utopie ou le Traité de la meilleure forme de gouvernement, texte latin édité par Marie Delcourt ; Paris, 1936, in-8 ; p. 204, 19-21 : ... Quaedam conspiratio divitum, de suis commodis reipublicae nomine tituloque tractantium. - Il Principe, 19, p. 20 : Il populo desidera non essere comandato ne oppresso da' grandi, e li grandi desiderano commandare e opprimere il populo. - Discorsi, I, 4, p. 63 : E' sono in ogni republica due umori diversi, quello del popolo e quello de' grandi. - Cf. p. 202, n. 81.

cccvii Il Principe, 19, p. 20 : E da questi dua appetiti diversi nasce nelle città uno de'tre effetti, o principato o libertà o licenzia.

cccviii Il Principe, 19, p. 10 : Vedendo e' grandi non potere resistere al populo, cominciano a voltare la reputazione a uno di loro, e fannolo principe per potere, sotto la sua ombra, sfogare il loro appetito. El populo ancora, vedendo non potere resistere a' grandi, volta la reputazione a uno, e lo fa principe, per essere con la autorità sua difeso...

cccix Il Principe, 19, p. 21. 
${ }^{\text {ccx }}$ La Cité antique, IV, 7, p. 323-324.

cccxi Il Principe, 19, p. 20.

cccxii Cf. p. 184, n. 83. Il Principe, 19, p. 30 : Quello del populo è più onesto fine che quello de'grandi, volendo questi opprimere, e quello non essere oppresso.

cccxiii Ibid., p. 21 : E perchè gli uomini, quando hanno bene da chi credevano avere male, si obligano più al benificatore loro, diventa el popolo, subito, più suo benivolo che se si fussi condotto al principato con li favori suoi.

cccxiv Ibid., p. 21 : Mai si troverrà ingannato da lui.

cccxv Ibid., p. 21 : Sogliono questi principati periclitare quando sono per satire dallo ordine civile allo assoluto...

cccxvi Ibid., p. 20 : Ne a pervenirvi è necessaria o tutta virtù o tutta fortuna, ma più presto una astuzia fortunata.

cccxvii Il Principe, 11. De principatibus ecclesiasticis; p. 23 : Costoro soli hanno stati, e non li defendano ; sudditi, e non li governano ; e li stati, per essere indifesi, non sono loro tolti; e li sudditi, per non essere governati, non sene curano, ne pensano ne possono alienarsi da loro. Solo adunque questi principati sono sicuri e felici.

cccxviii Ibid. : Ma sendo quelli retti da cagioni superiore, aile quali mente umana non aggiugne, lascerò il parlarne.

cccxix V.p. 61, n. 46.

cccxx Discorsi, I, 27, p. 95 : Così Giovampagolo, il quale non stimava essere incesto e publico parricida, non seppe, o, a dir meglio, non ardì, avendone giusta occasione, fare una impresa, dove ciascuno avesse ammirato l'animo suo, e avesse di sè lasciato memoria eterna, sendo il primo che avesse dimostro a' prelati quanto sia da stimare poco chi vive e regna come loro...

cccxxi Il Principe, 11 p. 23-24.

cccxiii Ibid., p. 24 : Alessandro VI... mostrò quanto un papa, e con il danaio e con le forze, si posseva prevalere... E benchè lo intento suo non fussi fare grande la Chiesa, ma il duca, nondimeno ciò che fece tornò a grandezza della Chiesa.

cccxxiii V. p. 60, n. 42.

cccxiv Il Principe, 11, p. 24 : Ha trovato adunque la Santità del papa Leone questo pontificato potentissimo; il quale si spera, se quelli lo feciono grande con le arme, questo, con la bontà e infinite altre sue virtù, lo farà grandissimo e venerando. - Sur l'appel de Machiavel à Léon X, v. p. 98-100.

cccxxv Discorsi, I, 12, p. 79 : E chi considerasse i fondamenti suoi, e vedesse l'uso présente quanto è diverso da quelli, giudicherebbe essere propinquo, senza dubbio, o la rovina o il fragello.

cccxxvi V. n. 101. 
cccxxvii Il Principe, p. 3 : La quale opera non ho ornata nè ripiena di clausule ample o di parole ampullose e magnifiche...; perchè ho voluto, o che veruna cosa la onori, o che solamente la varietà della materia e la gravità del subietto la facci grata.

cccxxviii V.p. 82-83.

cccxix V. p. 194, n. 53. - De même, Discorsi, II, 2, p. 139-140 : Ma sopra tutto meravigliosissima è a considerare a quanta grandezza venne Roma, perchè la si liberò da' suoi Re. Le ragione è facile a intendere ; perchè non il bene particulare, ma il bene comune è quello che fa grandi le città... Dimodoché, subito che nasce una tirannide sopra uno vivere libero, il manco male che ne risulti a quelle città è non andare più innanzi, nè crescere più in potenza $\mathrm{o}$ in ricchezze : ma il più delle volte, anzi sempre, interviene loro che le tornano indietro.

cccxxx Il Principe, 2, p. 5 : De principatibus hereditariis.

cccxxi Il Principe, 6, p. 12-14 : De principatibus novis qui armis propriis et virtute acquiruntur. - P. 13 : Ha per nimici tutti quelli che degli ordini vecchi fanno bene, e ha tepidi defensori, tutti quelli che degli ordini nuovi farebbono bene...

cccxxii Il Principe, 6, p. 13 : E' necessario... esaminare se questi innovatori stanno per loro medesimi o se dependano da altri ; cioè se per condurre l'opera loro bisogna che preghino, ovvero possono forzare.

cccxxiii Il Principe, 6, p. 13 : Di qui nacque che tutti e' profeti armati vinsono, e li disarmati ruinorono.

cccxxiv Il Principe, 6, p. 13-14 : La natura de' populi è varia ; ed è facile a persuadere loro una cosa : ma è difficile fermarli in quella persuasione; e però conviene essere ordinato in modo che, quando e' non credono più, si possa fare loro credere per forza.

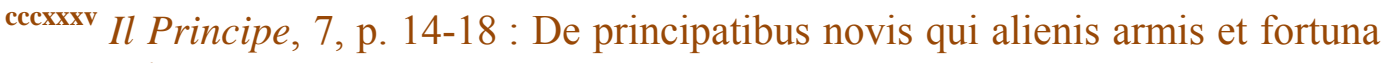
acquiruntur.

cccxxxvi Ibid., 7, p. 55 : Io non saprei che precetti mi dare migliori a uno principe nuovo, che lo esemplo delle azioni sua; e se gli ordini suoi non li profittorono, non fu sua colpa, perchè nacque da una estraordinaria ed estrema malignità di fortuna.

cccxxxvii Il Principe, 7, p. 16 : E perchè questa parte è degna di notizia e da essere imitata da altri, non la voglio lasciare indietro. Preso che ebbe il duca la Romagna, e trovandola suta comandata da signori impotenti, li quali più presto avevano spogliato i loro sudditi che corretti, e dato loro materia di disunione, non di unione, tanto che quella provincia era tutta piena di latrocinii, di brighe e di ogni altra ragione di insolenzia, iudicò fussi necessario, a volerla ridurre pacifica e obediente al braccio regio, darli buon governo. Però vi prepose messer Remirro de Orco, uomo crudele ed espedito, al quale dette pienissima potestà. 
cccxxxviii

Il Principe, 7, p. 16 : Lo fece a Cesena, una mattina, mettere in dua pezzi in sulla piazza, con uno pezzo di legno e uno coltello sanguinoso a canto. La ferocità del quale spettaculo fece quelli populi in uno tempo rimanere satisfatti e stupidi.

cccxxxix V. p. 58, n. 39.

cccxl Il Principe, 7, p. 18: E chi crede che ne' personaggi grandi e' beneflzii nuovi faccino dimenticare le iniurie vecchie, s'inganna. Errò, adunque, el duca in questa elezione ; e fu cagione dell'ultima ruina sua...

cccxli Ibid., 7, p. 17 : Raccolte io adunque tutte le azioni del duca, non saprei riprenderlo ; anzi mi pare, come ho fatto, di preporlo imitabile a tutti coloro che per fortuna e con l'arme d'altri sono ascesi allo imperio. Perchè lui, avendo l'animo grande, e la sua intenzione alta, non si poteva governare altrimenti ; e solo si oppose alli sua disegni la brevità della vita di Alessandro e la malattia sua.

cccxlii Ibid. : Assicurarsi de' nemici, guadagnarsi degli amici, vincere o per forza o per fraude, farsi amare e temere da' populi, seguire e riverire da' soldati, spegnere quelli che ti possono o debono offendere, innovare con nuovi modi gli ordini antiqui, essere severo e grato, magnanimo e liberale, spegnere la milizia infedele, creare della nuova, mantenere le amicizie de' re e de' principi in modo che ti abbino a beneficare con grazia o offendere con respetto...

cccliii Il Principe, 8, p. 18-20 : De his qui per scelera ad principatum pervenere.

cccxliv Ibid., p. 19-20 : ... Crudeltà male usate o bene usate. Bene usate si possano chiamare quelle (se del male è licito dire bene), che si fanno a uno tratto, per la necessità dello assicurarsi... Chi fa altrimenti, o per timidità o per mal consiglio, è sempre necessitato tenere il coltello in mano. Perchè le iniurie si debbono fare tutte insieme, accio che, assaporandosi meno, offendino meno; e' benefizii si debbono fare a poco a poco, acciò si assaporino meglio...

cccxlv Il Principe, 3, p. 6-10: De principatibus mixtis.

cccxlvi Ibid., 3, p. 6 : Come se è visto che ha fatto la Borgogna, la Brettagna, la Guascogna e la Normandia, che tanto tempo sono state con Francia, e benchè vi sia qualche disformità di lingua, nondimeno e' costumi sono simili, e possonsi fra loro facilmente comportare.

cccxlvii Ibid., p. 6-8.

cccxlviii Ibid., p. 8-10.

cccxlix Ibid., p. 9-10 : E se alcuni altri allegassino la fede che il re aveva obligata al papa..., respondo con quello che per me di sotto si dirà circa la fede de'principi e come le si debbe osservare (V. p. 268-272).

cccl V. p. 66, n. 65.

cccli Il Principe, 3, p. 10 : E per esperienza si è visto che la grandezza in Italia di quella e di Spagna è stata causata da Francia, e la ruina sua causata da loro. 
ccclii Discorsi, I, 26, p. 9\$: Uno principe nuovo, in unà città o provincia presa da lui, debbe fare ogni cosa nuova ;... fare nuovi governi con nuovi nomi, con nuove autorità, con nuovi uomini, fare i ricchi poveri, i poveri ricchi, come fece Davit quando ei diventò re : « qui esurientes implevit bonis, et divites dimisit inanes " ; edificare, oltre di questo, nuove città, disfare delle edificate, cambiare gli abitatori da un luogo a un altro ; ed in somma, non lasciare cosa niuna intatta in quella provincia, e che non vi sia nè grado, nè ordine, nè stato, nè richezza, che chi la tiene non la riconosca da te ; e pigliare per sua mira Filippo di Macedonia... E chi scrive di lui dice che tramutava gli uomini di provincia in provincia, come e' mandriani tramutano le mandrie loro.

cccliii Ibid. : Sono questi modi crudelissimi... Ma gli uomini pigliono certe vie del mezzo, che sono dannosissime ; perchè non sanno essere nè tutti cattivi nè tutti buoni. - Cf. 27, p. 94-95 : Sanno rarissime volte gli uomini essere al tutto cattivi o al tutto buoni.

cccliv Discorsi, III, 6, Delle congiure ; p. 199-212.

ccclv V.p. 195, n. 56.

ccclvi Discorsi, III, 6, p. 199-200 : Acciocchè, dunque, i principi imparino a guardarsi da questi pericoli, e che i privati più timidamente vi si mettino ; anzi imparino ad essere contenti a vivere sotto quello imperio che dalla sorte è stato loro proposto... Che gli uomini hanno ad onorare le cose passate, e ad ubbidire alle presenti ; e debbono desiderare i buoni principi, e, comunque ei si sieno fatti, tollerargli.

ccclvii Istorie fiorentine, VII, 6, p. 566 ; cité p. 168, n. 21.

ccclviii Il Principe, 7, p. 14-15 : Acquistò la stato con la fortuna del padre, e con quella lo perdè.

ccclix V.p. 231, n. 26.

ccclx V.p. 59-61, 78-80, 161-162, 210-214.

ccclxi V. p. 126-126.

ccclxii V.p. 134, n. 20.

ccclxiii Il Principe, 6, p. 13 : Tutti e' profeti armati vinsono, e li disarmati ruinorono.

ccclxiv V.p. 12-14.

ccclxv Le Opere di Dante; Testo critico della Società dantesca italiana ; Florence, 1921, in- $8^{\circ}$; De Monarchia, I, 3 ; p. 357 : Nunc autem videndum est quid sit finis totius humane civilitatis... Propter quod sciendum primum quod «Deus et natura nil otiosum facit ", sed quioquid prodit in esse est ad aliquam operationem... Est ergo aliqua propria operatio humane universitatis, ad quam ipsa universitas hominum in tanta multitudine ordinatur; ad quam quidem operationem nec homo unus nec domus una, nec una vicinia, nec una civitas, nec regnum particulare pertingere potest... 
ccclxvi Ibid., p. 357 : Patet igitur quod ultimum de potentia ipsius humanitatis est potentia sive virtus intellectiva. - I, 4, p. 358 : Satis igitur declaratum est quod proprium opus humani generis totaliter accepti est actuare semper totam potentiam intellectus possibilis, per prius ad speculandum, et secundario propter hoc ad operandum per suam extensionem.

ccclxvii De Monarchia, I, 4, p. 358 : Opus quod fere divinum est, juxta illud : « Minuisti eum paulo minus ab angelis ».

ccclxviii Ibid. : Unde manifestum est quod pax universalis est optimum eorum que ad nostrani beatitudinem ordinantur.

ccclxix Il suffit de rappeler le premier distique de l'épitaphe composée, au début du $\mathrm{XV}^{\mathrm{e}}$ siècle, par Giovanni del Virgilio :

Theologus Dantes, nullius dogmatis expers,

Quod foveat claro Philosophia sinu.

ccclxx A. Renaudet, Études érasmiennes, p. 72-85.

ccclxxi Thomas More, L'Utopie ou le Traité de la meilleure forme de gouvernement; texte latin édité par Marie Delcourt; Paris, 1936, in- $8^{\circ}$; Lib. II ; De re militari, p. 170-171, 173.

ccclxxii A. Renaudet, Études érasmiennes, p. 87-102.

ccclxxiii Ibid., p. 91-92, 95-97.

ccclxxiv Discorsi, II, 15, p. 158-i60 ; - P. 159 : E se i Fiorentini avessero notato questo testo, non arebbono avuto co' Franciosi nè tanti danni nè tante noie nella passata che il re Luigi di Francia XII fece in Italia contro a Lodovico duca di Milano.

ccclxxv Discorsi, III, 31, p. 243 : I quali nella buona fortuna, parendo loro aversela guadagnata con quella virtù che non avevano...

ccclxxvi Ibid., p. 244 : ... Ma la viltà dello animo loro, causata dalla qualità de' loro ordini non buoni nelle cose della guerra, gli fece ad un tratto perdere lo stato e l'animo. E sempre interverrà così, a qualunque si governa come loro.

ccclxxvii Il Principe, 12, p. 24-27 : Quot sint genera militiae et de mercenariis militibus ; - p. 24 ; E' principali fondamenti che abbino tutti li stati, così nuovi come vecchi o misti, sono le buone legge e le buone arme; e perchè non può essere buone legge dove non sono buone arme, e dove sono buone arme conviene sieno buone legge... - Discorsi, III, 31, p. a44 : E benchè altra volta si sia detto, come il fondamento di tutti gli stati è la buona milizia, e come, dove non è questa, non possono essere nè leggi buone, nè alcuna altra cosa buona, non mi pare superfluo replicarlo; perchè ad ogni punto nel leggere questa istoria si vede apparire questa necessità.

ccclxxviii Il Principe, 12, p. 20 : Con più difficultà viene alla obedienzia di uno suo cittadino una republica armata di arme proprie. 
ccclxxix La pensée exacte de Machiavel se trouve fort vraisemblablement exprimée par Montesquieu, Cahiers, p. 211 : Il faudra mettre cette réflexion que, dans une république, il seroit dangereux de séparer les fonctions civiles des militaires; qu'il faut que les fonctions militaires ne soient qu'un accessoire de la magistrature civile, qu'un homme se fasse citoyen plutôt que soldat, magistrat plutôt qu'officier, consul ou sénateur plutôt que général.

ccclxxx Il Principe, 14, p. 29-30 : Quod principem deceat circa militiam.

ccclxxxi Il Principe, 12, p. 25-27; Quot sint genera militiae et de mercenariis militibus.

ccclxxxii Il Principe, 13, p. 27-29 : De militibus auxiliariis, mixtis et propriis ; p. 28. ccclxxxiii V. p. 63, n. 58.

ccclxxxiv Il Principe, 14, p. 29 : Debbe, pertanto, mai levare el pensiero di questo esercizio della guerra, e nella pace vi si debbe più esercitare che nella guerrra...

ccclxxxv Discorsi, I, 3o, p. 98. - Il Principe, 14, p. 29.

ccclxxxvi Il Principe, 14, p. 30 ; Cf. p. 107, n. 28.

ccclxxxvii Il Principe, 21, p. 43-45; Quod principem deceat ut egregius habeatur... Nessuna cosa fa tanto stimare uno principe quanto fanno le grandi imprese e dare di sè rari esempli.

ccclxxxviii A. Renaudet, Études érasmiennes, p. 109.

ccclxxxix Ibid., p. 109, 83, 72-74, 85-94.

cccxc Discorsi, II, 6 : Come i Romani procedevano nel fare la guerra ; p. 147 : La intenzione di chi fa guerra... è acquistare e mantenere lo acquistato ; e procedere in modo con essa, che l'arrichisca e non impoverisca il paese e la patria sua.

cccxi Il Principe, 20 ; Quod principem deceat ut egregius habeatur ; p. 43-44. Machiavel consacre une page importante à l'œuvre de Ferdinand.

cccxii Discorsi, II, 6, p. 147-149); Come i Romani procedevano nel fare la guerra ; p. 147 : Chi vuole fare tutte queste cose, conviene che tenga lo stile e modo romano; il quale fu in prima di fare le guerre, come dicano i Franciosi, corte e grosse. - P. 148 : Questi dua modi, adunque, e circa distribuire la preda, e circa il mandare delle colonie, feciono che Roma arricchiva della guerra; dove gli altri principi e republiche non savie impoveriscono. E si ridusse la cosa in termine, che a uno consolo non pareva potere trionfare, se non portava col suo trionfo assai oro ed argento, e d'ogni altra sorta preda, nello erario. - Montesquieu, Considérations sur les causes de la grandeur des Romains et de leur décadence ; ch. 6, De la conduite que les Romains tinrent pour soumettre tous les peuples ; - H. Taine, Essai sur Tite-Live, p. 176.

cccxiii Discorsi, II, 6 ; v. note précédente.

cccxiv Il Principe, 3, p. 8-10. 
cccxcv Discorsi, III, 24, p. 235 : La prolungazione degl' imperii fece serva Roma... Stando uno cittadino assai tempo commandatore d'uno esercito, se lo guadagnava e facevaselo partigiano; perchè quello esercito col tempo dimenticava il Senato, e riconosceva quello capo. Per questo Silla e Mario poterono trovare soldati che contro al bene publico gli seguitassono : per questo Cesare potette occupare la patria. - Montesquieu, Considérations..., ch. 9 : Deux causes de la perte de Rome... Les généraux, qui disposèrent des armées et des royaumes, sentirent leurs forces, et ne voulurent plus obéir... Ce ne furent plus les soldats de la république, mais de Sylla, de Marius, de Pompée, de César.

cccxcvi Il Principe, 21, p. 43 : Quod principem deceat ut egregius habeatur... Nessuna cosa fa tanto stimare uno principe, quanto fanno le grandi imprese...

cccxcvii Il Principe, 15, p. 30-31 ; De his rebus quibus homines et praesertim principes laudantur aut vituperantur; p. 33 : Ma sendo l'intento mio scrivere cosa utile a chi la intende, mi è parso più conveniente andare drieto alla verità effettuale della cosa, che alla imaginazione di essa. E molti si sono imaginati republiche e principati che non si sono mai visti nò conosciuti essere in vero ; perchè egli è tanto discosto da come si vive a come si doverrebbe vivere, che colui che lascia quello che si fa per quello che si doverrebbe fare impara piuttosto la ruina che la perservazione sua : perchè uno uomo che voglia fare in tutte le parte professione di buono, conviene rovini infra tanti che non sono buoni. Onde è necessario a uno principe, volendosi mantenere, imparare a potere essere non buono, e usarlo e non l'usare secondo la necessità. Lasciando adunque indrieto le cose circa uno principe imaginate, e discorrendo quelle che sono vere...

cccxcviii Discorsi, III, 40 ; p. 255 ; Come usare la fraude nel maneggiare la guerra è cosa gloriosa ; - 41, p. 206 ; Che la patria se debbe difendere o con ignominia o con gloria; ed in qualunque modo è bene difesa.

cccxcix Discorsi, III, 40, p. 255 : Ancora chè lo usare la fraude in ogni azione sia detestabile, nondimanco nel maneggiare la guerra è cosa laudabile e gloriosa... — 41, p. 206 : Dove si delibera al tutto della salute della patria, non vi debbe cadere alcuna considerazione nè di giusto nè d'ingiusto, nè di piatoso nè di crudele, nè di laudabile nè d'ignominioso ; anzi, posposto ogni altro rispetto, seguire al tutto quel partito che le salvi la vita, e mantenghile la libertà.

cd Discorsi, III, 41, p. 256 : La quale cosa è imitata con i detti e con i fatti dai Franciosi, per difendere la maestà del loro re e la potenza del loro regno ; perchè nessuna voce odono più impazientemente che quella che dicesse : - Il tale partito è ignominioso per il re - ; perchè dicono che il loro re non può patire vergogna in qualunque sua diliberazione, o in buona o in avversa fortuna; perchè, se perde, se vince, tutti dicono essere cose da re.

cdi A. Renaudet, Études érasmiennes, p. 74. 
Il Principe, 18, p. 34-35 : Quomodo fides a principibus sit servando ; - Discorsi, III, 42, p. 236-207 ; Che le promesse fatte per forza non si debbono osservare.

cdiii Il Principe, 18, p. 34 : Quanto sia laudabile in uno principe mantenere la fede e vivere con integrità e non con astuzia, ciascuno lo intende ; nondimanco si vede per esperienzia ne' nostri tempi, quelli principi avere fatto gran cose, che della fede hanno tenuto poco conto, e che hanno saputo con l'astuzia aggirare e' cervelli degli uomini ; e alla fine hanno superato quelli che si sono fondati sulla lealtà.

cdiv Ibid., p. 34 : Dovete adunque sapere come sono dua generazioni di combattere : l'uno con le leggi, l'altro con la forza : quel primo è proprio dello uomo, quel secondo è delle bestie; ma perchè el primo molte volte non basta, conviene ricorrere al secondo. Pertanto a uno principe è necessario sapere bene usare la bestia e l'uomo.

Ibid., p. 34 : Bisogna adunque essere golpe a conoscere e' lacci, e lione a sbigottire e' lupi. Coloro che stanno semplicemente in sul lione, non se ne intendano. Non può pertanto, uno signore prudente, nè debbe, osservare la fede, quando tale osservanzia li torni contro, e che sono spente le cagioni che la feciono promettere.

cdvi Discorsi, III, 42, p. 256 : Non è vergognoso non osservare quelle promesse che ti sono state fatte promettere per forza; e sempre le promesse forzate che riguardano il publico, quando e' manchi la forza, si romperanno, e fla sanza vergogna di che le rompe.

cdvii Discorsi, III, 4o, p. 255 : Dirò solo questo, che io non intendo quella fraude essere gloriosa...; ancora che la ti acquisti, qualche volta, stato e regno..., la non ti acquisterà mai gloria.

Il Principe, 18, p. 34 : E se gli uomini lussino tutti buoni, questo precetto non sarebbe buono; ma perchè son tristi, e non la osserverebbono a te, tu etiam non l'hai ad osservare a loro. Nè mai a uno principe mancorono cagioni legittime di colorire la inosservanzia. Di questo se ne potrebbe dare infiniti esempli moderni e mostrare quante paci, quante promesse sono fatte irrite e vane per la infidelità de' principi ; e quello che ha saputo meglio usare la golpe è meglio capitalo. - Discorsi, III, 42, p. 267 : Di che si leggono in tutte le istorie vari esempli ; e ciascuno dì, ne' presenti tempi, se ne veggono. - Il Principe, 18, p. 34 : Ma è necessario questa natura saperla bene colorire, ed essere gran simulatore e dissimulatore ; e sono tanto semplici gli uomini, e tanto obediscano alle necessità presenti, che colui che inganna, troverrà sempre chi si lascerà ingannare.

cdix Il Principe, 18, p. 34-35 : Alessandro VI non fece mai altro, non pensò mai ad altro, che a ingannare uomini ; e sempre trovò subietto da poterlo fare. E non fu mai uomo che avessi maggiore efficacia in asseverare, e con maggiori giuramenti affermassi una cosa, che la osservassi meno; nondimeno, sempre li 
succederono gli inganni ad votum, perchè conosceva bene questa parte del mondo... Alcuno principe de' presenti tempi, quale non è bene nominare, non predica mai altro che pace e fede, e dell'una e dell'altra è mimicissimo; e l'una e l'altra, quando e' l'avessi osservata, gli arebbe più volte tolto o la reputazione o lo stato.

cdx A. Renaudet, Études érasmiennes, p. 84. - Desidera Erasmi Opera omnia, IV, $603 \mathrm{C}$ : Principum ea debet esse fides, in praestandis ea quae recipiunt, ut simplex horum promissum sanctius sit quovis aliorum jurejurando... Et tamen videmus id quotidio usu venire, nihil addo quorum vitio ; certe sino vitio non potest accidere

${ }^{\text {cdxi }}$ Literae virorum eruditorum ad Franciscum Craneveldium ; éd. H. De Vocht ; Louvain, 1938, in- $8^{\circ}$; Lettre de Jean de Fevyn à Fr. Cranevelt, Bruges, 14 novembre $1526 ; 211,15-18$ : Quasi nihil sit violare jusjurandum! Polluere se nota insigni, nimirum perfidie, cum ille hoc unico ceu dicteriolo juret : la foy de gentilhomme !

cdxii Il Principe, 15, p. 30-31; De his rebus quibus homines et praesertim principes laudantur aut vituperantur... Qualità che arrecano loro o biasimo o laude.

cdxiii Des. Erasmi Roterodami Opera omnia, IV 671 C : Caeleste quoddam animal, Nummi plus quam homini simile, omnibus virtutum numeris absolutum; omnium bono natura, imo datum a Superis sublevandis rebus mortalium; quod omnibus proficiat, omnibus consulat; cui nihil sit antiquius, nihil dulcius Republica ; cui plus quam paternus sit in omneis animus ; cui singulorum vita carior sit quam sua; quod noctes ac dies nihil aliud agat nitaturque, quam ut optime sit omnibus; apud quod praemia parata sint bonis omnibus, malis venia, si modo sese ad frugem meliorem referant; quod adeo gratis cupiat de civibus suis bene mereri, ut si necesse sit, non dubitet suo periculo illorum incolumitati consulere ; quod patriae commodum suum ducat esse lucrum ; quod semper vigilet, quo caeteris liceat dormire ; quod sibi nullum relinquat otium, quo patriae liceat in otio vitam agere ; quod se jugibus curis discruciet, quo civibus suppetat tranquillitas; a cujus unius virtute publica pendeat felicitas.

cdxiv V. p. 265, n. 38. - Il Principe, 15, p. 30 : Molti si sono imaginati republiche e principati che non si sono mai visti nè conosciuti essere in vero... Onde è neccessario a uno principe, volendosi mantenere, imparare a potere essere non buono, e usarlo e non l'usare secondo la necessità.

cdxv Il Principe, 15, p. 31 : E io so che ciascuno confesserà che sarebbe laudabilissima cosa in uno principe trovarsi, di tutte lo soprascritte qualità, quelle che sono tenute buone ; ma perchè le non si possono avere nè interamente osservare, per le condizioni umane che non lo consentono, gli è necessario essere tanto prudente che sappia fuggire l'infamia di quelli vizii che li torrebbano lo stato, e di quelli che non guene tolgano, guardarsi se egli è possibile; ma, non possendo, vi si può con meno respetto lasciare andare. 
cdxvi Il Principe, 18, p. 35 : E hassi a intendere questo, che uno principe, e massime uno principe nuovo, non può osservare tutte quelle cose per le quali gli uomini sono tenuti buoni, sendo spesso necessitato, per mantenere lo stato, operare contro alla fede, contro alla carità, contro alla umanità, contro alla religione. E però bisogna che gli abbia uno animo disposto a volgersi secondo ch' e' venti della fortuna e le variazioni delle cose li comandano, e, come di sopra dissi, non partirsi dal bene, potendo, ma sapere intrare nel male, necessitato.

cdxvii Ibid., p. 35 ; Debbe adunque avere uno principe gran cura che non gli esca mai di bocca una cosa che non sia piena delle soprascritte cinque qualità ; e paia, a vederlo e udirlo, tutto pietà, tutto fede, tutto integrità, tutto umanità, tutto religione. E non è cosa più necessaria a parere di avere che questa ultima qualità.

cdxviii Ibid., p. 35 : E gli uomini in universale, iudicano più agli occhi che alle mani ; perchè tocca a vedere a ognuno, a sentire a pochi. Ognuno vede quello che tu pari, pochi sentono quello che tu se' ; e quelli pochi non ardiscano opporsi alla opinione di molti che abbino la maestà dello stato che li defenda.

cdxix Ibid., p. 35 : E nelle azioni di tutti gli uomini, e massime de' principi, dove non è iudizio a chi reclamare, si guarda al fine. Facci dunque uno principe di vincere e mantenere lo stato ; e' mezzi saranno sempre iudicati onorevoli e da ciascuno laudati; perchè il vulgo ne va sempre preso con quello che pare, e con lo evento della cosa; e nel mondo non è se non vulgo; e li pochi non ci hanno luogo quando li assai hanno dove appoggiarsi.

cdxx Il Principe. 16, p. 31-32 ; De liberalitate et parsimonia. - Cf. Aristote, Politique, V, 9, 11-12, 1314 a 40-b 18.

cdxxi Il Principe, 16, p. 31... A volersi mantenere infra gli uomini el nome del liberale, è necessario non lasciare indietro alcuna qualità di suntuosità... Sarà necessitato alla fine... gravare e' populi estraordinariamente ed essere fiscale... In modo che, con questa sua liberalità, avendo offeso gli assai e premiato e' pochi, sente ogni primo disagio, e periclita in qualunque primo periculo ; il che conoscendo lui, e volendosene ritrarre, incorre subito nella infamia del misero.

cdxxii Ibid., p. 32 : Cesare con la liberalità pervenne allo imperio... ma se poi che vi fu venuto, fussi sopravvissuto e non si fussi temperato da quelle spese, arebbe destrutto quello imperio.

cdxxiii Ibid., p. 37-32 : Ne' nostri tempi, noi non abbiamo veduto fare gran cose se non a quelli che sono stati tenuti miseri ; gli altri essere spenti. Papa Iulio II, come si fu servito del nome di liberale per aggiugnere al papato, non pensò poi a mantenerselo, per potere far guerra; el re di Francia presente ha fatto tante guerre sanza porre uno dazio estraordinario a' suoi, solum perchè alle superflue spese ha sumministrato la lunga parsimonia sua; el re di Spagna presente, se fussi tenuto liberale, non arebbe fatto nè vinto tante imprese. 
cdxxiv Ibid., p. 32 : E di quello che non è tuo, o de' sudditi tuoi, si può essere più largo donatore, come fu Ciro, Cesare ed Alessandro ; perchè lo spendere quello degli altri non ti toglie reputazione, ma te ne aggiugne.

cdxxv Il Principe, 21 ; Quod principem deceat ut egregius habeatur ; p. 45 : Debbe ancora un principe mostrarsi amatore delle virtù, dando recapito alli uomini virtuosi, e onorare gli eccellenti in una arte.

cdxxvi Ibid. : Apresso debbe animare li sua cittadini di potere quietamente esercitare gli esercizi loro, e nella mercanzia e nella agricultura e in ogni altro esercizio degli uomini ; e che quello non tema di ornare le sua possessioni per timore che le gli sieno tolte, e quell'altro di aprire uno traffico per paura delle taglie ; ma debbe preparare premi a chi vuol fare queste cose, e a qualunque pensa, in qualunque modo, ampliare la sua città o il suo stato. - Sur lès idées très sommaires, en matière d'économie, de Machiavel, v. l'étude de G. Arias, citée p. 135, n. 22 ; quelques brèves indications dans l'ouvrage de J. Thévenet, cité à la même page.

cdxxvii Ibid. : Tenere occupati e' populi con le feste e spettaculi, raunarsi... con loro qualche volta, dare di sè esemplo di umanità e di munificenzia, tenendo sempre ferma nondimanco la maestà della dignità sua, perchè questo non vuole mai mancare in cosa alcuna. - Montesquieu, moins familier que Machiavel, exprime dans le même langage la nécessité qui s'impose au prince de se tenir en contact avec un inonde plus étroit; Cahiers, p. 104 : Le Prince doit se communiquer aux gens de sa cour, non pas assez pour avilir sa dignité, mais assez pour faire sentir qu'il vit avec des hommes.

cdxxviii Il Principe, 17, p. 32-34 : De crudelitale et pietate ; et an sit melius amari quam timeri, vel e contra.

cdxxix Ibid., p. 32-33 : Era tenuto Cesare Borgia crudele; nondimanco quella sua crudeltà aveva racconcia la Romagna, unitola, ridottala in pace e in fede... Debbe pertanto uno principe non si curare della infamia di crudele, per tenere li sudditi suoi uniti e in fede ; perchè, con pochissimi esempli, sarà più pietoso che quelli e' quali, per troppa pietà, lasciono seguire e' disordini, di che ne nasca occisioni e rapine... Nondimanco debbe essere grave al credere e al muoversi, né si fare paura da se stesso...

cdxxx Ibid., p. 33 : Perchè degli uomini si può dire questo generalmente, che sieno ingrati, volubili, simulatori e dissimulatori, fuggitori de' pericoli, cupidi di guadagno ; e mentre fai loro bene, sono tutti tua, offerenti el sangue, la vita, e' figliuoli, come de sopra dissi, quando il bisogno è discosto ; ma quando ti si appressa, e' si rivoltano. E quel principe che si è tutto fondato in sulle parole loro, trovandosi nudo di altre preparazioni, rovina... L'amore è tenuto da un vinculo di obligo, il quale, per essere gli uomini tristi, da ogni occasione di propria utilità è rotto; ma il timore è tenuto da una paura di pena che non ti abbandona mai. 
cdxxxi Ibid., p. 33... Il che farà sempre, quando si astenga dalla roba de' sua cittadini e de' sua sudditi, e dalle donne loro. E quando pure li bisognasse procedere contro al sangue di alcuno, farlo quando vi sia iustificazione conveniente e causa manifesta ; ma sopra tutto, astenersi dalla roba d'altri ; perchè gli uomini sdimenticano più presto la morte del padre che la perdita del patrimonio.

cdxxxii H. Barckhausen, Montesquieu, l'Esprit des Lois et les Archives de la Brède ; Bordeaux, 1904 ; in-4 ; p. 29 : Mais c'est le délire de Machiavel d'avoir donné aux princes, pour le maintien de leur grandeur, des principes qui ne sont nécessaires que dans le gouvernement despotique, et qui sont inutiles, dangereux et même impraticables, dans le monarchique. Cela vient de ce qu'il n'en a pas bien connu la nature et les distinctions : ce qui n'est pas digne de son grand esprit. - C'est par ces quelques lignes que devait se terminer, au livre III, le chapitre 9, Du principe du gouvernement despotique. Montesquieu a préféré les supprimer.

cdxxxiii Il Principe, 17, p. 33 : Ma quando el principe è con gli eserciti e ha in governo moltitudine di soldati, allora al tutto è necessario non si curare del nome di crudele...

cdxxxiv Il Principe, 18, p. 35 : Tutto pietà... tutto religione. - V. p. 181, n. 12.

cdxxxv Discorsi, I, 12, p. 78-79; v. p. 179-182. - I, 11, p. 76-78, Della religione de’ Romani ; p. 77 : Dove manca il timore di Dio, conviene o che quel regno rovini, o che sia sostenuto dal timore d'une principe che sopperisca a' difetti della religione. E perchè i principi sono di corta vita, conviene che quel regno manchi presto...

${ }^{\text {cdxxxvi }}$ V p. 181, n. 12.

cdxxxvii Il Principe, 18, p. 85 : E non è cosa più necessaria a parere di avere che questa ultima qualità.

cdxxxviii A. Renaudet, Études érasmiennes, p. 102.

cdxxxix Il Principe, 18, p. 34 : Nè mai a uno principe mancorono cagioni leggitime di colorire la inosservanzia... Ma è necessario questa natura saperla bene colorire... E sono tanto semplici gli uomini, ... che colui che inganna troverrà sempre chi si lascerà ingannare.

${ }^{\text {cdxl }}$ Ibid., p. 35 : Tutto fede, tutto integrità, tutto umanità, tutto religione.

cdxli Ibid., p. 35 : Facci dunque uno principe di vincere e mantenere lo stato : e' mezzi saranno sempre iudicati onorevoli e da ciascuno laudati.

cdxlii Maximes d'État, publiées par G. Hanotaux, dans Collection de documents inédits, Mélanges historiques, III ; Paris, 1880, in-4 $4^{\circ}$; ${ }^{\circ} \mathrm{CXXV}, \mathrm{p} .785$.

cdxliii Vita Cn. Julii Agricolae, 3.

cdxliv V. p. 194, n. 48 : Une città che ancora viva politicamente.

cdxlv V.p. 43 et n. 16.

cdxlvi Esprit des Lois, XI, 13. 


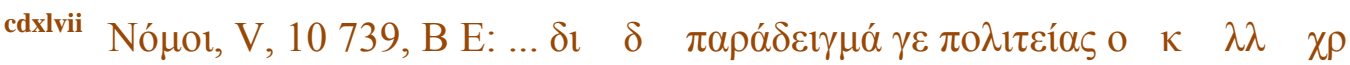

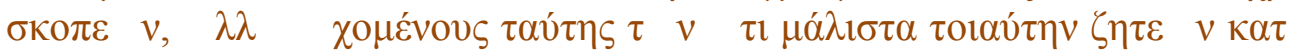

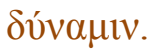

cdxlviii V. p. 204, n. 83.

cdxlix Benedetto Croce, Storia di Europa nel secolo decimonono, Bari, 1932, in$8^{\circ}$, p. 165-166 ; Di un governo che faccia veramente opera politica, è impossibile o affatto arbitrario dire che esso sia aristocratico o borghese o piccolo borghese, perchè esso comprende di necessità queste e tutte le altre classi o tende a superarle tutte.

cdl V.p. 204, n. 83.

cdli Discorsi, I, 58 : La moltitudine è più savia et più costante che uno principe ; $p$. 131 : E non sanza cagione si assomiglia la voce d'un popolo a quella di Dio — I, 57, p. 129-130 : La plebe insieme è gagliarda di per sè e debole. — I, 53, p. 123-125 : Il popolo molte volte desidera la rovina sua, ingannato da una falsa spezie di beni ; et come le grandi speranze et gagliarde promesse facilmente lo muovono.

cdlii Discorsi, II, 23, p. 175 : Une governo non è altro che tenere in modo i sudditi che non ti possano o debbano offendere.

cdliii Esprit des Lois, XXV, 2.

cdliv Benedetto Croce, Storia d'Italia dal 1871 al 1915 ; Bari, 1928, p. VII. A chi... cerca sempre il vero moto e il vero dramma negli intelletti e nei cuori. 